\title{
2000 Savannah River Biological Surveys for Westinghouse Savannah River Company
}

by

M. Arnett

Westinghouse Savannah River Company

Savannah River Site

Aiken, South Carolina 29808

This paper was prepared in connection with work done under the above contract number with the U.S.

Department of Energy. By acceptance of this paper, the publisher and/or recipient acknowledges the U. S.

Government's right to retain a nonexclusive, royalty-free license in and to any copyright covering this paper, along with the right to reproduce and to authorize others to reproduce all or part of the copyrighted paper. 
2000 Savannah River Biological Surveys

for

Westinghouse Savannah River Company

Report No. 01-16F

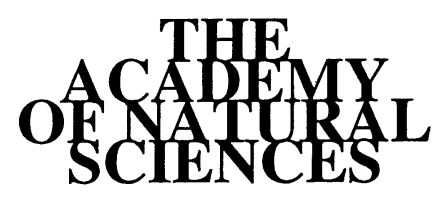

South Carolina DHEC Laboratory I.D. \#89011

Patrick Center for Environmental Research 1900 Benjamin Franklin Parkway

Philadelphia, PA 19103-1195

30 September 2001 
This document was prepared in conjunction with work accomplished under Contract No. DEAC09-96SR18500 with the U.S. Department of Energy.

\section{DISCLAIMER}

This report was prepared as an account of work sponsored by an agency of the United States Government. Neither the United States Government nor any agency thereof, nor any of their employees, makes any warranty, express or implied, or assumes any legal liability or responsibility for the accuracy, completeness, or usefulness of any information, apparatus, product or process disclosed, or represents that its use would not infringe privately owned rights. Reference herein to any specific commercial product, process or service by trade name, trademark, manufacturer, or otherwise does not necessarily constitute or imply its endorsement, recommendation, or favoring by the United States Government or any agency thereof. The views and opinions of authors expressed herein do not necessarily state or reflect those of the United States Government or any agency thereof.

This report has been reproduced directly from the best available copy.

Available for sale to the public, in paper, from: U.S. Department of Commerce, National Technical Information Service, 5285 Port Royal Road, Springfield, VA 22161

phone: (800) 553-6847

fax: (703) 605-6900

email: orders@ntis.fedworld.gov

online ordering: http://www.ntis.gov/support/index.html

Available electronically at http://www.osti.gov/bridge

Available for a processing fee to U.S. Department of Energy and its contractors, in paper, from: U.S. Department of Energy, Office of Scientific and Technical Information, P.O. Box 62, Oak Ridge, TN 37831-0062

phone: (865)576-8401

fax: (865)576-5728

email: reports@adonis.osti.gov 


\section{NON-TECHNICALSYNTHESIS}

\section{Overview and Rationale}

The Academy's

monitoring program,

conducted since 1951,

assesses the effects of the

Savannah River Site on

the health of the Savannah

he Academy of Natural Sciences of Philadelphia has
been conducting biological and water quality studies
of the Savannah River since 1951. These studies are designed to assess potential effects of Savannah River Site (SRS) contaminants and warm-water discharges on the general health of the river and its tributaries. They therefore look for spatial patterns of biological disturbance that are geographically associated with the site, and for temporal patterns of change that indicate improving or deteriorating conditions.

River ecosystem.

Components of the Academy's Savannah River studies have included basic water chemistry, diatoms, other attached algae,

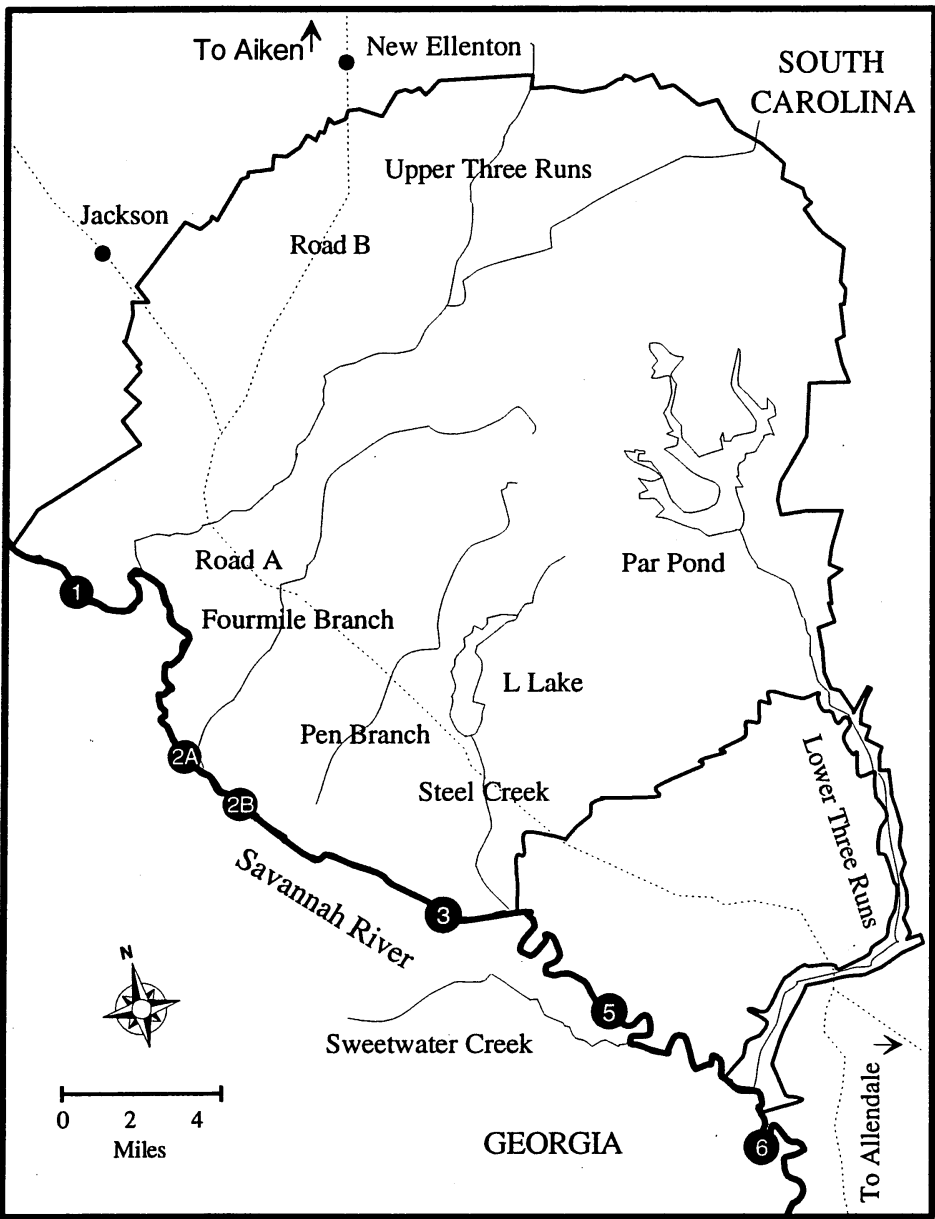

aquatic macrophytes (mosses and rooted aquatic plants), protozoa, aquatic insects, noninsect macroinvertebrates, and fish. The study design includes multiple biological groups spanning a broad range of ecological roles, both because no single group is the best indicator of every component of water quality and because there is widespread agreement that protecting the entire system is important.

Prior to 1997, four basic types of studies were conducted by the Academy: Comprehensive Surveys, Cursory Surveys, Diatometer Studies, and Plant Vogtle Surveys. Comprehensive Sur- 


- Conducted Every Year
- Four Sampling Periods
- Fewer Study Components
Fewer Sampling Stations
Comprehensive
- Roughly Every Four Years
Two Sampling Periods
- All Study Components
All Sampling Stations

veys included the largest number of study components, were carried out roughly every four years, and included two sampling periods during the year. Cursory Surveys included a reduced set of study components - typically attached algae, insects, and fish-but were conducted annually, with four sampling periods per year (except in years with Comprehensive Surveys, which substituted for two of the usual Cursory sampling periods). Thus, Cursory Surveys provided more narrowly focused information, but on a more frequent basis. Diatometer Studies addressed only the diatom flora but provided year-round annual monitoring. Plant Vogtle Surveys, which included the same components as Comprehensive Surveys but different sampling stations, were initiated in 1985 in order to assess potential impacts of Georgia Power and Light's Vogtle Nuclear Power Plant so that these could be separated from potential SRS impacts.

Beginning with the 1997 study, several changes were made in the monitoring program in order to reduce the number of types of studies conducted. Aspects of the Diatometer Study and the Cursory, Comprehensive, and Plant Vogtle Surveys were combined into a single, comprehensive study. The number of study components was reduced by eliminating assessments of water chemistry and protozoa. The scale of the diatometer component was also reduced, with both the number of sampling stations and the number of exposure periods being decreased.

Components of the new study design include diatoms (diatometer sampling using artificial substrates), attached algae and aquatic macrophytes (hand collections from natural substrates), aquatic insects, non-insect macroinvertebrates, and fish. Diatometers are deployed for one two-week exposure period in each month of the year. Four sampling stations are employed in each study component: three exposed to SRS influence (Stations 2B, 5, and 6) and an upstream reference station that is thought not to be exposed to SRS influence (Station 1). (Station locations are shown in the map on the previous page.) Multiple exposed stations are employed because of the complex pattern of SRS inputs along the river.

As in previous Academy studies on the Savannah River, potential impacts of the SRS are assessed in the new study design by determining whether differences exist between the exposed and reference stations that are either greater or of a 
different character than would be expected if they were due merely to natural differences among sampling sites. For example, the character of differences among stations is judged in part by comparing the individual species collected. Evidence of impact exists if a station shows elevated abundances of species known to be moderately or highly tolerant of pollution and depressed abundances of species known to be intolerant of pollution. If this pattern is detected at the exposed stations but not at the reference station, then there is evidence that the impact originates within the study area and further studies would be recommended to determine the exact type and source of pollution. If, however, the pattern is seen at the reference station, then the impact must be due to sources upstream from the study area.

Other potential types of evidence for impact include decreased numbers of species, decreased numbers of individuals, and numerical dominance by a small proportion of the species present. These patterns arise because pollution tends to reduce population sizes in a majority of species, while a few tolerate or thrive in such conditions.

Determining whether exposed and reference stations differ is complicated by the fact that considerable variation exists even among samples collected at the same time from the same location. Apparent differences may therefore be spurious if each station is characterized by only a single sample. For this reason, several components of the Academy's studies collect multiple samples from each station, making it possible to quantify both of the important components of variation: within and among stations. Compelling evidence for station differences exists if average variation among samples from different stations is significantly greater than average variation among samples from the same station, as judged by appropriate statistical techniques (e.g., analysis of variance).

When statistically significant biological differences among stations are found, it is advisable to determine whether these might be caused by differences in physical characteristics of the stations rather than pollution. For example, the fish fauna at a station with shallow, fast-moving water is likely to differ from that at a station with deep, slow-moving water. The possible role of differences in physical characteristics such as water depth, current speed, and substrate type can be investigated using a statistical technique called analysis of covari- 
ance. The basic idea is to determine a simple statistical relationship between the measured physical and biological characteristics, then use this relationship to remove the effect of station differences in physical characteristics from the biological data. If station differences persist after this adjustment, they probably are caused by something other than the measured physical factors.

Another type of variation that the Academy's studies address is variation over time. Important components of temporal variation include seasonal trends, multiyear trends, and trendless (random) variation. All of these components can be assessed using the unique dataset generated by the Academy's longterm monitoring program in the Savannah River. Regular sampling has continued with relatively little change in methods since the early 1950s, making this one of the most comprehensive ecological datasets available for any of the world's rivers.

Such long-term records of biological change are valuable for several reasons. Since they allow the normal degree of yearto-year variability at a site to be quantified, changes observed from one survey to the next can be assessed to determine whether they fall within the normal range, much as one would use a control chart. Changes that are outside this range provide evidence of altered conditions at the study site.

These datasets are also useful in distinguishing between potential impacts of the Savannah River Site and variation caused by other factors. For example, part of the biological variation observed over time is caused by documented changes in river flow, wastewater treatment methods, dredging activities, and so on. Identifying correlations between the known history of such changes on the one hand, and components of variation in long-term datasets on the other, provides evidence that these components of biological variation are not attributable to SRS operations.

Finally, long-term datasets can provide compelling evidence for multiyear trends of improvement or deterioration in ecosystem health. The Academy's long-term data suggest, for example, that there has been a relatively steady increase in the number of species of aquatic insects living in the river during the last 35 years. Since aquatic insect diversity is believed to be a sensitive measure of environmental quality, this pattern 
may indicate a long-term trend of improving water quality in the Savannah River.

\section{Summary of Results}

\section{Diatometer Study}

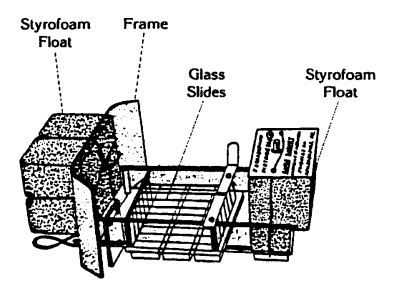

C

atherwood diatometers were deployed at Stations 1, $2 \mathrm{~B}, 5$, and 6 for 12 2-week exposure periods, with retrieval dates spanning 18 January to 27 December 2000. All diatoms were identified to species. (Diatometers were also deployed at Station 2A; these samples were archived but were not analyzed.)

The diatom flora on diatometer slides was analyzed for species richness (= number of species), percent dominance (= percent of total specimen count on a slide comprising dominant species, where a dominant species is operationally defined as one with more than 1024 counted cells), Shannon-Wiener diversity (= a joint measure of species richness and the similarity of species abundances, derived from information theory), and relative abundances of dominant species. To remove the pronounced seasonal variation from station comparisons, data on species richness at the four stations were ranked for each exposure period, and the ranks were then statistically analyzed via analysis of variance. Data on percent dominance and Shannon-Wiener diversity were analyzed in the same way.

The species composition of the diatom assemblage was similar at all stations. No statistically significant differences among stations were detected for species-richness rank, but the reference station (Station 1) showed significantly lower dominance rank and higher diversity rank than did the exposed stations (Stations 2B, 5, and 6). The reduction in diversity at Station 6 was not as severe as found in studies conducted in 1986 through 1996. Variation among seasons in 2000 was found to be more pronounced than variation among stations. Ecological and pollution tolerances of the dominant species were found to be similar at all stations, with most of the dominant species being characteristic of alkaline waters with moderately high nutrient concentrations. The fact that the reference station showed lower dominance rank and 

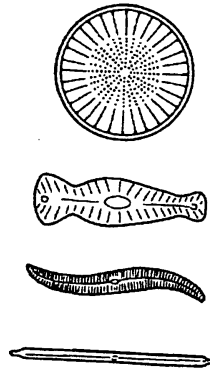

higher diversity rank than any of the exposed stationsits sistent with an SRS impact, but there was no corresponc( pattern in ecological or pollution tolerances of the domi ing species. Evidence is therefore equivocal regarding a pot int SRS impact on water-quality components to which diat ing
are most sensitive.

\title{
Attached Algae and Aquatic Macrophytes
}

\author{
A \\ ttached algae and aquatic macrophytes were sam \\ qualitatively (via hand collections) at Stations 1 , \\ 5 and 6 during 8-11 September 2000. All specin \\ were identified to species.
}

Station and year comparisons were based on the number species in major taxonomic groups and on known pollutia tolerances and relative abundances of species.

The algal flora was similar at all four stations. It also show evidence of nutrient enrichment at all stations, apparently from sources upstream from the study site. No significant beds of submerged aquatic vegetation were observed, as $h_{4}$ been true since 1990 (inclusive). Species richness and com sition of both algae and aquatic macrophytes were similar 1 those of previous studies. These results provide no evidena of an SRS impact on the algal flora or aquatic macrophytes.

\section{Non-insect Macroinvertebrates}
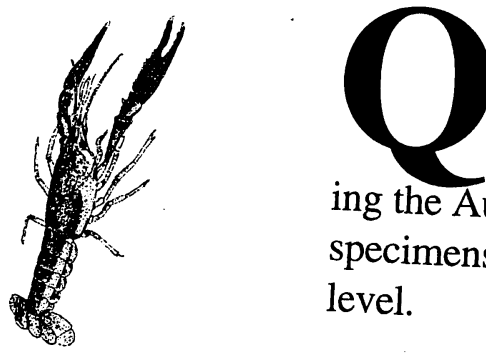

ualitative samples of non-insect macroin vertebrat were collected at Stations 1, 2B, 5 and 6 during 2 28 August and 8-11 September 2000. Sampling $d$ ing the August period concentrated on mussel habitats. All specimens were identified to the lowest practical taxonomic level.

With the exception of mussels, the non-insect macroinvertebrate fauna in 2000 was broadly similar to that in recent surveys (1976 to 1999), with four major assemblages dominati in (bivalves, snails, crustaceans, and leeches). In total, 30 taxa were collected. This total is significantly below the average for the previous 9 studies $(=42.33)$ and is less than the total 


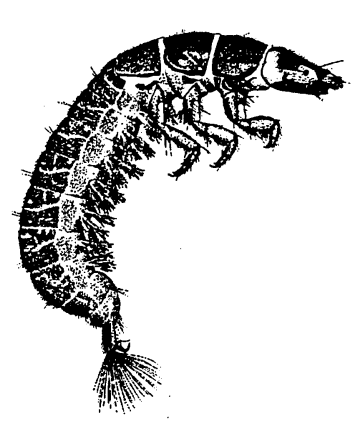

for any of the previous four studies (range $=37$ to 49 ), though it is within the range for the previous 9 studies ( $=27$ to 60 ). Relatively low taxa richness was also observed in 1999 (total taxa =37). The decrease in 2000 compared to 1999 mainly reflects a decrease from 13 to 8 in the number of mussel species collected. The reasons for these low totals are not known.

The number of taxa collected in 2000 was higher at Stations 2B and 5 (= 20 and 21, respectively) than at Stations 1 and 6 (= 17 and 16 , respectively). This pattern is opposite the pattern observed in 1999 and is not consistent with an SRS impact.

\section{Aquatic Insects}

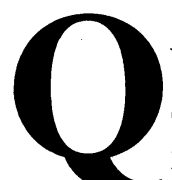

uantitative and qualitative samples of aquatic insects were collected at Stations 1, 2B, 5 and 6 during 25-28 April and 10-13 September 2000. The quantitative samples were collected using standardized artificial substrates, which permit replicate samples at each station and rigorous statistical comparisons. Qualitative samples were collected from a wide variety of natural substrates and habitat types. Specimens were identified to the lowest practical taxonomic level (usually species).

Station and season comparisons were based both on visual inspection of data from the qualitative collections and on statistical analysis (analysis of variance) of quantitative estimates of several types of indices. These indices include densities of selected taxa, total species richness, richness of selected groups of pollution-sensitive taxa (Ephemeroptera, Plecoptera, Trichoptera) and pollution-tolerant taxa (Chironomidae), Shannon-Wiener species diversity, relative abundance of Chironomids (\% Chironomidae), relative abundance of the most abundant taxon and the five most abundant taxa (\% Dominance-1, \% Dominance-5), and overall degree of pollution tolerance (Hilsenhoff Biotic Index, North Carolina Biotic Index).

Total species richness in the qualitative collections was much higher than in the quantitative samples. For the April and September samples combined, qualitative samples contained 195 taxa while quantitative samples contained only 104 taxa; 46 taxa were unique to the qualitative collections while only 10 taxa were unique to the quantitative samples. These differ- 
ences probably are due mainly to the fact that qualitative samples were collected from all major habitat types while quantitative samples largely reflect species typical of snag and debris habitats.

The species composition of insect faunas found in the April and September collections was similar to those in previous years and contained numerous and abundant pollution-sensitive taxa. Of the major insect groups found in qualitative collections, the most species-rich were dipterans (61 taxa, mainly Chironomidae), beetles (39 taxa), dragonflies and damselflies (27 taxa), mayflies (26 taxa), and caddisflies (26 taxa). Total species richness was much higher than in most previous years, including the highest recorded numbers of mayfly, caddisfly, beetle, dragonfly/damselfly, and dipteran species at one or more stations and seasons. Most of the additional taxa collected in 2000 , however, were not common. The dominant taxa were therefore similar to those in previous years and were also similar among the four sampling stations.

Statistical analysis of the quantitative samples revealed a few differences among stations and between seasons, but none of these differences was consistent with the pattern expected for an SRS impact. On the contrary, the results indicate that the condition of the aquatic insect assemblage at the exposed stations tends to be superior to the condition at the reference station. The same conclusion was demonstrated by results of the 1999 study.

Overall, results of the 2000 aquatic insect study suggest that differences detected among sites and seasons reflect natural spatial and temporal variation found in all rivers and streams. The results provide no evidence of a negative SRS impact on the aquatic insect assemblage.

\section{Fish}

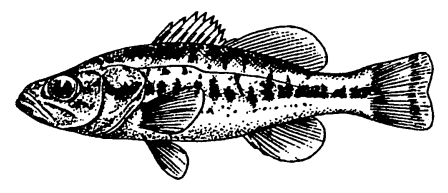

Tish were sampled at Stations 1, 2B, 5 and 6 during 812 September 2000 . The main collecting techniques were seining, boat electrofishing in the main channel, and walk-along electrofishing in backwaters. All specimens were identified to species.

Species richness, species diversity (Shannon-Wiener index), and densities of individual species were estimated for each 
quantitative seine sample. These data were analyzed using analysis of variance and analysis of covariance. Densities and total population sizes of fish collected in backwater areas via electrofishing were estimated statistically by a depletion technique.

In total, 50 species of fish were collected in the 2000 survey, with five species (spottail shiner, bannerfin shiner, bluegill, brook silverside, and whitefin shiner) composing approximately three fourths of the total catch. No statistically significant among-station differences were found for species richness, species diversity, or density. These results are similar to those of the 1999 study and provide no evidence of an SRS impact on the fish assemblage.

\section{Conclusions}

s in previous Savannah River studies, the 2000 re-
sults for diatometer samples and for attached algae
and aquatic macrophytes indicate nutrient enrichment at all stations, evidently due to sources upstream from the study area. Several differences among stations were detected in various components of the survey, but the only patterns consistent with an SRS impact were that dominance rank was significantly lower and diversity rank was significantly higher in diatometer samples at the reference station than at any of the exposed stations. Because evidence from other study components did not corroborate this pattern, and because there was no corresponding pattern in ecological or pollution tolerances of the dominant diatom species in diatometer samples, we conclude that results of the 2000 comprehensive study do not provide compelling evidence of an SRS impact on water quality or biological communities in the Savannah River. 


\section{QUALITY ASSURANCE STATEMENT}

Study Number: 760

Study Title: $\quad 2000$ Savannah River Biological Surveys for Westinghouse Savannah River Company.

This study was performed under the general provisions of the Patrick Center's Quality Assurance Implementation Plan (Rev. 1, June 1998). The final report was determined to be an accurate reflection of the data obtained.

The dates that Quality Assurance activities on this study are given below.

Data Review:

Gauge Height: $\quad 9 / 25 / 01$

Diatometer: $\quad 9 / 21 / 01$

Algae: $\quad 9 / 19 / 01$

Macroinvertebrates: $\quad 9 / 22 / 01$

Aquatic Insects: $\quad$ 9/20/01

Fish: $\quad 9 / 27 / 01$

Report Review: $\quad$ 8/27-30/01

ARCHIVING: Raw data and the final report are filed in the Patrick Center's archives.

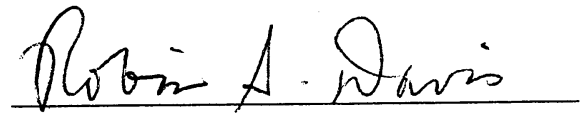

Robin S. Davis

Quality Assurance Unit

Patrick Center for Environmental Research

Academy of Natural Sciences 


\section{TABLE OF CONTENTS}

NON-TECHNICAL SYNTHESIS $\ldots \ldots \ldots \ldots \ldots \ldots \ldots \ldots \ldots \ldots \ldots \ldots$

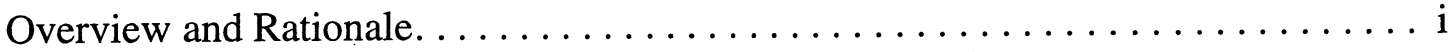

Summary of Results. . . . . . . . . . . . . . . . . . . . . . . . .

Diatometer Study . . . . . . . . . . . . . . . . . . . . . . . .

Attached Algae and Aquatic Macrophytes................... vi

Non-insect Macroinvertebrates. . . . . . . . . . . . . . . . . . vi

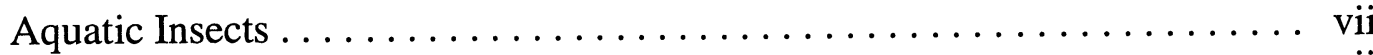

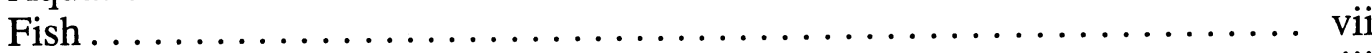

Conclusions $\ldots \ldots \ldots \ldots \ldots \ldots \ldots \ldots \ldots \ldots \ldots \ldots \ldots \ldots \ldots \ldots$ viii

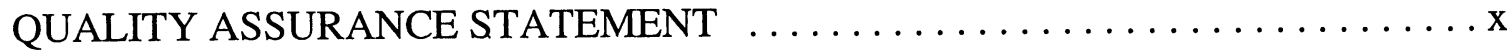

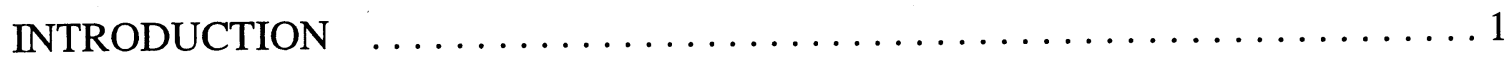

PERSONNEL AND ACKNOWLEDGMENTS $\ldots \ldots \ldots \ldots \ldots \ldots \ldots \ldots$

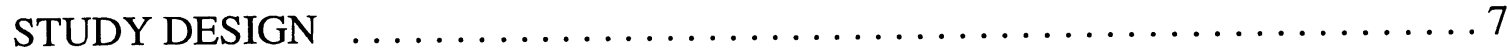

LOCATION AND DESCRIPTION OF STATIONS $\ldots \ldots \ldots \ldots \ldots \ldots \ldots$

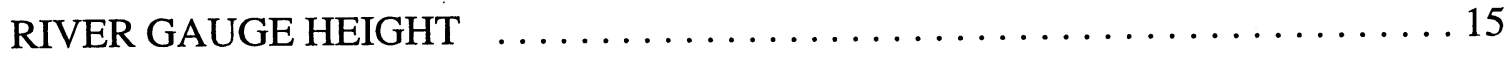

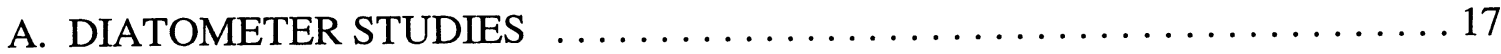

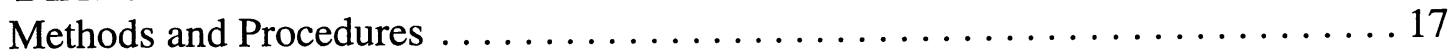

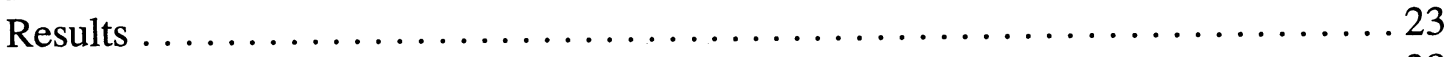

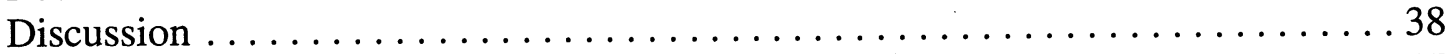

Appendix A ............................ 47

B. ATTACHED ALGAE AND AQUATIC MACROPHYTES $\ldots \ldots \ldots \ldots \ldots \ldots 62$

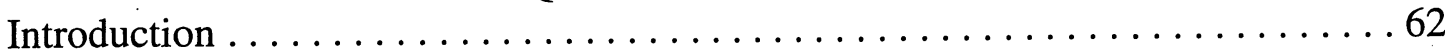

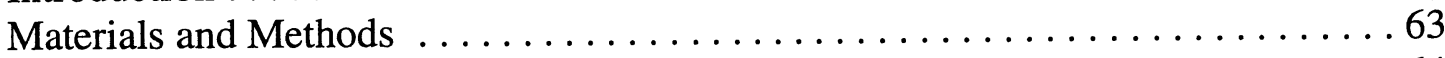

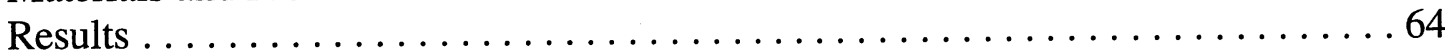

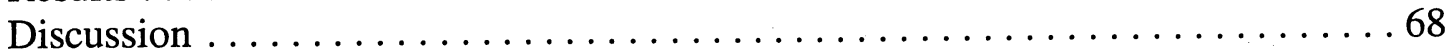

Appendix B . . . . . . . . . . . . . . . . . . . . . . 71

C. NON-INSECT MACROINVERTEBRATES $\ldots \ldots \ldots \ldots \ldots \ldots \ldots \ldots \ldots$

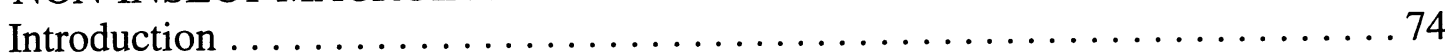

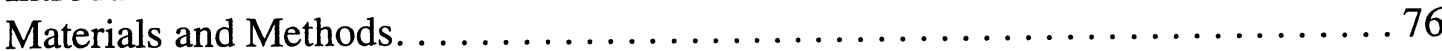

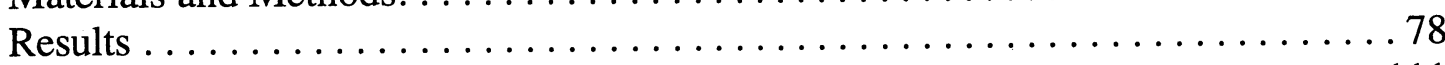

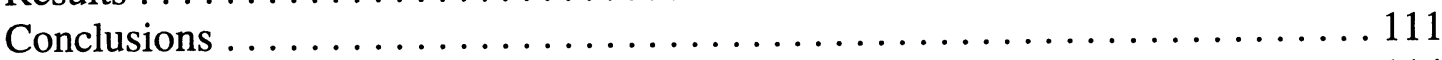

Mussel Fauna . . . . . . . . . . . . . . . . . . . . . . . . . . 114

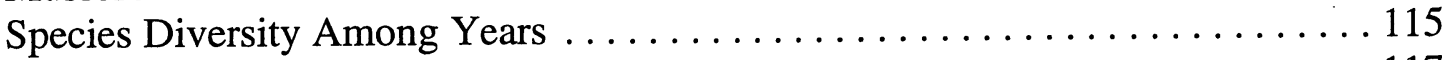

Species Diversity Among Stations. . . . . . . . . . . . . . . . . . . 117

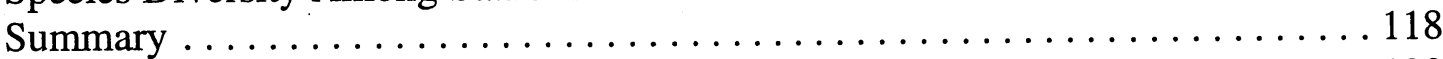

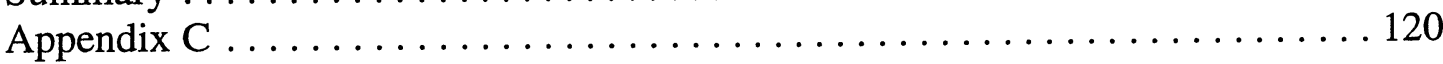




\section{TABLE OF CONTENTS}

Page

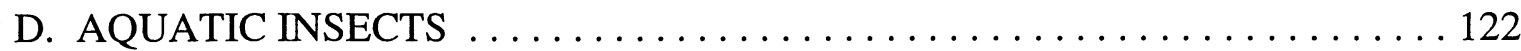

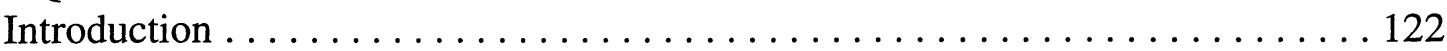

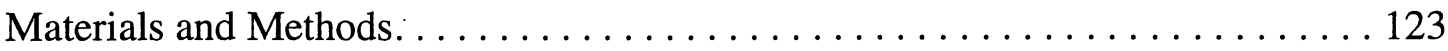

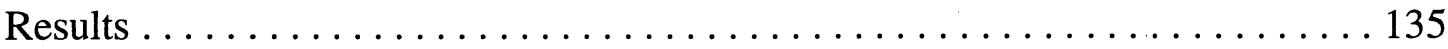

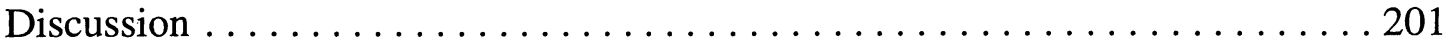

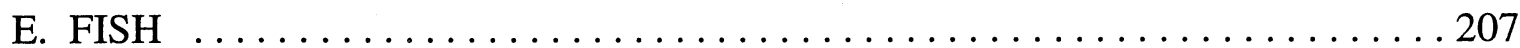

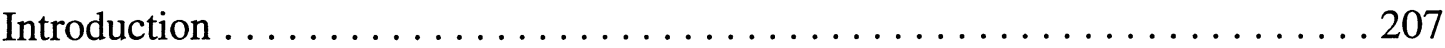

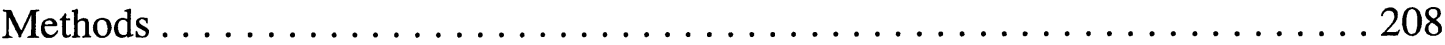

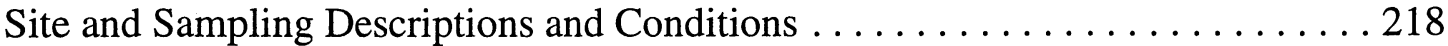

Results ... . . . . . . . . . . . . . . . . . . . . . . . . . . . . . 221

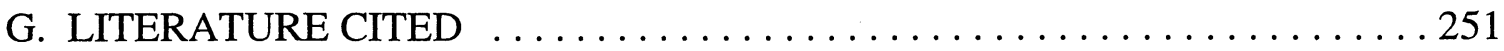




\section{INTRODUCTION}

In the longest study of a large river in the U.S., The

Academy has monitored

the biology and chemistry

of the Savannah River Site

since 1951, and near

Plant Vogtle since 1985,

to assess potential effects

of those facilities on the

river ecosystem.
I n 2000, The Academy of Natural Sciences of Philadelphia (ANSP) conducted biological monitoring of the Savannah River for Westinghouse Savannah River Company. This was the forty-ninth in a series of multiple trophic level biological studies of the river in the vicinity of the Savannah River Site, near Augusta, Georgia. The first survey was conducted in 1951 and 1952 before the operation of the Savannah River Site and the construction of Clark Hill Dam "to establish an objective measure of the aquatic life ... so that any significant effect ... could be determined in the future" (ANSP, 1953:2). This study was conducted during each of the spring through winter seasons to establish baseline water quality conditions, as reflected primarily in the diversity of the aquatic biota, in the vicinity of the plant prior to operations. The first postoperational (SRS and Clark Hill Dam) study was undertaken in 1955 and 1956 "to determine whether any change had occurred ... in the aquatic life and general environmental factors in the Savannah River" (ANSP, 1957:1). The operation of Clark Hill Dam reduced the wide seasonal variations in discharge and reduced the silt loads, except as determined by local meteorological conditions. Vegetation was able to become more generally established in sheltered areas. Since the first postoperational study, comprehensive river investigations were conducted approximately every four years $(1955 / 56,1960,1965,1968,1972,1976$, $1980,1984,1989$ and 1993) to monitor spatial and temporal chemical and biological patterns in the river.

The comprehensive surveys were augmented by less intensive, but more frequent cursory studies. These cursory investigations were intended to provide a relatively frequent, cost-effective interim assessment of whether there has been any major change in the biota since the most recent comprehensive survey. Generally, fewer elements of the biota [fishes, algae and macroinvertebrates (primarily insects)] were studied at various times of the year (once, twice and 
four times a year for the fishes, algae and macroinvertebrates, respectively) in cursory surveys.

Within the Savannah River study area (Fig. 1), studies have also been conducted in the vicinity of Georgia Power and Light's Vogtle Nuclear Power Plant. The first survey was designed and conducted in 1985 with an additional preoperational study in 1986. The purpose of the 1985 and 1986 studies was to establish baseline water quality conditions, as reflected primarily in the diversity of the aquatic biota, in the vicinity of the plant prior to plant operation. Commercial production of the Vogtle facility commenced in early summer 1987, after which the first operational survey was undertaken. Since that time seven more operational studies (1988, 1990, 1991, 1993, 1994, 1995 and 1996) have been undertaken to monitor spatial and temporal chemical and biological changes in the river.

The presence of the Plant Vogtle survey stations can be seen as additional data points in the longest comprehensive study of a large river in the United States.

The Catherwood Diatometer program, conducted for the past 48 years, is designed for continuous biological monitoring of the Savannah River. Diatoms are used as biological indicator organisms because they represent the predominant periphyton (attached algae) in most water bodies, and because they are reliable indicators of adverse impact on water quality due to their characteristic patterns of species composition and assemblage structure. These studies consist of analyses of the diatom flora growing on Diatometer substrates (glass slides) in the river. The exposed substrates are retained at The Academy as a permanent record of water conditions.

The results of these various studies (comprehensive, cursory, Plant Vogtle, Diatometer) constitute the primary biological history of the Savannah River in the region of the Savannah River Site from 1951 through 1996. Beginning with the 1997 survey, modifications in the program were implemented. These changes combined aspects of all four studies into a single program that is referred to herein as a comprehensive study. The primary changes included sampling at Station 2B (formerly Vogtle Station V-2) rather than Station 3, Diatometer monitoring monthly (biweekly in 1996), quantitative insect sampling semiannually (semiannually in 1996 and quarterly in 1995), qualitative algal and macrophyte studies 


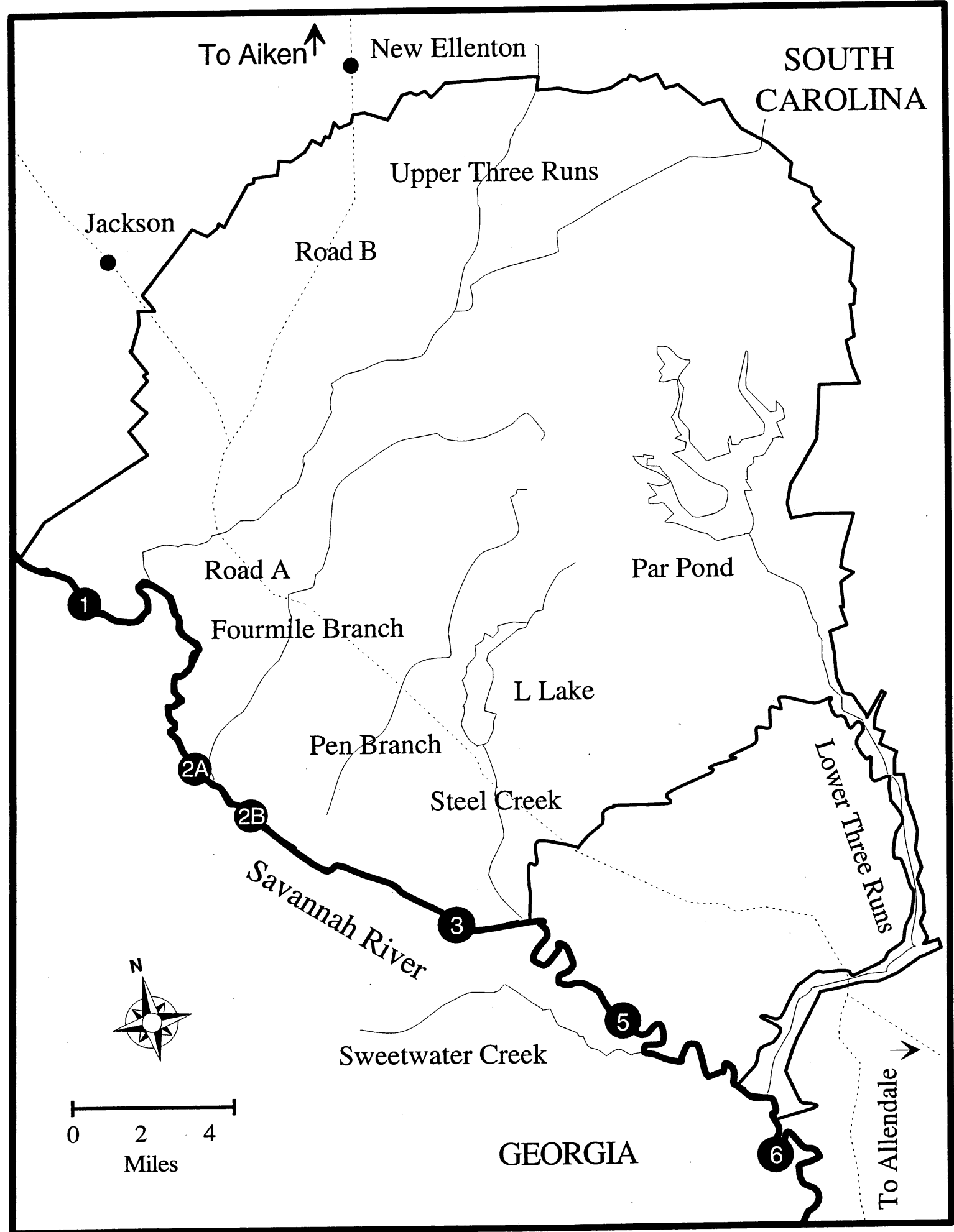

Figure 1. Survey stations on the Savannah River in the vicinity of the Savannah River Site. Stations 1, 2A, 2B, 5 and 6 were sampled for the 2000 Diatometer studies and Stations 1, $2 \mathrm{~B}, 5$ and 6 were sampled for the comprehensive investigation. 
annually [annually in 1996 (generally biannually in cursory studies and quarterly in comprehensive investigations)]. Further modifications were made in the program beginning in 1999. These included the qualitative algal study concentrating on filamentous algae (archiving diatom samples) and noting only significant changes in the aquatic vascular plant flora. Protozoan surveys were omitted from the Academy studies in 1999.

Major alterations in the river during the survey years have been due to dredging and the creation of oxbows by cutting off meanders. These modifications have changed base flows and altered or removed sheltered habitats, as well as resulted in spoil deposition and siltation. The increased development of beds of aquatic plants that started with upriver controls of river flows reached their peak by the time of the 1972 survey. At this time luxuriant beds of aquatic vascular plants were present in the river and presumably reflected elevated organic loadings from effluents emanating from the Augusta, Georgia area. By the 1976 survey, improved effluent treatments resulted in an improvement in water quality and a sharp reduction in the extent of the vascular plant beds. Since 1990, submerged aquatic vascular plant beds have been absent from the main stem of the Savannah River.

For 2000, a comprehensive study was conducted in April and August/September (comprehensive studies in the September to October period have historically been referred to as the fall survey). The impacts of water conditions and vegetation to particular elements or sampling methods are discussed in each section. See the section River Gauge Height for a discussion of river heights and their relevance to the field sampling effort. 


\title{
PERSONNEL AND ACKNOWLEDGMENTS
}

7 hese studies were performed under the supervision of Dr. David D. Hart, Director, of the Patrick Center of Environmental Research of The Academy of Natural Sciences of Philadelphia. Dr. Raymond W. Bouchard, Project Leader, was responsible for the professional quality of all field and laboratory work. Robin S. Davis, Scientific Editor, coordinated all the data for the report for this program. The direction and implementation of individual project elements were the responsibility of the Principal Scientific Investigators. The following are the personnel who participated in the 2000 Savannah River studies.

\section{Diatometer Studies}

Supervisor and Principal Scientific

Investigator: Frank Acker, M.S.

Laboratory Biologists: Frank Acker, M.S.,

Heidi Brabazon, Erin Hagen and

Eduardo Morales, Ph.D.

Graphics: Su-ing Yong

Quality Assurance: Charles W. Reimer, Ph.D.

\author{
Algae Studies \\ Supervisor, Field Biologist and Principal \\ Scientific Investigator: Robert Grant, Jr. \\ Laboratory Biologists: Robert Grant, Jr. and \\ Frank Acker, M.S.

\section{Macroinvertebrate Studies} \\ Supervisor and Principal Scientific Investigator: \\ Raymond W. Bouchard, Ph.D. \\ Field Biologists: Raymond W. Bouchard, Ph.D., \\ Judith W. Bouchard, M.S. Roger Thomas and \\ Paul Overbeck \\ Laboratory Biologist: Raymond W. Bouchard, Ph.D.
}



the sun's energy into forms usable by other organisms. Free oxygen as a by-product of this process is an essential element of most aquatic organisms. Macrophytes and large filamentous algae are important as shelter and habitat for the aquatic fauna. Macroinvertebrates are an eclectic assemblage that provide the main route of energy flow between the primary producers (algae) and particulate organic matter to higher trophic levels such as fishes. Because of the sedentary nature of many species and their wide range of pollution tolerances, they are viewed by state and federal environmental agencies as one of the most important measures of the health of an aquatic ecosystem. In general, fishes are the top carnivores in the ecosystem and those species of greatest interest to the public. Because of their value and popularity, they constitute, with invertebrates, the groups of most concern by regulatory agencies in monitoring the health of aquatic ecosystems.

Shallow-water habitats are generally considered to contain the greatest proportion of species in a riverine environment, and therefore these areas were studied most intensively. Benthic organisms which are sessile or which move only relatively short distances give the most accurate indication of conditions in a river over time, while bacterial and chemical studies indicate conditions only at the time of sampling. In addition to the impact of river heights on the biota and the sampling thereof, which are discussed in the section "River Gauge Height," there has been a conspicuous absence of submerged aquatic vascular plant beds beginning with the 1990 study. Loss of this vegetation and factors that may have led to its absence (e.g., rapid changes in the hydrodynamics of the river from flooding and shifting substrates and turbidity) are coincident with changes reflected in the biota. 


\section{LOCATION AND DESCRIPTION OF STATIONS}

Monitoring programs

include routine

examination of both

reference and indicator

locations to assess

potential impacts.
The areas of a river chosen for comparative study should include stations which have comparable ecological habitats. This assures that the possibility of finding a particular species is equal at all stations. The total area of the station is considered less important than the inclusion of all types of habitats. Among the general conditions considered in selecting stations are:

(1) structure, contour and stability of the riverbed;

(2) current and sedimentation;

(3) type and quantity of debris;

(4) surrounding vegetation;

(5) logistic factors.

To assess the impact of a particular effluent upon its receiving waters, sampling must be conducted in ecologically similar habitats in river segments influenced by the discharge and in an area unaffected by the specific discharge. In this manner, the effects of the discharge on the aquatic community can be isolated from natural factors or non-point sources of pollution. The general survey area is depicted in Figure 1. Four stations have been utilized for the comprehensive Savannah River studies. Although every effort is made to make the stations as comparable as possible in terms of habitat types, Stations and 5 and 6 appear to be more similar physically than the other stations. They occur in a more downriver meandering section of the river and contain nearby oxbows and sloughs as potential sources of biota. The locations and general habitats of the stations are discussed below. Due to modifications of the river by the US Army Corps of Engineers between the 1955/56 and 1960 studies, Station 5 was stranded in a newly created oxbow. Since the main channel bypassed this station, a new Station 5 was established a short distance away in 1960. This new station has been utilized in all subsequent surveys. Modifications to the river have also changed distances of the stations from the mouth of the Savannah River. Therefore, the river mile (RM) designations 
for stations herein will not correspond to those in the older studies at all stations in 1951/52 to 1965 and Stations 1, 5 and 6 in 1968. Also the lengths of stations have been designated in certain past studies as slightly smaller or larger than presently depicted. Sampling slightly outside the designated areas has also occurred in order to include a particular biotope among the station samples.

\section{Station 1 (Fig. 1)}

This station comprises a section of the river upstream from Upper Three Runs Creek and any potential impacts of the SRS. The area lies approximately between RM 160.35 and RM 160.85, Burke County, Georgia, and Aiken County, South Carolina. The upper limit of the station is about 1.0 river mile downriver from Shell Bluff Landing, Burke County, Georgia. Pilings (\#78) are present near the upper limit of the station on the left (oriented downriver) or South Carolina side of the river, and the lower boundary is marked by a rip rap right bank and small tributary on the Georgia side of the river. Sandy beaches are present among the pilings. Electrofishing (rotenone in the past) sites originally consisted of residual pools behind a low levee next to the pilings. Due to siltation of these pools, two new upriver localities were selected. The first appropriate sites occurred downriver from Jackson's Landing, Aiken County, South Carolina. These two areas, associated with oxbows, are located at RM 168.9 in the upstream arm of an incipient oxbow near the main course of the Savannah River and in the inconspicuous upstream arm of an oxbow near RM 169.6. This reach of the river is here designated as Station 1A. At higher water levels electrofishing may still occur at Station 1.

\section{Station 3 (Fig. 1)}

tation 3 comprises a section of the river downriver
from Fourmile Branch and upstream from Steel Creek.
This station has only been surveyed during the compre-
hensive surveys every three to five (usually four) years from
1951 through 1993. Station 3 was not examined in the 1997
comprehensive investigation and is noted herein as a refer- 
ence when historical comparisons are made of the biota. It lies between RM 143.6 and RM 144.0, Burke County, Georgia, and Barnwell County, South Carolina. The lower limit of the station is near Brigham's Landing, Burke County, Georgia, and beaches on the opposite (South Carolina) side of the river. Pilings (\#56A and \#58) are present on the South Carolina side of the river with sandy beaches among the set of pilings. Near the lower boundary of the station is a steep rip rap right bank and small tributary on the Georgia side of the river near the landing. Electrofishing (rotenone in the past) areas occur in a backwater portion of the river below the downrivermost (= ultimate) row of pilings and in a residual pool behind a low levee between the penultimate and ultimate sets of pilings. The water level in this latter pool is controlled by a small outlet between the two aforementioned sets of pilings.

\section{Station 5 (Fig. 1)}

This station comprises a section of the river downriver
from Steel Creek and upstream from Lower Three
Runs Creek. It lies between RM 135.35 and RM 135.85, Allendale County, South Carolina, and Burke County, Georgia. The lower end of the station is approximately 0.8 river miles upstream from the oxbow entrance to Little Hell Landing, Allendale County, South Carolina. Pilings (\#55) are present on the Georgia side of the river near the upriver limit of the station. The oxbow at Devil's Elbow, Georgia, and a large sandy beach on the South Carolina side of the river mark the lower end of Station 5. A small outlet stream of the Savannah River occurs on the left bank (Wild Horse Slough or Swift Gut) with a steep rip rap bank downriver. Electrofishing (rotenone in the past) sites lie at the entrance of Wild Horse Slough and in an area behind a levee opposite Devil's Elbow. Behind the levee occurs a series of pools and the second downriver one is usually sampled. The present Station 5 was established in 1960 a short distance from its original siting after dredging and removal of river meanders between the 1955/56 and 1960 studies stranded the original station in a newly created oxbow. 


\section{Station 6 (Fig. 1)}

The downrivermost Savannah River station lies below the confluence with Lower Three Runs Creek, Screven County, Georgia, and Allendale County, South

Carolina. The upper end of the station is 1.75 river miles downriver from Johnson's Landing, Allendale County. The station consists of two sections referred to in the 1984, 1989 and 1993 studies as reaches. The upper reach, located between RM 123.00 and 123.55, contains a large sand beach on the left (South Carolina) bank near its upper end and another sand beach and large backwater along the right (Georgia) bank. The lower reach ranges from RM 122.85 downstream to RM 122.35. The upper limit of this reach includes a large left (oriented downriver) bank backwater at Ring Jaw Point and the lower extent is marked by a set of pilings (\#42) on the same side of the river. A large sand bar extends out and toward the left bank at Ring Jaw Point. Presently electrofishing (rotenone in the past) takes place at the back end of the backwater and along the peninsula behind Ring Jaw Point or, as in 1996 , at the back end of the backwater and at the \#42 pilings. Rotenone sampling began at Ring Jaw Point in 1968 in conjunction with the traditional Station 6 (large right bank backwater in the upper reach). From 1972 to 1994, the use of rotenone was confined to the South Carolina side of the river because sampling with rotenone was no longer permitted on the Georgia side. Beginning with the 1981 cursory survey, the pilings at the lower reach of Station 6 were sampled for algae. This same habitat was utilized for the next comprehensive study in 1984 by both the algal and protozoan investigators. In the 1989 comprehensive study, the insect, non-insect macroinvertebrate and fisheries (gill nets at pilings and rotenone at Ring Jaw) sampled the lower reach of Station 6. Prior to 1981 , other groups also, at times, extended their sampling from the upper reach into the backwater behind Ring Jaw Point. Currently only the fisheries comprehensive investigation continues to utilize the upper (seining along the sandy left bank beach) and lower reaches of Station 6 . 


\section{Station 2A (Fig. 1)}

This station comprises a section of the river upstream from Plant Vogtle at Mile 151.2, approximately 0.75

mi downstream (east) from Hancock Landing, Burke County, Georgia, across from Barnwell County, South Carolina. Pilings (\#72) are present on the South Carolina side of the river and mark the downstream limit of the station. Sandy beaches are present among the pilings, and a sandy beach is present at the upstream limit of the station on the Georgia side of the river. Electrofishing (rotenone in the past) areas occur up- and downriver from the downstreammost row of pilings. Only Diatometer monitoring took place at this station in 1997 and a mussel survey in 1998. This Station was not studied in 1999 or 2000.

\section{Station 2B (Fig. 1)}

This station comprises a section of the river at Mile 149.8 , approximately $0.25 \mathrm{mi}$ downstream (east) from Blue Bluff, Burke County, Georgia, across from Barnwell County, South Carolina. This station is located approximately $1 \mathrm{mi}$ downstream from the Vogtle Plant cooling water discharge. Pilings (\#68) are present on the South Carolina side of the river and mark the downstream limit of the station. Pilings (\#69) are also present on the Georgia side of the river and mark the upstream limit of the station. There are sandy beaches among both sets of pilings. Electrofishing (rotenone in the past) areas occur up- and downriver from the downrivermost row of pilings.

\section{Reference Materials}

The locations, mileages and piling numbers in this description are taken from the following sources:

1. United States Army Corps of Engineers (USACE), 1990. Navigation Charts, Savannah River, GA \& SC, Savannah to Augusta. USACE. Savannah, GA. 49 pp. 
2. Nautical chart 635-SC, Savannah River, Brier Creek to Augusta, South Carolina - Georgia. U.S. Department of Commerce, National Oceanic and Atmospheric Administration, National Ocean Survey.

The pilings themselves are marked with readily visible numbers attached near the top of one piling in each set. 


\section{RIVER GAUGE HEIGHT}

7 iver discharge levels, both prior to and during sur-

veys, are an important factor to consider when com-

- Daring survey results with those of prior years. The

extent to which suitable shallow-water habitat is available for the colonization of riverine organisms is often correlated with river stage, as well as with the degree of daily fluctuations in flow. Generally, larger, more diverse populations are collected throughout a study area when flow is low to moderate and has been rather constant for two or more weeks prior to field collections. In contrast, unusually high flow, or large daily fluctuations in discharge just prior to or during a survey can lead to smaller, less diverse population samples. This is often merely a reflection of habitat accessibility to the investigator; however, it may also reflect true differences in habitat availability to the organisms of interest.

Figure 2 displays the estimated mean daily gauge heights for the Savannah River at Augusta, Georgia, for 2000, with the survey periods highlighted. 


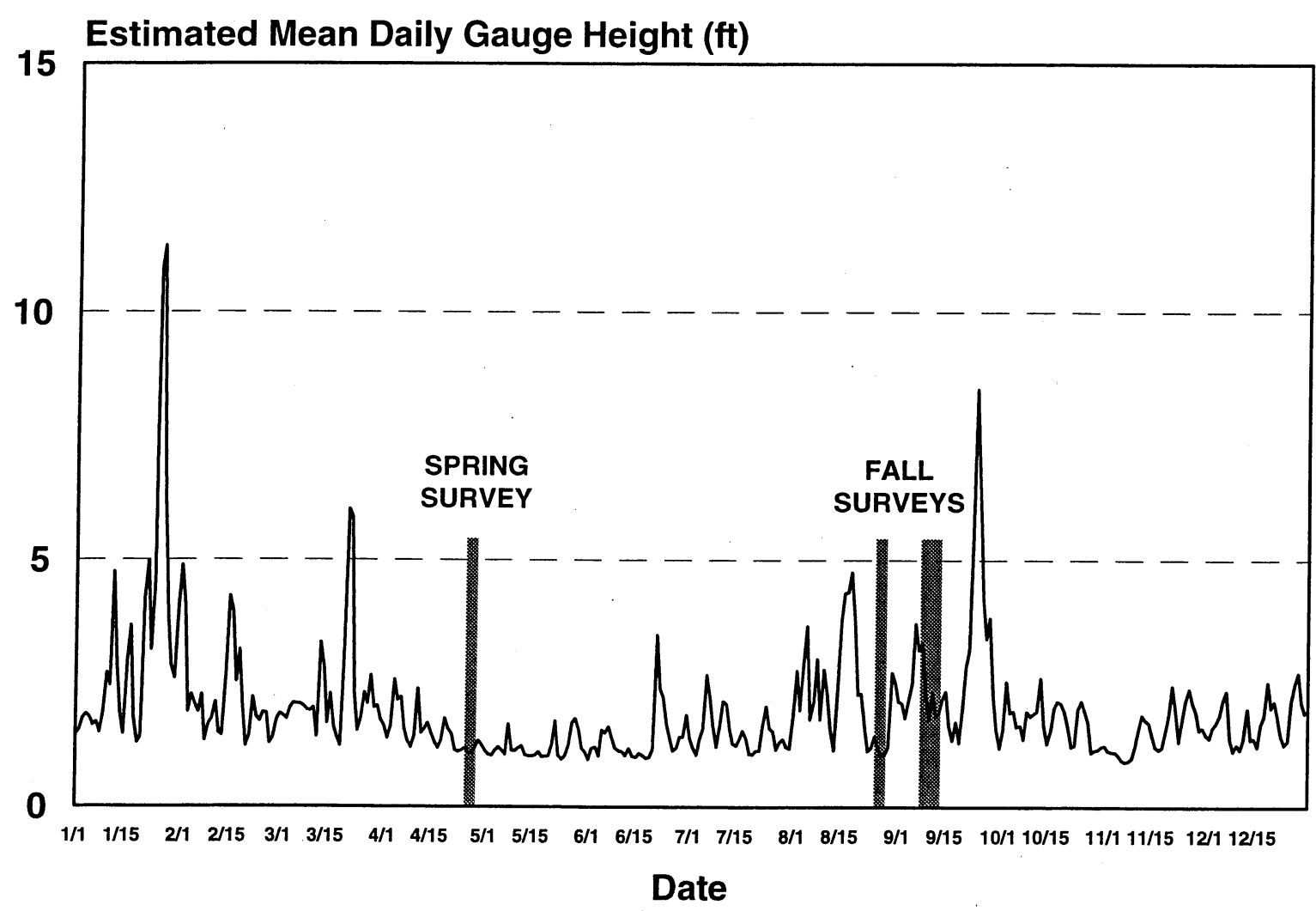

Figure 2. Estimated 2000 mean daily gauge heights of the Savannah River at Augusta, Georgia. A few original gauge height values were missing from the original USGS dataset. These values were calculated or derived from existing USGS discharge and gauge height data recorded at the same site. Shaded vertical bars indicate the approximate sampling time for aquatic insects in April, mussels in August, and algae, macroinvertebrates, aquatic insects and fishes in September. Diatometer monitoring occurred semimonthly from January through December 2000. 


\section{A. DIATOMETER STUDIES}

\section{Methods and Procedures}

\section{Sampling Method}

D iatoms were collected by a device called a Catherwood Diatometer (Fig. A-1), an apparatus designed to sample the diatom flora in a continuous and nonselective manner. Vertically oriented glass slides serve as artificial substrates for colonization by diatoms. The diatometers are designed to float so that the slides remain just below the water's surface. They are secured to pilings and/or tree branches by means of nylon cord and, by adjusting the length of this cord, they are kept afloat at all times, regardless of changing water levels.

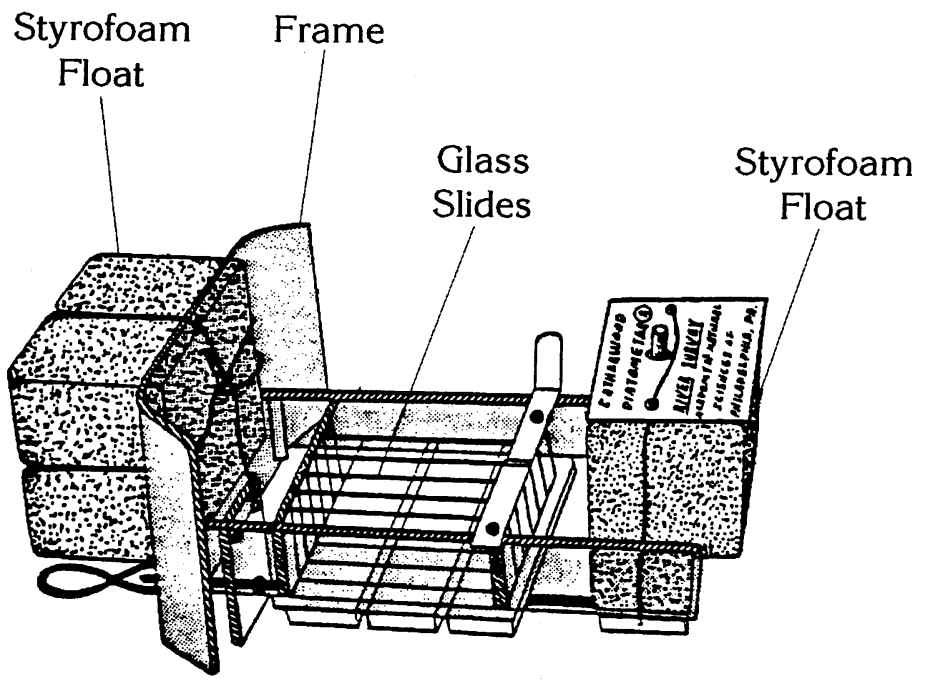

Figure A-1. Diagram of a Catherwood Diatometer. 
Diatometers were deployed at five stations (1, 2A, 2B, 5 and 6; Fig. 1) along a 59.9-km (37.2-mi) stretch of the Savannah River in the vicinity of the SRS. At each station, two diatometers were placed near the left bank and one diatometer was located near the right bank (by convention, right and left banks are determined by facing downstream). With the exception of Station 2A, slides from one diatometer at each station were analyzed for 12 monthly 2 -wk exposure periods (slides for Station 2A were stored for future reference). When possible, slides from a diatometer positioned on the side nearest the SRS (left bank) were analyzed (diatometers at Station 6 were lost during deployment for the October exposure period).

Previous studies (Patrick, Hohn and Wallace 1954) have determined that an exposure period of two weeks is optimal for the collection of a representative growth of diatoms. Exposure periods for 2000 studies are shown in Table A-1. After exposure, the glass slides are removed from the diatometers and allowed to air dry. The diatometers are replaced by cleaned diatometers and the exposed slides are shipped to The Academy's laboratory in Philadelphia for processing and retention as a permanent record of water conditions.

Table A-1. Dates of Installation and removal of diatometer slides for the report period 4 January through 27 December 2000, Savannah River, South Carolina. Slides from near the left bank at each of four stations $(1,2 \mathrm{~B}, 5$ and 6$)$ were analyzed according to the semi-detailed method (slides from Station $2 A$ were stored for future reference).

\begin{tabular}{cll}
\hline Exposure Period* & \multicolumn{1}{c}{ Installation Date } & \multicolumn{1}{c}{ Removal Date } \\
\hline 2 & January 4, 2000 & January 18, 2000 \\
4 & February 1, 2000 & February 15, 2000 \\
7 & March 21, 2000 & April 4, 2000 \\
9 & April 18, 2000 & May 2, 2000 \\
11 & May 17, 2000 & May 30, 2000 \\
12 & June 13, 2000 & June 27, 2000 \\
14 & July 5, 2000 & July 18, 2000 \\
17 & August 15, 2000 & August 29, 2000 \\
19 & September 6, 2000 & September 19, 2000 \\
22 & October 17, 2000 & October 31, 2000 \\
24 & November 14, 2000 & November 28, 2000 \\
26 & December 12, 2000 & December 27, 2000 \\
\hline
\end{tabular}

*Exposure period refers to the closest approximation to one of the 26 yearly 2-wk exposure periods monitored from 1978 through 1997.

a In addition to the semi-detailed reading analysis, the detailed reading analysis was performed during these exposure periods.

${ }^{b}$ Diatometers at Station 6 were lost during deployment. 


\title{
Laboratory Techniques
}

7 he dried slides are first soaked in distilled water, making it possible to remove the diatoms without breakage by scraping the glass slides. The material is then cleaned by a nitric acid digestion procedure (CEM Model 2000 microwave digestor) and, after rinsing by a repeated sedimentation and decanting process, resuspended in $20 \mathrm{ml}$ of distilled water. This procedure removes all organic material from the sample, leaving the empty siliceous shells (frustules) of the diatoms. A known quantity of the cleaned material is placed on an $18 \times 18-\mathrm{mm}$ coverslip, air-dried and mounted in Naphrax (a synthetic mounting medium of refractive index 1.6; ANSP SOP P-13-49) on a glass microscope slide.

\section{Identification and Counts}

\begin{abstract}
$\mathbf{S}$ pecimens on the prepared slides were progressively identified to species and variety, and counted and recorded using a compound microscope with an oil immersion objective and a minimum magnification of 1000x. The semi-detailed reading method (ANSP SOP P-13-09) was employed for all exposure periods, while the detailed reading method (ANSP SOP P-13-39) was also employed for the exposure periods ending 2 May and 31 October 2000. In the detailed readings, between 6,000 and 28,000 specimens were counted and identified until the criteria for a lognormal distribution, as described in Patrick, Hohn and Wallace (1954), were met. In the semi-detailed readings, after an initial count of one row or an approximately $2.5-\mathrm{mm}^{2}$ area of the coverslip, the total number of specimens per species was no longer recorded. The coverslip was then scanned for new species over an area determined from previous detailed readings to represent the area of a completed lognormal curve, as described by Hohn (1961). These methods ensured that comparable units of assemblages were compared from station to station and from year to year.
\end{abstract}




\section{Data Analysis}

7 he underlying assumption of the reading methods is that the relative abundance of diatom species of unpolluted rivers closely follows a lognormal distribution, with a few species very abundant and a few very rare, but the majority of the species represented by populations of moderate abundance. This type of distribution is represented in Figure A-2, with numbers of species in a hypothetical diatom assemblage grouped as a function of the numbers of individuals representing each species. The vertical axis identifies the numbers of species whose respective individuals fall within the log-scaled intervals of the horizontal axis. The mode of an extended count needed to produce such a curve is ideally positioned in the third interval. The body of the curve is composed of the majority of species, which are represented by populations of moderate abundance.

In Figure A-3, a hypothetical diatom assemblage that might be found in a polluted river is represented. Polluted conditions are often indicated by the loss of many species in the system. The body of the curve is composed of many fewer species represented by populations of moderate abundances and the tail of the curve is extended as the abundances of the dominant species become relatively greater.

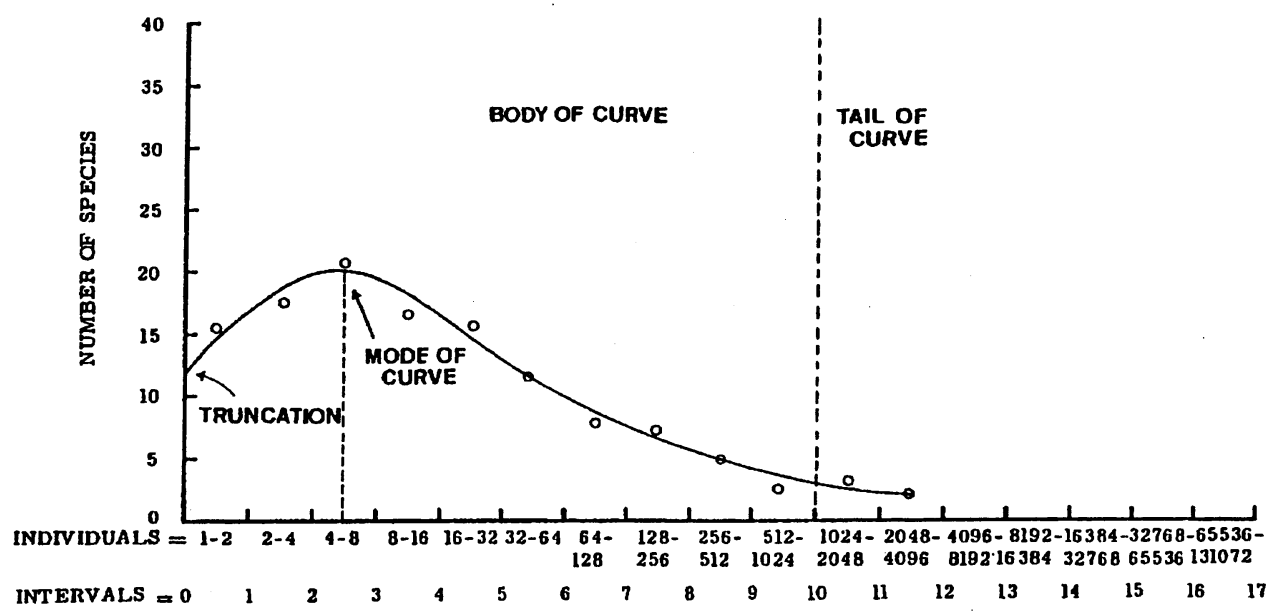

Figure A-2. Example of a lognormal curve fit to the frequency distribution of species within a hypothetical diatom assemblage not affected by pollution. 


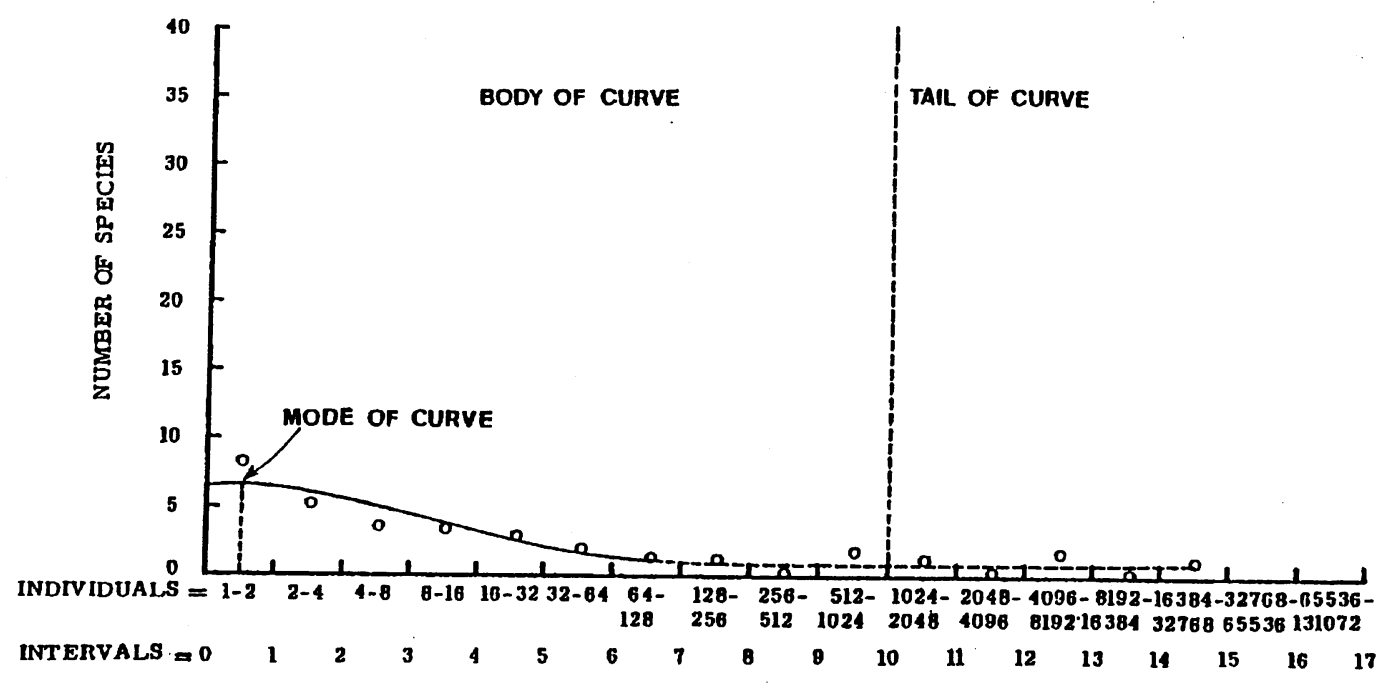

Figure A-3. Example of a lognormal curve fit to the frequency distribution of species within a hypothetical diatom assemblage severely affected by pollution.

The method used to construct these curves was adapted from procedures described by Patrick, Hohn and Wallace (1954), Cohen (1961) and Hendrickson (1998).

The model of a truncated normal curve to express the structure of a natural community of organisms was first used by Preston (1948) to express the structure of the communities of birds and moths. Patrick, Hohn and Wallace (1954) found that this method of analysis was excellent to show the structure of natural diatom communities.

\section{Observed Species Number: Richness Parameter}

7 he number of observed species (the number of species recorded at the termination of the count) in an assemblage is used as a direct measure of richness as expressed by species numbers. The termination of the count was based on the area determined from previous detailed readings of Savannah River diatometer slides to represent the area of a completed lognormal curve, as described by Hohn (1961); thus, the numbers of observed species can be compared among stations and reflect the species richness of the sample. 


\section{Percent Dominance: Assemblage Dominance Parameter}

he degree of assemblage dominance is a measure of
unevenness of an assemblage. In the majority of natu-
ral situations, most species have medium-sized populations; a few species are more common, and a few more rare. In this report, percent dominance is operationally defined as the percentage of the total specimen count made up of species with abundances greater than 1,024 individuals in a completed detailed reading (those populations falling beyond the 10th interval of a lognormal frequency distribution; Fig. A-3). In assemblages not affected by pollution in soft water rivers, the curve may extend over 12 intervals, thus exhibiting some degree of dominance.

\section{Shannon-Wiener Diversity Index}

he Shannon-Wiener Diversity Index (SWDI) is a pa-
rameter based on information theory (Shannon and
Wiener 1949) that expresses the concept of community diversity. The parameter is composed of both richness and evenness components.

\section{Species Relative Abundances}

$\mathbf{R}$ elative abundances of the dominant diatom species were calculated and plotted for the entire study period. Data were examined graphically to determine any seasonal or spatial patterns in the distribution of these species.

\section{Statistical Methods}

he parameters tested by statistical analyses (richness,
dominance and Shannon-Wiener Diversity) were
ranked among the four stations for each exposure period and an analysis of variance (ANOVA) was performed on these ranked values. A level of $\alpha=0.05$ was chosen as significant. A multiple range test (Ryan-Einot-Gabriel-Welsch; SAS Institute) was performed to locate any significant pairwise differences found in the ANOVA. 


\title{
Results
}

\section{Semi-Detailed Reading Analyses}

\section{Diatom Community Parameters}

\begin{abstract}
imilar to the previous three study years (1997 to 1999), diatom assemblages were analyzed from more stations (4 in 2000 compared with 2 or 3 prior to 1997) and for fewer exposure periods (12 in 2000 compared to 26 in years prior to 1997) in 2000 than earlier studies (1978 through 1996). There were fewer consistent trends, though a few seasonal and spatial (i.e., station) trends are evident. The results of the statistical analyses (ANOVA; Table A-2) indicate that assemblage evenness (converse of percent dominance) and diversity (Shannon-Wiener Diversity Index) were consistently higher at the reference station (Station 1) than at the SRS stations (Stations 2B, 5 and 6; $\alpha=0.05$ ). The number of diatom species (a parameter of assemblage species richness; Fig. A4) showed no statistically significant pairwise differences among stations (means of 94, 82, 73 and 68 and medians of 97, 71, 72 and 48, at Stations 1, 2B, 5 and 6, respectively; Table A-3), and few values exceeded 100 (only 2 to 4 values at each station exceeded 100 in 2000). Frequent large differences ( $50 \%$ or more) between the reference and SRS stations
\end{abstract}

Table A-2. Results of analyses of variance of diatom community parameters of richness, evenness and diversity for the 2000 study year; Savannah River, South Carolina. Stations in the last colun are listed in order of decreasing mean for each parameter.

\begin{tabular}{lcccc}
\hline & $\begin{array}{c}\text { Degrees of } \\
\text { Freedom } \\
\text { Error/Station }\end{array}$ & F & P & $\begin{array}{c}\text { Multiple } \\
\text { Range } \\
\text { Test }\end{array}$ \\
\hline $\begin{array}{l}\text { Number of } \\
\text { Diatom Species }\end{array}$ & $10 / 4$ & 4.834 & 0.0055 & $\overline{12 \mathrm{~B} \mathrm{56} 6}$ \\
$\begin{array}{l}\text { Percent } \\
\text { Dominance }\end{array}$ & $10 / 4$ & 10.308 & 0.0001 & $\overline{652 \mathrm{~B}} 1$ \\
$\begin{array}{l}\text { Shannon-Wiener } \\
\text { Diversity Index }\end{array}$ & $10 / 4$ & 7.968 & 0.0002 & $\overline{1} \overline{2 \mathrm{~B} \mathrm{5} \mathrm{6}}$ \\
\hline
\end{tabular}




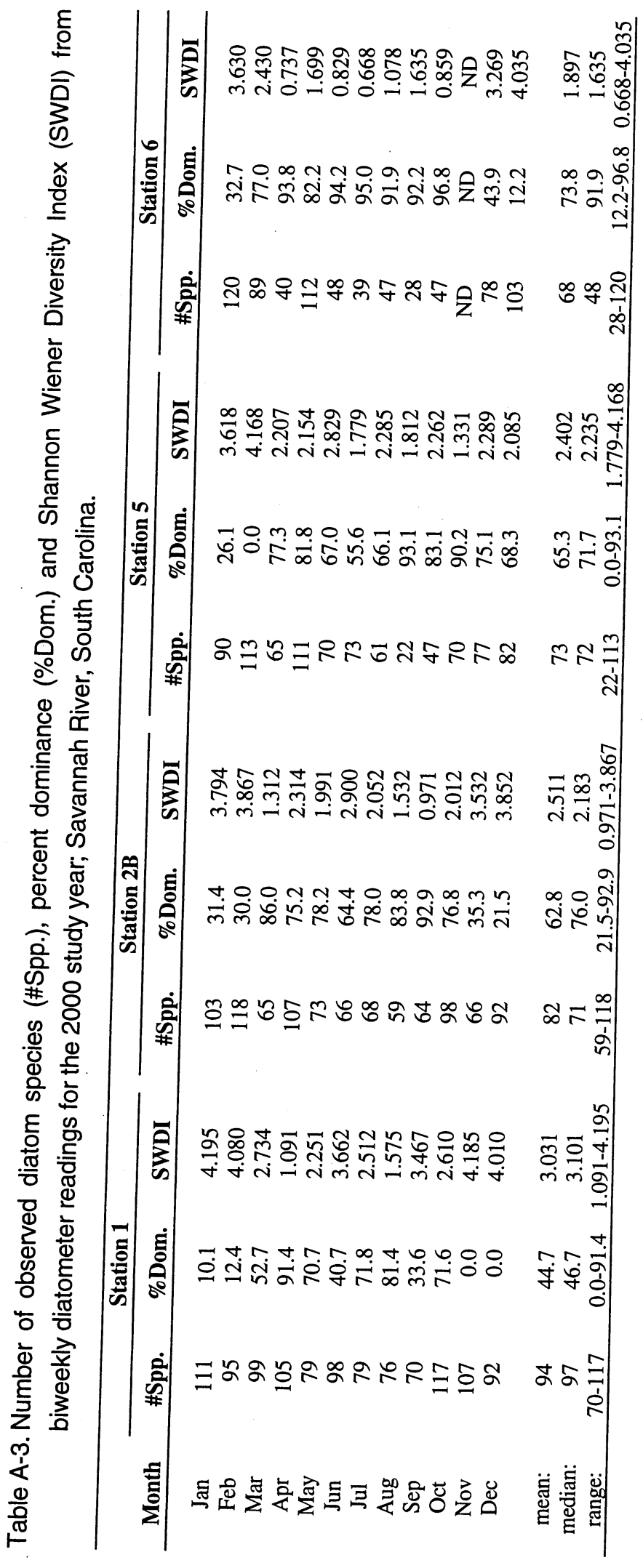




\section{Number of Diatom Species}

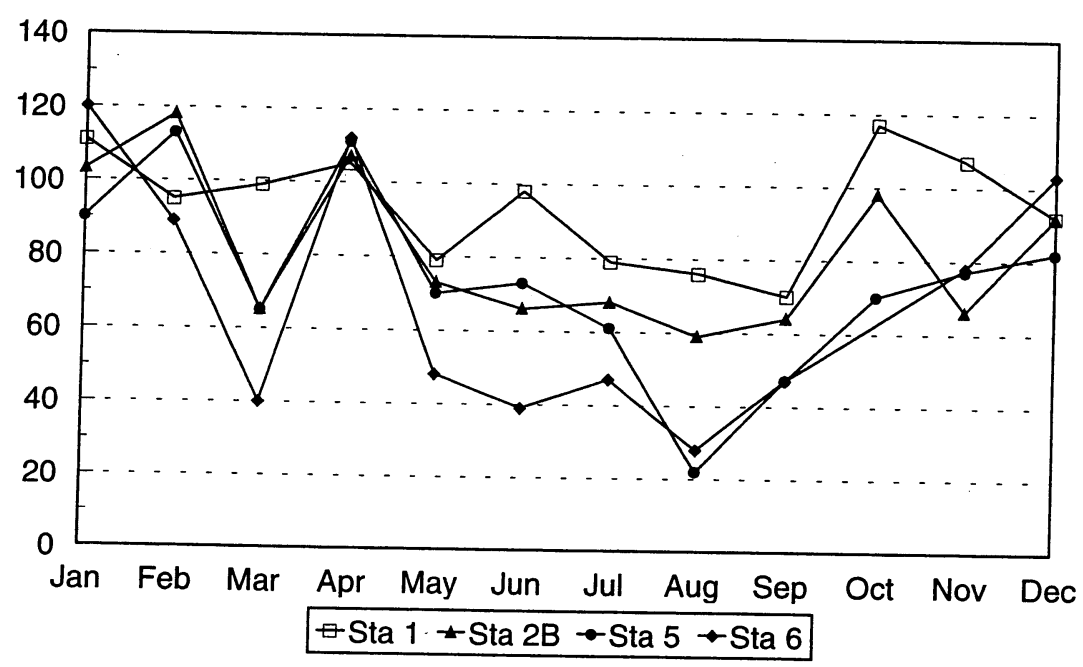

Figure A-4. Number of diatom species from diatometer readings for exposure periods ending 18 January through 27 December 2000; Savannah River, South Carolina. (See Table A-1 for dates of installation and removal of diatometers.)

were observed only for the station below Lower Three Runs (Station 6; decreases of 39-63\% occurred for 5 of the 6 exposure periods from March through August). The number of species was usually lower at the upper SRS stations than at the reference station (for 9 and 10 of the 12 exposures periods at Stations 2B and 5, respectively); however, these differences were not usually large and not significant in the statistical analyses $(\alpha=0.05)$. Seasonally, the number of species was higher in the cooler months (all values that exceeded 100 were observed from January through April and October through December).

The assemblage parameter of evenness (converse of percent dominance; Fig. A-5) indicates that assemblages were significantly $(\alpha=0.05)$ more even at the reference station than at the SRS stations (percent dominance means of 44.7, 62.8, 65.3 and 73.8 and medians of 46.7, 76.0, 71.7 and 91.9 at Stations 1, 2B, 5 and 6, respectively; Table A-3). Excessive dominance (values greater than $90 \%$ ) was more common in 2000 than 1999 ( $21 \%$ of the percent dominance values were greater than $90 \%$ ), but still less frequent than in prior studies. Similar to prior studies, the cooler exposure periods (January- February and November-December) had the highest assemblage evenness (i.e., lowest percent dominance values). 


\section{Percent Dominance}

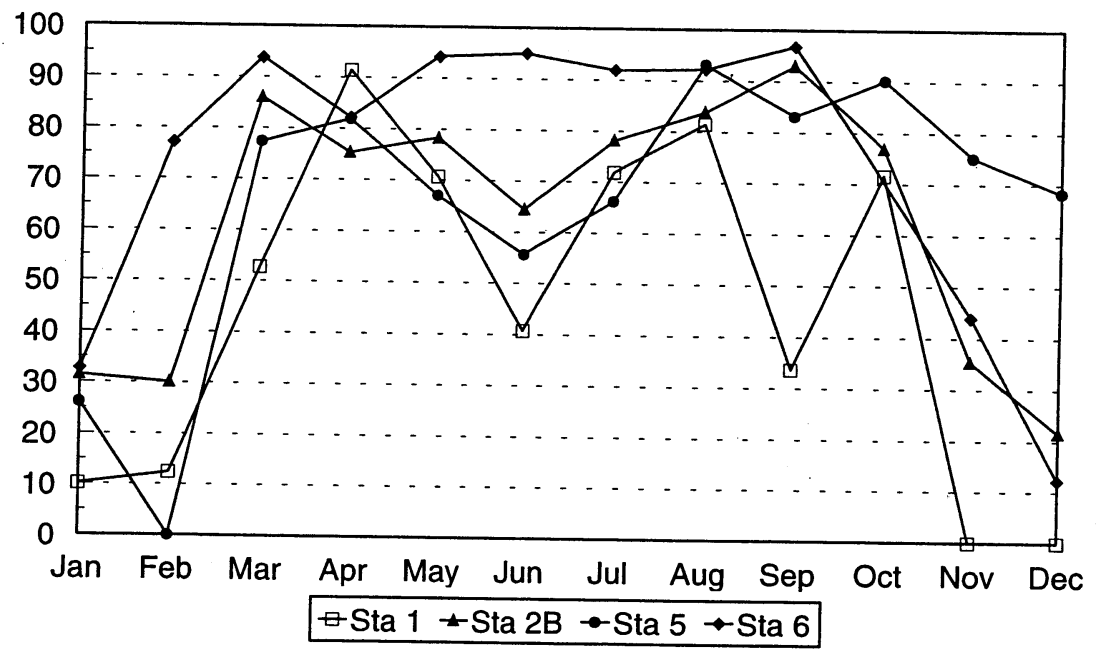

Figure A-5. Percent dominance values for diatom communities from diatometer readings for exposure periods ending 18 January through 27 December 2000; Savannah River, South Carolina. (See Table A-1 for dates of installation and removal of diatometers.)

Trends in the species diversity parameter (Shannon-Wiener Diversity Index [SWDI]; Fig. A-6) were similar to the evenness parameter, with significantly $(\alpha=0.05)$ higher species diversity at the reference station than at the SRS stations $(\alpha=0.05)$ (means of 3.031, 2.511, 2.402 and 1.897 and medians of 3.101, 2.183, 2.235 and 1.635 at Stations 1, 2B, 5 and 6 , respectively). The highest SWDI was observed during the coolest months (January-February and November-December) at all 4 stations ( 12 of the 13 values that exceeded 3.5 occurred during these months).

\section{Diatom Species Relative Abundances}

he seasonal and spatial patterns for the dominant dia-
tom species found during the study period 4 January
through 27 December 2000 are discussed below. Autoecological data for each species are compiled from several sources (Lowe 1974; Beaver 1981) including the ecology file of the Diatom Herbarium at the Academy of Natural Sciences of Philadelphia (ANSP). Data for comparison with other study periods came from previous reports (ANSP 1982; 1984a; 1984b; 1985a; 1988a; 1988b; 1990b; 1991c; 1992a; 1992b; 1993a; 1994c; 1995; 1996; 1997; 1998; 1999; 2000). 


\section{Shannon-Wiener Diversity Index}

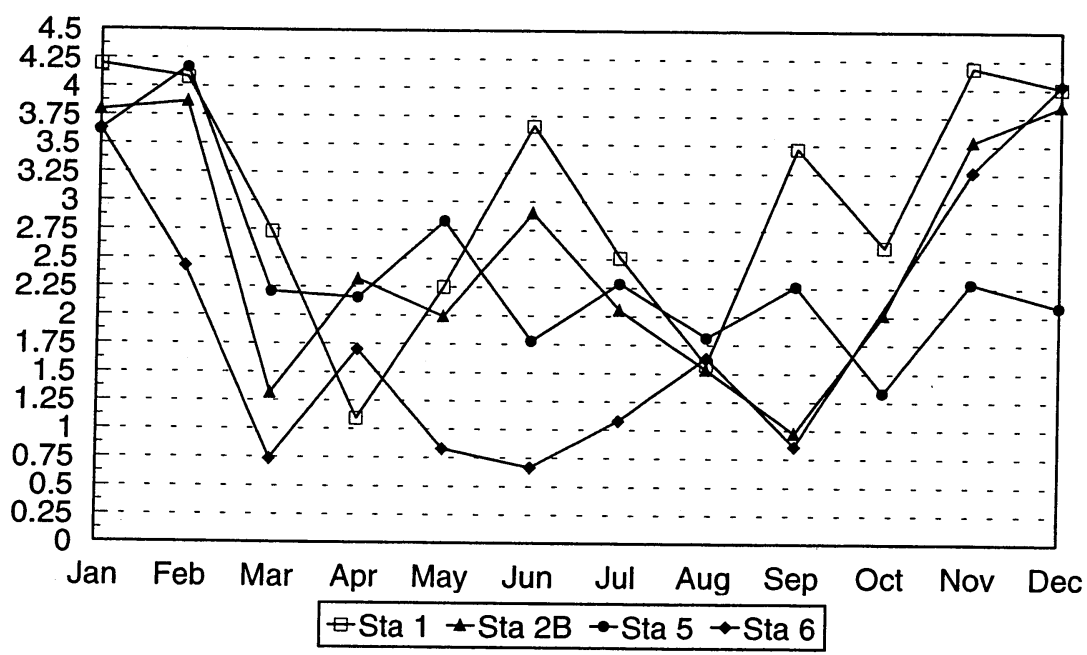

Figure A-6. Shannon-Wiener Diversity Index values for diatom communities from diatometer readings for exposure periods ending 18 January through 27 December 2000; Savannah River, South Carolina. (See Table A-1 for dates of installation and removal of diatometers.)

The rating of natural or polluted water species is from Patrick and Palavage (1994). In addition to the discussions of the 2000 study year trends, Appendix A-1 discusses the updated taxonomy and ecology of the dominant diatom species from 1978 through 2000. Appendix A-2 lists the updated taxonomy of the diatom species found in 2000 (compared to previous Savannah River Diatometer studies).

Achnanthes lanceolata subsp. biporoma (previous listed as $A$. biporoma and A. lanceolata var. biporoma; Fig. A-7)-was found only during the warmer months (June through October; relative abundances less than 3\% January through May and November through December). Relative abundances were lower at Station 1 (all $<5 \%$ ) and it was rarely abundant at Station $2 \mathrm{~B}$ (only 1 greater than $1 \%$ in June). The largest populations of this species occurred in June (64.6\% at Station 5) and August (33.7\% at Station 6). Achnanthes lanceolata v. biporoma was noted from 1982 through 1999 (except 1992), usually with highest relative abundances in warmer months and highest relative abundances at Station 5 (1983, 19871991, 1993-1995 and 1998). This species is characteristic of waters with $\mathrm{pH}$ near 7 and is found in natural waters. 


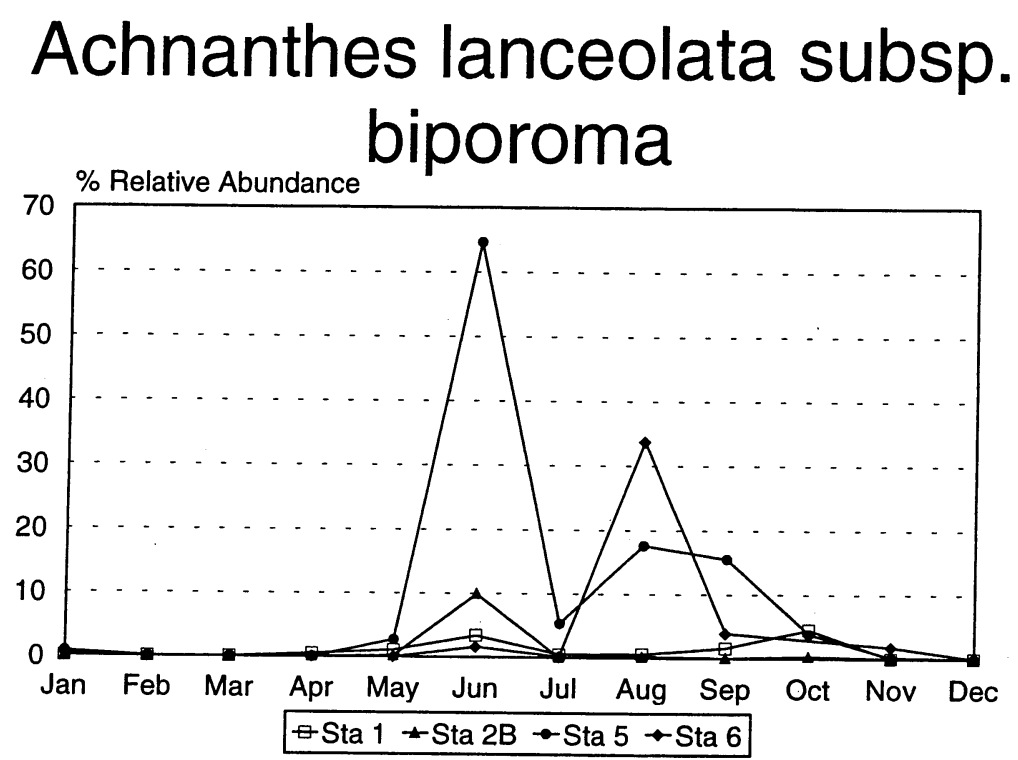

Figure A-7. Relative abundances (\%) of Achnanthes lanceolata v. biporoma for the 2000 study year; Savannah River, South Carolina.

Cocconeis fluviatilis —overall low in relative abundance; abundances were higher during the summer (exceeded $1 \%$ only in July and August). Highest relative abundances occurred at Station 5 (11.4\% in August; higher at Station 5 for two of the three values that exceeded $1 \%$ in the 2000 study year). This species has been a dominant in a few other study years (1981 through 1982, 1996 and 1999), but with very low relative abundances.

Cocconeis placentula v. lineata (Fig. A-8)-highest abundances occurred in warmer months (all relative abundance values that exceeded 5\% were observed from July through November) with largest populations in August (22.0 and $9.2 \%$ at Stations 5 and 6, respectively) and September $(22.3 \%$ at Station 5). Overall relative abundances were highest at Station 5 (four of five exposures that exceeded 5\%) and lowest at Station 2B (maximum of $3.2 \%$ in June). This species has been observed consistently as a dominant, with low relative abundances (1982 through 1989, 1994,1996 and 1999), usually during warmer exposure periods with few apparent spatial patterns. Cocconeis placentula v. lineata is characteristic of waters with $\mathrm{pH}$ greater than 7 (however, a large range, 4.79.0) and is found in natural waters.

Cyclotella meneghiniana-overall low in relative abundance (highest relative abundance of $2.4 \%$ at Station 5 in January) with highest values in cooler exposure periods (all values 


\section{Cocconeis placentula var. lineata}

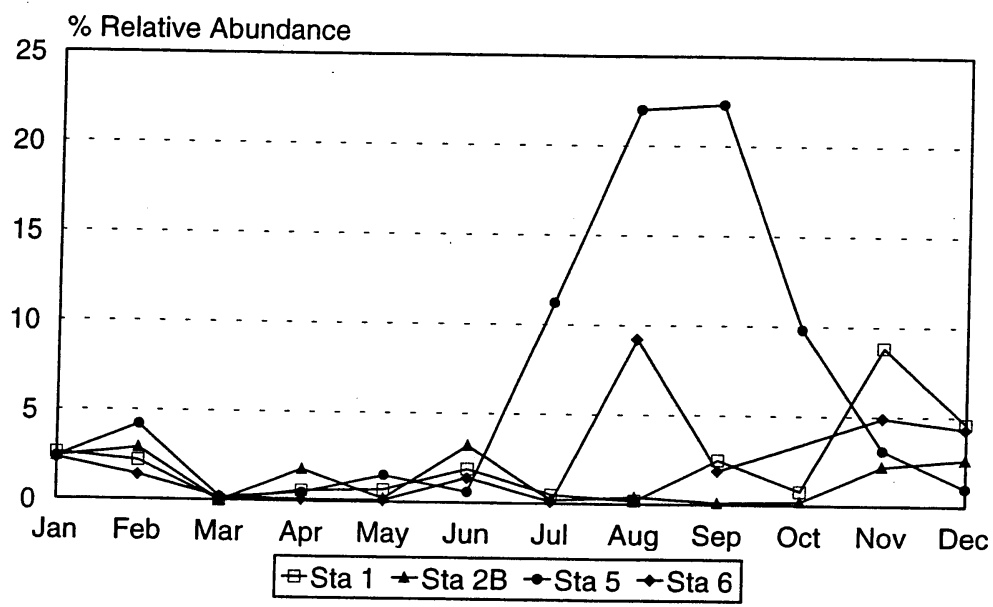

Figure A-8. Relative abundances (\%) of Cymbella minuta for the 2000 study year; Savannah River, South Carolina.

greater than $1 \%$ were observed in January through April and December). There were no discernible spatial patterns during the 2000 study year (exceeded $1 \%$ at each station in 2000).

Encyonema minutum (previously listed as Cymbella minuta) - low in overall abundance (highest relative abundances of $4.3,3.2$ and $1 \%$ at Stations $1,2 \mathrm{~B}$ and 5, respectively, for the May exposure period). This species was found mostly in April and May (less than $2 \%$ in all other months). Relative abundances were lowest at Station 6 (all values less than 1\%). This species has been observed consistently in the Savannah River diatometer studies (1982 through 1999), usually during warmer months (1998 through 2000 were exceptions) and usually with higher relative abundances at Stations 1 and 5 than at Station 6. E. minuta is found in natural waters.

Fragilaria capucina (Fig. A-9)—highest relative abundances occurred during cooler exposure periods (relative abundances exceeded $2 \%$ only during January through February and December). Spatial trends were hard to discern with largest populations during February (highest values of 10.8 and $19.4 \%$ at Stations 6 and 2B, respectively).

Fragilaria neoproducta (previously listed as Fragilaria construens var. venter; Fig. A-10)-highest relative abundances occurred during cooler exposure periods (relative abundances exceeded 5\% only in January through April and November through December). Relative abundances at Station 6 were 


\section{Fragilaria capucina}

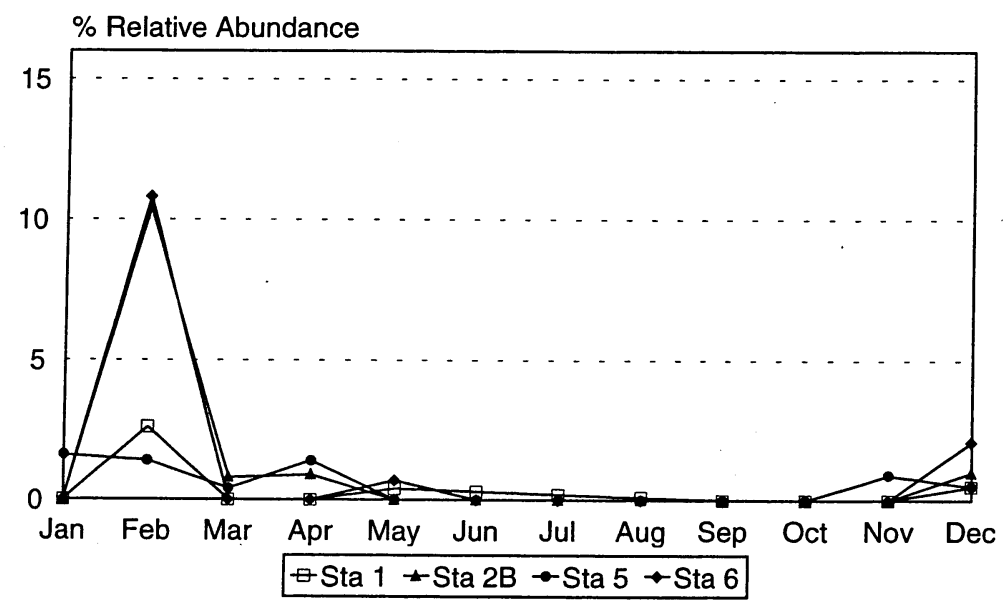

Figure A-9. Relative abundances (\%) of Fragilaria capucina for the 2000 study year; Savannah River, South Carolina.

\section{Fragilaria neoproducta}

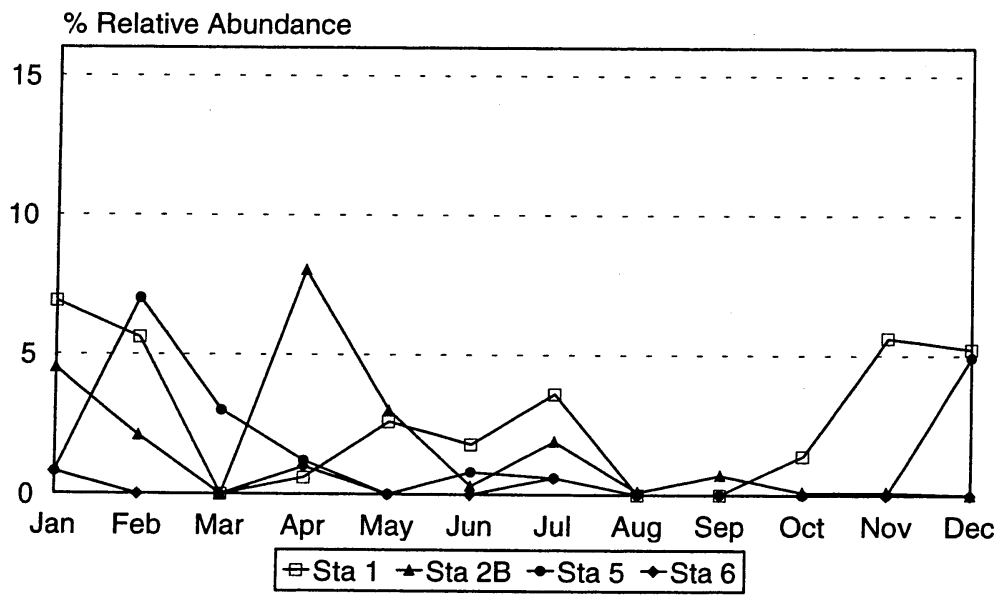

Figure A-10. Relative abundances (\%) of Fragilaria neoproducta for the 2000 study year; Savannah River, South Carolina.

lowest (highest relative abundance was $1 \%$ ) with most abundant populations in different months at different stations (populations of $8.0,7.0$ and $6.9 \%$ at Stations $2 \mathrm{~B}, 5$ and 1 , respectively for the exposure periods ending in April, February and January).

Fragilaria vaucheriae (Fig. A-11) - generally low in relative abundance (all values less than $8 \%$ ) with largest populations 


\section{Fragilaria vaucheriae}

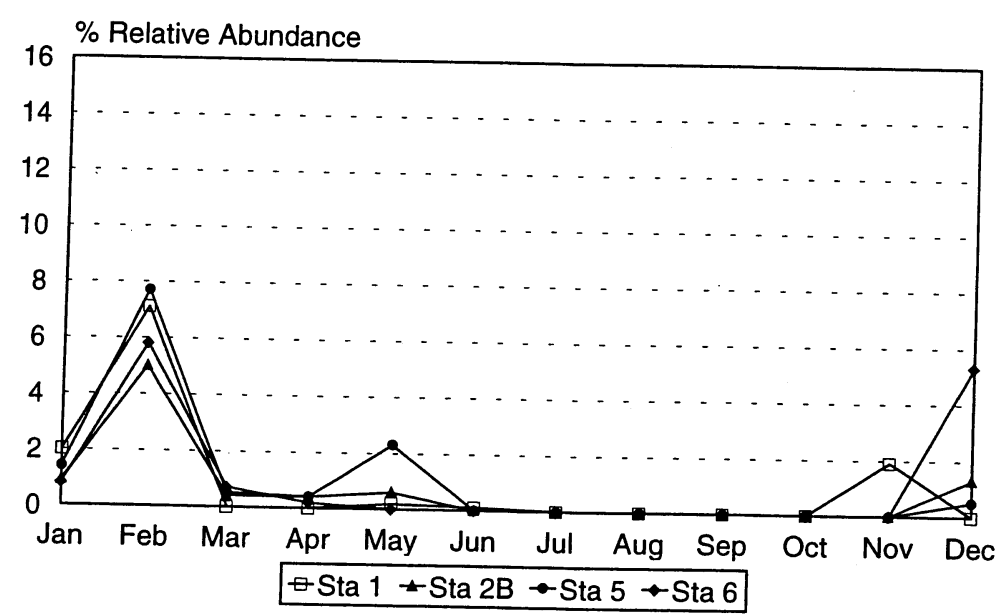

Figure A-11. Relative abundances (\%) of Fragilaria vaucheriae for the 2000 study year; Savannah River, South Carolina.

in cooler exposure periods (relative abundances exceeded $2 \%$ only in January through May and November through December). There were no notable spatial trends with largest populations in February (7.1, 7.7, 5.8 and 5.0\% at Stations 1, 2B, 5 and 6 , respectively). $F$. vaucheriae has been found consistently (1982 through 1999), during cooler exposure periods and from 1982 through 1988 with generally higher relative abundances at Station 5. This species is found in waters with $\mathrm{pH}$ between 6.5 and 9.0, develops optimally near $\mathrm{pH} 9$ and is found in polluted waters.

Gomphonema affine (Fig. A-12)-low relative abundances occurred during cooler exposure periods (3\% or less in January, February, November and December) with largest populations in different months (18 and $12.8 \%$ at Station 1 in September and June; 15.4 and $8.8 \%$ at Stations 5 and 2B in May and $7.8 \%$ in April at Station 5). Few discernible spatial patterns with possibly lower relative abundances at Station 6 (values exceeded $5 \%$ only once at Station 6).

Gomphonema gracile (Fig. A-13)-low relative abundances occurred at the start of the study year (less than 3\% in January through June) with largest populations in October (16.7 and $9.7 \%$ at Stations 1 and $2 \mathrm{~B}$, respectively). Relative abundances were lower at Stations 5 and 6 (all values less than 3\%) than at Stations 1 and $2 \mathrm{~B}$. 


\section{Gomphonema affine}

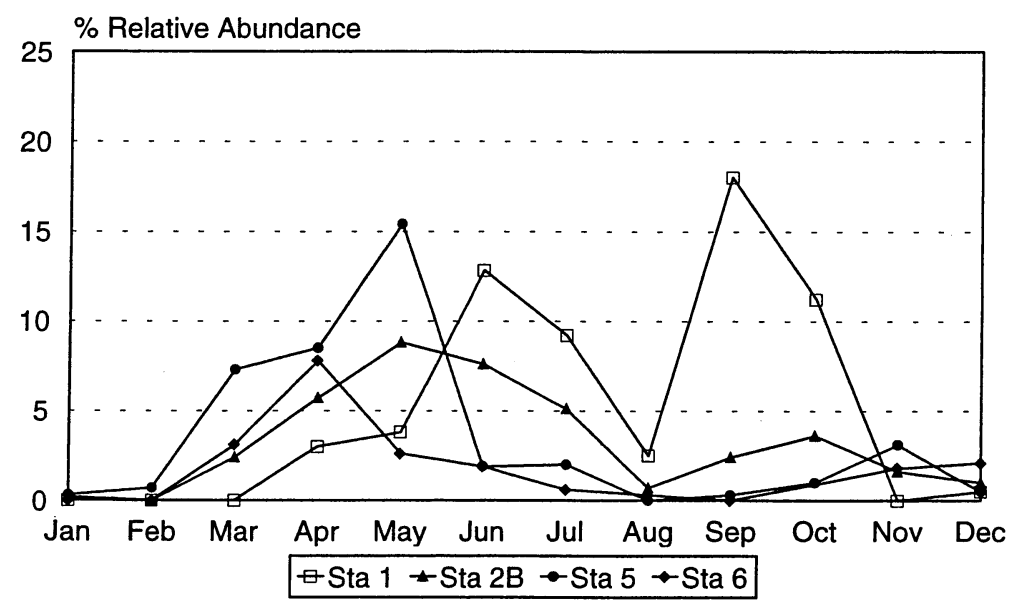

Figure A-12. Relative abundances (\%) of Gomphonema affine for the 2000 study year; Savannah River, South Carolina.

\section{Gomphonema gracile}

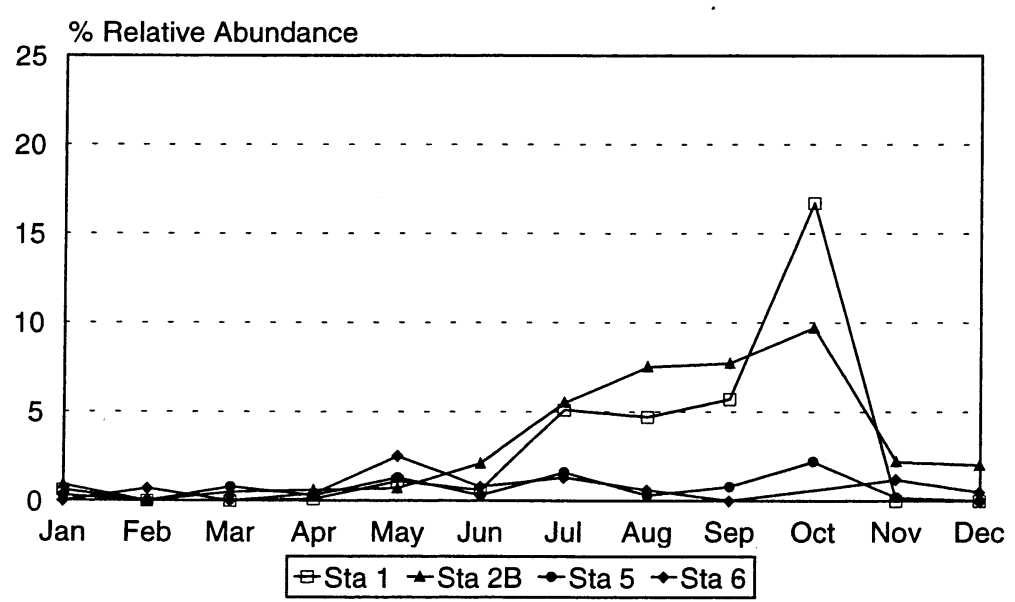

Figure A-13. Relative abundances (\%) of Gomphonema gracile for the 2000 study year; Savannah River, South Carolina.

Gomphonema parvulum (Fig. A-14)-was the most abundant diatom during the 2000 study year with relative abundances exceeding $75 \%$ at each station (only 3 of 27 relative abundance values from April through October were less than $25 \%$ ). Relative abundances were lowest in the coolest months (11 of 12 values in January, February and December were less than 10\%). Highest values were observed at Station 6 (exceeded $80 \%$ from May through July at Station 6). Gomphonema parvulum has been the most abundant diatom in all 


\section{Gomphonema parvulum}

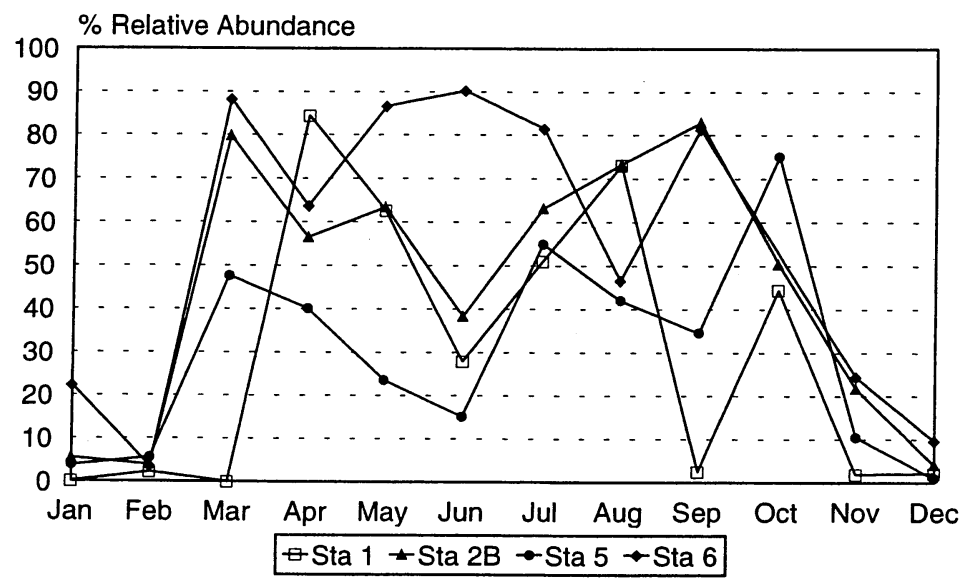

Figure A-14. Relative abundances (\%) of Gomphonema parvulum for the 2000 study year; Savannah River, South Carolina.

recent study periods (1982 through 1999), with highest relative abundances during warmer exposure periods. This species has a large ecological span and is tolerant of a range of pollution conditions, is considered a facultative nitrogen heterotroph, is usually indicative of a large organic load and is found in polluted waters.

Gomphonema pumilum - overall low in relative abundance (only exceeded 3\% once, at Station 2B in June) with no observations from August through December. Lowest relative abundances of this species occurred at Station 6 (always less than $1 \%$ ).

Melosira varians (Fig. A-15) - low in relative abundance from June through September (always less than 6\%). The highest relative abundances were observed at Station 5 (highest at Station 5 for 6 of the 8 exposure periods when values exceeded 5\%; highest values of 63.4 and $52.8 \%$ for the December and November exposure periods) and lowest at Station 1 (always less than 10\%). This species has been found consistently in previous studies (1982 through 1999), usually with several large populations and, unlike 2000, with unclear seasonal and spatial trends. Melosira varians has a large range of ecological tolerances with $\mathrm{pH}$ optimum near 8.0 (7.68.2).

Meridion circulare var. constrictum (Fig. A-16)-was found only in February (less than $1 \%$ in all other exposure periods) 


\section{Melosira varians}

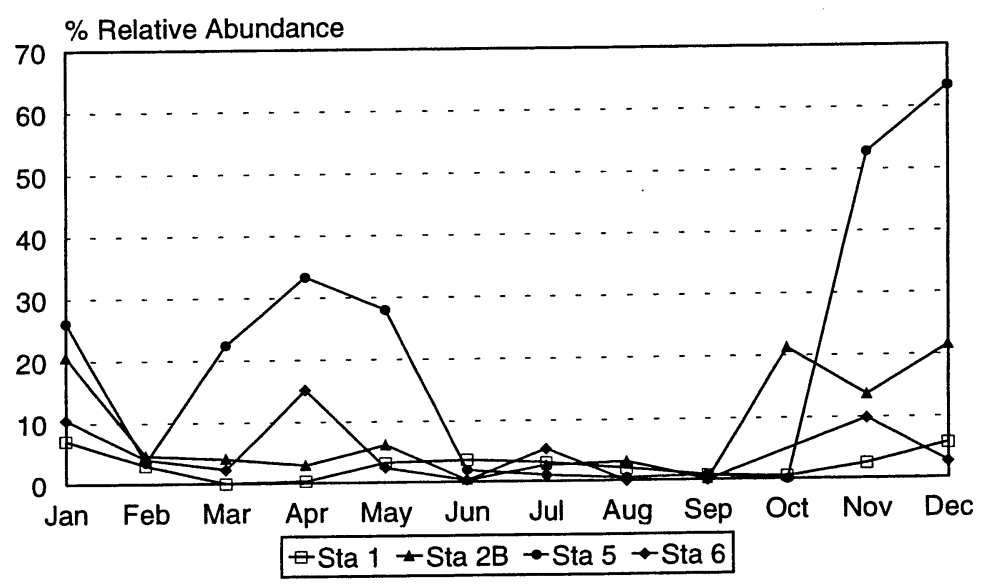

Figure A-15. Relative abundances (\%) of Melosira varians for the 2000 study year; Savannah River, South Carolina.

Meridion circulare var. constrictum

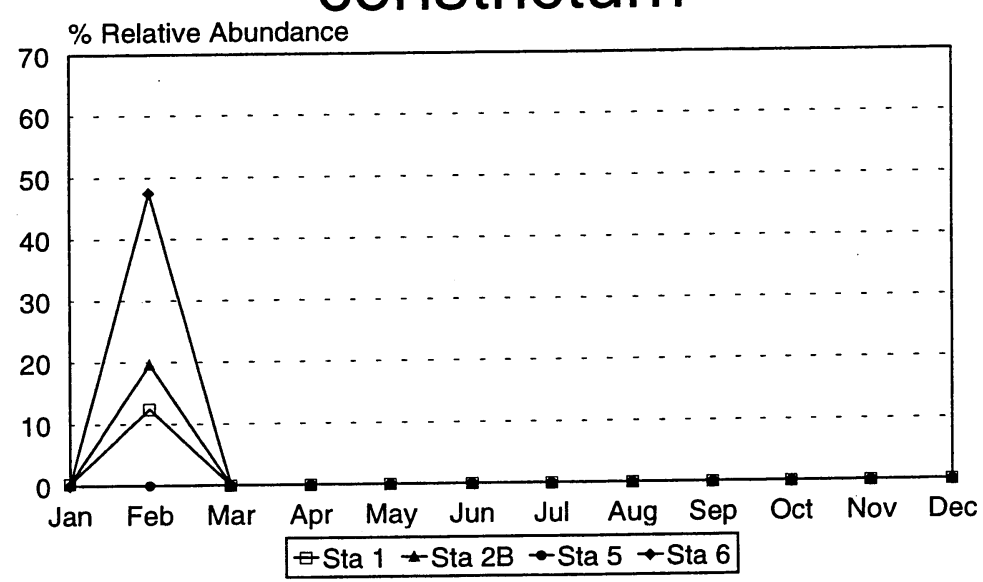

Figure A-16. Relative abundances (\%) of Meridion circulare var. constrictum for the 2000 study year; Savannah River, South Carolina.

with several large populations $(47.5,19.6$ and 12.4 at Stations $6,2 \mathrm{~B}$ and 1, respectively), though it was not found at Station 5. This species has been a dominant in 1993, 1995 and 199699 Savannah River diatometer studies. Meridion circulare v. constrictum has been found in cooler exposure periods.

Meridion circulare (nominate variety) has a wide $\mathrm{pH}$ range (acid conditions through 9+), but is found mostly at pH 7 (optimum 6.7-9.0) and in nutrient-rich (eutrophic) waters where 
pollutants have been broken down. This species is found in natural waters.

Navicula cryptocephala (Fig. A-17)-was found during the early, cooler exposure periods (relative abundances were less than $2 \%$ from March through December) with highest relative abundances in January (10.1, 5.5, 8.4 and 7.5\% at Stations 1, 2B, 5 and 6, respectively). There were no notable spatial patterns. Navicula cryptocephala has been found sporadically in previous studies (1982, 1983, 1987, 1994, 1997 and 1999), usually in cooler exposure periods. This species has an optimum $\mathrm{pH}$ near 8 , but has been found in a wide range ( 5.4 to 9.0 ), is considered tolerant of pollutants and is found in nutrient-rich waters (eutrophic). This species is found in polluted waters.

\section{Navicula cryptocephala}

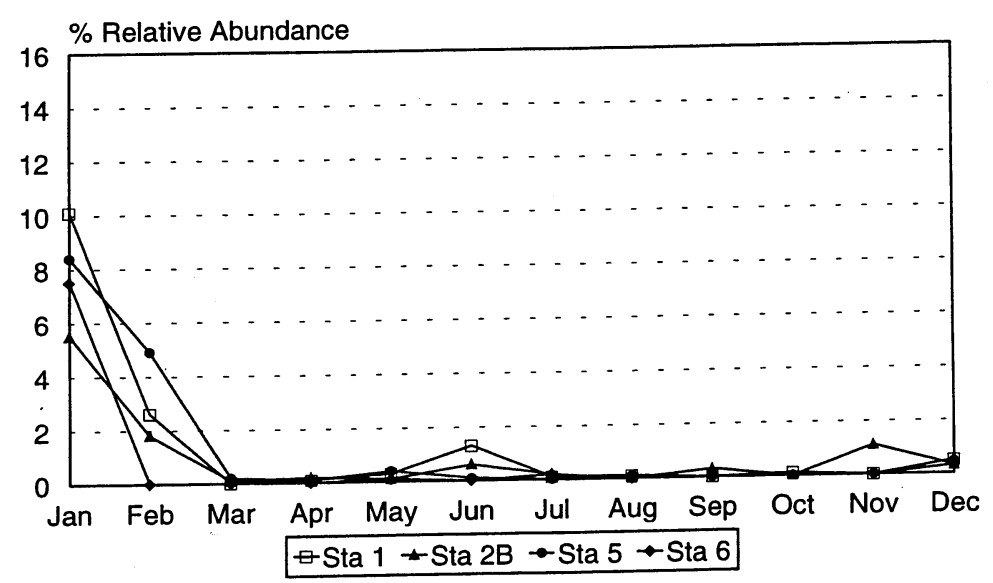

Figure A-17. Relative abundances (\%) of Navicula cryptocephala for the 2000 study year; Savannah River, South Carolina.

Navicula gregaria (Fig. A-18) -was found only during the cooler exposure periods (exceeded $2 \%$ only in January, February, November and December) with no notable spatial trends. Highest abundances were observed in January (9.3, 8.1, 4.9 and 7.9 at Stations 1, 2B, 5 and 6, respectively).

Nitzschia paleacea (Fig. A-19)-highest abundances occurred in the warmer exposure periods (June and July; relative abundance exceeded $2 \%$ only once in the other study months). Populations were most abundant at the upstream sta- 


\section{Navicula gregaria}

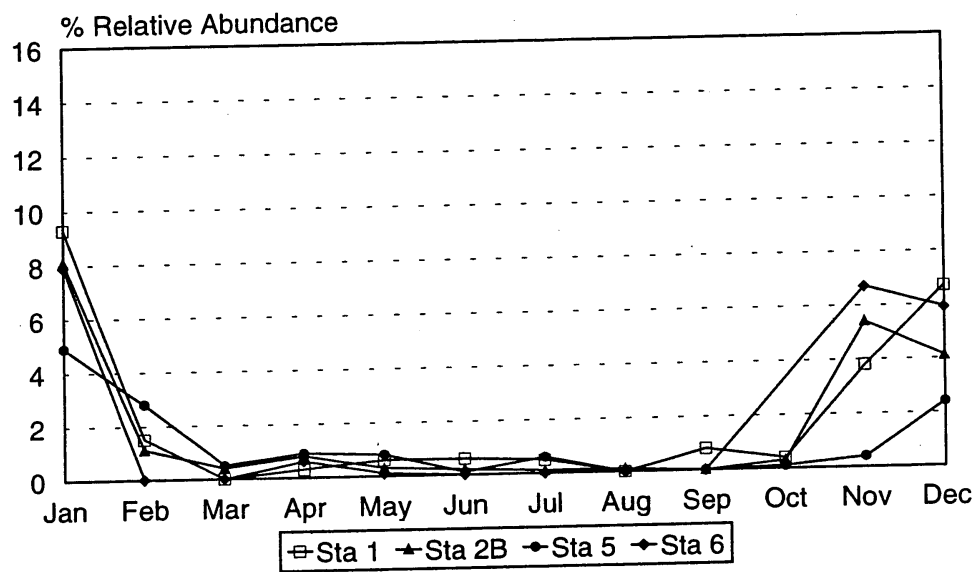

Figure A-18. Relative abundances (\%) of Navicula gregaria for the 2000 study year; Savannah River, South Carolina.

\section{Nitzschia paleacea}

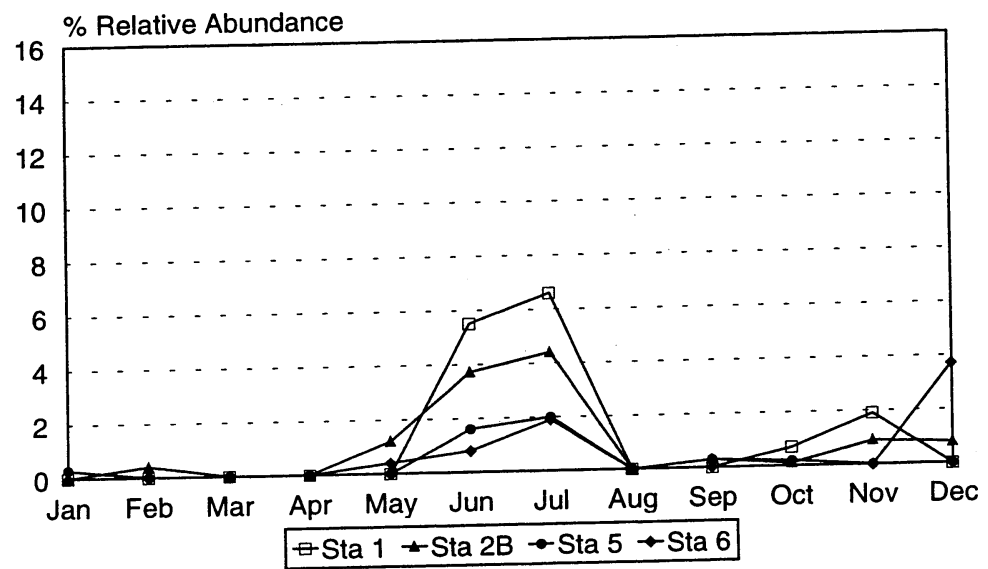

Figure A-19. Relative abundances (\%) of Nitzschia paleacea for the 2000 study year; Savannah River, South Carolina.

tions (5.5 and $6.6 \%$ at Station 1 and 3.7 and $4.4 \%$ at Station 2B for the June and July exposure periods, respectively).

Synedra ulna (Fig. A-20) - was found at the start (January and February) of the study year and in the fall (September through December) of the study year with highest abundances at different times (peaks of $15.6 \%$ at Station 1 in September, $12.2 \%$ at Station 6 in December, 11.8 at Station 5 in November and 10.9 at Station 2B in January). Synedra ulna has been found consistently in recent studies (1983, 1986-1987 and 


\section{Synedra ulna}

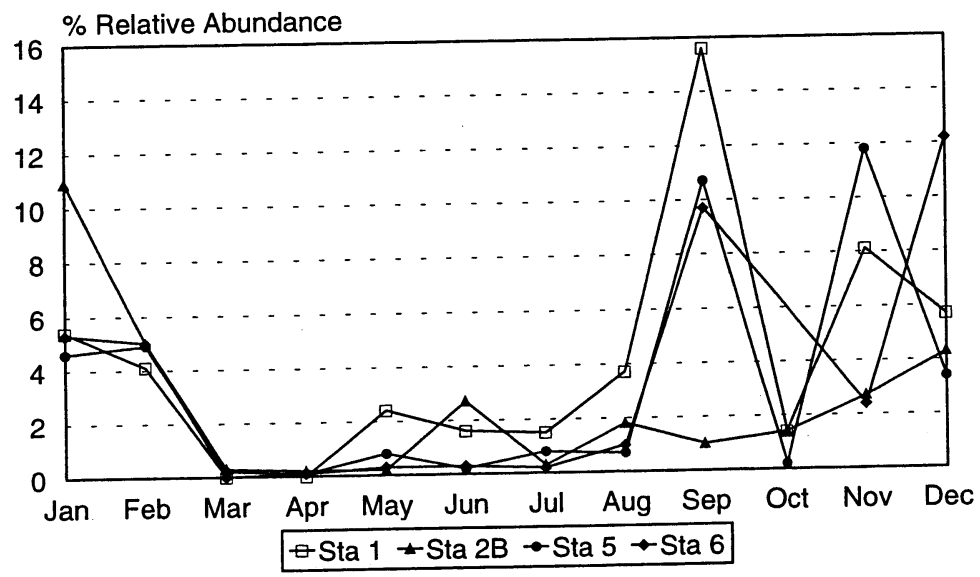

Figure A-20. Relative abundances (\%) of Synedra ulna for the 2000 study year; Savannah River, South Carolina.

1989 through 1999) during cooler exposure periods. This species has a large ecological span, including a $\mathrm{pH}$ range of 5.79.0 (usually alkaline), and it is found in polluted waters.

Synedra ulna var. contracta-overall low in relative abundance with highest values in May, July and November (highest relative abundance was $3.3 \%$ at Station 6 for the July exposure period). Abundance was low at Stations 1 and 5 (always less than $1 \%$ ).

\section{Detailed Reading Analyses}

D etailed diatometer readings were carried out for the exposure period ending 2 May and 31 October 2000. The modes of the species distribution curves (Figs. A21 and A-22), are positioned as follows:

\begin{tabular}{ccccc}
\hline & \multicolumn{4}{c}{ Distribution Mode } \\
\cline { 2 - 5 } Exposure Period & Sta. 1 & Sta. 2B & Sta. 5 & Sta. 6 \\
\hline $5 / 2 / 00$ & 1.366 & 2.109 & 2.290 & 2.072 \\
$10 / 31 / 00$ & 1.588 & 2.244 & 1.312 & no data \\
\hline
\end{tabular}




\section{Detailed Readings - 5/2/2001}

(A)

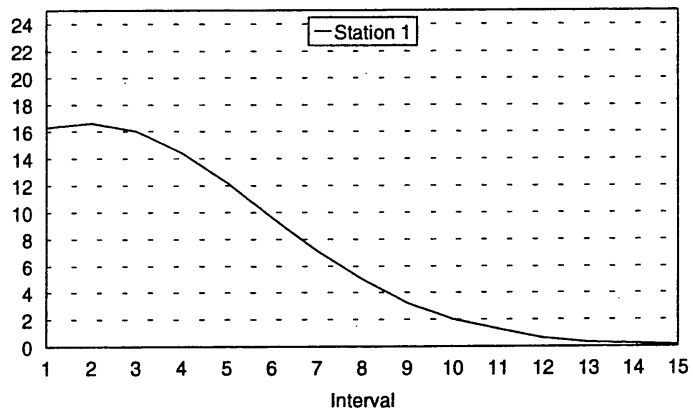

(B)

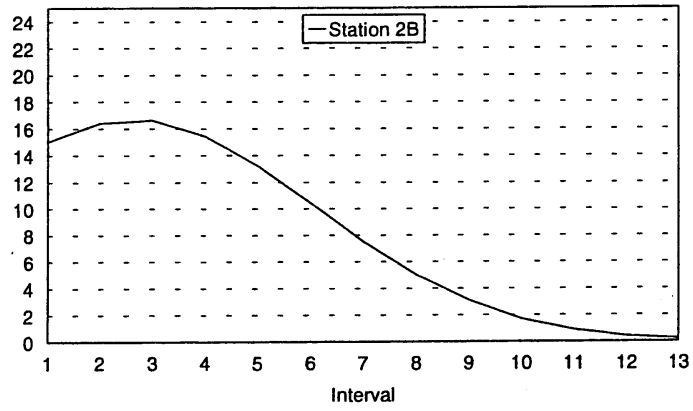

(C)

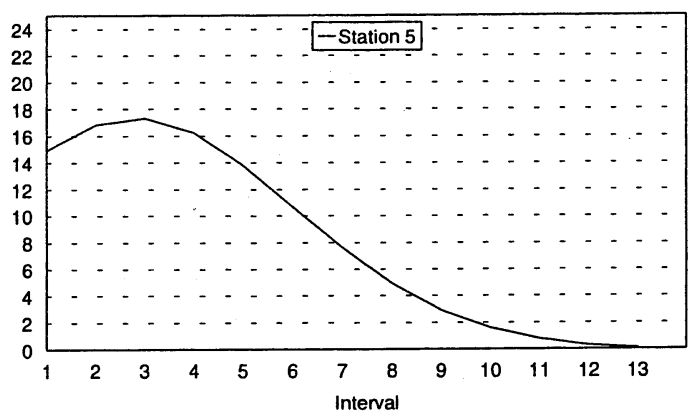

(D)

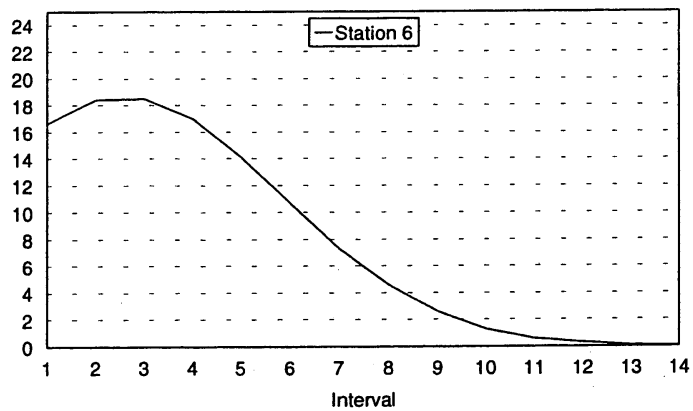

Figure A-21. Frequency distributions of diatom species at (A) Station 1, (B) Station 2B, (C) Station 5 and (D) Station 6 from the detailed reading for the exposure period ending May 2, 2000; Savannah River, South Carolina. 


\section{Detailed Readings - 10/31/2001}

(A)

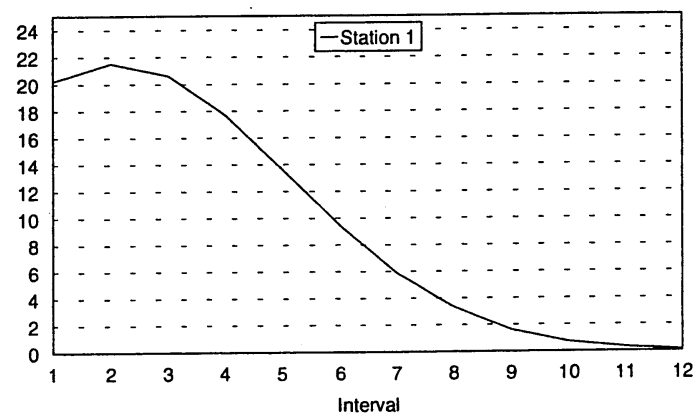

(B)

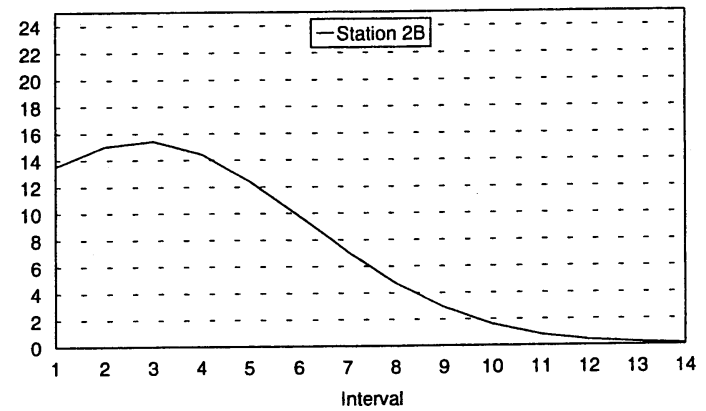

(C)

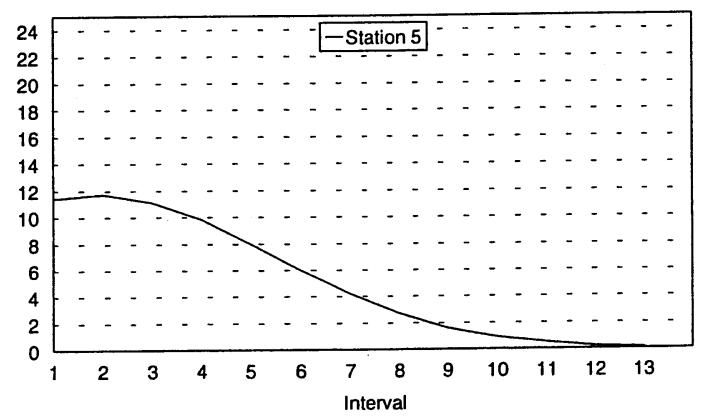

Figure A-22. Frequency distributions of diatom species at (A) Station 1, (B) Station $2 B$ and (C) Station 5 from the detailed reading for the exposure period ending October 31, 2000; Savannah River, South Carolina.

\section{Comments on the Structure of the Lognormal Curve}

7 he following comments are based on the detailed reading analyses and Appendix A-3. In May, the structure of the lognormal curve at Station 1 had a mode of approximately 17 species and extended over 15 intervals. 
This indicates that there was some organic enrichment. This statement is substantiated by the common occurrence of Gomphonema parvulum, which formed $84.27 \%$ of the population of diatoms. This diatom is known to become more common in the presence of organic pollution.

The results at Station 2B in May were similar. However, the mode was roughly 17 and the curve covers 13 intervals, whereas at Station 1 it extended to 15 intervals. The dominant diatom, as at Station 1, was Gomphonema parvulum, which indicates the presence of organic matter.

At Station 5 in May the height of the mode was 17.3. The curve extended over 13 intervals. Gomphonema parvulum was the most common species. At Station 6 the height of the mode was 18.7 or approximately 19 species indicating some improvement. The curve extended over 13 intervals

indicating an organic load. The communities at Stations 5 and 6 were very similar in May.

In October at Station 1, the heighth of the mode was 21.5 species and the length of the curve was 12 intervals which indicates natural river conditions. At Station $2 \mathrm{~B}$ the conditions were not quite as good as at Station 1, as the height of the mode was 15.4 and the number of observed species was 132 with the curve extending over 13 intervals, indicating some organic enrichment.

At Station 5 in October, the height of the mode was 11.7 species and the curve extended over 13 intervals. Station 5 shows degradation as compared to Stations 1 and 2B. Organic enrichment is indicated, but perhaps some toxic material is present as the curve is not excessively long. There are no data for Station 6 in October.

In conclusion, it would appear that in the fall of the year conditions were not as good in the vicinity of the plant site as they were in the spring of the year. In both the fall and spring of the year, the condition of the river in Station 1 seems to be healthy or normal. 


\section{Discussion}

7 he assessment of water quality in the vicinity of the SRS during 2000 (the $48^{\text {th }}$ year of studies) involves comparing diatom assemblages growing on artificial substrates at the reference station (Station 1) with those found at the SRS stations below the Georgia Power and Light's Vogtle Nuclear Power Plant (Station 2B), below Steel Creek (Station 5) and below Lower Three Runs (Station 6), and determining how the assemblages found during 2000 compare with previous studies, over a long period of time. Higher assemblage diversity, as richness (higher number of diatom species) and evenness (lower percent dominance), suggests better conditions with respect to components of water quality to which diatoms are most sensitive. Small differences, though consistent, might not indicate a difference in these components of water quality, since variation from other sources (physical and seasonal factors) could have a similar effect. Comparisons with previous studies must consider the large number of spatial comparisons (i.e., more stations in 1997 through 2000 than previous years) and fewer seasonal comparisons (11-12 exposure periods compared with $20-26$ in previous Savannah River diatometer studies).

The statistical analyses of diatom assemblage parameter data for 2000 indicate differences between the reference and SRS stations. There was significantly higher assemblage evenness (decreased percent dominance) and diversity (Shannon-Wiener Diversity Index) at the reference station than at the other SRS stations. No consistent trend of lower richness (number of diatom species), lower diversity and higher unevenness (increased percent dominance) at the station below Lower Three Runs (Station 6; compared to the reference Station 1) was observed in 2000 (as it was for the study years 1985 through 1996), but the overall means for these parameters were lower at Station 6. The 2000 study year is the fourth year (including 1997 through 1999) with monthly exposure periods and an additional station below Plant Vogtle and the fourth year where diatom assemblage parameters at Station 6 were not significantly different from other SRS stations.

Comparisons were made of diatom assemblage parameters from 1999 studies with means developed from previous stud- 
ies (ANSP 1978; 1980a; 1981b; 1982; 1984a; 1985a; 1988a; 1988b; 1988c; 1990b; 1991c; 1992a; 1993a; 1994c; 1995; 1996; 1997; 1998; 1999, 2000) in which semi-detailed readings were used for continuous monitoring (1978-2000 for Stations 1 and 6; 1982-2000 for Station 5; 26 two-week exposure periods per year except 1976, 1997, 1998, 1999, 2000; Figs. A-23 and A-24). The number of diatom species was lower than the established mean during 2000, especially in the warmer months. At the upper stations (Stations 1 and 5) the trend was apparent for 10 of the 12 exposure periods, by 1 s.d. for the exposure periods from July through September; a similar trend was observed at Station 6 ( 7 of 11 exposure periods) especially from May through September (all 5 exposure periods were less than the established mean by 1 s.d.).

Overall, values for percent dominance were lower at Station 1 (8 of 12 exposure periods, by 1 s.d. for 6 exposure periods) and Station 5 ( 7 of the 12 exposure periods, by 1 s.d. for 3 exposure periods) during 2000 studies, especially at the beginning of the study year (all four values for January and February at Stations 1 and 5 were less than the established mean by 1 s.d.). To the contrary, 2000 percent dominance values were usually higher than the established average at Station 6 (for 8 of 11 exposure periods, 1 by 1 s.d.), especially from March through September.

Detailed lognormal readings have been made for Stations 1 and 6 in the spring (usually April) and fall (usually October) beginning in 1954 (no fall 1996 or 2000 reading; ANSP, 1974b; 1978; 1980a; 1981b; 1982; 1984a; 1985a; 1988a; 1988b; 1990b; 1991c; 1992a; 1992b; 1993a; 1994c; 1995; 1996; 1997; 1998; 1999, 2000 appendix and original data sheets). The number of species varied considerably (Figs. A25 and A-26), and for the 2000 studies was nearly equal (no comparison for the October readings).

Although many distribution patterns were observed for the relative abundances of dominant species, most trends were seasonal, not spatial, nor related to the operation of the SRS. Most species exhibited maximum development during the early, cooler portion of the study year. Because of the overwhelming dominance at all stations of Gomphonema parvulum, and the presence, in at least low abundance, of most species at each station, the overall species composition was similar at the four stations in the vicinity of the SRS during 


\section{Number of Diatom Species}

1978 to 2000

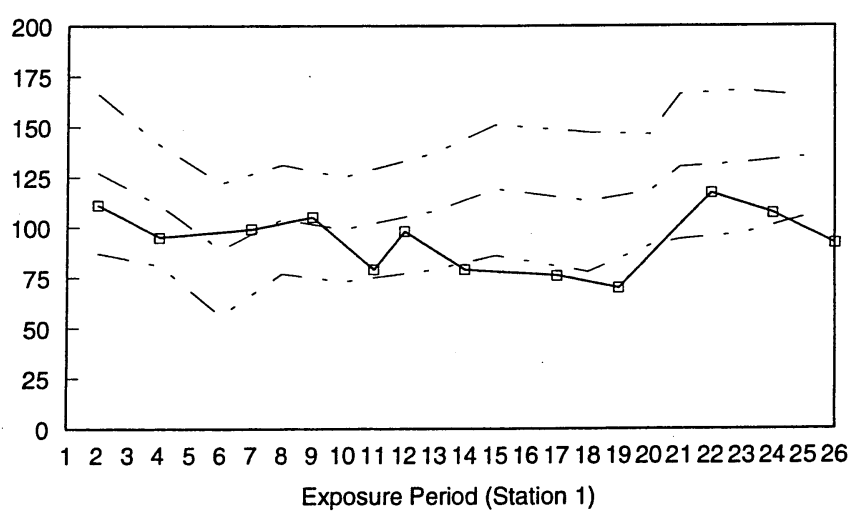

Number of Diatom Species

1978 to 2000

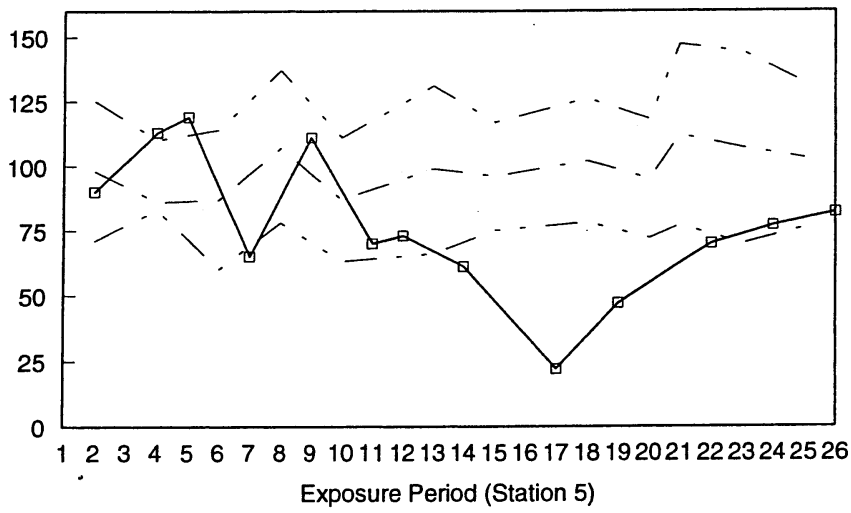

Number of Diatom Species

1978 to 2000

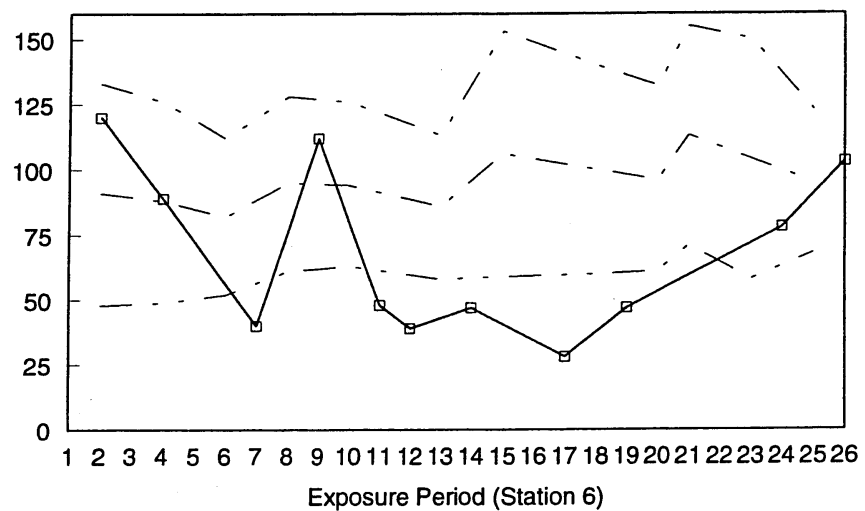

Figure A-23. Number of observed species from 2000 diatometer studies on the Savannah River (line connecting squares) compared with mean and 1 standard deviation of data from diatometer studies conducted from 1978 through 2000 (lines connecting dashes; Station 5 data are from 1982 through 2000) using semi-detailed reading method. Exposure periods represent 26 two-week exposures, starting in January and ending in late December. Note that only 20 exposure periods were analyzed in 1996. 


\section{Percent Dominance}

1978 to 2000

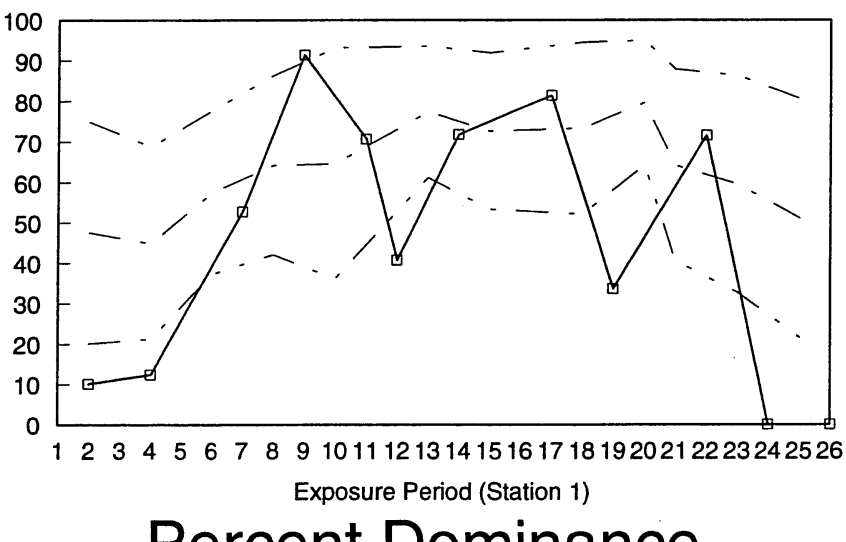

Percent Dominance

1978 to 2000

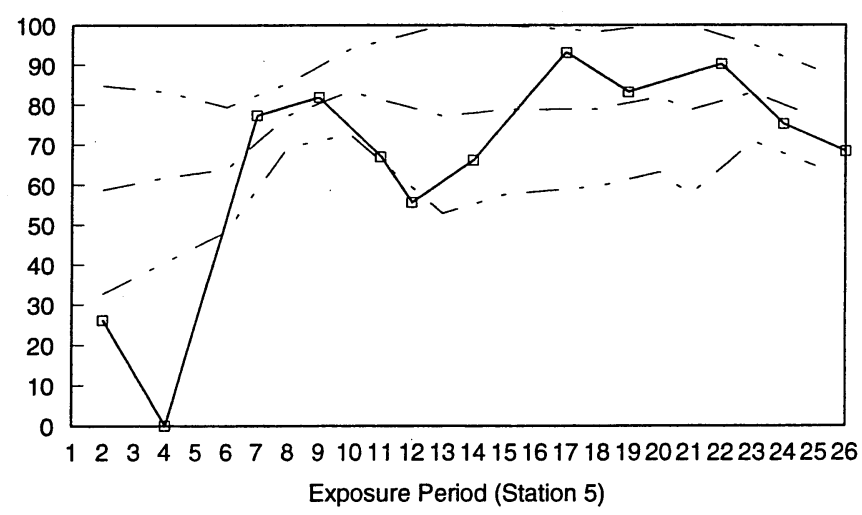

Percent Dominance

1978 to 2000

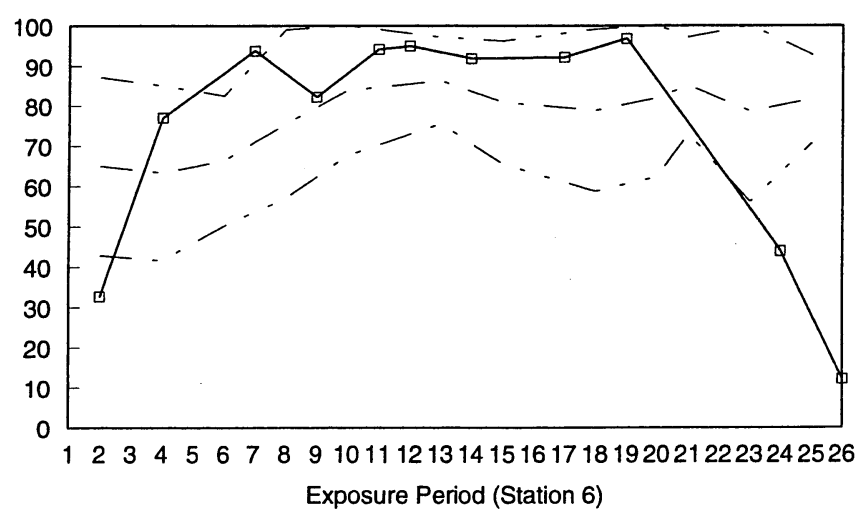

Figure A-24. Percent Dominance from 2000 diatometer studies on the Savannah River (line connecting squares) compared with mean and 1 standard deviation of data from diatometer studies conducted from 1978 through 2000 (lines connecting dots; Station 5 data are from 1982 through 2000) using semi-detailed reading method. Exposure periods represent 26 two-week exposures, starting in January and ending in late December. Note that only 20 exposure periods were analyzed in 1996. 


\section{Savannah River 1954 to 2000 \\ Detailed Reading Method}

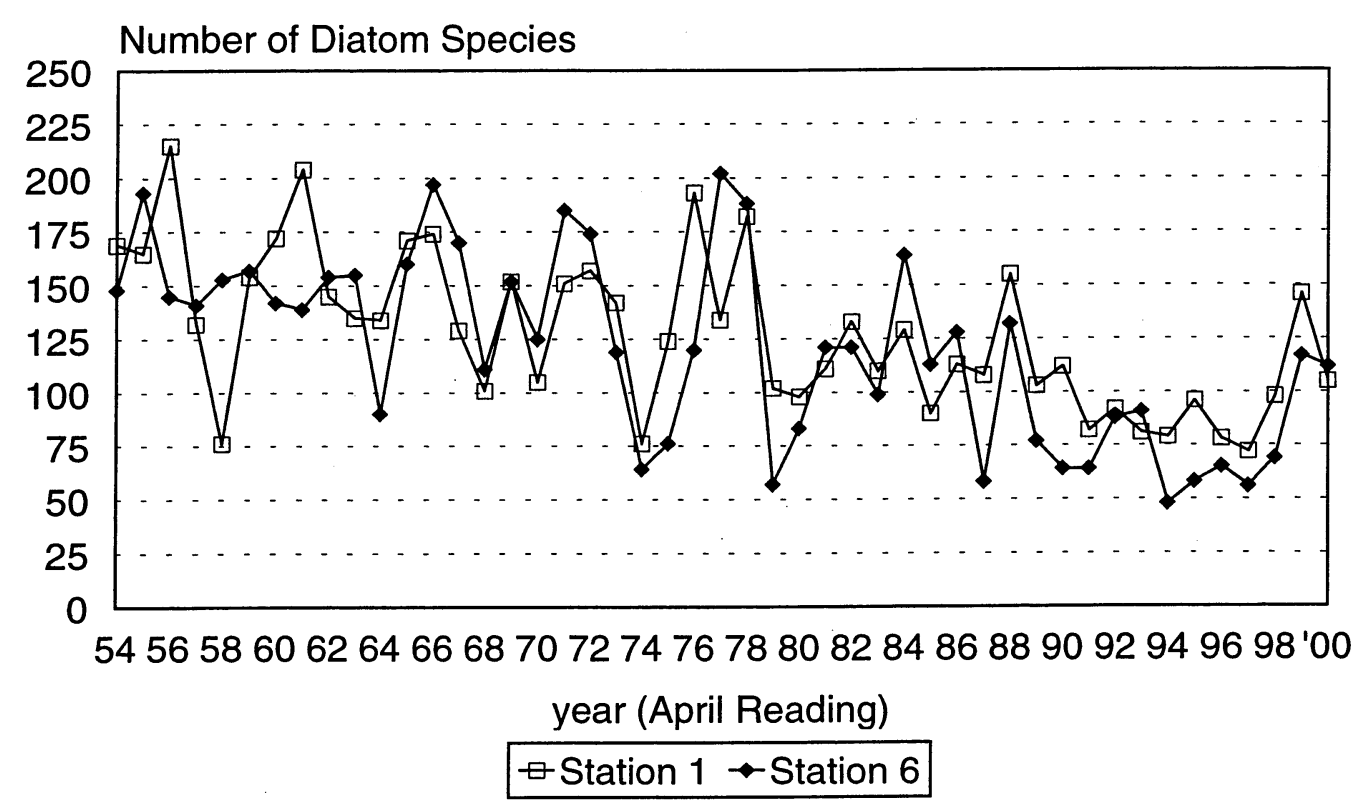

Figure A-25. Total number of diatom species from the fall (usually April) exposure period, 1954 through 2000 using the detailed lognormal reading method; Savannah River, South Carolina.

2000 studies. Ecological tolerances of diatom species found on diatometer slides in the Savannah River in the vicinity of the SRS during 2000 studies, determined from a compilation of diatom literature (Lowe 1974; Beaver 1981; ANSP ecological records), were similar for the dominant species at all stations. Nearly all of the dominant species were characteristic of alkaline waters (optimum growth when $\mathrm{pH}$ greater than 7). The most abundant diatom, Gomphonema parvulum, is considered $\mathrm{pH}$ indifferent, but with an optimum above $\mathrm{pH} 7$. Most of the dominant diatoms are considered characteristic of waters with moderately high nutrient concentrations (i.e., eutrophic; Lowe 1974). The most abundant species (especially Gomphonema parvulum) have wide tolerances and can adjust to a range of conditions; however, they are not usually indicative of severe conditions.

In summary, the composition and tolerances of diatom species on the Savannah River above and below the SRS were similar during the 2000 study. Differences in diatom assemblage structure (lowered evenness and diversity at the SRS 


\section{Savannah River 1954 to 2000 Detailed Reading Method}

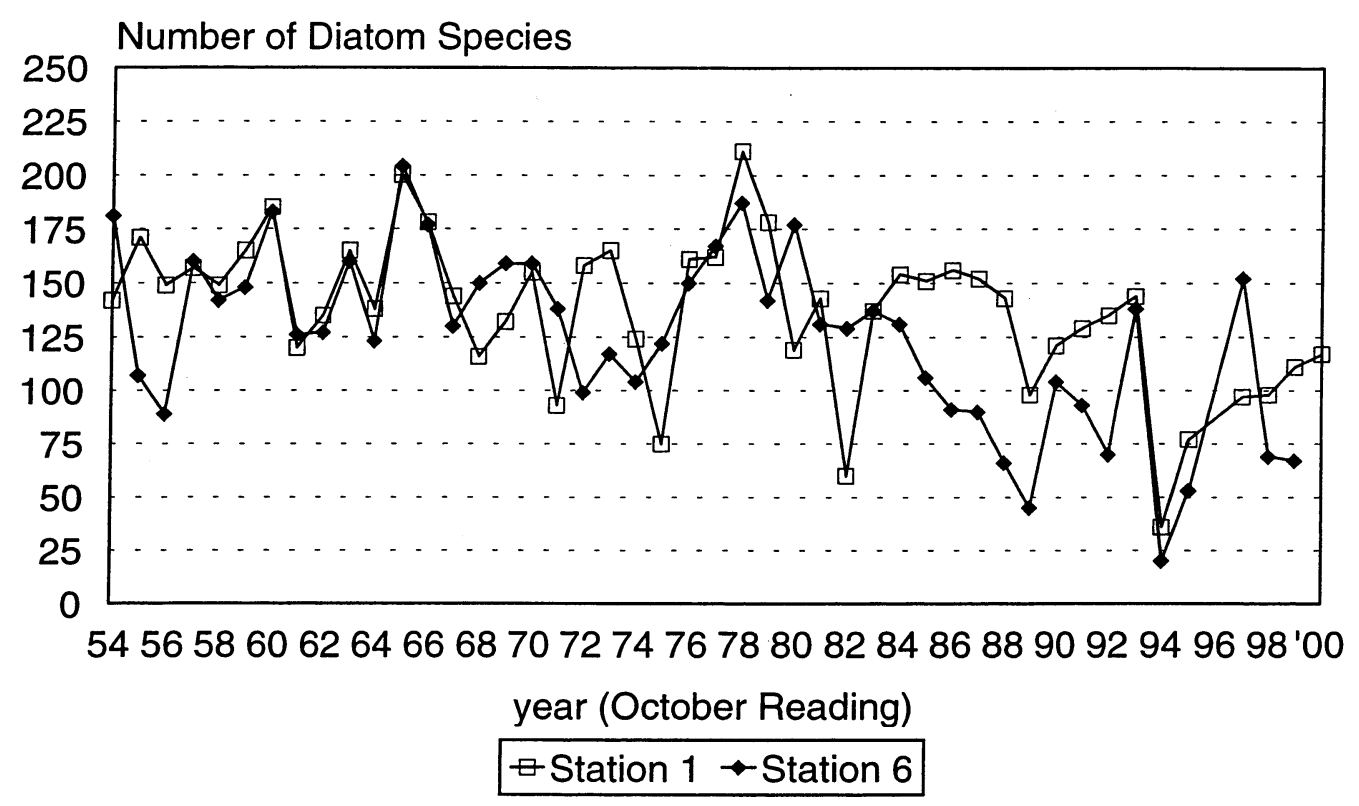

Figure A-26. Total number of diatom species from the spring (usually October) exposure period, 1954 through 2000 using the detailed lognormal reading method; Savannah River, South Carolina.

stations) were not as severe as the lowered diversity noted at the station below Lower Three Runs for biweekly studies from 1986 through 1996. The data in 1997 through 2000 (i.e., compared with the earlier 11 years), appear to indicate that deteriorated conditions (as noted by the lower diversity) observed previously on the Savannah River below Lower Three Runs were not present in 1997 through 2000. However, a less consistent and less severe trend of lowered diversity at the SRS stations (below Plant Vogtle, below Steel Creek and below Lower Three Runs) was noted for at least short periods in the 1998, possibly 1999 and now 2000 studies. Most of the dominant species observed in the 2000 study, similar to previous studies, are characteristic of alkaline, nutrient-enriched waters. 


\section{APPENDIX A-1}

\section{On the Adoption of New Diatom Genera Names for the Savannah Diatometer Study}

by Eduardo A. Morales

\section{Introduction}

ecent advances in light microscopy (LM) techniques and optics and the development of powerful scanning

Delectron microscopy tools (SEM) have revolutionized diatom taxonomy. In recent years the number of diatom genera (arguably, the taxonomic level that has been more impacted) has increased dramatically. Since the account presented by Round et al. (1990) there has been a substantial increase in the total number of diatom genera and today this number borders 1,000 (Fourtanier and Kocioleck 1999). Although these taxonomical changes are mainly based on morphological features of siliceous valves, many genus names seem to correlate with cytological, ecological, and molecular information. As broader geographical and ecological regions are studied more information is accumulated, which contributes to a more natural state in the classification of diatoms.

With the objective of incorporating recent systematic and taxonomic studies into the taxonomy used by analysts at the 
Academy of Natural Sciences (ANSP), the latter has organized several workshops. These workshops primarily have served to update the taxonomy used for the analyses of samples from the National Water Quality Assessment Program (NAWQA), a cooperative agreement between the United States Geological Survey (USGS) and the Patrick Center for Environmental Research (PCER) at ANSP.

During the NAWQA workshops, extensive review of the recent and past literature and thorough discussions about the majority of newly proposed names resulted in the acceptance or rejection of new genus names and subcategory taxonomic transfers (Morales and Potapova 2000). Subsequent workshops have dealt with specific groups of species and their varieties. Again, extensive research and discussion lead to clarification of the taxonomy of these groups (Morales 2001a,b).

In an effort to update the taxonomy used in the Savannah River project, many of the decisions from the NAWQA workshops mentioned above have been adopted. Hence, many changes at the genus, species, and variety levels have been introduced during counts of samples collected during year 2000. A list of equivalent species and variety names between the taxonomy used for samples collected in year 2000 and the previous year is presented in Appendix A-2. Here, we include a brief discussion on the reasons for adopting new genus names. Appropriate literature is cited where needed.

\section{New Genus Names Adopted for Year 2000 Samples}

\section{Centric Diatoms}

\section{Cyclostephanos}

7 his genus was created to contain species previously misidentified as taxa within Stephanodiscus (Theriot et al. 1987). Striae in Cyclostephanos continue onto 
the valve mantle, where they are composed of numerous rows of circular areolae. Cyclostephanos also possess internal ribs as does Cyclotella, however, in the latter the striae are interrupted midway toward the center of the valve face and there is a lack of a distinct ring of spines.

\section{Pleurosira}

This genus has been separated from Biddulphia. Its valve structure and ecology are different from true Biddulphia species. Pleurosira can be readily recognized by the presence of two large ocelli located opposite each other on the valve face. In addition, Pleurosira species are common in brackish habitats as opposed to the strictly marine habit of taxa in the genus Biddulphia (Round et al. 1990).

\section{Araphid Diatoms}

\section{Ctenophora}

The name Ctenophora had been applied as a subgenus of Synedra by Grunow (1862). In their revision of the genus Synedra, Williams and Round (1986) proposed the use of Ctenophora at the genus level due to the distinctive morphological features exhibited by $C$. pulchella, which then became the type of Ctenophora. Round et al. (1990) remark that Ctenophora is currently a monotypic genus, but that more species might be discovered as more detailed studies of brackish water diatoms are performed.

\section{Pseudostaurosira}

This name was introduced to the literature by Williams and Round (1987) in their revision of the genus Fragilaria.

Pseudostaurosira has very distinctive features especially regarding areolae and closing plates features, as well as apical pore fields and the position of the spines. These features are very different from those in Fragilaria (sensu stricto). Since Williams and Round's paper, many new species have been transferred to Pseudostaurosira, among them a number of brackish water species (Hallegraeff and Bufford 1996; Sabbe and Vyverman, 1995). One of the most ubiquitous species within this genus if $P$. brevistriata, the former Fragilaria brevistriata. 


\section{Staurosira}

This name was originally utilized by Ehrenberg to refer to Fragilaria construens, which then became the type of this genus. Williams and Round resurrected Staurosira based on conspicuous morphological differences between species allocated in this genus and taxa in Fragilaria (sensu stricto). The main differences are absence of rimoportulae (labiate processes), areolae and closing plate structure, and apical pore field and spine characteristics. Currently this genus hosts many species associated with Staurosira construens.

\section{Staurosirella}

Williams and Round (1987) separated the species associated with Fragilaria lapponica from Fragilaria (sensu stricto) and devised a separate genus (Staurosirella) to include them. Species of Staurosirella can be distinguished from closely associated genera such as Staurosira by the characteristics of the striae, closing plates and apical pore fields. Additionally, spines in Staurosirella are profusely branched often exhibiting complex arrangements at junctions between neighboring frustules. This genus also includes many species among which $S$. pinnata and S. leptostauron are the most geographically widespread.

\section{Tabularia}

This genus also resulted from the revision of the genus Synedra by Williams and Round (1986). Tabularia has since been studied in more depth and several species have been transferred into it (Snoeijs 1992). The type of areolae and apical pore fields are the most relevant features isolating this genus from other Synedra-like taxa.

\section{Monoraphid Diatoms}

\section{Achnanthidium}

This name had been applied by Kützing (1844) to the Achnanthes minutissima and Achnanthes microcephala group.

Round et al (1990) and Round and Bukhtiyarova (1996) resurrected and re-defined this genus. Species associated to the type of the genus (Achnanthidium microcephalum) are differ- 
ent from taxa in Achnanthes (sensu stricto) in many regards, including areolae, raphe, girdle and plastid structure.

\section{Eucocconeis}

This has also been recently separated from Achnanthes (sensu stricto). Eucocconeis had been used before by several authors as a subgenus within Achnanthes. Round et al. (1990) use this name at the genus level to include organisms related to Achnanthes flexella (now Eucocconeis flexella and the type of the genus). The contorted nature of the valves, and the striae characteristics justify the separation of Eucocconeis from other Achnanthes-related taxa.

\section{Kerayevia}

This genus also contains species previously classified in Achnanthes. The characteristics of the areolae composing the striae in both the raphe and pseudoraphe valves are different from those in Achnanthes, thus justifying the separation of Kerayevia as a distinct genus (Round and Bukhtiyarova, 1996).

\section{Lemnicola}

This genus has been based on Achnanthes hungarica (Round and Basson 1997) Although the morphology of the genus distinguishes it from other true achnanthoid taxa, its ecology is probably one of the most outstanding features. Lemnicola hungarica lives in the roots of Lemna minor, an aquatic dycotyledoneous plant.

\section{Psamothidium}

This genus was erected to contain species in the Achnanthes marginulata group (Bukhtiyarova and Round 1996). The characteristics of this genus, especially concerning the structure of the raphe and features of the axial and central areas in both raphe and pseudoraphe valves distinguish it from other Achnanthes-related taxa. 


\section{Biraphid Diatoms}

\section{Brachysira}

This genus was reestablished by Round and Mann (1981) and includes species commonly placed in the genus Anomoeoneis. Brachysira is different from Anomoeoneis in several aspects of its frustule morphology. The striae are composed of elongated areolae. There is a conspicuous clear area running along the valve edge and a single row of rectangular areolae on the valve mantle.

\section{Craticula}

Resurrected by Round et al. (1990), Craticula contains a number of species previously classified within Navicula. These species are different from Navicula (sensu stricto) by the areolae, which are round and lie on longitudinal channels. Other distinguishing features include the structure of the raphe, girdle bands and conspicuous pyrenoids in the chloroplasts of live cells.

\section{Diadesmis}

Also resurrected by Round et al. (1990) were members of the genus Diadesmis. Diadesmis contains species associated with $N$. confervacea. The valves of these species have a completely different morphology than taxa in Navicula sensu stricto. The striae are composed by rectangular or transapically elongated areolae that never touch either the axial area where the raphe lies or the valve edge. The valve mantle is characterized by the presence of a single row of round or rectangular areolae. Species of Diadesmis usually form ribbonlike chains with the aid of spines.

\section{Encyonema}

Encyonema comprises a group of species that were previously classified within the genus Cymbella. Encyonema is characterized mainly by the terminal ends of the raphe, which are bent toward the ventral side of the valves, and the fact that these produce mucilaginous tubes along which the frustules move. In contrast Cymbella (sensu stricto) possess terminal raphe ends that are bent toward the dorsal portion of the 
valves and are usually adnate to substrata by means of mucilaginous stalks.

\section{Fallacia}

This genus includes a group of species characterized by a Hshaped thickening on the valve face (Round et al. 1990). This thickening lacks additional ornamentation and can be clearly seen under the LM. Striae are composed of uniseriate areolae.

\section{Kobayasiella}

This genus has been devised to contain taxa related to Navicula subtilissima. The faint appearance of the striae and raphe make these taxa readily recognizable under the light microscope. At the SEM level, the striae appear as slits, which are completely different from the type of striae found in Navicula (sensu stricto). This genus was originally described as Kobayasia (Lange-Bertalot 1996). However, the latter name had already been used for a group of organisms belonging to the Fungi. Therefore Kobayasia was changed to Kobayasiella and $K$. bicuneus was made the type of the genus (Lange-Bertalot 1998).

\section{Luticola}

This genus was created by Mann (in Round et al. 1990) to contain species related to Navicula mutica. The raphe and pore structure, as well as the presence of a conspicuous stigma at the central area clearly distinguish this genus from other naviculoid genera.

\section{Placoneis}

This genus was created resurrected by Cox (1987) to include taxa associated with Navicula gastrum, which then became the type of the genus. Placoneis has very distinctive features separating it form other naviculoids. The characteristics of the chloroplasts, as well as the morphology of the frustule (raphe structure, striae and areolae characteristics) isolate this genus from Navicula and reveals that Placoneis is more closely related to Cymbella and Gomphonema (Round et al. 1990) 


\section{Sellaphora}

This genus was resurrected from the literature by Mann (1989; see also Round et al. 1990) to include the Navicula pupula group. Among the most prominent features are the thickenings at the apical ends of the valves, which are usually seen as clear areas under the light microscope. Also, the striation is different from that in species of the genus Navicula (sensu stricto). The areolae in Sellaphora are round becoming larger along the axial region and delimiting a thick structure along which the raphe runs.

\section{Tryblionella}

This genus was resurrected to contain the Nitzschia acuminata group (Round et al. 1990). Species in Tryblionella differ from Nitzschia by the wavy characteristic of the valve surface, elongate fibulae, and uni of biseriate striae interrupted by a single (or sometimes two) clear areas running along the apical axis of the valves.

\section{References}

Cox, E. J. 1987. Placoneis Mereschowsky: The re-evaluation of a diatom genus originally characterized by its chloroplast type. Diatom Research 2: 145-157.

Fourtanier, , E. \& Kocioleck, J. P. 1999. Catalogue of the diatom genera. Diatom Research 14: 1-190.

Grunow, A. 1862. Die österreichischen Diatomaceen nebst Anschluss einiger neuen Arten von andern Lokalitäten und einer kritischen Uebersicht der bisher bekannten Gattungen und Arten. Verhandlungen der kaiserlich-königlichen zoologisch-botanischen Gesellschaft in Wien XII: 40-472.

Hallegraeff, G. M. \& Buford, M. A. 1996. Some new or little known nanoplankton diatoms cultured from tropical and subtropical Australian shelf waters. Nova Hedwigia, Beiheft 112: 329-342.

Lange-Bertalot, H. 1994. Kobayasia bicuneus gen. et spec. nov. Iconographia Diatomologica 4: 277-287. 


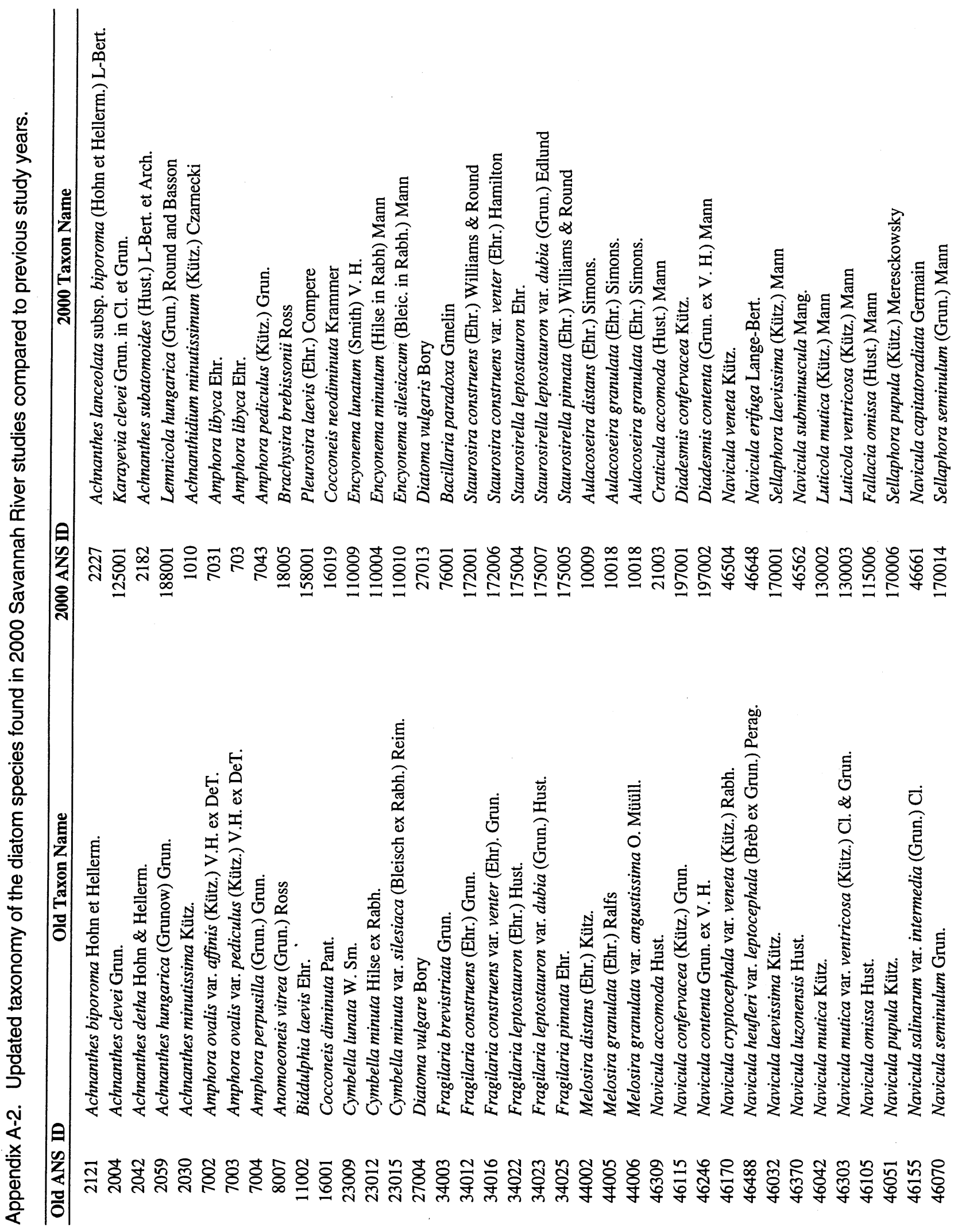


Appendix A-3. Summary of Catherwood Diatometer detailed readings parameters. Savannah River, SC, 1953 through 2000.

\begin{tabular}{|c|c|c|c|c|c|c|}
\hline \multirow[b]{2}{*}{ MONTH } & \multicolumn{2}{|c|}{$\begin{array}{c}\text { SPECIES } \\
\text { IN } \\
\text { MODE } \\
\text { Station }\end{array}$} & \multicolumn{2}{|c|}{$\begin{array}{l}\text { OBSERVED } \\
\text { SPECIES } \\
\text { Station } \\
\end{array}$} & \multicolumn{2}{|c|}{$\begin{array}{l}\text { SPECIES IN } \\
\text { THEORETICAL } \\
\text { UNIVERSE** } \\
\text { Station } \\
\end{array}$} \\
\hline & 1 & 6 & 1 & 6 & 1 & 6 \\
\hline OCT 1953 & 22 & 22 & 150 & 160 & 178 & 173 \\
\hline JAN 1954 & 19 & 21 & 151 & 147 & 181 & 172 \\
\hline APR 1954 & 24 & 20 & 169 & 148 & 200 & 184 \\
\hline JUL 1954 & 23 & 21 & 153 & 140 & 193 & 179 \\
\hline OCT 1954 & 21 & 23 & 142 & 181 & 168 & 181 \\
\hline JAN 1955 & 19 & 21 & 132 & 148 & 166 & 200 \\
\hline APR 1955 & 25 & 29 & 165 & 193 & 221 & 259 \\
\hline JUL 1955 & 20 & 21 & 132 & 124 & 180 & 180 \\
\hline OCT 1955 & 27 & 15 & 171 & 107 & 253 & 133 \\
\hline JAN 1956 & 30 & 27 & 185 & 175 & 229 & 207 \\
\hline APR 1956 & 35 & 23 & 215 & 145 & 252 & 168 \\
\hline JUL 1956 & 24 & 23 & 147 & 137 & 185 & 171 \\
\hline OCT 1956 & 23 & 13 & 149 & 89 & 206 & 100 \\
\hline JAN 1957 & 29 & 21 & 177 & 125 & 233 & 175 \\
\hline APR 1957 & 21 & 24 & 132 & 141 & 185 & 171 \\
\hline JUL 1957 & 29 & 28 & 181 & 168 & 203 & 223 \\
\hline OCT 1957 & 25 & 25 & 157 & 160 & 232 & 210 \\
\hline JAN 1958 & 27 & 24 & 152 & 149 & 212 & 237 \\
\hline MAY 1958 & 14 & 27 & 76 & 153 & 115 & 187 \\
\hline JUL 1958 & 22 & 24 & 139 & 149 & 191 & 211 \\
\hline OCT 1958 & 22 & 23 & 149 & 142 & 206 & 190 \\
\hline JAN 1959 & 24 & 23 & 147 & 144 & 197 & 193 \\
\hline APR 1959 & 26 & 27 & 154 & 157 & 186 & 184 \\
\hline JUL 1959 & 27.6 & 30.5 & 168 & 161 & 227 & 194 \\
\hline OCT 1959 & 27.4 & 24.2 & 165 & 148 & 212 & 194 \\
\hline JAN 1960 & 19.8 & 24.2 & 118 & 143 & 194 & 195 \\
\hline APR 1960 & 30.2 & 26.7 & 172 & 142 & 242 & 200 \\
\hline JUL 1960 & 28.2 & 30.3 & 169 & 169 & 257 & 204 \\
\hline OCT 1960 & 31.0 & 28.6 & 185 & 183 & 212 & 224 \\
\hline JAN 1961 & 31.5 & 36.5 & 188 & 206 & 254 & 264 \\
\hline APR 1961 & 36.5 & 21.8 & 204 & 139 & 258 & 176 \\
\hline JUL 1961 & 25.8 & 25.5 & 143 & 140 & 167 & 200 \\
\hline OCT 1961 & 20.4 & 20.8 & 120 & 126 & 141 & 182 \\
\hline JAN 1962 & 24.1 & 24.9 & 156 & 146 & 203 & 180 \\
\hline APR 1962 & 24.3 & 26.2 & 145 & 154 & 192 & 220 \\
\hline JUL 1962 & 24.0 & 25.8 & 143 & 145 & 208 & 204 \\
\hline OCT 1962 & 20.4 & 20.4 & 135 & 127 & 175 & 171 \\
\hline JAN 1963 & 30.6 & 31.6 & 186 & 191 & 272 & 265 \\
\hline APR 1963 & 21.6 & 27.3 & 135 & 155 & 196 & 208 \\
\hline JUL 1963 & 28.8 & 24.4 & 163 & 147 & 225 & 202 \\
\hline OCT 1963 & 29.3 & 25.7 & 165 & 160 & 205 & 223 \\
\hline
\end{tabular}


Appendix A-3 (continued). Summary of Catherwood Diatometer detailed readings parameters. Savannah River, SC, 1953 through 2000.

\begin{tabular}{|c|c|c|c|c|c|c|}
\hline \multirow[b]{2}{*}{ MONTH } & \multicolumn{2}{|c|}{$\begin{array}{c}\text { SPECIES } \\
\text { IN } \\
\text { MODE } \\
\text { Station } \\
\end{array}$} & \multicolumn{2}{|c|}{$\begin{array}{l}\text { OBSERVED } \\
\text { SPECIES } \\
\text { Station } \\
\end{array}$} & \multicolumn{2}{|c|}{$\begin{array}{l}\text { SPECIES IN } \\
\text { THEORETICAL } \\
\text { UNIVERSE** } \\
\text { Station } \\
\end{array}$} \\
\hline & 1 & 6 & 1 & 6 & 1 & 6 \\
\hline JAN 1964 & 20.5 & 33.8 & 144 & 185 & 195 & 211 \\
\hline APR 1964 & 23.1 & 13.3 & 134 & 90 & 192 & 128 \\
\hline JUL 1964 & 25.9 & 24.2 & 150 & 157 & 185 & 245 \\
\hline OCT 1964 & 24.0 & 22.6 & 138 & 123 & 168 & 155 \\
\hline JAN 1965 & 25.4 & 24.9 & 149 & 131 & 225 & 164 \\
\hline APR 1965 & 29.1 & 28.4 & 171 & 160 & 216 & 245 \\
\hline JUL 1965 & 30.4 & 31.4 & 183 & 171 & 244 & 186 \\
\hline OCT 1965 & 35.1 & 36.0 & 200 & 204 & 254 & 235 \\
\hline JAN 1966 & 27.3 & 29.8 & 169 & 175 & 208 & 209 \\
\hline APR 1966 & 28.4 & 35.2 & 174 & 197 & 231 & 276 \\
\hline JUL 1966 & 31.3 & 34.3 & 200 & 186 & 217 & 202 \\
\hline OCT 1966 & 29.3 & 30.4 & 178 & 177 & 197 & 180 \\
\hline JAN 1967 & 26.2 & 27.6 & 154 & 167 & 176 & 190 \\
\hline APR 1967 & 22.9 & 28.6 & 129 & 170 & 140 & 200 \\
\hline JUL 1967 & 23.7 & 22.9 & 135 & 139 & 163 & 160 \\
\hline OCT 1967 & 24.2 & 21.6 & 144 & 130 & 169 & 153 \\
\hline JAN 1968 & 27.8 & 21.4 & 148 & 130 & 170 & 150 \\
\hline APR 1968 & 15.5 & 18.2 & 101 & 111 & 120 & 130 \\
\hline JUL 1968 & 24.3 & 24.0 & 145 & 138 & 159 & 147 \\
\hline OCT 1968 & 18.7 & 29.1 & 116 & 150 & 132 & 169 \\
\hline JAN 1969 & 29.7 & 24.5 & 174 & 145 & 197 & 165 \\
\hline APR 1969 & 25.0 & 26.4 & 152 & 152 & 177 & 178 \\
\hline JUL 1969 & 14.4 & 26.0 & 90 & 152 & 104 & 172 \\
\hline OCT 1969 & 22.0 & 28.1 & 132 & 159 & 152 & 191 \\
\hline JAN 1970 & 24.4 & 24.6 & 141 & 142 & 166 & 161 \\
\hline APR 1970 & 17.4 & 22.9 & 105 & 125 & 155 & 146 \\
\hline JUL 1970 & 27.6 & 30.8 & 149 & 151 & 172 & 172 \\
\hline OCT 1970 & 28.5 & 27.8 & 155 & 159 & 178 & 179 \\
\hline JAN 1971 & 25.8 & 26.3 & 144 & 154 & 166 & 177 \\
\hline APR 1971 & 25.2 & 31.4 & 151 & 185 & 180 & 222 \\
\hline JUL 1971 & 28.8 & 20.7 & 174 & 124 & 298 & 198 \\
\hline OCT 1971 & 15.8 & 23.2 & 93 & 138 & 108 & 221 \\
\hline JAN 1972 & 49.2 & 52.3 & 305 & 307 & 377 & 363 \\
\hline APR 1972 & 25.9 & 30.3 & 157 & 174 & 188 & 214 \\
\hline JUL 1972 & 28.7 & 26.8 & 183 & 168 & 222 & 207 \\
\hline OCT 1972 & 27.9 & 16.0 & 158 & 99 & 180 & 116 \\
\hline JAN 1973 & 33.8 & 23.2 & 181 & 141 & 211 & 170 \\
\hline APR 1973 & 22.7 & 17.3 & 142 & 119 & 167 & 145 \\
\hline JUL 1973 & 15.0 & 20.4 & 96 & 131 & 163. & 160 \\
\hline OCT 1973 & 29.7 & 16.8 & 165 & 117 & 186 & 143 \\
\hline JAN 1974 & 24.5 & 19.5 & 170 & 141 & 219 & 177 \\
\hline APR 1974 & 10.4 & 8.6 & 76 & 64 & 95 & 77 \\
\hline JUL 1974 & 21.8 & 13.1 & 133 & 91 & 180 & 122 \\
\hline OCT 1974 & 24.8 & 15.6 & 124 & 104 & 159 & 146 \\
\hline
\end{tabular}


Appendix A-3 (continued). Summary of Catherwood Diatometer detailed readings parameters. Savannah River, SC, 1953 through 2000.

\begin{tabular}{|c|c|c|c|c|c|c|}
\hline \multirow[b]{2}{*}{ MONTH } & \multicolumn{2}{|c|}{$\begin{array}{l}\text { SPECIES } \\
\text { IN } \\
\text { MODE } \\
\text { Station } \\
\end{array}$} & \multicolumn{2}{|c|}{$\begin{array}{l}\text { OBSERVED } \\
\text { SPECIES } \\
\text { Station } \\
\end{array}$} & \multicolumn{2}{|c|}{$\begin{array}{l}\text { SPECIES IN } \\
\text { THEORETICAL } \\
\text { UNIVERSE** } \\
\text { Station } \\
\end{array}$} \\
\hline & 1 & 6 & 1 & 6 & 1 & 6 \\
\hline JAN 1975 & 19.4 & 13.7 & 98 & 81 & 119 & 116 \\
\hline APR 1975 & 20.7 & 11.1 & 124 & 76 & 178 & $102 *$ \\
\hline JUL 1975 & 13.6 & 11.2 & 73 & 70 & $97^{*}$ & 101 \\
\hline OCT 1975 & 10.4 & 18.0 & 75 & 122 & $99 *$ & 165 \\
\hline JAN 1976 & 25.2 & 21.2 & 153 & 122 & 223 & $196 *$ \\
\hline APR 1976 & 32.2 & 32.8 & 193 & 120 & $311 *$ & $384 *$ \\
\hline JUL 1976 & 82.7 & 51.8 & 176 & 159 & $913 * \dagger$ & $628 * \dagger$ \\
\hline OCT 1976 & 28.2 & 26.4 & 161 & 150 & 213 & $283 *$ \\
\hline JAN 1977 & 23.2 & 15.5 & 98 & 86 & $275^{*}$ & 120 \\
\hline APR 1977 & 19.1 & 29.3 & 134 & 202 & $198 *$ & $273 *$ \\
\hline JUL 1977 & 23.7 & 22.7 & 144 & 138 & $200 *$ & 193 \\
\hline OCT 1977 & 33.6 & 28.3 & 162 & 167 & 199 & 263 \\
\hline JAN 1978 & 38.0 & 30.9 & 210 & 176 & 294 & 234 \\
\hline APR 1978 & 30.5 & 31.9 & 182 & 188 & 230 & $291 *$ \\
\hline JUL 1978 & 30.5 & 51.5 & 159 & 232 & 296 & $415 \dagger$ \\
\hline OCT 1978 & 38.2 & 32.4 & 211 & 187 & 281 & 230 \\
\hline JAN 1979 & 45.0 & 28.8 & 221 & 154 & 275 & 207 \\
\hline APR 1979 & 16.9 & 7.8 & 102 & 57 & 140 & $73 *$ \\
\hline JUL 1979 & 37.6 & 25.7 & 191 & 139 & 239 & $249 *$ \\
\hline OCT 1979 & 31.0 & 54.5 & 178 & 142 & $246^{*}$ & $645^{*}$ \\
\hline JAN 1980 & 73.0 & 36.9 & 133 & 158 & $200 *$ & $486 \dagger$ \\
\hline APR 1980 & 24.1 & 13.0 & 98 & 83 & $311 \dagger$ & 105 \\
\hline JUL 1980 & 30.0 & 30.4 & 119 & 177 & $378 \dagger$ & 282 \\
\hline OCT 1980 & 24.6 & 50.2 .2 & 119 & 177 & 155 & $550 * \dagger$ \\
\hline JAN 1981 & 33.8 & 24.0 & 155 & 129 & $265^{*}$ & 193 \\
\hline APR 1981 & 17.5 & 20.7 & 102 & 110 & 141 & 156 \\
\hline JUL 1981 & 18.1 & 19.0 & 111 & 121 & 152 & 158 \\
\hline OCT 1981 & 25.5 & 22.7 & 143 & 131 & 238 & $217^{*}$ \\
\hline
\end{tabular}


Appendix A-3 (continued). Summary of Catherwood Diatometer detailed readings parameters. Savannah River, SC, 1953 through 2000.

\begin{tabular}{|c|c|c|c|c|c|c|c|c|c|}
\hline \multirow[b]{2}{*}{ MONTH } & \multicolumn{3}{|c|}{$\begin{array}{l}\text { SPECIES } \\
\text { IN } \\
\text { MODE }\end{array}$} & \multicolumn{3}{|c|}{$\begin{array}{l}\text { OBSERVED } \\
\text { SPECIES }\end{array}$} & \multicolumn{3}{|c|}{$\begin{array}{l}\text { SPECIES IN } \\
\text { THEORETICAL } \\
\text { UNIVERSE** }\end{array}$} \\
\hline & 1 & 5 & 6 & 1 & 5 & 6 & 1 & 5 & 6 \\
\hline $\begin{array}{l}\text { APR } 1982 \\
\text { OCT } 1982\end{array}$ & $\begin{array}{l}27.0 \\
23.0\end{array}$ & $\begin{array}{l}13.0 \\
11.8\end{array}$ & $\begin{array}{l}20.4 \\
24.4\end{array}$ & $\begin{array}{l}133 \\
129\end{array}$ & $\begin{array}{l}83 \\
60\end{array}$ & $\begin{array}{l}121 \\
129\end{array}$ & $\begin{array}{l}186 \\
172\end{array}$ & $\begin{array}{c}118 \\
90^{*}\end{array}$ & $\begin{array}{l}237 \\
237\end{array}$ \\
\hline $\begin{array}{l}\text { APR } 1983 \\
\text { OCT } 1983\end{array}$ & $\begin{array}{l}18.4 \\
25.6\end{array}$ & $\begin{array}{r}12.0 \\
6.7\end{array}$ & $\begin{array}{l}14.7 \\
31.8\end{array}$ & $\begin{array}{l}110 \\
137\end{array}$ & $\begin{array}{l}74 \\
44\end{array}$ & $\begin{array}{r}99 \\
167\end{array}$ & $\begin{array}{l}151 \\
247\end{array}$ & $\begin{array}{l}86^{*} \dagger \\
65^{*}\end{array}$ & $\begin{array}{l}146 \\
298 \dagger\end{array}$ \\
\hline $\begin{array}{l}\text { APR } 1984 \\
\text { OCT } 1984\end{array}$ & $\begin{array}{l}22.4 \\
27.6\end{array}$ & $\begin{array}{r}8.2 \\
13.0\end{array}$ & $\begin{array}{l}33.1 \\
27.0\end{array}$ & $\begin{array}{l}129 \\
154\end{array}$ & $\begin{array}{l}54 \\
80\end{array}$ & $\begin{array}{l}164 \\
131\end{array}$ & $\begin{array}{l}182 \\
200\end{array}$ & $\begin{array}{r}62 * \\
113^{*}\end{array}$ & $\begin{array}{l}206 \\
267 *\end{array}$ \\
\hline $\begin{array}{l}\text { APR } 1985 \\
\text { OCT } 1985\end{array}$ & $\begin{array}{l}14.5 \\
28.0\end{array}$ & $\begin{array}{l}40.4 \\
21.7\end{array}$ & $\begin{array}{l}18.3 \\
17.4\end{array}$ & $\begin{array}{r}90 \\
151\end{array}$ & $\begin{array}{l}136 \\
135\end{array}$ & $\begin{array}{l}113 \\
106\end{array}$ & $\begin{array}{l}133 \\
192\end{array}$ & $\begin{array}{l}510 \dagger \\
184\end{array}$ & $\begin{array}{l}165 \\
137^{*}\end{array}$ \\
\hline $\begin{array}{l}\text { APR } 1986 \\
\text { OCT } 1986\end{array}$ & $\begin{array}{l}19.6 \\
27.4\end{array}$ & $\begin{array}{l}22.6 \\
26.0\end{array}$ & $\begin{array}{l}23.1 \\
15.0\end{array}$ & $\begin{array}{l}113 \\
156\end{array}$ & $\begin{array}{l}130 \\
148\end{array}$ & $\begin{array}{r}128 \\
91\end{array}$ & $\begin{array}{l}168 \\
201\end{array}$ & $\begin{array}{l}193^{*} \\
205\end{array}$ & $\begin{array}{l}206 * \\
142\end{array}$ \\
\hline $\begin{array}{l}\text { APR } 1987 \\
\text { OCT } 1987\end{array}$ & $\begin{array}{l}13.4 \\
26.0\end{array}$ & $\begin{array}{l}13.4 \\
23.9\end{array}$ & $\begin{array}{r}8.8 \\
15.4\end{array}$ & $\begin{array}{l}108 \\
152\end{array}$ & $\begin{array}{r}91 \\
145\end{array}$ & $\begin{array}{l}58 \\
90\end{array}$ & $\begin{array}{l}115^{*} \\
211\end{array}$ & $\begin{array}{l}139 \\
201 *\end{array}$ & $\begin{array}{c}87 \\
115^{*}\end{array}$ \\
\hline $\begin{array}{l}\text { APR } 1988 \\
\text { OCT } 1988\end{array}$ & $\begin{array}{l}26.5 \\
29.1\end{array}$ & $\begin{array}{l}22.8 \\
20.7\end{array}$ & $\begin{array}{l}20.2 \\
12.2\end{array}$ & $\begin{array}{l}155 \\
143\end{array}$ & $\begin{array}{l}141 \\
121\end{array}$ & $\begin{array}{r}132 \\
66\end{array}$ & $\begin{array}{l}204 \\
180\end{array}$ & $\begin{array}{l}192 \\
132\end{array}$ & $\begin{array}{l}191^{*} \\
105^{*}\end{array}$ \\
\hline $\begin{array}{l}\text { APR } 1989 \\
\text { OCT } 1989\end{array}$ & $\begin{array}{l}17.2 \\
19.2\end{array}$ & $\begin{array}{l}26.1 \\
26.9\end{array}$ & $\begin{array}{r}11.9 \\
7.6\end{array}$ & $\begin{array}{r}103 \\
98\end{array}$ & $\begin{array}{l}148 \\
153\end{array}$ & $\begin{array}{l}77 \\
45\end{array}$ & $\begin{array}{l}135 \\
215^{*}\end{array}$ & $\begin{array}{l}206 \\
226\end{array}$ & $\begin{array}{r}111^{*} \\
60 *\end{array}$ \\
\hline $\begin{array}{l}\text { APR } 1990 \\
\text { OCT } 1990\end{array}$ & $\begin{array}{l}16.8 \\
18.8\end{array}$ & $\begin{array}{l}25.4 \\
28.3\end{array}$ & $\begin{array}{r}9.9 \\
17.9\end{array}$ & $\begin{array}{l}112 \\
121\end{array}$ & $\begin{array}{l}148 \\
137\end{array}$ & $\begin{array}{r}64 \\
104\end{array}$ & $\begin{array}{l}165^{*} \\
164^{*}\end{array}$ & $\begin{array}{l}239^{*} \\
183\end{array}$ & $\begin{array}{r}80^{*} \\
156^{*}\end{array}$ \\
\hline $\begin{array}{l}\text { APR } 1991 \\
\text { OCT } 1991 \\
\text { APR } 1992 \\
\text { OCT } 1992\end{array}$ & $\begin{array}{l}11.7 \\
23.4 \\
13.0 \\
22.6\end{array}$ & $\begin{array}{l}17.6 \\
30.7 \\
20.7 \\
25.6\end{array}$ & $\begin{array}{l}10.9 \\
16.6 \\
13.0 \\
10.4\end{array}$ & $\begin{array}{r}82 \\
129 \\
92 \\
135\end{array}$ & $\begin{array}{l}111 \\
129 \\
129 \\
139\end{array}$ & $\begin{array}{l}64 \\
93 \\
88 \\
70\end{array}$ & $\begin{array}{l}123^{*} \\
197^{*} \\
157 \\
200^{*}\end{array}$ & $\begin{array}{l}176^{*} \\
314^{*} \\
232^{*} \\
206^{*}\end{array}$ & $\begin{array}{l}163^{*} \\
145^{*} \\
128 \\
89^{*}\end{array}$ \\
\hline $\begin{array}{l}\text { APR } 1993 \\
\text { OCT } 1993\end{array}$ & $\begin{array}{l}15.7 \\
26.3\end{array}$ & $\begin{array}{l}20.7 \\
24.7\end{array}$ & $\begin{array}{l}25.8 \\
23.7\end{array}$ & $\begin{array}{r}81 \\
144\end{array}$ & $\begin{array}{l}120 \\
142\end{array}$ & $\begin{array}{r}91 \\
138\end{array}$ & $\begin{array}{l}233 * \dagger \\
232 *\end{array}$ & $\begin{array}{l}230^{*} \\
192^{*}\end{array}$ & $\begin{array}{l}330 * \dagger \\
189 *\end{array}$ \\
\hline $\begin{array}{l}\text { APR } 1994 \\
\text { OCT } 1994\end{array}$ & $\begin{array}{r}11.2 \\
6.6\end{array}$ & $\begin{array}{l}12.2 \\
11.7\end{array}$ & $\begin{array}{l}7.1 \\
2.7\end{array}$ & $\begin{array}{l}79 \\
36\end{array}$ & $\begin{array}{l}70 \\
66\end{array}$ & $\begin{array}{l}48 \\
20\end{array}$ & $\begin{array}{c}102 * \dagger \\
59 *\end{array}$ & $\begin{array}{l}102 * \\
103^{*}\end{array}$ & $\begin{array}{l}56^{*} \\
24^{*}\end{array}$ \\
\hline $\begin{array}{l}\text { APR } 1995 \\
\text { OCT } 1995\end{array}$ & $\begin{array}{l}14.3 \\
14.1\end{array}$ & $\begin{array}{r}11.2 \\
9.4\end{array}$ & $\begin{array}{l}8.6 \\
9.6\end{array}$ & $\begin{array}{l}96 \\
77\end{array}$ & $\begin{array}{l}71 \\
57\end{array}$ & $\begin{array}{l}58 \\
53\end{array}$ & $\begin{array}{l}134^{*} \\
137^{*}\end{array}$ & $\begin{array}{c}105^{*} \dagger \\
76^{*}\end{array}$ & $\begin{array}{l}74^{*} \\
95^{*}\end{array}$ \\
\hline APR 1996 & 11.7 & 9.7 & 9.1 & 78 & 71 & 65 & 142 & 98* & $88^{*}$ \\
\hline $\begin{array}{l}\text { APR } 1997 \\
\text { OCT } 1997\end{array}$ & $\begin{array}{l}11.1 \\
20.4\end{array}$ & $\begin{array}{l}12.0 \\
26.3\end{array}$ & $\begin{array}{l}10.0 \\
31.7\end{array}$ & $\begin{array}{l}72 \\
97\end{array}$ & $\begin{array}{r}76 \\
110\end{array}$ & $\begin{array}{r}56 \\
152\end{array}$ & $\begin{array}{r}88^{*} \\
186^{*}\end{array}$ & $\begin{array}{l}103 * \\
224 *\end{array}$ & $\begin{array}{c}76^{*} \\
259\end{array}$ \\
\hline $\begin{array}{l}\text { APR } 1998 \\
\text { OCT } 1998\end{array}$ & $\begin{array}{l}15.0 \\
45.0\end{array}$ & $\begin{array}{l}12.0 \\
14.0\end{array}$ & $\begin{array}{l}19.0 \\
18.0\end{array}$ & $\begin{array}{r}98 \\
192\end{array}$ & $\begin{array}{l}86 \\
75\end{array}$ & $\begin{array}{l}69 \\
90\end{array}$ & $\begin{array}{l}154 \\
346\end{array}$ & $\begin{array}{l}113 \\
111\end{array}$ & $\begin{array}{r}82 \\
130\end{array}$ \\
\hline $\begin{array}{l}\text { APR } 1999 \\
\text { OCT } 1999\end{array}$ & $\begin{array}{l}29.3 \\
22.4\end{array}$ & $\begin{array}{l}27.4 \\
41.3\end{array}$ & $\begin{array}{l}23.7 \\
13.4\end{array}$ & $\begin{array}{l}146 \\
111\end{array}$ & $\begin{array}{l}106 \\
168\end{array}$ & $\begin{array}{r}117 \\
67\end{array}$ & $\begin{array}{l}230.7 \\
173.5\end{array}$ & $\begin{array}{l}257.7 \\
360.4\end{array}$ & $\begin{array}{l}165.5 \\
121.4\end{array}$ \\
\hline $\begin{array}{l}\text { APR } 2000 \\
\text { OCT } 2000 \\
\end{array}$ & $\begin{array}{l}16.3 \\
25.9 \\
\end{array}$ & $\begin{array}{l}35.1 \\
13.9 \\
\end{array}$ & $\begin{array}{l}31.7 \\
\text { ND } \\
\end{array}$ & $\begin{array}{l}105 \\
115 \\
\end{array}$ & $\begin{array}{r}108 \\
68 \\
\end{array}$ & $\begin{array}{l}112 \\
\text { ND }\end{array}$ & $\begin{array}{l}151 \\
256 \\
\end{array}$ & $\begin{array}{l}510 \\
154 \\
\end{array}$ & $\begin{array}{l}415 \\
\text { ND } \\
\end{array}$ \\
\hline
\end{tabular}

*Curve fit produced a negative mode; the first local minimum was substituted.

** See Patrick, Hohn and Wallace (1954) for an explanation of this term.

†Best curve fit was not a good truncated lognormal.

$\S$ Calculations for these parameters are based on only 10 intervals; data used to generate the detailed curves in the report. 


\section{B. ATTACHED ALGAE AND AQUATIC MACROPHYTES}

\section{Introduction}
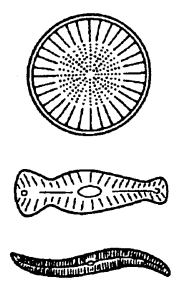

$\Longleftarrow$
Algae and aquatic

macrophytes are ideal for

water quality assessment:

being mostly immobile,

they must adapt to existing

conditions, and the ability

of many diatom species to

tolerate pollution is known

and can be used to

characterize aquatic

environments. ttached algae and aquatic macrophytes are of consid$\triangle$ erable importance in riverine ecosystems. As pri1 mary producers, algae and macrophytes synthesize food resources (principally carbohydrates) from carbon dioxide, thus transforming solar energy into a form available for other organisms. Photosynthetic activity of algae and aquatic plants results in the net production of oxygen, an essential element for nearly all aquatic life. In addition to their role in energy transfer and oxygen production, algal and aquatic plant communities provide habitat and shelter for diverse aquatic organisms and are often critical for the successful growth and reproductive activities of various species of invertebrates and fish.

Attached algae and aquatic macrophytes can be used as indicators of ecological conditions in aquatic systems. Since these plants are sessile, they can be presumed to reflect prevailing physical and chemical conditions at a given location.

Algae are particularly sensitive to water quality with respect to dissolved nutrients, metals and organics (e.g., Weitzel 1979). Among the various classes of algae commonly occurring in the river environment, diatoms (golden-brown algae) are invariably the most diverse. The analysis of diatom assemblages has proven to be especially important in water quality studies. Knowledge of the growth requirements and pollution tolerances of freshwater diatoms and blue-green algae has grown considerably over the years (Sladecek 1973; Lowe 1974; Beaver 1981; VanLandingham 1982; Patrick and Palavage 1994).

On the other hand, aquatic macrophytes are often most influenced by the physical nature of the environment (Ferren and Schuyler 1980; Schuyler 1988). Factors such as substrate 
type, water clarity and river velocity, whether varying naturally or as a result of anthropogenic perturbations, often define the kinds of macrophytes present as well as their areal extent within river reaches. The presence (or absence) and expanse of various macrophyte assemblages can have a profound influence on the kinds and numbers of other organisms supported within the water body (Hynes 1972).

The purpose of this study was to characterize the attached algae and aquatic macrophyte communities at the stations on the Savannah River in the vicinity of the Savannah River Site. The one Comprehensive Survey (at Stations 1, 2B, 5 and 6) was conducted during 8-11 September 2000. Species composition data of algal and aquatic macrophyte communities are compared with data from previous Comprehensive $\mathrm{Au}-$ gust/September algal surveys (1955-1999) conducted on the Savannah River.

\section{Materials and Methods}

$\mathbf{S}$ everal different techniques were employed to sample the algae adequately. The varied habitats in which algae can grow necessitate such a procedure. All available habitats were sampled within each station and sampling was continued for at least $30 \mathrm{~min}$ after the last obviously new species was discovered.

On relatively solid habitats, such as surfaces of logs, twigs, stones, etc., forceps or a knife was used. The material, if filamentous or in patchy colonies, was picked off with forceps. In cases of more uniform growth, the material was scraped off the substrate with a knife. On soft sand or mud surfaces or thickly coated stems and logs, a pipette with a suction bulb was used to avoid picking up material deposited under the algal colonies during previous seasons.

Moss colonies, other aquatic plants and rootlets were usually collected in a mass and placed in a white pan; with the addition of a little clean water the algae were easily picked out against this background. If the algal material separated readily from the moss plants or rootlets, the algae were then removed from the pan. If the material and the algae did not separate, the entire substrate was placed in a collecting con- 
tainer. Sometimes algae are so firmly associated with a substrate that it is necessary to collect the entire substrate.

All samples were finally placed in 17-ml vials. The untreated collections were brought to the field laboratory where a sample from each was examined. This was necessary for several reasons. First, certain of the fragile algae are more readily identified in a living condition. Second, it is important to observe the condition of the cell contents in the various algae. Finally, the relative number of empty frustules gives a very good index of the overall condition of the diatom community.

Blue-green algae and other important filamentous forms were dried on herbarium cards and wrapped in packets for transfer to The Academy of Natural Sciences of Philadelphia (ANSP) where they were curated into the permanent collections.

Diatom samples were removed from collections containing abundant diatoms and preserved with 1-2 drops of formaldehyde. The remaining collections were preserved with formaldehyde (final concentration was 3-5\%) and transferred to ANSP.

At the ANSP laboratory, diatom collections were placed in permanent storage, but no slides were made. Collections of algae other than diatoms were re-examined on wet mounts at 400x and 100x magnification. Further identifications were made by comparison with previous voucher collections and specimens in The Academy herbarium. The most abundant species were determined, and the samples were cataloged and saved as voucher specimens. A list of the algal species other than diatoms collected during the 2000 survey and the stations where they were collected is presented in Appendix B-1.

\section{Results}

Station 1

The water level was moderately low during the September 2000 survey, but there was evidence that the water level had recently risen at least $2 \mathrm{ft}$. Algal growth was light with small, scattered colonies of green algae, blue-green algae and diatoms at the station. No red or yel- 
low-green algae were found at the station. There was no dominant group of algae at Station 1.

Green algae were represented by four species at Station 1 (Table B-1). Three of the four species were collected from a colony of alligator weed growing among the pilings on the South Carolina side of the river. These were Oedogonium sp., Characium pringsheimii and Stigeoclonium lubricum. The other species of green algae (Closterium moniliferum) was present in several of the diatom collections.

Table B-1. Comparison of numbers of algal species, by division, found at Stations 1, 2B, 5 and 6 during the September 2000 survey conducted on the Savannah River by ANSP.

\begin{tabular}{lcccc}
\hline & \multicolumn{3}{c}{ Station } \\
\cline { 2 - 6 } \multicolumn{1}{c}{ Algal Division } & $\mathbf{1}$ & 2B & $\mathbf{5}$ & $\mathbf{6}$ \\
\hline Chlorophyta & 4 & 5 & 7 & 8 \\
Chrysophyta & 0 & 1 & 0 & 2 \\
Cyanophyta & 5 & 5 & 6 & 8 \\
Rhodophyta & 0 & 0 & 0 & 1 \\
TOTAL & & $\mathbf{1 1}$ & $\mathbf{1 3}$ & $\mathbf{1 9}$ \\
\hline
\end{tabular}

Blue-green algae were widespread at the station, but always in small colonies. A total of five species was recorded at Station 1. Three species were present in a number of collections. These were Microcoleus vaginatus, Schizothrix calcicola and Porphyrosiphon splendidus. Entophysalis lemaniae was present on the alligator weed with the green algae and $E$. rivularis was scraped from a log caught on pilings.

Diatom growth was scattered about the station, similar to the other algal groups, as diatom communities were present in a variety of floating habitats such as trailing ropes, floating plants or logs caught on pilings. All the diatom collections examined were in good condition.

Aquatic macrophytes observed at this station were the mosses Fissidens fontanus, Fontinalis filiformis and Amblystegium fluviatile, the liverwort Porella pinnata, some Lemna sp. with alligator weed (Alternanthera philoxeroides), parrotfeather (Myriophyllum aquaticum) and water hyacinths (Eichornia crassipes) among the pilings and Micranthemum umbrosum on a trailing rope. No submerged beds of aquatic macrophytes were observed. 


\section{Station 2B}

The water level was moderately low during the September 2000 survey with flooded terrestrial plants giving evidence of a recent rise. Algal growth was light and no one algal group was dominant.

Five species of green algae were recorded at Station 2B. Oedogonium sp. was present on a log caught on pilings, $M i$ crospora sp. was locally common on a fallen tree, and several of the diatom collections contained colonies of Closterium moniliferum. A second species of Closterium, $C$. lunula was present with blue-green algae in fast water. A fringe of Spirogyra sp. filaments was found on a fallen tree. A patch of the yellow-green alga Vaucheria sp. was growing with the Spirogyra on the fallen tree.

Blue-green algae were present in small, scattered colonies. Two of the five species recorded at Station 2B were present in a number of collections. These were Microcoleus vaginatus and Schizothrix calcicola. Two of the other three (S. arenaria and Oscillatoria lutea) were present in two collections while Nostoc commune was locally common in only one collection (taken from a log on the pilings). No red algae were observed at this station.

Diatom growth was modest at Station 2B. All of the collections examined were in good condition.

The aquatic macrophyte flora was almost identical to the flora at Station 1. The only difference was the presence of Hydrocotyl americana at Station 2B and not at Station 1. No submerged beds of aquatic macrophytes were observed.

\section{Station 5}

he water level was moderately low during the Sep-
tember 2000 survey with evidence of a recent rise in
water level. Algal growth was light with scattered colonies on floating habitats. No one algal group was notably more abundant than the others.

Seven species of green algae were recorded at Station 5. A mix of Oedogonium sp. and Spirogyra sp. was growing on a sunken log. Growing nearby on a submerged branch were 
Cladophora glomerata, Microspora sp. and Characium pringsheimii. Closterium moniliferum was abundant in one of the diatom collections and Stigeoclonium lubricum was collected from a log on pilings near the South Carolina shore. No red or yellow-green algae were observed at Station 5.

A total of six species of blue-green algae was recorded from Station 5. Four of these species were collected from a sunken $\log$ between sets of pilings on the Georgia side of the river. These were Microcoleus vaginatus, Schizothrix calcicola, Oscillatoria lutea and Anabaena oscillariodes. In addition Porphyrosiphon splendidus was collected from the deep end of a sunken $\log$ and Schizothrix arenaria was collected from shallow water. Diatoms were present as small colonies in a number of habitats. All the diatom collections examined were in good condition.

The three aquatic mosses and the liverwort were growing in the usual habitats such as pilings and submerged branches. Duckweed (Lemna sp.) was common among the debris below the pilings along with a little alligator weed (Alternanthera philoxeroides). Micranthemum umbrosum was present on submerged branches along both banks of the river. Some bedraggled water hyacinths (Eichornia crassipes) were floating in a backwater and a colony of Hydrocotyl americana was growing on a very muddy log. No submerged beds of aquatic macrophytes were observed.

\section{Station 6}

The water level was moderately low at Station 6 during the September 2000 with evidence of a recent rise. Algal growth was light with the best representation on floating habitats. No one algal group was dominant over the others.

The 19 species of algae recorded here were present in widely scattered small colonies. Green algae were represented by eight species. Oedogonium sp., Stigeoclonium lubricum, Closterium moniliferum, Spirogyra sp., Microspora sp. and Characium pringsheimii were all present at two or more of the other stations. The remaining two species were not observed at any of the other stations. These were Ulothrix zonata mixed with blue-green algae on a muddy log and a thin fringe of Zygnema sp. on a log near the South Carolina 
shore. Yellow-green algae were present as a few colonies of Vaucheria sp. on pilings and one colony of Tribonema sp. among aquatic moss.

Blue-green algae were widespread with small colonies on both sides of the river. The most diverse collection was taken from a diatometer cord. Four species were present there including Schizothrix calcicola, Microcoleus vaginatus, $S$. arenaria and Calothrix parietina. Also, Porphyrosiphon splendidus was collected from a punky log, Entophysalis lemaniae was collected from two locations on pilings, Oscillatoria lutea was common in one location in shallow water and Anabaena oscillariodes was taken from a muddy log. The only colony of red algae was recorded from Station 6. This was Compsopogon coeruleus which was present on a sunken log. Diatom communities were small and scattered about the station. All of the diatom collections examined were in good condition.

The ubiquitous mosses Fissidens fontanus, Amblystegium fluviatile and Fontinalis filiformis were recorded at this station along with the liverwort Porella pinnata. Duckweed (Lemna sp.) parrotfeather (Myriophyllum aquaticum) and alligator weed (Alternanthera philoxeroides) were floating behind the pilings and colonies of Micranthemum umbrosum were present on submerged branches on both sides of the river. A few water hyacinths (Eichornia crassipes) were caught behind the pilings and some Hydrocotyl americana was growing on a log caught on the pilings. No submerged beds of aquatic macrophytes were observed.

\section{Discussion}

The water level was moderately low during the September 2000 survey, but it had risen several feet during the recent past and as a result, the algal growth was mainly restricted to floating habitats at the four stations. Overall algal growth was light and no one algal group dominated the assemblage at any station. No differences were apparent in the field when the four stations $(1,2 \mathrm{~B}, 5$ and 6$)$ were compared with each other. All the diatom collections examined were in good condition. 
The aquatic macrophyte growth was similar at all four stations. The three aquatic mosses and the liverwort were present at all four stations along with duckweed, alligator weed, water hyacinths and Micranthemum umbrosum. Hydrocotyl ranunculoides and parrotfeather were present at three of the four stations (Appendix B-2).

The number of recorded algal species other than diatoms ranged from 9 to 19 at the 4 stations during the September 2000 survey (Table B-2). These figures all fall within the range recorded for previous August and September (1955 to 1999) surveys at Stations 1, 5 and 6 (Station 2B has been sampled only once previously during August or September.) The 12-year observed species averages for algae other than diatoms at Stations 1, 5 and 6 are very similar. They are, respectively, $15.25,14.25$ and 14.42 . The two year average for Station 2B is 12.50 . The most common species encountered during the September 2000 study were included among the species that have been recorded regularly at all the stations since the studies were initiated. These include the green algae Oedogonium sp., Spirogyra sp. and Closterium moniliferum, the blue-green algae Microcoleus vaginatus, Schizothrix calcicola and S. arenaria and the yellow-green alga Vaucheria sp. Despite the light growth the usual array of species was present at the four stations during the September 2000 study. The results of the September 2000 algal and aquatic macrophyte survey show no evidence that the operations of the SRS were having a detrimental effect on water quality of the Sa-

Table B-2. Comparison of numbers of algal taxa other than diatoms found at Stations 1, 2B, 5 and 6 during the August/September Comprehensive Surveys conducted on the Savannah River, 1955-2000.

\begin{tabular}{lcccc}
\hline & \multicolumn{3}{c}{ Station } \\
\cline { 2 - 5 } \multicolumn{1}{c}{ Survey Date } & I & 2B & $\mathbf{5}$ & $\mathbf{6}$ \\
\hline Aug./Sept. 1955 & 13 & $* *$ & 19 & 16 \\
Aug./Sept. 1960 & 10 & $* *$ & 12 & 9 \\
Sept. 1965 & 17 & $* *$ & 16 & 14 \\
Aug./Sept. 1968 & 17 & $* *$ & 14 & 10 \\
Sept. 1972 & 26 & $* *$ & 18 & 12 \\
Aug. 1976 & 13 & $* *$ & 13 & 11 \\
Sept. 1980 & 18 & $* *$ & 10 & 15 \\
Sept. 1984 & 16 & $* *$ & 15 & 13 \\
Sept. 1989 & 15 & $* *$ & 11 & 14 \\
Sept. 1993 & 15 & $* *$ & 16 & 19 \\
Sept. 1999 & 14 & 14 & 14 & 13 \\
Sept. 2000 & 9 & 11 & & 13 \\
\end{tabular}


vannah River. The differences noted in the aquatic flora were all consistent with seasonal and moderately low water conditions. The algal and aquatic macrophyte communities were fundamentally similar to those present during previous Savannah River surveys and represent typical Southeastern Coastal Plain river flora.

Evidence of some organic loading continues to be present at all stations. The blue-green algae Microcoleus vaginatus, $M$. lyngbyaceus and Schizothrix calcicola and the green alga Stigeoclonium lubricum are listed as associated with pollution (Patrick and Palavage 1994; VanLandingham 1982). 
Appendix B-1. List of algal species collected at Stations 1, 2B, 5 and 6 on the Savannah River during the September 2000 survey.

\begin{tabular}{cccccc}
\hline & \multicolumn{5}{c}{ Station } \\
\cline { 2 - 6 } & Taxa & 1 & $2 B$ & 5 & 6 \\
\hline
\end{tabular}

Division Cyanophyta

Class Myxophyceae

Order Chroococcales

Family Entophysalidae

Entophysalis lemaniae (Ag.) Dr. \& Daily

E. rivularis (Kutz.) Dr. \& Daily

Order Hormogonales

Family Oscillatoriaceae

Microcoleus vaginatus (Vauch.) Gom.

Oscillatoria lutea Ag.

Porphyrosiphon splendidus (Grev.) Dr.

Schizothrix arenaria (Berk.) Gom.

S. calcicola (Ag.) Gom.

Family Nostocaceae Anabaena oscillariodes Bory

Nostoc commune Vauch.

Family Rivulariaceae

Calothrix parietina (Nag.) Thur.

$X$
$X$

X

$\mathrm{X}$

$\overline{\mathrm{X}}$

$\frac{x}{x}$

$\bar{x}$

$-\quad \bar{x}$

$\mathrm{X}$

$\mathrm{X}$

-

$\mathrm{X}$

$\mathrm{X}$

- $\quad$ - $\quad$ X

ision Rhodophyta

Class Rhodophyceae

Order Bangiales

Family Erythrotrichiaceae

Compsopogon coeruleus (Balb.) Mont.

Division Chlorophyta

Class Chlorophyceae

Order Ulothricales

Family Ulothricaceae

Ulothrix zonata (Web. \& Mohr) Kutz.

Order Microsporales

Family Microsporaceae

Microspora sp.

Order Chaetophorales

Family Chaetophoraceae Stigeoclonium lubricum (Dillw.) Kütz.

Order Cladopherales

Family Cladophoraceae

Cladophora glomerata (L.) Kutz.

Order Oedogoniales

Family Oedogoniaceae

Oedogonium sp.

Order Chlorococcales

Family Characium Characium pringsheimii A. Braun

Order Zygnematales

Family Zygnemataceae

Spirogyra sp.

Zygnema sp.

Family Desmidiaceae

Closterium lunula Nitz.

C. moniliferum Breb.

$\mathrm{X} \quad \mathrm{X}$

$\mathrm{X} \quad \mathrm{X}$

$X \quad X$

$\mathrm{X} \quad \mathrm{X}$

$\mathrm{X} \quad \mathrm{X}$

$\mathrm{X} \quad \mathrm{X}$

- $\quad-$

$\begin{array}{llll}- & - & - & \mathrm{X}\end{array}$

$\begin{array}{lllll}- & - & - & \end{array}$

一

$\begin{array}{llll}- & \mathrm{X} & \mathrm{X} & \mathrm{X}\end{array}$

$\begin{array}{lllll}\mathrm{X} & - & \mathrm{X} & \mathrm{X}\end{array}$

- $-1-10$

$\begin{array}{llll}\text { X } & \text { X } & \text { X } & \text { X }\end{array}$

$\begin{array}{llll}\mathrm{X} & - & \mathrm{X} & \mathrm{X}\end{array}$

\begin{tabular}{lll} 
X & $\mathrm{X}$ & $\mathrm{X}$ \\
\hline
\end{tabular}

$\begin{array}{llll}- & - & - & \end{array}$

$\begin{array}{llll}\bar{X} & \mathrm{X} & \overline{\mathrm{X}} & \overline{\mathrm{X}}\end{array}$

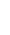


Appendix B-1 (continued). List of algal species collected at Stations 1, 2B, 5 and 6 on the Savannah River during the September 2000 survey.

\begin{tabular}{|c|c|c|c|c|}
\hline \multirow[b]{2}{*}{ Taxa } & \multicolumn{4}{|c|}{ Station } \\
\hline & 1 & 2B & 5 & 6 \\
\hline $\begin{array}{l}\text { Division Chrysophyta } \\
\text { Class Xanthophyceae } \\
\text { Order Heterotrichales } \\
\text { Family Tribonemamataceae }\end{array}$ & & & & \\
\hline $\begin{array}{l}\quad \text { Tribonema sp. } \\
\text { Order Heterosiphonales } \\
\text { Family Vaucheriaceae }\end{array}$ & - & - & - & $X$ \\
\hline
\end{tabular}




\section{NON-INSECT MACROINVERTEBRATES}

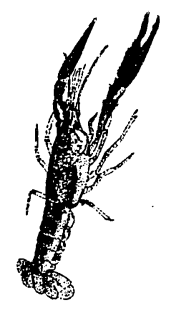

Non-insect

macroinvertebrates are

reliable indicators of water

pollution because many

species are sedentary and

are sensitive to a wide

range of ecological

perturbations.

\section{Introduction}

7 he Savannah River survey of non-insect macroinvertebrates was conducted on 25 to 28 August and 8 to 11 September 2000 in order to (1) compare an inventory of these organisms with earlier surveys for possible developing faunal trends, (2) relate the faunal characteristics and trends to such variables as habitat (e.g., relative aquatic vascular plant densities), river hydrodynamics and water quality changes as reflected by the sensitivities of the non-insect macroinvertebrates and (3) compare the faunas among stations upriver and downriver from the Savannah River Site. This report will also provide habitat and distribution information on the biota. The 25 to 28 August survey concentrated on mussel habitats to monitor the Savannah River populations of the most endangered invertebrate group in North America.

In order to provide a comprehensive and comparative examination of the 2000 results of the non-insect macroinvertebrate fauna of the Savannah River at the four stations (Appendix C) with those from previous surveys, a data summary that includes previous studies is included (Tables C-1 and C-2). The 1997 through 1999 surveys were the only years that Stations $1,2 \mathrm{~B}, 5$ and 6 were sampled as a single study for non-insect macroinvertebrates. In 1993, these same stations were examined as part of two separate studies [comprehensive at Stations 1, 3, 5 and 6 and Plant Vogtle at Stations V-1 (=2A) and V-2 (=2B) ]. For comparisons among the 1993 through 1999 years, data will be extracted from the 1993 studies from Stations 1, 2B, 5 and 6. Comparisons will also be made with the August or September portion of previous comprehensive surveys from Stations 1, 5 and 6 back to 1976 when less eutrophic conditions existed. Eutrophic conditions prevailed in the Savannah River in 1972, and these data will be used for comparisons, where applicable. Four station comparisons of the 
Table C-1. Numbers of taxa collected by hand from the Savannah River at Stations 1, 2B (1993, 1997, 1998, 1999 and 2000), 3 (1989 to 1972), 5 and 6 in August to October 1972, 1976, 1980, 1984, 1989, 1993, 1997, 1998, 1999 and 2000. Numbers for 1993 (except for Station 2B), 1997, 1998, 1999 and 2000 include the mussel studies.

\begin{tabular}{cccccc}
\hline & \multicolumn{5}{c}{ Stations } \\
\cline { 2 - 6 } Year & $\mathbf{1}$ & $\mathbf{3 / 2 B}$ & $\mathbf{5}$ & $\mathbf{6}$ & Total \\
\hline 2000 & 17 & 20 & 21 & 16 & 30 \\
1999 & 29 & 25 & 23 & 29 & 37 \\
1998 & 20 & 25 & 33 & 39 & 47 \\
1997 & 32 & 37 & 38 & 37 & 49 \\
1993 & 26 & 13 & 26 & 32 & 47 \\
1989 & 21 & 16 & 14 & 17 & 27 \\
1984 & 16 & 18 & 28 & 26 & 36 \\
1980 & 16 & 9 & 20 & 23 & 33 \\
1976 & 26 & 18 & 31 & 21 & 45 \\
1972 & 37 & 30 & 34 & 47 & 60 \\
\hline
\end{tabular}

Table C-2. Numbers of taxa in the dominant classes collected by hand from the Savannah River at Stations 1, 2b (1993, 1997, 1998, 1999 and 2000), 5 and 6 in August to October. Species totals for 1993-2000 include mussel surveys. [Numbers in parenthesis (1989 to 1972) represent additional species from Station 3 [e.g., 6(1) =7 species at Stations 1, 3, 5 and 6 to permit four station comparisons 1999 to 1972].

\begin{tabular}{cccccc}
\hline & Leeches & Snails & $\begin{array}{c}\text { Clams/Mussels } \\
\text { Bivalves }\end{array}$ & Crustaceans & Mites \\
\hline 2000 & 4 & 5 & $4 / 8$ & 4 & 1 \\
1999 & 3 & 6 & $2 / 13$ & 5 & 2 \\
1998 & 4 & 7 & $7 / 13$ & 7 & 1 \\
1997 & 6 & 10 & $6 / 14$ & 5 & 2 \\
1993 & 4 & 8 & $5 / 13$ & 6 & 2 \\
1989 & $2(1)$ & 7 & $4(1) / 2$ & 4 & 1 \\
1984 & $2(1)$ & $6(1)$ & $3(1) / 9$ & 5 & 0 \\
1980 & 2 & 7 & $5 / 9$ & 5 & 1 \\
1976 & 6 & 8 & $4 / 14$ & $4(1)$ & 2 \\
1972 & 10 & 11 & $5 / 15$ & 5 & 7 \\
\hline
\end{tabular}

1993 through 1999 data with the 1972 through 1989 studies are made in Tables C-1 and C-2 utilizing Station 3 from these earlier surveys. Comparisons of the mussel data will be across all Academy comprehensive Savannah River surveys (1951 through 1999) at all stations (1, 2B, 3, 5 and 6) and seasons (typically two) beginning with the first study in 1951. Comparisons of data sets among years permits the best and most thorough understanding of the fauna, their distributions, and 
their habitats under various conditions, and it provides taxonomic consistency among the years.

Biological inventories are widely recognized as establishing necessary baseline data against which important comparisons with later investigations can be made to discern environmental changes. Traditionally, benthic non-insect macroinvertebrates have been chosen as reliable indicators of water pollution because many species exhibit sedentary habits, some taxa are long-lived with low reproductive rates, and others exhibit complex, easily interrupted reproductive life histories and different tolerances to stress. Together the group possesses phylogenetic, physiological, behavioral and ecological diversity with a sensitivity to a wide range of ecological perturbations. Alterations in community composition and population sizes reflect changes in the ecosystem. Consequently, studies of benthic macroinvertebrates are an important component of synoptic surveys that are designed for environmental impact assessment (Wilhm and Dorris 1968, Starrett 1971, Hynes 1972, 1974, Goodnight 1973, Hart and Fuller 1974, Olive and Smith 1975, Whitton 1975, Taylor 1980, Downing and Rigler 1984, Krueger et al. 1988, Maret 1988, Abel 1989, Root 1990, Rosenberg and Resh 1993, Peterson 1993, Bright 1994, Loeb and Spacie 1994, Norris et al. 1995, Bournaud et al. 1996, Barbour et al. 1996, Brown 1996, Karr and Chu 1998 and Rabeni et al. 1999).

\section{Materials and Methods}

$\mathbf{T}$

The comprehensive non-insect macroinvertebrate study consisted of a survey of the mussel fauna on 25 to 28 August and the remaining groups on 10 to 14

September 1999. The non-insect macroinvertebrates were sampled at four stations (1, 2B, 5 and 6) on the Savannah River (see Location and Description of Stations). Approximately 5 to $7 \mathrm{hr}$ were spent at each station, including time to survey the area by foot or boat to identify accessible habitats that differ in substrate type, current velocity and water depth. Sampling was done in shallow water areas that could be accessed in waders. No attempt was made to sample any parasitic (e.g., leeches, crustaceans) or commensal (e.g., branchiobdellids, mite) species from their vertebrate or invertebrate hosts during the survey. 
Because non-insect macroinvertebrates exhibit numerous morphologies and behaviors, they were sampled in a number of ways. Slow moving and sedentary forms usually were best collected by hand, with smaller species being more easily removed with small forceps from the substrate. In deeper water these animals were collected with a variety of dip nets. Softbottomed sandy, silty or muddy substrates were sampled with a Wildco bottom aquatic dip net (\#425-A50) and a Wildco dip net (\#484-D82) with a 3-mm (1/8-in) ace mesh. Harder, packed sand substrate areas in swifter currents were collected with the dip net placed perpendicular to the bottom and in front of the collector who disturbed the substrate with his feet while moving backwards upstream; any dislodged infauna were swept by the current into the dip net. More mobile animals were taken by dipnets which were swept through debris, leaf litter, aquatic vascular plants, flooded grasses and exposed root mats of riparian trees. Rip rap, woody deadfalls and debris trapped around pilings or in shallows along the shore were examined and organisms removed with forceps. The pilings themselves were also searched in the same manner for specimens.

The contents of the nets were rinsed in the river to remove sediment and then were placed in a shallow aluminum tray. In this manner even small animals were easily observed and removed. Common species were immediately identified, recorded and released. Some reference material and taxa which could not be identified with certainty in the field were preserved in 95\% ethyl alcohol and taken to the Philadelphia laboratory for identification. Before storage in alcohol, highly contractile organisms such as planarians, leeches, earthworms and tubificid worms were relaxed. They were passed through an intermediate step in $10 \%$ formalin solution and washed before storage in $80 \%$ alcohol. The habitat and relative abundance of all the taxa were noted and the macroinvertebrates later identified to the lowest practical taxon. Relative abundances were defined on the basis of the number of animals collected as rare (1 individual), uncommon ( 2 to 3 ), moderately common (4 to 15 ), common (16 to 30 ) and abundant (31 or more).

Mussels and Asian clams (Corbicula fluminea) were collected quantitatively from areas delineated with a $1.0-\mathrm{m}^{2}$ quadrat. The perimeter of a sample area was delineated with flagged rebar at the $0.6 \mathrm{~m}$ depth. Study areas chosen in 2000 
occurred immediately downriver from the downrivermost set of pilings (Stations 1 and 2B) or at the junction of the main channel and a backwater oxbow (Stations 5 and 6UR). To encompass a variety of flows, substrates and depths, three transects were established roughly perpendicular to the shoreline. Along each transect, three quadrats were set at various depths (= nine quadrats). Based upon depth, substrate and flow, a tenth quadrat was selected in likely mussel habitat. This last quadrat was chosen to add species and specimens to contribute mussel size distribution information. Sediments were scooped to a depth of approximately $19.5 \mathrm{~cm}$ (7.75 in) with a 2-L polyethylene scoop and passed through a $30.5-\mathrm{OD} X$ $8.89-\mathrm{D} \mathrm{cm}$ (12 X 3.5-in) sieve with a $2-\mathrm{mm}$ (0.0787-in) mesh. The sediment within each quadrat was then searched by hand for animals that might occur deeper than the bite of the scoop. All bivalve molluscs were counted and all mussels measured. Animals were returned to areas near where they were originally found. The common and scientific names of molluscs follows Turgeon et al. (1998).

\section{Results}

I n 2000, low water levels (mean river height of 1.2 and $2.4 \mathrm{ft}$ on 25 to 28 August and 8 to 11 September 2000, respectively) were present during the mussel and comprehensive non-insect macroinvertebrate surveys. Water levels were so low that 2000 marked the first mussel survey in which the assistance of the U.S. Army Corps of Engineers was not needed to control water levels. Although when compared to other Savannah River studies, water levels were low, they were higher than prior water levels in the summer months of 2000 (q.v., Fig. 2). The less vagile to sessile non-insect macroinvertebrate fauna primarily existed below the base level established during the low water summer months. Higher water levels during the comprehensive non-insect macroinvertebrate study resulted in less access to the biota living below the base level water line. Riparian grasses, including paspalum grass (Paspalum species), at the newly established river margin were flooded by high (relatively) water levels and provided habitat for macroinvertebrates (e.g., crustacea and some snails). The beds of submerged aquatic vascular plants absent from the study area since 1990 were 
still absent in 2000. Present, however, were scattered growths of water hyacinth (Eichornia crassipes), alligator weed (Alternanthera philoxeroides), shade mudflower (Micranthemum umbrosum), water-milfoil (Myriophyllum species) and water pennywort (Hydrocotyl ranunculoides). These patches of aquatic vascular plants provided habitat for a range of macroinvertebrates (see individual accounts below).

\section{Sponges (Porifera)}

The 2000 survey included the observation of colonies
of an undetermined species of sponge at all stations.
It was uncommon at Stations 5 (branch) and 6 (small log), moderately common [woody debris (e.g., logs and branches)] at Station 2B and common at Station 1 (woody debris). From the 1999 survey, colonies this undetermined species of sponge were found to be moderately common on woody substrates at Stations 1 and 2B and rare at Station 6. In 1998, small colonies of sponge were abundant on rocky rip rap and a log and branch at Station 5, common on logs and roots at Station 6 and branches and logs at Station 1 and uncommon on a log at Station 2B. In 1997, large colonies of sponge were abundant on rocky rip rap and common on logs at Station 1. This taxon was found on roots and logs at the remaining stations where it was common at Station $2 \mathrm{~B}$ and moderately common at Stations 5 and 6. In 1993, colonies of sponge were common on logs and were encrusting riparian roots at Station 1. Sponges were common at Station 2B as small colonies on logs and branches. This sponge was also found to be common on the left bank rip rap downriver from Wild Horse Slough (= Swift Gut) at Station 5. The observation of two large colonies on a small branch at Station 6 marks the first time this species had been sampled from this area [6UR (=upper reach) or 6LR (=lower reach) ] (see Location and Description of Stations) since May 1972. In 1989, large colonies of sponge were common on rocks near shore along one of the pilings at Station 1 and this sponge was scattered on logs trapped by pilings at Station 5. Sponges were present in the 1980 (Station 1) and August 1976 (Station 1) studies. The Academy surveys reveal this sponge to generally be a widespread and common component of the Savannah River system in sheltered areas, and it is especially found wherever rocky substrata have been introduced. 


\section{Flatworms (Platyhelminthes)}

he 2000 study found Dugesia tigrina rare at Stations
1 (bark) and 6 (crawling on the outside of a plastic
bottle) and moderately common at Station 5 (moderately common on woody debris). In 1999, this species was uncommon in muddy stick litter at Station 1 and on a log at Station 6. The 1998 survey found this same species of flatworm to be moderately common on a plastic cup at Station 1 and under the bark of a log at Station 5 and rare in water hyacinth roots and uncommon in willow roots at Station 6. In 1997 , this planarian was found to be common on leaves and logs and among roots at Station 1, uncommon on leaf and stick liter at Station 2B, moderately common among roots and on loose bark and a branch at Station 5 and on alligator weed and willow roots at Station 6. Planarians were most often taken in 1993 from the surface of logs. On this habitat it was common at Station 2B, moderately common at Stations 1 and 6 and uncommon at Station 5. The 1989 study found this species usually living among growths of aquatic vascular plants such as alligator weed, coon-tail (Ceratophyllum demersum) and waterweed (Egeria densa) at all stations. This flatworm was also collected at all stations during the 1984 survey, Stations 5 and 6 in 1980 and Stations 1, 5 and 6 in August 1976. This planarian has been and remains an uncommon to locally common part of the Savannah River fauna in the areas surveyed.

\section{Roundworms (Nematoda)}

s in recent surveys, no roundworms were taken in
2000. They occupy a wide range of habitats, and al-
though they, along with ceratopogonid (biting midges) larvae, display a distinctive thrashing mode of locomotion in samples, they are often overlooked because of their small size. Roundworms were rare in collections of leaf litter at Station 1 in 1993. In 1989 these small worms were found in muddy to peaty sediments and among the root masses of aquatic vascular plants at Stations 1, 5 and 6. This group was collected from unnamed habitats in 1984 at Stations 5 and 6. No representatives of this group were recorded at Stations 1, 
5 and 6 in 1980 or August 1976. Their poor representation in collections is probably a reflection of their small size.

\section{Horsehair Worms (Nematomorpha)}

n undetermined species of horsehair worm of the
family Chordodidae was uncommon in 2000 at Sta-
tion 2B in floating grasses. Horsehair worms were rare in 1999 at Stations 1 and 2B and uncommon at Station 5. The nematomorph at Station 2B was noted from open water, while those taken from Stations 1 and 5 were removed from root mats. Horsehair worms were rare in 1998 at Stations 1, 5 and 6. All worms were taken from open water habitats either by dip net (Stations 1 and 5) or seine (Station 6 by the fisheries team). Single horsehair worms were collected from Stations 1 and 5 in 1997. The individual from Station 1 was collected by seine, while the horsehair worm at Station 5 was scooped up by hand while it was "swimming" in open water. A single animal was recorded in 1993 after it was found in a pile of small branches and leaf litter at Station 5. Not since May 1972, when a single horsehair worm was collected from undefined habitat at Station 1, had this group been represented in the Savannah River surveys. Nematomorphs are infrequently taken in aquatic surveys and less so in large rivers. The reason for their more widespread or common appearance in samples during the last four surveys is unknown.

\section{Moss Animals (Ectoprocta)}

$\mathbf{F}$ rom a backwater at Station 5 in 2000, three small colonies of the gelatinous bryozoan Plumatella magnifica were observed on a section of old trot line. This is the first time this species has been noted from the Savannah River studies and is probably more a reflection of the quiet backwater habitat and low flows in 2000 . The branching ectoproct Plumatella repens is the typical bryozoan found in the main stem of the river. Although no ectoprocts were observed in the 1999 investigation, in 1998 P. repens was moderately common on rocky rip rap and two sparse colonies were found on a branch at Station 5 and one meager colony was noted from a $\log$ at Station 1. Plumatella repens was uncommon on rocks - at Station 5 and portions of a colony were found in a 
sample of riparian roots at Station 6 in 1997. In 1993, this species was found at only Station 5. Here two large colonies were noted from flat rocks at the rip rap bank downriver from Wild Horse Slough (= Swift Gut). This bryozoan was not found in 1989 but was taken from unspecified habitats at Stations 5 and 6 in 1984. A second bryozoan, Pottsiella erecta was recorded that same year from Station 6. In 1980, P. repens was tentatively identified from submerged wood at Stations 1, 5 and 6. The bryozoan from the August 1976 investigation was tentatively identified as $P$. emarginata. It was found on "submerged vegetable trash" at all stations (ANSP 1977:40). Plumatella repens is generally rare to uncommon on hard substrates such as rip rap, finished board and logs in this portion of the Savannah River.

\section{Segmented Worms (Annelida)}

nnelids found free living in the Savannah River are
represented by tubificids, earthworms and leeches.
The 2000 study was marked by the lack of both tubificids and earthworms. Both groups are found in sediments and woody debris. Sediments were less accessible during the period of the comprehensive survey in 2000 due to relatively higher water levels. In 1999, two species of tubificids were recorded. One was common in root mats and associated with logs at Station 1, while the second taxon was uncommon at Stations $2 \mathrm{~B}$ and 5 and rare at Station 6. This latter species was found in muddy stick litter at Station 2B, root mats (rarely) and logs at Station 5 and from an undetermined habitat at Station 6. During the 1998 survey the tubificid Branchiura sowerbyi was moderately common in muddy detritus and fine muds at Station 5, while an undetermined species was common in detritus and fine muds at Station 5, common in muddy leaf litter and under the bark of logs at Station 2B and rare in root mats and muddy detritus at Stations 1 and 6, respectively. An undetermined species of tubificid was uncommon at Stations 2B, 5 and 6 and rare at Station 1 in 1997. Habitat at the various stations included root mats (Stations $2 \mathrm{~B}$ and 6), leaf and stick litter (Station 2B), woody detritus (Station 1), a $\log$ (Station 5) and detritus (Station 5). They were poorly represented in the 1993 study. At this time they were rare under the bark of a floating tree trunk (Station 1) and in streamside root mats (Station 6). Tubificids were collected from 
1989 to 1976 at the following stations: 1989 at Station 1, 1984 at Stations 5 and 6, 1980 at Station 1 and in August 1976 at Stations 1 and 5.

The earthworm, Lumbriculus variegatus, in 1999, was moderately common in root mats and associated with logs at Stations 1 and 6 and uncommon at Stations 2B (root mats and muddy stick litter) and 5 (root mats and logs). In 1998, earthworms were moderately common under the bark of logs at Station 2B and rare in a sandy substrate, muddy detritus and muddy leaf litter at Stations 1, 5 and 6, respectively. This same species of earthworm was, in 1997, rare in a log and gallery within a branch at Stations 1 and 6, respectively, and in leaf and stick litter at Station 2B. This species was moderately common under the bark of a log at Station 5. In 1993, this taxon was poorly represented in terms of numbers and distribution. A single individual was found among a pile of branches at Station 5. No earthworms were found in 1989, and specimens were taken at Stations 1, 5 and 6 in 1984. Earthworms are widespread and generally uncommon in the study areas of the Savannah River.

Despite the elevated water levels, the leech fauna was as diverse, on average, as has been found in the study segments of the river between 1976 and 1999. In 2000, the leech fauna consisted of Desserobdella phalera, Helobdella triserialis, Placobdella papillifera and an undetermined species of erpobdellid leech. A single Desserobdella phalera was collected from the shell of a living Savannah lilliput (Toxolasma pullus) taken at Station 6 during the mussel portion of the study. Desserobdella phalera has been found free living or parasitizing the bluegill, Lepomis macrochirus (Klemm 1985). The leeches Helobdella triserialis and $P$. papillifera were rare at Stations 5 (paspalum grass) and 2B (seined by the fisheries team). The undetermined species of erpobdellid leech was found in flooded grasses at Station 5.

The 1999 leech fauna consisted of $H$. triserialis, $P$. montifera and $P$. parasitica. At Station 1 the leeches $H$. triserialis and $P$. montifera were rare. They were found in root mats and on a log, although the specific habitat for each species was not defined. Helobdella triserialis was also collected from root mats at Station 6. The leech P. parasitica, a parasite of turtles (Klemm, 1985), was rare in a habitat consisting of root mats and leaf litter. 
The leech fauna in 1998 consisted of D. phalera, H. triserialis, $P$. papillifera and $P$. parasitica. Desserobdella phalera was rare in leaf litter at Station 2B, while H. triserialis was rare in muddy leaf litter at Station 6. Placobdella papillifera and $P$. parasitica each occurred at two stations. Placobdella papillifera was uncommon on a branch and in leaf litter at Station 5 and rare in muddy leaf litter at Station 6. Placobdella parasitica was uncommon in leaf litter and on a $\log$ at Station $2 \mathrm{~B}$ and one individual each was found in detritus and root mats at Station 5. In 1997, the leech fauna consisted of $D$. phalera, $H$. triserialis, $P$. montifera, $P$. nuchalis, $P$. papillifera and $P$. parasitica. Desserobdella phalera was rare on roots at Station 1, rare on the variable spike (Elliptio icterina) at Station 2B and uncommon in water pennywort and roots at Station 6. Helobdella triserialis was uncommon in an undetermined habitat at Station 1 and on the variable spike $(E$. icterina) and Carolina slabshell (E. congaraea) at Station 5 and rare on water pennywort at Station 6. Placobdella montifera was found on the variable spike and rayed pink fatmucket (Lampsilis splendida) at Station 2B and P. nuchalis in roots at Station 5. Placobdella papillifera was the most common species of leech in 1997. It was rare $(\log )$ at Station 1 , moderately common at Station 2B (one on the eastern elliptio, $E$. complanata, and three in leaf and stick litter), rare at Station 5 (on the eastern creekshell, Villosa delumbis) and rare on the Carolina slabshell at Station 6. Placobdella parasitica was present on undefined habitat at Station 2B and on a log at Station 5.

Leeches collected in September 1993 included Mooreobdella melanostoma (Station 6), D. phalera (Stations 2B and 6), $P$. multilineata (Station 6) and $P$. parasitica (Stations 5 and 6). Leeches were rare to uncommon in 1993 . None of the species was represented by more than one or two individuals. The erpobdellid leech M. melanostoma was taken from root mats and the root tuft of a water hyacinth at Station 6. The habitats for the remaining species included logs $(D$. phalera, $P$. papillifera and $P$. parasitica), root mats (D. phalera, $P$. multilineata and $P$. parasitica), mud ( $P$. papillifera) and the surface of the Atlantic spike (E. producta).

Two species of leeches were found in September 1989 ( $H$. triserialis and $P$. parasitica). Most specimens were collected from aquatic vascular plants, although one individual of $P$. parasitica was taken while swimming in open water. In 
1984, two species of leeches were collected as follows: $B$. phalera at Stations 5 and 6, and $P$. parasitica at Station 6. The 1980 survey produced two species of leeches: $B$. phalera at Stations 1 and 5 and $P$. parasitica at Station 5. In the August 1976 study six taxa of leeches were observed. Desserobdella phalera was found at the same stations as in the 1980 survey, $P$. papillifera at Station 5, P. montifera at Stations 5 and 6 and Myzobdella lugubris, an unidentified leech (sight record) and an unidentified erpobdellid leech at Station 1.

The four species of leeches in 2000 at Stations 1, 2B, 5 and 6 is equal to the four species collected at these same stations in 1998 and September 1993. The 2000 species richness is less than that of 1997 and August 1976 (six species each) but greater than the September 1980 to 1989 and 1999 surveys at Stations 1, 5 and 6 (two species in 1980, two each in 1984 and 1989 and three in 1999). Inasmuch as the comparisons of four stations in 2000 through 1993 are with three sites from the earlier surveys, a second comparison utilizing four stations from earlier studies incorporates the results from Station 3 in the 1972 through 1989 surveys (Table C-2). However, among these surveys, only in 1984 and 1989 is an additional species of leech added to the diversity of this group. The 6 species of leeches in 1997 and 1976 is decidedly lower than the 10 species (with or without Station 3) collected in 1972. The differences among the surveys are due to water levels, extent and distribution of vegetation and collecting effort in other habitats during years when vegetation was less abundant. In general, the extent, density and distribution of submerged aquatic vascular vegetation has varied since 1972 . These vegetated areas not only included stands in sheltered areas, but also patches of aquatic vasculars in the current. In 1972, when eutrophic conditions existed, dense stand of submerged aquatic vegetation existed in the Savannah River.

\section{Molluscs (Mollusca)}

\section{Snails}

Tn 2000, five species of snails were noted: Campeloma decisum (pointed campeloma), Pseudosuccinea columella (mimic lymnaea), Physella heterostropha (pewter physa), Ferrissia rivularis (creeping ancylid) and Novisuc- 
cinea ovalis (oval ambersnail). The pointed campeloma was common in sand at Station 1 and moderately common at Stations 2B, 5 and 6 in sands and muds. The mimic lymnaea was common at Station 1, where it was primarily found on woody debris and pilings with an uncommon presence on alligator weed. This species was moderately common at Stations 2B, 5 and 6 in woody debris with an uncommon occurrence on a plastic bottle at Station 6 . The pewter physa occurred in a range of abundances and habitats. It was moderately common at Stations 1 and 2B, common at Station 5 and abundant at Station 6. It occurred on woody debris, emergent and floating vascular plants (water hyacinth, shade mudflower and water pennywort), mud surfaces, undetermined flooded grasses and paspalum grass. The creeping ancylid was moderately common on plastic floats at Station 1 and uncommon on alligator weed stems at Station 2B. In the past, the amphibious oval ambersnail has not been well represented in the Savannah River surveys. In past studies it has been rarely collected and only at Station 6 in 1997 and 1993. In 2000, a year of reduced flows and flooding events, this land snail was found at all stations where it was moderately common at Station 1 and uncommon at the remaining study sections of the river. It was collected from woody debris at Stations 1, 2B and 5, plastic bottles at Stations 5 and 6 and alligator weed at Station 6.

Six species of snails were collected in 1999 . They included the pointed campeloma, Amnicola limosus (mud amnicola), mimic lymnaea, pewter physa, creeping ancylid and Laevapex fuscus (dusky ancylid). The pointed campeloma was common at Station 1 (root mats and on logs), moderately common at Station 6 (muddy substrates, root mats and logs) and uncommon at Stations 2B (root mats and muddy stick liter) and 5 (root mats and logs). The mud amnicola was observed in root mats and logs where it was moderately common at Station 1 and uncommon at Station 6. The mimic lymnaea was moderately common in root mats and on logs at Stations 5 and 6 and uncommon at Station 1 on logs. The pewter physa was abundant at Stations 1 and 6 on logs and in root mats and moderately common at Stations $2 \mathrm{~B}$ and 5 on logs and in root mats and muddy stick litter. The creeping ancylid was slightly less widespread than its ancylid relative the dusky ancylid. In the Savannah River, the creeping ancylid prefers firm to hard substrates in faster flowing waters. Here it was found to be uncommon on woody substrates 
at Stations 1 and 2B and rare at Station 5. The dusky ancylid prefers static or slow moving waters and was uncommon (Stations 1 and 2B) to rare (Stations 5 and 6) on logs and in leaf litter and root mats.

The seven species of snails represented in 1998 included the pointed campeloma, mud amnicola, mimic lymnaea, bugle sprite (Micromentetus dilatatus), marsh rams-horn (Planorbella trivolvis) ), pewter physa and dusky ancylid. The pointed campeloma was abundant at all stations in a range of sand to muddy-sand and mud substrates with occasional individuals found on logs and in root mats at Station 1. The mud amnicola was moderately common at Stations 1 (root mats) and 6 (log with a single animal taken from muddy leaf litter) and uncommon at Station 2B (leaf litter). The mimic lymnaea was moderately common on pilings at Stations $2 \mathrm{~B}$ and 6 (one snail was collected from a patch of pennywort at Station 6) and rare at Station 1 on a log. The bugle sprite was rare in root mats and on a log at Stations 5 and 6, respectively. The marsh rams-horn was uncommon at Stations 1 and 5 on logs and one marsh rams-horn was found crawling on wet sand onshore at Station 5. The pewter physa was common at Station 1 in root mats and on logs and moderately common at Stations 2B, 5 and 6. At Stations 2B and 5 the pewter physa occurred in the same root and log habitat as the population at Station 1, while at Station 6 it was found in both root mats and patches of pennywort. The dusky ancylid was the only ancylid collected in 1998. It was moderately common on logs at Station 1.

The snail fauna in 1997 consisted of 10 species: pointed campeloma, mud amnicola, mimic lymnaea, Helisoma anceps (two-ridge rams-horn), bugle sprite, marsh rams-horn, pewter physa, creeping ancylid, dusky ancylid and oval ambersnail. The pointed campeloma was abundant at all stations in sand and mud substrates with a single snail removed from a rotten $\log$ at Station 1 . The mud amnicola was moderately common at Station 5 and abundant at the remaining stations. They were picked from branches (Stations 1 and 2B) and a log (Station 5), separated from leaf and stick litter (Station 2B) and found in samples of root mats (Stations 1,2B and 6) and a patch of alligator weed (Station 6). The mimic lymnaea was moderately common at Station 6 (logs), uncommon at Stations 1 (piling) and 5 (piling and $\log$ ) and rare at Station 2B (piling). An uncommon snail in the 1997 survey was the two- 
ridge rams-horn. Two snails were obtained from logs at Station 1 . The bugle sprite was collected from logs and roots. It was moderately common at Stations 1 and 5 and rare at Station 6. At Station 1, this species was more common in roots than on logs. Similar to the two-ridge rams-horn, the marsh rams-horn was uncommon at Stations 1 and 6 and rare at Station 2B. At each of these stations the marsh rams-horn was found in a different habitat as follows: Station 1 on logs, Station 2B in leaf and stick litter and Station 6 in willow roots. The pewter physa was found in a variety of habitats that can be basically lumped into hard surfaces such as logs, branches and sticks (Stations 1, 2B and 5) and fine roots (all stations). The pewter physa was abundant at Stations 1 and 6, moderately common at Station 5 and common at Station 2B. Of the two ancylid snails, the dusky ancylid was the more abundant and widespread. It was abundant at Station 2B, moderately common at Station 1 and rare at Station 5. At Station 1, single snails occurred on a log and among roots, while most individuals were collected from willow and sycamore leaf litter. The population at Station 2B was found on sticks, especially fresh, less seasoned, ones. The one dusky ancylid taken at Station 5 was found on a log. The less common creeping ancylid was rare on a $\log$ at Station 5 and on roots at Station 6. A single oval ambersnail was recorded from willow roots at Station 6.

Eight species of gastropods were obtained during the September 1993 survey at Stations 1, 5 and 6. The following snails were collected from the surfaces of logs: mud amnicola (Stations 1, 2B and 6), pewter physa (all stations), marsh ramshorn (Station 1), two-ridge rams-horn (Station 1), and dusky ancylid (Station 1). Two of the species mentioned above (dusky ancylid and pewter physa) occurred in other habitats. One dusky ancylid was found on a leaf and one was removed from an artificial insect substrate. Besides logs, the pewter physa grazed a wide range of habitats that included rocks, root mats and leaf litter. Of the two remaining species, one of them, the mimic lymnaea had a spotty distribution on pilings and logs. Where found, they were moderately to very common on from one to three pilings but lacking from other such structures. Besides the pilings, the mimic lymnaea was present on a branch. The pointed campeloma, was collected in mud, muddy sand and sand substrates, primarily in areas with 
at least some mud at all stations. Single individuals were also collected from a log and among a root mass.

Seven species of gastropods were obtained during the September 1989 survey. The following snails were collected from aquatic vascular plants in sheltered areas as follows: mud amnicola, pewter physa, marsh rams-horn and mimic lymnaea. Two of the species mentioned above occurred more (mimic lymnaea) or less (pewter physa) in other habitats. Most mimic lymnaea were found on the leeward side of pilings. Pewter physa were also picked off logs trapped by pilings and swept from riparian grasses hanging into the water, while the pointed campeloma was collected in muddy, muddy sand and detrital substrates. The oval ambersnail was taken from riparian vegetation hanging into the water at Station 6. The dusky ancylid was removed from rocky substrates with one individual found on a decaying leaf.

In 1984, six species of snails were collected at Stations 1, 5 and 6. The dusky ancylid (Laevapex fuscus as Lepyrium showalteri) was found at Stations 1 and 5, the pointed campeloma (C. decisum as Campeloma sp.) at Stations 1, 5 and 6, the mud amnicola ( $A$. limosus as $A$. limosa) at Stations 1,5 and 6, the mimic lymnaea at Stations 1, 5 and 6, the bugle sprite ( $P$. dilatatus as Promenetes sp.) at Station 1 and the pewter physa (Physella heterostropha as Physa s.p.) at Stations 1, 5 and 6. The 1980 survey found the following seven species: pointed campeloma (C. decisum as Campeloma sp.) at Stations 5 and 6 in September, mud amnicola (A. limosus as $A$. limosa) at Stations 1 and 6, mimic lymnaea at Stations 1, 5 and 6, two-ridge rams-horn at Station 1, bugle sprite [Promenetus dilatatus as Menetus (Micromenetus) dilatatus] at Station 1, pewter physa (Physella heterostropha as Physa sp.) at Stations 1, 5 and 6 and three-ridge valvata (Valvata tricarinata) at Station 6.

The August 1976 survey collected eight taxa of snails which included the pointed campeloma (C. decisum as Campeloma sp.) at all stations, mud amnicola (A. limosus as $A$. limosa) at Stations 1 and 5, mimic lymnaea (Pseudosuccinea columella as Lymnaea columella) at Stations 1 and 5, marsh fossaria (Fossaria humilis as Lymnaea humilis) at Station 1, bugle sprite (Promenetus dilatatus as Menetes dilatatus) at Stations 1 and 6, pewter physa (Physella heterostropha as Physa sp.) at Stations 1, 5 and 6, an unidentified ancylid snail at Station 
6 and an unidentified snail probably belonging to the family Valvatidae at Station 5.

The snail assemblage of the 2000 survey (five species) at Stations 1, 2B, 5 and 6 was only slightly less than the six species in 1999 and September 1984, seven species in 1998, September 1989 and September 1980 and eight species in September 1993 and August 1976. Only in the 1997 (10 species) and September 1972 (11 species) studies were significantly more species collected than in the other study years (Table C-2). The above comparisons of the 1999 through 1993 surveys at Stations 1, 2B, 5 and 6 were with earlier surveys having three sites (Stations 1, 5 and 6). A second comparison utilizing four stations from the earlier studies incorporates the results from Station 3 in the 1972 through 1989 surveys. However, among these surveys, only in 1984 was an additional species of snail added to the diversity of this group (total of seven species, q.v., Table C-2). Snails occupy a wide range of habitats from hard substrates to vegetation, and many of the species are more abundant in submerged aquatic vegetation in this portion of the Savannah River (e.g., mud amnicola, two-ridge rams-horn, bugle sprite, marsh rams-horn, pewter physa and creeping ancylid). Species that are more common on vegetation are still present in the river, although in smaller numbers. During the late summer to fall, it appears that a large number of the taxa present in the Savannah River can be collected irrespective of the amount of vegetation present [see section above on Segmented Worms (Annelida) ], although abundance for these species will be relative to the presence and extent of submerged aquatic vegetation.

\section{Bivalves}

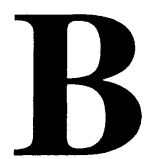

ivalve molluscs in this portion of the Savannah River consist of the Asian clam, fingernailclams, peaclams and mussels. Because of the importance of the mussel fauna, the following discussion of the bivalve fauna initially compares the distributions and habitats of the clams among surveys, with a separate discussion of the mussels. The bivalve fauna in 2000 consisted of 12 taxa divided between 4 species of clams and 8 mussel taxa. 


\section{Clams}

he clam fauna in 2000 consisted of the Asian clam, a
fingernailclam and peaclams. The introduced Asian
clam, Corbicula fluminea, was abundant at all stations in the quantitative mussel survey. It occurred in a range of substrates that graded from silts and muds through sands and gravel with scattered rocks. In areas consisting of finer particles, detritus was common and algae covered the substrate at some areas of Station 5. Most of the fingernailclams and peaclams were also primarily collected during the mussel survey. Musculium securis, swamp fingernailclam, Pisidium compressum, ridgebeak peaclam, and $P$. dubium, greater eastern peaclam. The swamp fingernailclam was moderately common at Station 5, where it was rare in willow roots and moderately common in muds sifted as part of the quantitative mussel survey. Except for one greater eastern peaclam taken from muds at Station 6 in the comprehensive survey, all other greater eastern and ridgebeak peaclams were obtained while sifting mud sediments during the mussel study. The ridgebeak peaclams were moderately common at Stations 2B and 5, while the greater eastern peaclam was rare at Station 1 and moderately common at Station 2B.

Of the clam species collected from the Savannah River in 1999, the Asian clam was collected at Stations 1, 5 and 6. At all three stations it was found in fast flowing sand and gravel substrates. It was common at Station 1, moderately common at Station 6 and uncommon at Station 5. The ubiquitous peaclam, $P$. casertanum, was the only species of fingernailclam collected in 1999. This species was uncommon in root mats and an unidentified habitat at Station 6.

The Asian clam, in 1998, was present at all stations. It was abundant in substrates ranging from sand (Stations 2B and 5) to muddy-sand (Station 2B). This species was common in sand substrates at Station 6 and moderately common in muddy leaf litter at Station 1. Three species of fingernailclams ( $M$. transversum, long fingernailclam, swamp fingernailclam, and Eupera cubensis, mottled fingernailclam) and two taxa of peaclams (ridgebeak peaclam, and greater eastern peaclam) were also noted. The long fingernailclam was uncommon at Station 5 in fine mud, while the numbers of the swamp fingernailclam ranged from abundant (Station 6 in 
mud), to common (Station 1 in muddy leaf litter), to moderately common (Station 5 in fine muds) and rare (Station 2B in muddy leaf litter). In 1998, mottled fingernailclams were only noted from Station 6 in root mats where they were moderately common. The ridgebeak peaclam was abundant at Station 2B in mud and leaf litter, while the greater eastern peaclam was abundant in root mats and fine muds at Station 5 and rare in mud at Station 6.

In 1997, the clam species included the Asian clam at all stations in sand and mud substrates of slow to moderate currents. Three species of fingernailclams (long fingernailclam, swamp fingernailclam and mottled fingernailclam) and two taxa of peaclams (ridgebeak peaclam and greater eastern peaclam) were also noted. All the sphaeriids were sampled from root mats, with the ridgebeak peaclam and greater eastern peaclam found as well in leaf and stick litter at Station 2B. The long fingernailclam was rare at Station 5, swamp fingernailclam common at Stations 5 and 6 and moderately common at Station 1 and mottled fingernailclam abundant at Station 5, common at Station 2B, moderately common at Station 6 and rare at Station 1. The ridgebeak peaclam was abundant at Station 2B, uncommon at Station 1 and rare at Station 6. The greater eastern peaclam was moderately common at Station $2 \mathrm{~B}$ and uncommon at Station 1.

The clams collected in September 1993 included the Asian clam at all stations. It occurred in sand and mud substrates as well as the roots of riparian trees. This species occurred in high densities and was the only bivalve in the packed sand areas with at least a moderate current. In the September comprehensive study and October mussel survey, an examination of oxbow areas found the substrate away from the mouth of the oxbows to consist of an especially fine, soupy mud. Bivalves in this substrate were rare with only occasional paper pondshells, Utterbackia imbecillis, and the Asian clam. The three genera of sphaeriids or fingernailclams and peaclams collected from the Savannah River in 1993 included the swamp fingernailclam, mottled fingernailclam and two taxa of peaclams (ubiquitous peaclam and greater eastern peaclam). All the sphaeriids were collected from root mats. The swamp fingernailclam was collected at Stations 1, 5 and 6 , the mottled fingernailclam at Stations 5 and 6, ubiquitous peaclam at Station 6 and greater eastern peaclam at Station 1 . 
The sphaeriids and corbiculid in 1989 were represented by four species at Stations 1, 5 and 6. The four species included two species of Pisidium (greater European peaclam, amnicum, at Station 6 and ridgebeak peaclam at Station 1) as well as a single member of the genus Musculium (swamp fingernailclam, securis as transversum) at Station 1 and the Asian clam at Stations 1, 5 and 6. The clam fauna in 1984 included the ubiquitous peaclam only at Station 1 , greater eastern peaclam at Stations 5 and 6 and the Asian clam at Stations 1, 5 and 6. Clams collected in 1980 included the ubiquitous peaclam and ridgebeak peaclam at Stations 1 and 6, greater eastern peaclam at Station 6, long fingernailclam at Station 1 and Asian clam at Stations 1, 5 and 6. In August 1976, the mottled fingernailclam (Station 5), long fingernailclam, Musculium transversum (as Sphaerium transversum, at Station 1), an unidentified species of peaclam (Pisidium at Station 1) and Asian clam $C$. fluminea (as $C$. manilensis at Stations 1, 5 and 6) were taken. From the September 1972 survey four species of sphaeriids were found at Stations 1, 5 and 6 as follows: ridgebeak peaclam, ubiquitous peaclam, long fingernailclam, Musculium transversum (as Sphaerium transversum) and mottled fingernailclam.

\section{Mussels}

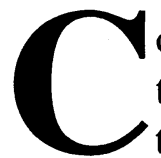

omparisons of the 2000 mussel survey results with those from previous years will include not only those stations (1, 2B, 5 and 6) surveyed in 2000 but also Station 3, which was part of the comprehensive (generally two times a year) river studies until 1993 (q.v., Tables C3 and $\mathrm{C}-4$ ).

In 2000, 118 mussels were recorded from a quantitative survey using $1.0-\mathrm{m}^{2}$ quadrats. Past surveys have included qualitative hand collections in shallow waters and diving in deeper areas. The addition of a quantitative aspect was initiated primarily to address the statement that there was an "almost uniform distribution" of mussels "from juveniles through old adults (over eight years of age) " in the 1960 survey (ANSP 1961:48). With the exception of the Savannah lilliput in 1998 and Savannah lilliput and paper pondshell in 1997 and 1993 there has been a scarcity of juveniles in qualitative collections. In addition, the quantitative collections would provide information on the population size of the introduced Asian 
Table C-3. Species of mussels collected during comprehensive surveys of the Savannah River, near the Savannah River Site, Georgia and South Carolina, from 1951 through 2000. ('51 = 1951 \& 1952, ' $55=1955$ \& 1956) $(X=$ present, - = absent) (*identified as E. complanata in earlier surveys).

\begin{tabular}{|c|c|c|c|c|c|c|c|c|c|c|c|c|c|c|c|}
\hline & '51 & '55 & $\mathbf{6 0}$ & '65 & '68 & & 76 & '80 & & '89 & & 97 & '98 & 9 & '00 \\
\hline Alasmidonta tri & - & - & $\mathrm{X}$ & - & - & $\mathrm{X}$ & $\mathrm{X}$ & - & - & - & - & $\mathrm{X}$ & $X$ & $\mathrm{X}$ & - \\
\hline A. couperiana & $\mathrm{X}$ & - & $\mathrm{X}$ & $\mathrm{X}$ & 一 & $\mathrm{X}$ & $\mathrm{X}$ & - & - & $\mathrm{X}$ & $X$ & $X$ & $\mathrm{X}$ & - & - \\
\hline Elliptio complanata & $\mathrm{X}$ & $X$ & $X$ & $X$ & $\mathrm{X}$ & $X$ & $\mathrm{X}$ & $X$ & $X$ & - & $X$ & $\mathrm{X}$ & $\mathrm{X}$ & $\mathrm{X}$ & $X$ \\
\hline E. congaraea & - & $X$ & $\mathrm{X}$ & $\mathrm{X}$ & $\mathrm{X}$ & $\mathrm{X}$ & $\mathrm{X}$ & $\mathrm{X}$ & $X$ & - & $\mathrm{X}$ & $X$ & $\mathrm{X}$ & $\mathrm{X}$ & $\mathrm{X}$ \\
\hline E. fra & 一 & 一 & 一 & - & - & $X$ & - & 一 & 一 & - & - & - & - & $\overline{-}$ & - \\
\hline E. ic & - & 一 & 一 & $\mathrm{X}$ & $X$ & $\mathrm{X}$ & $\mathrm{X}$ & $\mathrm{X}$ & $X$ & $\mathrm{X}$ & $\mathrm{X}$ & $X$ & $X$ & $X$ & $\mathrm{X}$ \\
\hline E. $p r$ & $\mathrm{X}$ & $X$ & $\mathrm{X}$ & $\mathrm{X}$ & $X$ & $X$ & $X$ & $X$ & $X$ & - & $X$ & $X$ & $X$ & $X$ & $X$ \\
\hline E. ro & - & - & - & - & - & - & 一 & - & - & - & $X$ & $X$ & $X$ & $X$ & \\
\hline Lamp & $X$ & $X$ & $X$ & $X$ & $X$ & $X$ & $X$ & $X$ & $X$ & - & $X$ & $X$ & $\mathrm{X}$ & $\mathrm{X}$ & - \\
\hline L. sple & $X$ & - & $\mathrm{X}$ & $X$ & $X$ & $X$ & $X$ & $\mathrm{X}$ & $X$ & - & $X$ & $X$ & $\mathrm{X}$ & $\mathrm{X}$ & $\mathrm{X}$ \\
\hline Pygal & $X$ & $X$ & $X$ & $X$ & - & $\mathrm{X}$ & $X$ & $X$ & $X$ & - & $X$ & $X$ & $X$ & $\mathrm{X}$ & - \\
\hline Stropl & - & - & - & $X$ & - & $X$ & $X$ & - & - & - & - & - & - & - & - \\
\hline Toxolast & - & - & - & $X$ & $X$ & $X$ & $X$ & - & - & $X$ & $X$ & $X$ & $X$ & $X$ & $\mathrm{X}$ \\
\hline Unior & $\mathrm{X}$ & - & - & $\mathrm{X}$ & $\mathrm{X}$ & $\mathrm{X}$ & $X$ & - & - & $X$ & X & $X$ & $\mathrm{X}$ & $X$ & \\
\hline Utter & - & $X$ & $X$ & $X$ & $X$ & $X$ & $X$ & $X$ & $X$ & - & $X$ & $X$ & X & X & X \\
\hline Villos & $X$ & $X$ & $X$ & $X$ & $X$ & $\mathrm{X}$ & $\mathrm{X}$ & $\mathrm{X}$ & $\mathrm{X}$ & $X$ & $X$ & $X$ & $X$ & $X$ & $X$ \\
\hline
\end{tabular}

Table C-4. Species of mussels and stations collected during comprehensive surveys of the Savannah River, near the Savannah River Site, Georgia and South Carolina, from 1951 through 2000. ( $X=$ present, - = absent).

\begin{tabular}{llllll}
\hline \multicolumn{1}{c}{ Station } & $\mathbf{1}$ & 2B & $\mathbf{3}$ & $\mathbf{5}$ & $\mathbf{6}$ \\
\hline Alasmidonta triangulata & - & $\mathrm{X}$ & - & $\mathrm{X}$ & $\mathrm{X}$ \\
Anodonta couperiana & $\mathrm{X}$ & $\mathrm{X}$ & $\mathrm{X}$ & $\mathrm{X}$ & $\mathrm{X}$ \\
Elliptio complanata & $\mathrm{X}$ & $\mathrm{X}$ & $\mathrm{X}$ & $\mathrm{X}$ & $\mathrm{X}$ \\
E. congaraea & $\mathrm{X}$ & $\mathrm{X}$ & $\mathrm{X}$ & $\mathrm{X}$ & $\mathrm{X}$ \\
E. fraterna & - & - & - & - & $\mathrm{X}$ \\
E. icterina & $\mathrm{X}$ & $\mathrm{X}$ & $\mathrm{X}$ & $\mathrm{X}$ & $\mathrm{X}$ \\
E. producta & $\mathrm{X}$ & $\mathrm{X}$ & $\mathrm{X}$ & $\mathrm{X}$ & $\mathrm{X}$ \\
E. roanokensis & $\mathrm{X}$ & $\mathrm{X}$ & $\mathrm{X}$ & $\mathrm{X}$ & $\mathrm{X}$ \\
Lampsilis cariosa & $\mathrm{X}$ & $\mathrm{X}$ & $\mathrm{X}$ & $\mathrm{X}$ & $\mathrm{X}$ \\
L. splendida & $\mathrm{X}$ & $\mathrm{X}$ & $\mathrm{X}$ & $\mathrm{X}$ & $\mathrm{X}$ \\
Pyganodon cataracta & - & $\mathrm{X}$ & $\mathrm{X}$ & $\mathrm{X}$ & $\mathrm{X}$ \\
Strophitus undulatus & - & - & - & $\mathrm{X}$ & - \\
Toxolasma pullus & $\mathrm{X}$ & $\mathrm{X}$ & - & $\mathrm{X}$ & $\mathrm{X}$ \\
Uniomerus carolinianus & $\mathrm{X}$ & $\mathrm{X}$ & $\mathrm{X}$ & $\mathrm{X}$ & $\mathrm{X}$ \\
Utterbackia imbecillis & $\mathrm{X}$ & $\mathrm{X}$ & $\mathrm{X}$ & $\mathrm{X}$ & $\mathrm{X}$ \\
Villosa delumbis & $\mathrm{X}$ & $\mathrm{X}$ & $\mathrm{X}$ & $\mathrm{X}$ & $\mathrm{X}$ \\
\hline
\end{tabular}


clam, a competitor to the mussel fauna for habitat and food resources in the Savannah River. Although employing quantitative measures by passing sediments through a sieve does a better job of collecting small individuals, the intensity of the labor involved results in a much smaller survey area. The smaller areal coverage tends to miss some taxa, especially rarer species.

The fauna at the four stations consisted of 8 species as follows:

Elliptio icterina (variable spike), E. congaraea (Carolina slabshell), E. producta (Atlantic spike), E. complanata (eastern elliptio), Lampsilis splendida (rayed pink fatmucket), Villosa delumbis (eastern creekshell), Toxolasma pullus (Savannah lilliput) and Utterbackia imbecillis (paper pondshell). Species collected in 1999 and not 2000 included E. roanokensis (Roanoke slabshell), Uniomerus carolinianus (as $U$. obesus) (Florida pondhorn), L. cariosa (yellow lamp mussel) and Alasmidonta triangulata (southern elktoe). The remaining taxon collected in recent surveys, Anodonta couperiana (barrel floater), was last taken in 1998 (diving) and 1997 (hand collecting). The Uniomerus in the Savannah River is assigned to the species carolineanus following Turgeon et al (1998). Although Clarke (1981) synonymyzed triangulata with $A$. undulata, it is the opinion of Dr. Arthur Bogan (North Carolina State Museum of Natural Sciences) that, due to the continuing confusion concerning the taxonomic status of triangulata, it is tentatively recognized in spite of the conchological work of Clarke. Therefore, the name triangulata is applied herein to the Alasmidonta from the Savannah River.

The 2000 species richness is lower than the highest numbers in hand collections in 1972 (15), 1976 (14), 1993 (13), 1997 (14) 1998 (13) and 1999 (13), similar to the species totals in 1980 and 1984 (9 species) and greater than 1989 (5 species). Only the Savannah lilliput was found at all four stations. (Savannah River populations of $T$. pullus were originally described as a separate species, Carunculina patrickae Bates, 1966 (see Johnson 1967, 1970) ). Three species were taken at three stations and included the Atlantic spike and eastern creekshell at Stations $1,2 \mathrm{~B}$ and 5 and the rayed pink fatmucket at Stations 1, 2B and 6UR. Only the eastern elliptio was collected at two stations (2B and 6UR), while the Caro- 
lina slabshell (Station 5) variable spike (Station 2B) and paper pondshell (Station 5) were collected at a single station.

The Savannah lilliput constituted 55.1\% (65 animals) of the mussels collected in 2000. Together with the eastern creekshell $(19,16.1 \%)$ and variable spike $(12,10.2 \%)$ they represented $81.4 \%$ (96 animals) of the mussel fauna in 2000 . The numbers of mussels and percent abundance of the remaining five species from highest to lowest are as follows: Atlantic spike $(8,6.8 \%)$, eastern elliptio $(6,5.1 \%)$, rayed pink fatmucket $(5,4.2 \%)$, paper pondshell $(2,1.7 \%)$ and Carolina slabshell $(1,0.8 \%)$.

The quadrat sampling was successful in collecting young mussels of the eastern elliptio, rayed pink fatmucket, Savannah lilliput, paper pondshell and eastern creekshell. Asian clams and sphaeriids (fingernailclams and peaclams) were also taken. The survey at 4 stations ( 40 quadrats) produced 4,073 bivalves consisting of 25 sphaeriids (0.61\%), 118 mussels (2.9\%) and 3,930 Asian clams (96.5\%). Of the 40 quadrats sampled, 36 were placed along transects in a variety of habitats (e.g., river flow, substrate, depth, organic content) and 4 were chosen in likely mussel habitats to slightly increase the opportunities to add to a small 2000 mussel database. The mean number of mussels in quadrats 1 to 9 was 2.1 , while the mean number of mussels in quadrat 10 was 6.8 . From these 40 quadrats $98.25 \%$ of the bivalves taken were Asian clams, $2.9 \%$ were mussels of 8 species and $0.61 \%$ were sphaeriids of 3 species. It is apparent that the introduced Asian clam numerically dominates the benthic habitat of the Savannah River and because of its great numbers competes with the mussels for space and food resources.

Yearly ranking of abundance between 1993 and 1999 in hand collections deviate slightly, but the five most abundant (Carolina slabshell, Savannah lilliput, variable spike, Atlantic spike and eastern creekshell) taxa, five least abundant (Florida pondhorn, eastern floater, yellow lamp mussel, barrel floater and southern elktoe) and four moderately abundant (paper pondshell, eastern elliptio, rayed pink fatmucket and Roanoke slabshell) species generally fall within the same three main categories each year. Five of the most abundant and three of the moderately abundant taxa were represented in 2000. Of note was the most abundant species in the long-term hand collection data set, the Carolina slabshell, ranked eighth in 2000. 
One of the moderately abundant species and all five of the least abundant taxa were not collected in 2000 . The use of quadrats in 2000 produced the expected results of doing a better job of collecting small mussels but performing less well at collecting the range of species present, especially the rarer taxa.

The drought and low flows in the Savannah River in 2000 resulted in low water levels that left many mussel habitats dry or with reduced water levels at Station 5. Mussel habitat downriver from the downrivermost (ultimate) set of \#55 pilings at Station 5 was left dry and covered with a mix of terrestrial and emergent aquatic vegetation. An abundant population of mussels was collected here in 1997 and 1999. As with many such habitats downriver from the ultimate set of pilings, a ridge of sand separates a diagonally oriented shoreside trough of fine muds, leaves and sticks from the main channel. Most mussels collected here in 1997 and 1999 occurred in the trough. Unfortunately the physiognomy of this habitat traps mussels behind the ridge of sand when water levels are lowered, and its impact on the mussel population downriver from the ultimate set of \#55 pilings was probably catastrophic. A series of muddy pools is present on the South Carolina side of the river opposite the mouth of Devil's Elbow (Georgia). This area, for the most part, is separated from the river by a vegetated sand ridge and is connected with the river at its up- and downriver ends during periods of high water. This region was surveyed in 1993 and 1999 and supported a variety of mussels dominated by the Savannah lilliput. On 10 September 2000, the uprivermost pool at its maximum depth (following an 8 September 2000 precipitation) was 18 in and was choked with emergent vegetation. The substrate was slightly compacted and one large adult male Savannah lilliput and several Asian clams were found. There was insufficient time to sample the entire site, but it seems apparent that the mussel population here is severely reduced. A third locale outside Station 5 consisted of a perched, left bank (oriented downriver) shallow depression of muds and muddy sand upriver from the entrance to Little Hell Landing. In 1993 and 1997, this site supported a small variety of mussels dominated by the Savannah lilliput. In 2000, it consisted of an area approximately 12 by $18 \mathrm{ft}$ and 4 to 5 in maximum depth. This small region was thoroughly surveyed and a single Savannah lilliput, eight Asian clams, four pointed cam- 
pelomas and two bluegills were collected. The substrate in this pool had apparently dried out and consisted of hard pan. The Savannah lilliput was lying on the surface of the hard bottom. This population of the Savannah lilliput was all but eliminated by low water levels in 2000 .

In 1999, 2,002 mussels were recorded from hand collections at all sites with 1,645 of them collected at Stations 1, 2B, 5 and 6 . The fauna at the four stations consisted of 13 species. Eight of the mussel species were found at all four stations and included the variable spike, Carolina slabshell, Atlantic spike, eastern elliptio, Roanoke slabshell, rayed pink fatmucket, $U$. carolineanus (as U. obesus) (Florida pondhorn) and eastern creekshell. Three species were found at three stations and included $L$. cariosa (yellow lamp mussel) and Pyganodon cataracta (eastern floater) at Stations 1, 2B and 5 and Savannah lilliput at Stations 2B, 5 and 6. Two taxa were found at two stations and consisted of paper pondshell at Stations 1 and 2B and southern elktoe at Stations 2B and 6. The remaining taxon collected in prior recent surveys, the barrel floater, was not represented in the 1999 study.

The Carolina slabshell, eastern creekshell, Atlantic spike, Savannah lilliput and variable spike were the most common species, while the southern elktoe, yellow lamp mussel, paper pondshell, eastern floater and eastern elliptio were the least common species. The numbers of mussels and percent abundance at these four stations in order from highest to lowest are as follows: Carolina slabshell $(668,40.6 \%)$, eastern creekshell $(257,15.6 \%)$, Atlantic spike $(194,11.8 \%)$, Savannah lilliput $(185,11.2 \%)$, variable spike $(157,9.5 \%)$, rayed pink fatmucket $(85,5.2 \%)$, Roanoke slabshell $(30,1.8 \%)$,Florida pondhorn $(24,1.5 \%)$, eastern elliptio $(20,1.2 \%)$, eastern floater $(11,0.7 \%)$, paper pondshell $(6,0.4 \%)$, yellow lamp mussel $(5,0.3 \%)$ and southern elktoe $(3,0.2 \%)$.

The 1,916 mussels recorded from all hand and dive collections in 1998 were distributed among 14 species. The 802 animals tabulated from only hand collections at Stations 1, 2B, 5 and 6LR were divided among 13 species. In 1998, the Savannah lilliput, Carolina slabshell, variable spike, Atlantic spike and eastern creekshell were the most common species, while the yellow lamp mussel, rayed pink fatmucket, Florida pondhorn, eastern elliptio, eastern floater and southern elktoe were uncommon to rare. The numbers of mussels and percent abun- 
dance from hand collections at Stations 1,2B, 5 and 6 in order from highest to lowest are as follows: Savannah lilliput $(332,41.4 \%)$, Carolina slabshell $(129,16.1 \%)$, variable spike $(121,15.8 \%)$, Atlantic spike $(67,8.3 \%)$, eastern creekshell $(57,7.1 \%)$, paper pondshell $(28,3.5 \%)$, Roanoke slabshell $(20,2.5 \%)$, rayed pink fatmucket $(13,1.6 \%)$, eastern floater $(13,1.6 \%)$, eastern elliptio $(12,1.5 \%)$,Florida pondhorn (8, $1.0 \%)$, yellow lamp mussel $(1,0.1 \%)$ and southern elktoe $(1$, $0.1 \%)$.

The 1,648 mussels recorded in 1997 hand collections at Stations 1, 2B, 5, 6LR were distributed among 14 species. The numbers of mussels and percent abundance in order from highest to lowest were as follows: Carolina slabshell (710, $43.1 \%)$, variable spike $(281,17.0 \%)$, Savannah lilliput (180, $10.9 \%$ plus fresh shells from 31 individuals recently stranded by low water levels just upriver from the entrance to Little Hell Landing and one from Station 6), Atlantic spike (175, $10.6 \%)$, eastern creekshell $(136,8.3 \%)$, rayed pink fatmucket $(48,2.9 \%)$, Roanoke slabshell $(41,2.5 \%)$, eastern elliptio (34, $2.1 \%)$, paper pondshell $(13,0.8 \%)$, yellow lamp mussel (11, $0.7 \%)$, Florida pondhorn $(9,0.5 \%)$, eastern floater $(5,0.3 \%)$, barrel floater $(4,0.2 \%)$ and southern elktoe $(1,0.1 \%)$.

In 1997, the Carolina slabshell, variable spike, Savannah lilliput, Atlantic spike and eastern creekshell were the most common species, while the paper pondshell, yellow lamp mussel, Florida pondhorn, eastern floater, barrel floater and southern elktoe were uncommon to rare.

Like the 1998 survey, the 1993 mussel study included both shallow water hand collecting and sampling of deeper waters with divers. It should be noted that Station 3 was examined as part of the 1993 comprehensive program and not Station 2B (a mussel survey was not part of the Plant Vogtle program). This explains the low number of species at Station 2B in Table $\mathrm{C}-1$. The 1,483 mussels recorded from all sites were distributed among 13 species. The original report of the 1993 study (ANSP 1994b) listed 14 species from Stations 1, 3, 5 and 6. Molecular comparisons of the Savannah River mussel fauna by Dr. Margaret Mulvey (formerly of the Savannah River Ecology Laboratory) revealed the pod lance, E. folliculata, collected at Station 3 in 1993 to be conspecific with the Atlantic spike. The only other times the pod lance morph has been recorded from the Academy surveys was in the summer 
and fall surveys of 1951 (as the delicate spike, E. arctatus) from Station 3.

From the two collecting methods in 1993 (i.e., shallow water hand collections and diving), eight species were taken in greater numbers in shallow waters. These included the eastern floater ( 8 vs 0 diving), barrel floater ( 7 vs 0 ), paper pondshell (79 vs 5), variable spike (123 vs 29), rayed pink fatmucket (19 vs 3), Savannah lilliput (266 vs 2),Florida pondhorn ( 7 vs 0 ) and eastern creekshell ( 27 vs 3 ). Only the Roanoke slabshell (13 vs 77 ) and the yellow lampmussel (1 vs 8) were much more common in the deeper water. The Atlantic spike (96 vs 59 diving) was approximately a third more common in the shallow water collections, while the eastern elliptio (46 vs 41 diving) and Carolina slabshell (267 vs 297) were roughly equally common in both shallow and deep water areas.

The four species that were the most common in the October 1993 shallow water hand collections by total and percent abundances were as follows: Carolina slabshell (247, 27.8\%), Savannah lilliput $(266,27.7 \%$ plus fresh shells of 36 animals found in a drying muddy depression on the left bank of Station 6UR),variable spike $(123,12.8 \%)$ and Atlantic spike (96, $10.0 \%)$. The four least common species in hand collections included the eastern floater $(8,0.8 \%)$, Florida pondhorn $(7$, $0.7 \%)$, barrel floater $(7,0.7 \%)$ and yellow lamp mussel $(3$, $0.3 \%$ ).

The collection of mussels in 1989, as part of the comprehensive non-insect macroinvertebrate surveys, was augmented by a late summer survey of this group downriver from Station 1 (17 August) and in a wide area from Johnson's Landing downriver almost to U.S. Highway 301 (18 August). This latter area encompasses both the upper (historic) and lower (present) reaches (UR and LR) of Station 6. The survey by Dr. Arthur Bogan concentrated solely on mussels and produced single specimens of the Florida pondhorn (near Station 1) and the variable spike (near Station 6). Both of these species had been collected during the June 1989 period. The mussel fauna in 1989 consisted of the barrel floater (Station 6LR in June), Savannah lilliput, (Station 6LR in June and September), Florida pondhorn (Station 3 in June and in the area of Station 6LR in August), variable spike (Station 3 in June and in the area of Station 1 in August), and the eastern creekshell 
(Station 1 in September). The barrel floater and Savannah lilliput were collected from a backwater mud substrate, while the Florida pondhorn and variable spikes taken in June were found in a muddy backwater vegetated with emergent aquatic vasculars and isolated from the main stream by low water levels. Shallow water substrates of sand, gravel and mixtures of the two were searched but produced no bivalves or only the introduced Asian clam. With the exception of the common presence of the Savannah lilliput and paper pondshell, the other species were rare.

In 1984, nine species of mussels were collected as follows: the paper pondshell, Utterbackia imbecillis (as Anodonta imbecillis) at Stations 5 and 6, eastern floater, Pyganodon cataracta (in part as Anodonta catarata (misspelling) and $A$. gibbosa) at Stations 5 and 6, Carolina slabshell at Stations 5 and 6, eastern elliptio, E. complanata, at Stations 5 and 6, variable spike at Station 5, Atlantic spike, E. producta (as E. lanceolata) at Stations 5 and 6, rayed pink fatmucket, Lampsilis splendida (as L. radiata splendida at Stations 5 and 6, yellow lampmussel at Station 5, and eastern creekshell at Stations 5 and 6 . The mussel faunas between 1980 and 1984 are essentially the same.

The ten species found to occur at the four stations in 1980 represented a return to the typical numbers of species found prior to the nutrient enrichment seen in 1972 (ANSP 1974a). However, in contrast to the mussel faunas of the early surveys, this group was rare at Stations 1 and 3 where only the variable spike (Station 1) and yellow lamp mussel (Station 3) were collected. The paper pondshell, Utterbackia imbecillis (as Anodonta (U.) imbecillis), Atlantic spike, E. producta (as $E$. lanceolata), rayed pink fatmucket, $L$. splendida (as $L$. radiata splendida) and eastern creekshell were collected at Stations 5 and 6. The Carolina slabshell and eastern elliptio were taken at Station 5, eastern floater, Pyganodon cataracta (as Anodonta (P.) c. cataracta and A. (U.) gibbosa) at Station 6, yellow lampmussel at Stations 3 and 6 and the variable spike at Stations 1, 5 and 6.

In 1980, the mussel fauna in the mouth of the oxbow at Devil's Elbow at Station 5 (right bank) had disappeared. A small variety of mussels, mostly Elliptio, persisted in a muddy backwater area along the left bank. In 1993, this muddy area had a shallow connection with the river [covered 
by grasses in 2000 , reflecting an extended period(s) of low flow(s) ] at its upper end and was divided into a series of pools that are contiguous only during high water. For the most part this series of pools is separated from the river by a vegetated sand ridge. At this site in 1993, the paper pondshell was the most common species, while in 1999 it was the Savannah lilliput. The only members of the genus Elliptio collected in recent surveys were icterina and producta in 1993 and 1999, respectively. In 1980, a reasonably diverse mussel fauna was encountered principally in the large backwater along the lower end of the right bank at the upper reach of Station 6. The population of the eastern floater, Pyganodon cataracta (as Anodonta ( $P$.) cataracta) found at Station 6 was considered to be on the increase. Mussels were all but eliminated at Stations 1 and 3 (only the variable spike and rayed pink fatmucket were found), and greatly reduced at Stations 6 (upper reach) and 5 (to a lesser extent). Fuller attributes this decline in fauna to competition from the Asian clam. The Asian clam first appeared in collections in 1972 and by 1976 (present at all stations) it was apparent to Fuller that through competition it was damaging the native mussel fauna (Fuller and Richardson 1977).

The single August 1976 sampling period found only one less species (brother spike) than the two surveys in 1972. The distributions of the 14 species include the Florida pondhorn, $U$. carolinianus (as U. tetralasmus) at Stations 3 and 5; Savannah lilliput, Toxolasma pullus (as Carunculina pulla) at Station 6; Strophitus undulatus (creeper) at Station 5; and $A$. triangulata (as A. undulata) at Stations 5 and 6. The Carolina slabshell and variable spike were collected at all stations; rayed pink fatmucket, Lampsilis splendida (as "Lampsilis" radiata splendida), yellow lampmussel and eastern creekshell at Stations 3, 5 and 6; paper pondshell, Utterbackia imbecillis (as Anodonta imbecillis) and eastern elliptio at Stations 1, 5 and 6; E. producta (as E. lanceolata) at Stations 5 and 6; barrel floater at Station 5; and eastern floater, Pyganodon cataracta (as Anodonta c. cataracta) at Station 6. The Asian clam was identified as the chief threat to the survival of freshwater mussels in the study areas.

The 1972 studies were conducted in May-June and September. The highest number of mussel species (15) ever recorded during a comprehensive Academy survey was collected that year. All the species known to occur in the 
river at that time, including three of the rarest taxa in the study area, the brother spike and southern elktoe at Station 6 and creeper at Station 5, were part of the 1972 survey. The brother spike was found in 1972 for the first time since it was originally described in 1852 (ANSP 1974a:73). The taxonomic status of the Savannah River population of the brother spike is still uncertain at this time (q.v., Britton and Fuller, 1979:12). The other taxa and the stations from which they were recorded are as follows: Carolina slabshell at Stations 3, 5 and 6; eastern elliptio at Stations 1, 5 and 6; Atlantic spike, E. producta (as E. lanceolata) at Stations 1, 5 and 6; variable spike at all stations; $U$. carolineanus (as $U$. tetralasmus) at Station 6; eastern floater, Pyganodon cataracta (as Anodonta c. cataracta) at Stations 3, 5 and 6; paper pondshell, Utterbackia imbecillis (as Anodonta imbecillis) at Station 6; barrel floater at Station 5; eastern creekshell at all stations; yellow lampmussel at Stations 3, 5 and 6; rayed pink fatmucket, $L$. splendida (as L. radiata splendida) at all stations; and Savannah lilliput, Toxolasma pullus (as Carunculina pulla) at Station 6 . The 15 species listed in the 1972 survey constitute more than half of the 25 taxa presently recognized from the whole drainage basin.

In 1972, the importance was noted of habitat at the mouth of the right bank backwater (substation 6B) at the lower end of the upper reach of Station 6 for the greater portion of the macroinvertebrates, probably also including the mussels. Fuller, in Britton and Fuller (1979:12), indicates the habitat of the 1972 specimens of the brother spike to be sand bars beneath one or two feet of water.

The five species that were the most common in the combined 1993 through 1999 shallow water hand collections (totals and percent abundances) were as follows: Carolina slabshell (1774, 35.1\%), Savannah lilliput $(963,19.1 \%)$, variable spike $(682,13.5 \%)$, Atlantic spike $(531,10.5 \%)$ and eastern creekshell $(477,9.4 \%)$. The eastern creekshell, in 1993 , is the only one of the five species that was not the most abundant in hand collection in each of the four surveys. The five least common species in hand collections during this period included the southern elktoe $(5,0.1 \%)$, barrel floater $(11,0.2 \%)$, yellow lamp mussel $(20,0.4 \%)$, eastern floater $(37,0.7 \%)$ and Florida pondhorn $(48,0.9 \%)$. The remaining species include the paper pondshell, eastern elliptio, rayed pink fatmucket and Roanoke slabshell. The five species that were the most com- 
mon in the combined 1993 and 1998 deeper water dive collections were as follows: Carolina slabshell $(447,54.3 \%)$, Roanoke slabshell (101, 12.3\%), Atlantic spike $(87,10.6 \%)$ variable spike $(82,10.0 \%)$ and eastern elliptio $(55,6.7 \%)$. The five least common species in dive collections during this period included the southern elktoe (0), eastern floater (0), barrel floater $(1,0.1 \%)$, Savannah lilliput $(3,0.4 \%)$ and Florida pondhorn $(4,0.5 \%)$. The remaining species in the dive collections include the paper pondshell, eastern creekshell, yellow lampmussel, and rayed pink fatmucket.

From the two collecting methods in 1998 and 1993 (i.e., shallow water hand collections and diving), six species were taken in greater numbers in shallow waters. These included the Savannah lilliput, southern elktoe, eastern floater, barrel floater, paper pondshell and eastern creekshell. Only the Roanoke slabshell and the yellow lampmussel were much more common in the deeper water. This distribution of the lampmussel is especially interesting considering its once prominence in earlier Academy investigations. The Atlantic spike, eastern elliptio, Carolina slabshell, variable spike, rayed pink fatmucket and Florida pondhorn were roughly as common in both shallow and deep water areas.

Any adverse impacts on the Savannah lilliput are especially important because of its limited range. This species is known only from four localities in North Carolina as follows: University Lake, Orange County; Lake Waccamaw; and two populations in Uwharrie National Forest (John Alderman, pers. com.). A fifth population is known from the Saluda River drainage in South Carolina (John Alderman, pers. com.) and a sixth as scattered populations in the Savannah River from RM 160.5 (\#78 Pilings at Station 1) downriver to RM 118.9 (\#38 Pilings, immediately upriver from the U.S. Highway 301 bridge). Only marginal populations have been found at the upriver sites at the \#70 (Station 2A) and \#69 (Station 2B at RM 149.8) pilings. To date the Savannah lilliput has been found to be common only at \#78 Pilings at Station 1 and from River Mile 138.1 (\#54 Pilings, upriver from Jack of Clubs Point, between Stations 3 and 5) downriver to River Mile 118.9. Of note is no populations of this species were located downriver from the U.S. Highway 301 bridge by John Alderman and Chris McGrath (Nongame and Endangered Wildlife Program, North Carolina Wildlife Resources Commission) in October 1993. This species was originally known 
only from Station 6. In view of the range extensions of this species to Station 5 in 1993, Station 2B in 1997, Station 2A and the U.S. Highway 301 bridge in 1998 and Station 1 in 2000, reexamining sites upriver from Station 1 and downriver from the U.S. Highway bridge is warranted.

The mussel fauna in the Savannah River in the area of the Savannah River Site has changed in character since 1951 (ANSP 1953). The yellow lampmussel and eastern elliptio were the two most common species in the 1951/52 and 1955/56 studies. In the 1993 through 1999 period, 5056 specimens divided among 14 species were taken in hand collections at the study stations and the yellow lamp mussel ranked twelfth in abundance (20 specimens, $0.4 \%$ ) and the eastern elliptio eighth (112 specimens, 2.2\%). In 1960, these two species along with the Carolina slabshell and Atlantic spike were the dominant taxa. Surveys in the years from 1993 through 1999, the Carolina slabshell was the most common species in hand collections ( 1,774 specimens, $35.1 \%)$, while the Atlantic spike ranked fourth (532 specimens, 10.5\%).

The 1968 (ANSP 1970) study discusses the reduced mussel fauna from 1965 (ANSP 1966) with only the "hardier forms" having "persisted as widely as in recent years" (ANSP 1970:65). These "hardier forms" included the eastern elliptio and yellow lampmussel of earlier surveys and the variable spike and rayed pink fatmucket. The variable spike, a species whose type locality lies in the Savannah River near Augusta, was not reported with certainty until 1965 . This species may well have been considered a variant of the eastern elliptio in earlier surveys. The variable spike is presently one of the more common species in the Savannah River. It ranked third in abundance from 1993 through 1999 (682 specimens, $13.5 \%$ ) and rayed pink fatmucket ranked sixth (165 specimens, 3.3\%). In the 1980 study, mussels were considered all but eliminated at Stations 1 and 3, reduced at Station 5 (eliminated from the mouth of the oxbow at Devil's Elbow) and existing with a reasonably diverse fauna only at Station 6 . Six species of mussels were collected from the mouth and along the downstream side of the oxbow at Devil's Elbow in 1993 and 1998. This area was not sampled in 1997 or 1999.

One noteworthy observation in the 1960 survey not addressed until the 2000 study was the "almost uniform distribution" of mussels "from juveniles through old adults (over eight years 
of age)" in 1960 (ANSP 1961: 48). One conspicuous observation concerning the mussel surveys was the scarcity of juveniles. The Savannah lilliput in 1998 and Savannah lilliput and paper pondshell in 1997 and 1993 were the only taxa represented by a uniform distribution of age classes. In the 2000 survey, young mussels of the Savannah lilliput and paper pondshell were again collected as well as individuals of the eastern elliptio, rayed pink fatmucket and eastern creekshell. From the 1993 through 1999 period, it appears that the yellow lampmussel and rayed pink fatmucket have been reduced in numbers, while the Savannah lilliput appears to be more common.

The greater abundance of the Savannah lilliput, a species that was only discovered in the river in 1962, and first appeared in the comprehensive surveys in 1965 , may well be related to the regulated flows of the Savannah River. The species prefers shallow waters, and many of these habitats are less subject to drying with certain base flows being maintained in the river. However, extended periods of extremely low water levels in the Savannah River in 2000 have had an impact on this species by stranding populations in shallow linear depressions separated from the main channel by sand bars or shallow basins perched above the main channel. The impact of the extended period of low water levels in 2000 has been to severely reduce or extirpate some populations of the Savannah lilliput. With the return of normal water levels, monitoring the temporal scale of this species' population structure, growth rates and ability to repopulate areas in which it was formerly abundant will contribute to the knowledge of the biology of the Savannah lilliput.

Besides the brother spike, creeper and southern elktoe, which have always been rare in the Savannah River, recent mussel surveys reveal that the barrel floater, eastern floater and Florida pondhorn are also rare to uncommon but their abundance in previous studies is unknown. The record for the creeper at Station 5 between 1965 and 1976 was based upon a single individual which was recollected during this period (Samuel L. H. Fuller, pers. com.). Most of the mussels in backwater areas seem to be confined to deep troughs downriver from the last set of pilings and can only be hand collected if water conditions are low. Specimens are rarer in shallow shoreline areas around the troughs and along the-shorelines among the pilings. The construction of dykes, upriver dams and removal of 
meanders has resulted in changes in flow characteristics of the river and the slow development of mussel beds outside the original river banks, overflow channels, backwaters and shelves and has resulted in a change in the mussel fauna. It is expected that without wet collecting by hand during low water conditions, reduced numbers of mussels will mark the comprehensive surveys and close monitoring of the most endangered group of animals in North America is warranted.

\section{Crustaceans (Crustacea)}

$\mathbf{F}$ lour species of crustaceans were collected in 2000: the crayfish Procambarus enoplosternum, the riverine grass shrimp, Palaemonetes paludosus, the amphipods (scuds or sideswimmers) Hyalella azteca and an undetermined species of Gammarus. Procambarus enoplosternum was uncommon at Stations 1 and 6 in flooded grasses, root mats of the water hyacinth, a log gallery and one specimen was shocked into the water column by the Fisheries team. At Station 2B, this species was moderately common in flooded grasses and alligator weed, while at Station 5 it was moderately common in willow roots. The riverine grass shrimp was rare at Stations 1 in flooded grasses and moderately common at the remaining stations in flooded grasses, alligator weed, willow roots, paspalum grass and root mats of the water hyacinth. The amphipod $H$. azteca was abundant at Stations 1 (flooded grasses, water-milfoil, alligator weed and woody branches) and 6 (paspalum grass, water-starwort and water pennywort) and common at Stations 2B (flooded grasses and alligator weed) and 5 (root tufts of flooded grasses, paspalum grass and woody branches).

The gammarid amphipod was uncommon at Station 5 and rare at Station 6 in root mats, woody debris, and water-starwort.

Crustaceans collected in 1999 included the crayfishes $P$. enoplosternum and white river crayfish, $P$. acutus, the riverine grass shrimp, the amphipod $H$. azteca and the isopod (water slater) Caecidotea communis. Procambarus enoplosternum was found in root mats and leaf litter at Stations $1,2 \mathrm{~B}$ (moderately common) and 6 (uncommon), while the abundance of the white river crayfish ranged from moderately common (Station 1) to uncommon (Station 6) and rare 
(Station 5) in seine samples collected by the fisheries team. The riverine grass shrimp was moderately common at Stations $2 \mathrm{~B}$ and 6 in root mats and leaf litter and was uncommon at Station 5 in the same habitat. The amphipod $H$. azteca was predominantly found in root mats where is was common at Station 6, moderately common at Stations 1 and 2B, and uncommon at Station 5. The only other habitat noted for this species was its rare occurrence in muddy stick litter at Station 2B. The remaining species collected in 1999 was the isopod, C. communis, which was rare at Station 6 in root mats.

Crustaceans collected in the 1998 survey included the crayfishes $P$. enoplosternum and white river crayfish, the riverine grass shrimp, the amphipods $H$. azteca, an undetermined species of Crangonyx and an undescribed species of Gammarus and the isopod $C$. communis. The crayfish $P$. enoplosternum was found in root mats and leaf litter at Stations 1 and 2B (moderately common), root mats at Station 5 (abundant) and willow roots, detritus and leaf litter at Station 6 (common). The white river crayfish was moderately common in muddy leaf litter at Station 5, uncommon in willow roots at Station 6 and one crayfish was captured from an isolated pool at Station 1. The riverine grass shrimp was common at Station 6 in willow roots and moderately common at the remaining three stations in root mats as well as leaf litter at Stations 1 and 2B. The amphipod $H$. azteca was abundant at Stations 5 and 6 and moderately common at Station 2B. At Station 5 it was collected from root mats, under the bark of logs and in leaf litter, while at Station 6 it was abundant in pennywort and moderately common in water hyacinth roots. At Station $2 B$ it was picked from the fissures of rough bark and a clump of Spanish moss (Tillandsia usneoides) that had fallen into the river. The crangonyctid amphipod was uncommon at Station 6 in the same habitat as the other amphipods and rare at Stations 1 (root mats) and 2B (Spanish moss). The undescribed Gammarus was abundant at Station 6 in willow roots, detritus and from undercut banks and moderately common at Station 5 in the same habitat as the hyalellid amphipod. The isopod, $C$. communis, was common at Station 6 in root mats and detritus, moderately common in leaf liter and on logs at Station 2B and rare in muddy leaves at Station 5.

Crustaceans collected in the 1997 survey included five species consisting of the crayfish $P$. enoplosternum, the riverine grass shrimp, the amphipods $H$. azteca and an undescribed 
species of Gammarus and the isopod C. communis. Procambarus enoplosternum was common in the roots of riparian trees at all stations and pennywort and leaf and stick litter at Station 6. The riverine grass shrimp was common in root mats at all four stations. The amphipod H. azteca was abundant at Stations 1 and 6 and moderately common at Station 5 and uncommon at Station 2B. At Station 1 it was more common in moss and less so in root mats, while at Station 6 it was equally abundant in root mats and pennywort. At Stations $2 B$ and 5 it was found only in root mats. The undescribed Gammarus was also collected from root mats, where it was abundant at Station 6 and moderately common at Station 5. The isopod, $C$. communis, was moderately common at Station 6 in root masses.

Crustaceans were especially well represented in the 1993 survey with six species that included the crayfish $P$. enoplosternum, the riverine grass shrimp, the isopod, C. communis; and the amphipods, $H$. azteca, an undescribed species of Gammarus and an undetermined species of Crangonyx. The only crayfish collected in 1993 was $P$. enoplosternum. It was uncommon to common in the fine roots of riparian trees and leaf litter at Stations 1, 5 and 6 and uncommon at Station 2B where it was associated with brush piles and dense concentrations of root mats. The riverine grass shrimp was rare to very common at Stations 1, 5 and 6 and moderately common in riparian roots at Station 2B. The isopod was uncommon to very common at all study areas except Station 1 where it did not appear in samples. It was primarily found in the roots of riparian trees at all stations and the furrows of rugose logs at Station 5. The talitrid (Hyalella) and gammarid amphipods were collected at all stations, while the crangonyctid was found only at Station 6. All three amphipods were taken primarily from the same root mat and log habitats as the water slater. The gammarid was also recorded from leaf litter at Station 1 . This is the first time that the crangonyctid had been collected from the main stem of the Savannah River since 1965 (ANSP 1966).

Four species of crustaceans were collected in September 1989 and included the crayfish $P$. enoplosternum (as $P$. pubescens), the riverine grass shrimp and the amphipods $H$. azteca and an undescribed species of Gammarus. Procambarus enoplosternum was common along both banks in beds of submerged aquatic vascular plants, leaf litter, brush piles as well as the 
fine roots of riparian trees at Stations 1,5 and 6. The riverine grass shrimp was very abundant in submerged weed beds in both backwater areas and in the current at Stations 1, 5 and 6. The talitrid amphipod $H$. azteca and an undescribed species of gammarid in the genus Gammarus, were collected at Stations 5 and 6. Hyalella azteca was taken from submerged beds of aquatic vascular plants in backwater areas and among the stems of riparian grasses hanging in the water along the shore. The undescribed species of Gammarus was collected from weed beds in moderate current.

Five species of crustaceans were found in September 1984 at Stations 1, 5 and 6 and consisted of Caecidotea communis (as Asellus communis), H. azteca, Gammarus species, the riverine grass shrimp, and P. enoplosternum (as P. pubescens). The 1980 and 1976 surveys produced five and four species of crustaceans, respectively, as follows: the water slater at Station 5 (September 1980 and August 1976), talitrid amphipod at Stations 1, 5 and 6 in September 1980 and Stations 1 and 5 in August 1976, the gammarid amphipod (as G. fasciatus in 1976 and an undetermined species of gammarid in 1980) at Stations 5 and 6 (September 1980 and August 1976), the riverine grass shrimp $P$. paludosus (as $P$. kadiakensis in 1976) at Stations 5 and 6 in September 1980 and Stations 1, 5 and 6 in August 1976 and the crayfish P. enoplosternum (as $P$. pubescens) at Stations 1, 5 and 6 in 1980.

\section{Mites (Arachnida)}

$\mathbf{M}$ ites have generally been uncommon in Academy surveys dating back through the 1976 study. Although only a single species (Lebertia) of mite was discovered in 2000, it was common at Station 1 in flooded grasses at the river margin. In 1999, an undetermined species of Lebertia was represented in root mat habitat where it was moderately common at Station 1 and rare at Station 6. An undetermined species of aquatic mite was rare in the same root mat habitat at Station 6. In 1998, an undetermined species of Lebertia was rare in leaf litter at Station 2B and root mats at Station 6. In 1997, an undetermined species of mite was moderately common in roots at Station $2 \mathrm{~B}$, while the undetermined Lebertia species was moderately common at Stations 1 and 2B in roots and uncommon at Station 6 in roots and pennywort. A single undetermined species of mite oc- 
curred in litter samples from Station 6 in September 1993 and an undetermined species of Hydrachna was removed from a $\log$ at Station 2B. The undetermined species of Lebertia was moderately common at Stations 1 and 6 in 1989. No aquatic mites were collected in 1984 and the 1980 survey found only the Lebertia species at Station 6. The August 1976 study collected the Lebertia (?) species at Stations 1 and 5 and a mite of the genus Arrenurus at Station 1. During the 1972 survey six of seven species of mites (individuals of Unionicola are parasitic or commensal in the gills or mantle cavities of mussels) were collected from the luxuriant weed beds which were so prevalent at that time. With the decline in extent of these beds of aquatic vascular plants has been a decrease in the mite fauna that inhabits them. This group is most abundant in vegetated areas and is another of several taxa whose presence and/or abundance reflect the areal extent of submerged aquatic vascular plants.

\section{Conclusions}

\section{Dominant Macroinvertebrate Groups}

The results of the 2000 survey indicate that the principal groups of non-insect macroinvertebrates in the Savannah River in the vicinity of the Savannah River

Site, with the exception of the mussels, are broadly similar to studies in the 1976 to 1999 period (ANSP 1977, 1981a, 1985b, 1991b, 1994a, 1994b, 1998 and 1999) with four major assemblages dominating. In 2000, these four groups, collected at Stations 1, 2B, 5 and 6, consisted of the bivalves [12 species: mussels (8) and clams (4) ], snails (5), crustaceans (4) and leeches (4). These same four groups dominated the noninsect macroinvertebrate fauna of the previous eight studies (1999, 1998, 1997, 1993, 1989, 1984, 1980 and 1976) (Table C-2). Only in 1972 did an additional group, the mites, exhibit a diversity that made them a significant part of the fauna (Table C-2). The remaining, less well-represented, taxonomic groups have been historically either widely collected (e.g., the planarian, Dugesia tigrina; the earthworm, Lumbriculus variegatus; and an undetermined species of sponge), spotty in dis- 
tribution (e.g., the ectoprocts and a nematomorph), usually rarely collected (e.g., the nemertean, Prostoma rubrum) or are not given the collecting and/or taxonomic effort of larger forms (e.g., nematodes and tubificids).

The four species of leeches taken in 2000 are within the range of measures comparing the years 1972 through 1999 (range of 2 to 10 , mean of 4.6 , mode 3 to 4 species), but considerably lower than the 10 species collected in 1972. The number of snail taxa collected during the 1972 through 1999 surveys varies from 6 to 11 with an average of 7.6 species. The species totals from 1972 (11) and 2000 (5) represent the high and low ends of the range of species collected between these years; the 2000 total is below the modal (7) and mean (7.6) values for this period. As in the leech fauna, the greatest number of species (11) was collected in 1972 when eutrophic conditions created large areas of habitat in the form of submerged vascular plants. The slightly lower numbers in 2000 follow a trend observed in 1999 (6 species) and in 2000 primarily reflect the absence of the mud amnicola and any of the ramshorn snails (q.v., Results, Molluscs (Mollusca), Snails, for a review of the distribution (1972 to 1998), abundances (1997 and 1998) and habitats (1989 to 1998) of the rams-horn snails). A review of vegetation levels in the 1972 through 2000 period and other factors affecting species totals is discussed below in the section "Species Diversity Among Years."

The number of clam species collected has varied from 2 to 7 (mean 4.7, mode 5) taxa over this time period. The elevated water levels in 2000 , relative to levels prior to the survey, limited access to permanently watered bed sediments during the comprehensive study, and several taxa that inhabit these substrates (e.g., earthworms, tubificid worms, mud amnicola, sphaeriid clams) were little or not collected in the hand collections. Of the 27 sphaeriid clams taken in 2000, 25 were collected only in sediments during the mussel study when water levels were lower than during the comprehensive study. Of the two specimens taken in the comprehensive survey, one was taken from muds and the other from root mats.

The number of mussel species recorded from hand collections in the Savannah River surveys during the August to October period has ranged from 2 to 15 species with an average of 11.3 taxa. The most salient trend in the mussel data can be 
seen in the decrease of species from 1972 to 1989 (q.v., Table C-2). Prior to 1993, comprehensive studies were conducted twice a year and comparisons within and among years were made using both seasonal and combined data sets. The combined June and September 1989 total of 5 mussel species continued the trend of decreasing mussel diversity [15 (1972) to 14 (1976), 9 (1980 and 1984) to 5 (1989) ]. In addition, a Savannah River mussel survey undertaken by Dr. Arthur Bogan (formerly of the Academy's Malacology Department) in August 1989 produced only single specimens of two of the five species collected in the June and September studies. The 1972 through 1989 trend prompted a more thorough mussel survey in 1993. Part of the 1993 effort included a review of the longterm data set of Academy studies and discussions with present and former personnel associated with the earlier Academy Savannah surveys. It was surmised that sampling the macroinvertebrate fauna to a depth that could be thoroughly searched in waders and spreading the field effort across all taxonomic groups had resulted in the collection of a more diverse non-mussel macroinvertebrate fauna but fewer mussels [q.v., Tables C-1 (dominant taxa) and C-2 (total numbers of taxa) ]. Between 1972 and 1984, samples were collected in waters up to neck deep. The effort in deeper water resulted in access to more permanently watered substrates and the collection of more mussel species (9 to 15). However, fewer non-mussel taxa were collected during this period. Studies from 1993 through 2000 have included both deeper water sampling at low water levels for mussels and a comprehensive sampling of the other macroinvertebrates. The two sampling efforts typically result in a more thorough assessment of the complete macroinvertebrate fauna [i.e., more species (see 1993 through 1998) including mussels (see 1972 to 1976 and 1993 through 1999) ]. The conclusions of the mussel survey are discussed in a separate section below.

The number of crustacean taxa in 2000 (four species) is slightly below the mean (5.2) and modal (5) values of crustaceans collected at four Savannah River stations. This number is at the lower end of the 4 to 7 range of previous studies. Other species of crustaceans that have been collected in past surveys and not 2000 include several species of crayfishes, an isopod and a crangonyctid amphipod. They have all been taken in small numbers, and their presence in the surveys has been spotty, although one or more are typically collected. 
However, their absence from a survey would not be unexpected.

Additional details on habitat, abundance, frequency of occurrence and range of the dominant groups (leeches, snails, bivalves and crustaceans), as well as the once diverse mite fauna (q.v., Table C-2), can be found in the section Results, for each group.

\section{Mussel Fauna}

The nature of the mussel fauna in the Savannah River in the area of the Savannah River Site has changed

Lince the early 1951 to 1968 studies when the yellow lamp mussel, eastern elliptio, Carolina slabshell, Atlantic spike, variable spike and rayed pink fatmucket were all listed as the most abundant species. Only the Carolina slabshell, variable spike and Atlantic spike were among the dominant taxa in hand collections in 1993 through 1999. The eastern elliptio and rayed pink fatmucket were moderately common and the yellow lamp mussel uncommon in the recent surveys. The "almost uniform distribution" of mussels "from juveniles through old adults (over eight years of age) " reported in 1960 was only observed in the paper pondshell in 1993 and 1997 and the Savannah lilliput in 1993, 1997 and 1998. The Savannah lilliput is known from only six populations (four in North Carolina, one in South Carolina and the Savannah River population in the area of the Savannah River Site, Georgia and South Carolina). Near the Savannah River site, most mussels are found in backwater areas near pilings and can only be studied by hand collecting at low water levels. Reasons for the decline in some species is unknown at this time.

The reduced numbers of juvenile mussels in hand collections since 1960 prompted the use of a quantitative method in 2000 that would pass sediments through a sieve to recover small mussels. In addition, this method would provide abundance measures of mussels and Asian clams relative to one another. The schedule of one day per station did not permit a sufficient number of quadrats to be sampled to provide relative abundances for the species in the study sections of the river. The quadrat sampling was successful in collecting young mussels of the eastern elliptio, rayed pink fatmucket, Savannah lil- 
liput, paper pondshell and eastern creekshell. Young Asian clams and sphaeriids (fingernailclams and peaclams) were also taken. The survey at 4 stations (40 quadrats) produced 4,073 bivalves consisting of 25 sphaeriids (0.61\%), 118 mussels (2.9\%) and 3,930 Asian clams (96.5\%). Of the 40 quadrats sampled, 36 were placed along transects in a variety of habitats (e.g., river flow, substrate, depth, organic content) and 4 were chosen in likely mussel habitats to slightly increase the opportunities to collect young mussels. From these 40 quadrats, $98.25 \%$ of the bivalves taken were Asian clams, $2.9 \%$ were mussels of eight species and $0.61 \%$ were sphaeriids of 3 species. It is apparent that the introduced Asian clam numerically dominates the benthic habitat of the Savannah River and because of its great numbers competes with the mussels for space and food resources.

The impact of low flows severely reduced or extirpated mussel populations, especially the Savannah lilliput at and near Station 5 (see Results, Mussels).

\section{Species Diversity Among Years}

The total number of species collected during the 1972 through 2000 surveys has varied from a low of 27 (1989) to a high of 60 (1972). The 2000 total (30 species) is less than the average (mean 41.1), significantly lower than recent studies (47 to 49 in 1993 through 1998) and slightly lower than 1999 (37 species). The total for 2000 is more similar to the results of 1999 (37), 1989 (27), 1984 (36) and 1980 (33). Species totals in 1989 were low, compared to 2000 , as a result of storm events and an impending hurricane during the September survey. Stations 3 and 5 were collected the same day under rising water levels and Station 6 was surveyed under high water conditions. Compared to the next lowest total in 1999 (37 species), the lower numbers in 2000 (30 species) reflect less diversity in the mussel community (5 species), and 1 less species of snail and crustacean. The differences in the mussel fauna reflect quantitative sampling that surveyed much smaller areas of substrate that would be expected to miss many of the rarer taxa. The elevated water lev- 
els in 2000, relative to levels prior to the survey, limited access to permanently watered bed sediments during the comprehensive study, and several taxa that inhabit these substrates (earthworms, tubificid worms, mud amnicola, sphaeriid clams) were not collected in the hand collections. The modal number of crustaceans taken during the 1972 to 1999 period is 5 species. All the other crustaceans that have been collected in past surveys (several species of crayfishes, an isopod and a crangonyctid amphipod) have occurred in small numbers in the past and their occasional absence from a survey would not be unexpected. Differences in the crustacean fauna may also be related to the generally very low water levels in 2000 , washing fewer taxa into the main channel from backwater or tributary areas and/or the elevated water levels during the comprehensive study limiting access to permanently watered areas. The addition of the mussels alone would place the 2000 results in line with those from 1999, 1989, 1984 and 1980.

The higher numbers of species in some groups, as well as the total number of taxa in 1972, correlates with the dense stands of submerged aquatic plants. With the exception of the mussels, most members of the dominant five groups in Coastal Plain regions are typically abundant in areas associated with these dense stands, and their species richness and/or abundance reflects the areal extent of these growths. Since 1990 (ANSP 1991a, 1991b), the weed beds have been absent from the study areas, and population densities of many species have declined (e.g., snails sphaeriid clams, crustaceans and mites). The differences between the 1989 to 1976 and 1972 surveys reflect variation in effort, water levels and density of vegetation. In 1976, relative to 1972, there was a near disappearance of submerged vascular vegetation at Station 1 (ANSP 1977:37), vegetation among the pilings at Station 3 disappeared (op. cit: 38 ), the weed beds at Station 5 all but disappeared (loc. cit.) and Station 6 was expanded downriver into the present day lower section of Ring Jaw Point to reach weed beds (op. cit: 39 ). Almost no weed beds were present in the upper portion of Station 6 (loc. cit) in 1976. In 1980 there was a loss of vegetation at Station 1 (ANSP 1981a:78), no weed beds at Stations 3 and 5 (op. cit:80) and smaller weed beds at Station 6 (op. cit:81). In 1984, submerged aquatic vascular plants varied from scarce at Stations 1 and 3 (ANSP 1985b:107) to lush and dense beds at Stations 5 and 6 (op. 
cit:107, 108). In 1989 (ANSP 1991b), patches of aquatic plants were common, but by 1990 the submerged aquatic flora was either lacking, reduced to an occasional patch or represented by a few plants carried into the station by the river's current and ensnared by branches or logs. The greater species richness in 1972 reflects an abundance of this habitat (=dense growths of submerged aquatic vascular plants). Submerged macrophytes provide one of the most important habitats in Coastal Plain streams, since this region generally lacks the well-indurated substrates of rock and cobble typical of lotic habitats above the Fall Line zone. The higher numbers of species in 1993 and 1997, when the submerged flora was reduced, are due to a greater effort in other habitats (see individual species accounts). Two areas of strongest differences since the 1972 survey can be found in a comparison of the leech and mite species richness. A slightly higher total number of snail taxa was also collected in 1972. The decline in total numbers of taxa and dominance and abundance of some groups (leeches, snails, fingernailclams, peaclams, crustaceans and mites) is probably a reflection of the areal extent of the vegetation. The bagging of bottom debris and sorting of samples in a field laboratory in 1972 likely contributed some taxa to the species list.

\section{Species Diversity Among Stations}

comparison of the species numbers of non-insect
macroinvertebrates collected between 1972 and
2000 at Stations 1, 2B (1993-2000), 3 (1972-1989), 5 and 6 reveals a generally higher average number of species collected at Stations 5 (26.8) and 6 (28.7) than at Stations 1 (24.0) or 2B/3 (21.1). The long-term database for the August to October period indicates that, in a given survey, slightly more species are typically collected at Stations 5 and 6 than at Stations 1 or 2B. The 1989 study is the only survey in which more species have been collected at Station 1 than any other station. The lower numbers in 1989 at Stations 3, 5 and 6, as noted above (q.v., Table C-1), were the result of sampling at Stations 3 and 5 for only a portion of a day and high waterl conditions limiting collecting at Station 6. The high numbers 
of species at Station 1 in 1999 reflects a greater effort over a two-day period. No sampling year between 1972 and 2000 has resulted in more species being collected at Stations $2 \mathrm{~B}$ or 3 . The 2000 study is the only year in which the fewest number of species has been collected at Station 6. There were no obvious reasons for the decline in species diversity other than the high water levels relative to flows for most of the year (q.v., Table C-1).

\section{Summary}

The most salient aspects of the 2000 study are the lower to slightly lower numbers of species in the dominant groups (Table C-2) and lower total number of species (Table C-1). These lower numbers are a continuation of a trend that began in 1999 and primarily reflect drought conditions in the basin and lower flows in the Savannah River during these years. Water levels in the Savannah River have been low since June 1998. Low summer flows are normal, but these conditions have persisted with only a few occasional spikes in water levels into 1999 and 2000 (cf., ANSP 1994b, 1998, 1999, 2000 and Figure 2 herein). The 2000 study was conducted in a year with the lowest flows to date. Compared to 1999, the lower numbers in 2000 were, in part, the result of limited access to habitats because of, ironically, higher water levels during the survey and, primarily, the use of a quantitative sampling technique (quadrats) for mussels. Continued low flows during the summer months of 2000 lowered the base water level of the river. A new shoreline was established, root mat habitat was left high and dry and many populations of sessile and less vagile macroinvertebrate species were extirpated. Elevated water levels during the study, although still low in an historical context, limited access to species that occurred below the newly established base level. Quadrat sampling for mussels, although collecting a wider range of size classes, produces fewer species. This is especially true for the rarer taxa due to the smaller area surveyed. Most of the taxa collected in 1999 but not in 2000 were the rarest mussel species in the study area. Although the results of the 2000 study produced fewer taxa than recent studies (1993, 1997, 1998 and 1999), the numbers fall within the long-term trends (1972 to 1999) (Table C-1). With its large number of 
less vagile species, non-insect macroinvertebrates appear to have been impacted by this extended period of low flows, including the loss of some mussel populations. The 2000 results reflect the drought conditions in the Savannah River and are part of a faunal trend that was first apparent in the 1999 study. The 2000 results do not indicate an impact on the non-insect macroinvertebrate biota of the Savannah River by the Savannah River Site. 
Appendix C. List of taxa of non-insect macroinvertebrates collected 25 to 28 August and 8 to 11 September 2000 at Stations 1, 2b, 5 and 6 on the Savannah River, Georgia and South Carolina ( $X=$ present; - = not present).

\begin{tabular}{cccccc}
\hline & \multicolumn{5}{c}{ Station } \\
\cline { 2 - 6 } & Taxa & 1 & $2 B$ & 5 & 6 \\
\hline
\end{tabular}

Phylum Porifera

Class Demospongiae

Order Haplosclerina

Family Spongillidae

Undet. sp.

Phylum Platyhelminthes

Class Turbellaria

Order Tricladida

Family Dugesiidae Dugesia tigrina (Girard)

Phylum Nematomorpha

Order Gordioidea

Family Chordodidae

Undet. sp.

Phylum Ectoprocta

Class Phylactolaemata

Family Pectinatellidae

Pectinatella magnifica (Leidy)

Phylum Annelida

Class Oligochaeta

Class Hirudinea

Order Rhynchobdellida

Family Glossiphoniidae

Desserobdella phalera (Graf)

Helobdella triserialis (Blanchard)

Placobdella papillifera (Verrill)

Order Pharyngobdellida

Family Erpobdellidae

Undet. sp.

Phylum Mollusca

Class Gastropoda

Order Mesogastropoda

Family Viviparidae

Campeloma decisum (Say)

Order Basommatophora

Family Lymnaeidae

Pseudosuccinea columella (Say)

Family Physidae

Physella heterostropha (Say)
X

X

$\mathrm{X}$

$\mathrm{X}$

$\mathrm{X}-\mathrm{X} \quad \mathrm{X}$

- $\quad \mathrm{X}$

X

-

X

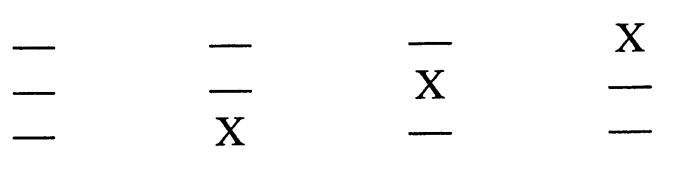

$\mathrm{X}$

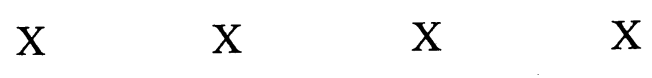

X $\quad$ X $\quad$ X $\quad$ X

X

X

$\mathrm{X}$

$\mathrm{X}$ 
Appendix $C$ (continued). List of taxa of non-insect macroinvertebrates collected 25-28 August and 8-11 September 2000 at Stations 1, 2B, 5 and 6 on the Savannah River, Georgia and South Carolina $(X=$ present; $-=$ not present).

\begin{tabular}{|c|c|c|c|c|}
\hline \multirow{2}{*}{ Taxa } & \multicolumn{4}{|c|}{ Station } \\
\hline & $\mathbf{1}$ & 2B & 5 & 6 \\
\hline \multicolumn{3}{|l|}{ Family Ancylidae } & - & - \\
\hline \multicolumn{5}{|l|}{ Order Stylommatophora } \\
\hline Family Succineidae & & & & \\
\hline \multicolumn{5}{|l|}{ Novisuccinea ovalis (Say) } \\
\hline \multicolumn{5}{|l|}{ Class Bivalvia } \\
\hline \multicolumn{5}{|l|}{ Order Unionida } \\
\hline \multicolumn{5}{|l|}{ Family Unionidae } \\
\hline Elliptio icterina (Conrad) & - & $\mathrm{X}$ & - & - \\
\hline E. complanata (Lightfoot) & - & $\mathrm{X}$ & - & $\mathrm{X}$ \\
\hline E. congaraea (Lea) & - & - & $\mathrm{X}$ & - \\
\hline E. producta (Conrad) & $\mathrm{X}$ & $\mathrm{X}$ & $\mathrm{X}$ & - \\
\hline Lampsilis splendida (Lea) & $\mathrm{X}$ & $\mathrm{X}$ & - & $\mathrm{X}$ \\
\hline Villosa delumbis (Conrad) & $\mathrm{X}$ & $\mathrm{X}$ & $\mathrm{X}$ & - \\
\hline Toxolasma pullus (Conrad) & $\mathrm{X}$ & $\mathrm{X}$ & $\mathrm{X}$ & $\mathrm{X}$ \\
\hline Utterbackia imbecillis (Say) & 一 & - & $X$ & - \\
\hline \multicolumn{5}{|l|}{ Order Veneroida } \\
\hline \multicolumn{5}{|l|}{ Family Sphaeriidae } \\
\hline Musculium securis (Prime) & - & - & $\mathrm{X}$ & - \\
\hline$P$. compressum Prime & - & $\mathrm{X}$ & $\mathrm{X}$ & - \\
\hline P. dubium (Say) & $\mathrm{X}$ & $\mathrm{X}$ & - & $\mathrm{X}$ \\
\hline Family Corbiculidae & & & & \\
\hline Corbicula fluminea (Muller) & $\mathrm{X}$ & $\mathrm{X}$ & $X$ & $\mathrm{X}$ \\
\hline \multicolumn{5}{|l|}{ Phylum Arthropoda } \\
\hline \multirow{2}{*}{\multicolumn{5}{|c|}{ Class Crustacea }} \\
\hline \multirow{2}{*}{\multicolumn{5}{|c|}{$\begin{array}{l}\text { Order Amphipoda } \\
\text { Familv Gammaridae }\end{array}$}} \\
\hline \multirow{2}{*}{\multicolumn{5}{|c|}{$\begin{array}{l}\text { Family Gammaridae } \\
\text { Gammarus sp. }\end{array}$}} \\
\hline & & & & \\
\hline Family Hyalellidae & & & & \\
\hline Hyalella azteca (Saussure) & $\mathrm{X}$ & $\mathrm{X}$ & $\mathrm{X}$ & $\mathrm{X}$ \\
\hline \multicolumn{5}{|l|}{ Order Decapoda } \\
\hline \multicolumn{5}{|l|}{ Family Cambaridae } \\
\hline Procambarus enoplosternum Hobbs & $\mathrm{X}$ & $\mathrm{X}$ & $\mathrm{X}$ & $\mathrm{X}$ \\
\hline Family Palaemonidae & & & & \\
\hline Palaemonetes paludosus (Gibbes) & $\mathrm{X}$ & $\mathrm{X}$ & $\mathrm{X}$ & $\mathrm{X}$ \\
\hline Class Arachnoidea & & & & \\
\hline Lebertia sp. & $X$ & - & - & - \\
\hline Total & 17 & 20 & 21 & 16 \\
\hline
\end{tabular}




\section{AQUATIC INSECTS}

\section{Introduction}

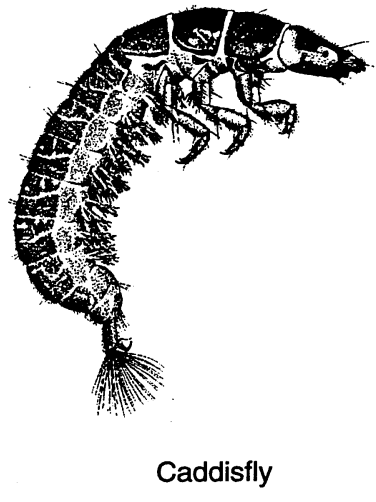

(Hydropsyche orris) quatic organisms have provided water quality assessment programs with valuable insight for more than 100 years (Cairns and Pratt 1993), and benthic (i.e., bottom-dwelling) macroinvertebrates (especially aquatic insects, but also crustaceans, worms, molluscs, and other non-insects) are the most common group of aquatic organisms included in these programs (Hellawell 1986). Aquatic insects are included in water quality assessment programs because: (1) they provide an extended temporal perspective (relative to traditional water samples that are collected periodically) as a result of their limited mobility and relatively long life spans (e.g., a few months for some chironomid midges to a year or more for some beetles and dragonflies); (2) they are an important link in the aquatic food web, converting plant and microbial matter into animal tissue that is then available to fish; (3) the group has measurable responses to a wide variety of environmental changes and stresses; and (4) they are abundant and their responses can be easily analyzed statistically (Weber 1973). Thus, the presence or conspicuous absence of certain aquatic insect species at a site is a meaningful record of environmental conditions during the recent past, including ephemeral events that might be missed by assessment programs that rely only on periodic sampling of water chemistry.

The structure and function of the aquatic assemblage in the Savannah River can be affected by a diverse group of environmental factors, including direct and indirect interactions with depth, temperature, current velocity, volume of water input and release, nutrient levels, dissolved oxygen concentration, substrate type, sedimentation, erosion, metals, pesticides, herbicides, food availability, intra- and interspecific competitors, and predators. These factors can vary temporally and spatially in response to natural processes (e.g., river topography, 
riparian vegetation, seasonal and annual changes in temperature or precipitation), as well as human influences (e.g., local fisheries management practices or urban, agricultural, forestry, mining, and/or industrial developments that result in non-point sources and discharges from numerous point sources within the watershed).

The Savannah River monitoring program uses long-term and recent data for aquatic insects to: (1) use spatial variation in the aquatic insect assemblage to assess current habitat and water quality in the Savannah River near the Savannah River Site (SRS), (2) evaluate these current conditions with regard to conditions observed at these stations in previous surveys, and (3) identify the effect (if any) of upstream factors (i.e., above Station 1) that may be affecting habitat and water quality in the Savannah River near SRS, and (4) understand mechanisms that determine the distribution and abundance of aquatic insect populations within the Savannah River. These goals are addressed in the 2000 report by describing the aquatic insect assemblage at Stations 1, 2B, 5, and 6 in April and September 2000, and by comparing the 2000 aquatic insect assemblage at these stations with the assemblages observed in recent surveys.

\section{Materials and Methods}

\section{Location and Habitat Characteristics of the Study Area}

I n 2000, qualitative and quantitative aquatic insect collections were made at four stations (Stations 1, 2B, 5, and 6, (25-28) and Septembe in 2000 (and also in 1999) was earlier than in 1998, because there were no delays due to high river discharge. Specifically, 2000 samples were collected about eight weeks earlier than 1998 samples while 1999 samples were collected about six weeks earlier than 1998 samples. In contrast, fall sampling during all recent surveys (1998-2000) has been completed during the same general time period (September 10-20) due to consistently low river flows. 
Table D-1. Information concerning the placement, retrieval, and processing of Conservation Webbing traps from four stations (on the Savannah River in the vicinity of the SRS) in 2000. Qualitative collections were made on the same dates as traps were retrieved.

\begin{tabular}{cccccc}
\hline Station & $\begin{array}{c}\text { Placement } \\
\text { Date }\end{array}$ & $\begin{array}{c}\text { Retrieval } \\
\text { Date }\end{array}$ & $\begin{array}{c}\text { Number } \\
\text { Placed }\end{array}$ & $\begin{array}{c}\text { Number } \\
\text { Retrieved }\end{array}$ & $\begin{array}{c}\text { Number } \\
\text { Processed }\end{array}$ \\
\hline \multirow{2}{*}{1} & 21 Mar 2000 & 26 Apr 2000 & 4 & 3 & 3 \\
& 15 Aug 2000 & 10 Sep 2000 & 4 & 4 & 4 \\
2B & 21 Mar 2000 & 25 Apr 2000 & 4 & 3 & 3 \\
& 15 Aug 2000 & 13 Sep 2000 & 4 & 4 & 4 \\
5 & 21 Mar 2000 & 28 Apr 2000 & 4 & 4 & 3 \\
& 15 Aug 2000 & 11 Sep 2000 & 4 & 4 & 3 \\
6 & 21 Mar 2000 & 27 Apr 2000 & 4 & 4 & 3 \\
& 15 Aug 2000 & 12 Sep 2000 & 4 & 3 & 3 \\
\hline
\end{tabular}

All effluent and runoff from the SRS enter the Savannah River downstream of Station 1. Thus, river conditions observed at Station 1 are unaffected by the SRS, and the station was designated a priori as a reference site for this study. The aquatic insect sampling area at Station 1 included all available habitats among the pilings near marker 78 on the left bank (facing downstream) and along the right bank opposite the pilings. In addition, any unique habitats observed within approximately $75 \mathrm{~m}$ upstream or downstream of these areas (on either bank) were also sampled.

Station 2B is exposed to discharge from the Georgia Power and Light's Vogtle Nuclear Power Plant as well as discharge and runoff from the northern portion of the SRS (primarily from Four Mile Branch, but also the lower portion of Upper Three Runs). Station 2B was designated a priori as a potential impact site, integrating the effects of the Plant Vogtle and the northern portion of the SRS. The aquatic insect sampling area at Station 2B included all available habitats among the pilings near marker 68 on the left bank (facing downstream) and along the right bank opposite the pilings. In addition, any unique habitats observed within approximately $75 \mathrm{~m}$ upstream or downstream of these areas (on either bank) were also sampled.

Station 5 is downstream of Steel Creek and upstream of Lower Three Runs. Aquatic insects at this station are exposed to discharge from Plant Vogtle as well as discharge and runoff from the entire SRS (except what is carried in Lower Three Runs). Station 5 was designated a priori as a potential impact site, integrating the effects of Plant Vogtle and most of 
the SRS. The aquatic insect sampling area at Station 5 included all available habitats among the pilings near marker 55 on the right bank and along the left bank opposite the pilings. In addition, any unique habitats observed within approximately $75 \mathrm{~m}$ upstream or downstream of these areas (on either bank) were also sampled.

Station 6 is the downstream most site on the Savannah River, below the confluence with Lower Three Runs. Aquatic insects were collected in the lower reach of this station, between RM 122.35 and 122.85. Aquatic insects at this station are exposed to discharge from Plant Vogtle and any discharge/runoff from the entire SRS, including what is carried in Lower Three Runs. Station 6 was designated a priori as a potential impact site, integrating the effects of Plant Vogtle and the SRS. The aquatic insect sampling area at Station 6 included all available habitats among the pilings near marker 42 on the left bank (facing downstream) and along the right bank opposite the pilings. In addition, any unique habitats observed within approximately $75 \mathrm{~m}$ upstream or downstream of these areas (on either bank) were also sampled.

Stations 1, 5 and 6 have typically been sampled as part of the Academy's Savannah Cursory and Comprehensive surveys. Station 2B has historically been sampled as part of the Academy's Savannah River surveys related to Plant Vogtle.

\section{Qualitative Sampling}

The strategy for the qualitative sampling program was to collect the insect fauna from all possible microhabitats within each station that could be safely sampled. This includes root masses (primarily willow); submerged and floating woody debris; floating and submerged vegetation; river pilings; rock, sand, and silt sediments; and edge habitat (very shallow areas along the shoreline). Collecting was generally along the margin of the river where the water was not as deep. We attempted to locate the same microhabitats at each station so that the collections were comparable. Overall, any recognizable microhabitat was examined intensively and the fauna present collected. Two people collected at each station, and the duration of collecting ranged from 8-10 person hours per station. In general, if no new recognizable species were found after 
collecting at a site for a few hours, it was assumed that the majority of species from the station had been collected. This method was the standard protocol used during previous surveys by The Academy of Natural Sciences (ANSP SOP S-0401), although the overall collecting effort in 2000 (and also 1998-1999) may exceed recent efforts (e.g., 1990-1997) at these same sites.

Aquatic insects were collected from each station by sweeping a D-net through roots and submerged detritus; by removing medium-sized rocks and woody debris from the river, placing them in a bucket, and scrubbing them with a brush; by scrubbing submerged substrates (e.g., pilings in the river) with a net held downstream to collect dislodged specimens; by handpicking specimens from natural substrates (leaves, wood, etc.); and by sieving smaller sediments through 4.76-mm, $1.47-\mathrm{mm}$, and $125-\mu \mathrm{m}$ mesh sieves. Collected material was examined in enamel pans, insects were separated into larger taxonomic groups (e.g., orders), and all specimens were preserved in $90 \%$ ETOH immediately. Observations concerning important ecological characteristics such as depth, velocity, siltation, algal and weed growth, and physical disturbance were noted in the field. Additional notes were made concerning the distribution, relative abundance, and habitat preference of particular species.

All specimens were brought to the Stroud Water Research Center (SWRC). In the laboratory, the contents of each sample jar were transferred to petri dishes, and specimens identified to the lowest practical level (usually species), depending on size and condition of the individual specimens, and the availability of taxonomic keys. Identifications were done with the aid of a dissecting microscope (4-50 X magnification) or compound microscope (40-1000 X magnification). Chironomids were not subsampled in 2000 , and all collected specimens were identified to genus. Selected specimens collected in 2000 have been incorporated into the permanent collections at the SWRC. Various terms including uncommon, rare, moderately abundant, abundant, and dominant are used in discussing the results of qualitative sampling and refer only to the relative size of populations in the opinion of the collectors.

Hypotheses concerning potential effects of effluent/runoff from the SRS were defined a priori. For aquatic insects, a 
negative impact resulting from SRS effluent was defined as a meaningful decrease in Total Richness, a decrease in richness of a pollution-sensitive group such as mayflies, or a decrease in relative abundance of a pollution-sensitive group such as mayflies (Weiderholm 1984). These decreases could be apparent at Stations 2B, 5 and/or 6. Declines in richness would reflect the rareness or absence of species (or species groups), especially those known to be pollution sensitive (Hilsenhoff 1987, Lenat 1993). Concurrently, the relative abundance of pollution-tolerant species (or species groups) may increase (Weiderholm 1984). Personal judgment (i.e., for J.K. Jackson, Ph.D., D.A. Lieb, D.H. Funk) based on $>40$ years of field and laboratory experience, the 2000 data, and the historical data from the Savannah River near the SRS was used to evaluate the conditions at each station and the significance of differences among stations.

These data were summarized in tables and figures that list all taxa found at the separate stations, total numbers of species in each major order for each station and across stations, and total numbers of species for each station and across stations. Longterm qualitative data (1965-2000) for late spring/summer were available for Stations 1, 5 and 6, but not Station 2B. Long-term qualitative data for late summer/fall were available for Stations 1, 5 and 6 (1955-2000) and Station 2B (19852000). The long-term data for the Savannah River near the SRS presented in this report are from ANSP (1974a), ANSP (1977), ANSP (1980b), ANSP (1981a), ANSP (1985b), ANSP (1990a), ANSP (1991a), ANSP (1992b,c), ANSP (1993b), ANSP (1994a,b), ANSP (1996a), and ANSP (1996b). Additional data may be available from other surveys, and will provide further perspective in future assessments as these data are incorporated into the comparisons.

\section{Quantitative Sampling}

F loating artificial substrates (insect "traps") were used to provide quantitative samples of insect abundance, even if high flow conditions made qualitative collections difficult. Traps were constructed of $0.64-\mathrm{cm}(0.25-\mathrm{in})$ mesh hardware cloth in the form of a box, with dimensions of $15.2 \mathrm{~cm} \times 20.3 \mathrm{~cm} \times 30.5 \mathrm{~cm}$ (6 x $8 \times 12$ in). Each trap was filled with 9-10 rectangular sheets (approximately $20.3 \times 30.5$ $\mathrm{cm}$ ) of Conservation Webbing (3M Company) to provide an 
interior substrate for aquatic insects. One rectangular piece of Styrofoam was added to the top of each trap for buoyancy because traps that sink tend to fill with silt, contain fewer insects, and can be difficult to retrieve in the field. The traps were tied to tree branches or pilings and left floating in the water. Four traps were placed in the field at the beginning of the colonization period. After colonization, the traps that remained (3-4 of the 4 placed in the field) were removed from the river and placed separately in large plastic tubs. Upon retrieval, current velocities varied among traps (i.e., some traps were retrieved from slow current while others were retrieved from fast current). On shore, the insects were removed from the traps by placing the traps in a water-filled basin (20-gallon) and rinsing each piece of Conservation Webbing with clean river water from a battery powered pump. Slapping the webbing against the side of the basin also helped dislodge some specimens. Then, each piece of webbing was scrubbed with a large plastic brush and clean river water was sprayed onto the webbing to remove the last of the attached detritus/insects. Finally, the contents of the holding tub and wash basin were poured through a pair of sieves which included a homemade sieve with $1.8 \times 1.4-\mathrm{mm}$ rectangular mesh (used in 1997 and earlier and referred to as the coarse sieve) followed by a standard $0.5 \times 0.5-\mathrm{mm}$ mesh sieve (used in 1998 and 1999 and referred to as the fine sieve). All material (both insects and detritus) retained by the coarse sieve was transferred into a jar containing $10 \%$ buffered formalin. All material retained by the fine sieve was transferred into a separate jar which also contained $10 \%$ buffered formalin. Material retained by the coarse sieve was kept separate from that retained by the fine sieve in order to examine the potential impact of a reduction in mesh size (from $1.8 \times 1.4-\mathrm{mm}$ to 0.5 $x$ 0.5-mm; done at the request of the SRS) on the quantitative data and allow samples collected in 2000 to be compared to those collected prior to 1998. Each sample was labeled (with permanent black ink) on the lid and outside of the jar with information concerning river, station, date, and trap number. Notes pertaining to trap placement, conditions, and any other pertinent information were recorded in the field notebook. Samples were transported to the Stroud Center and stored until processing.

In the laboratory, 3-4 trap samples from each site and sampling date were processed. Each trap sample was split into 
four subsamples (each =1/4th of a sample unit), one of these subsamples was split again into four subsamples (each = $1 / 16$ th of a sample unit), and finally one of these subsamples was split into four subsamples (each $=1 / 64$ th of a sample unit). Subsamples were then processed (sorted and identified) until 100-200 individuals were examined. Since macroinvertebrate densities varied across sites and seasons, some samples required more processing than others (i.e., some samples were processed in their entirety while for other samples a $1 / 64$ th produced the required number of insects). Sample processing involved separating the aquatic insects from the detritus under a dissecting microscope and, as with the qualitative samples, specimens were identified to the lowest practical level (usually species). The level of identification depended on the size and condition of the individual specimens and the availability of taxonomic keys. Identifications were done with the aid of a dissecting microscope (4-50 X magnification) or compound microscope (40-1000 X magnification). All chironomids (as opposed to a subset as in years prior to 1998) in a subsample were identified to genus. Individuals of each taxon from a given sample were enumerated and most taxa were placed in separate vials and preserved in $80 \%$ ETOH for future reference. Selected specimens collected in 2000 have been incorporated into the permanent collections at the SWRC. Our ability to separate insects from detritus and other material (i.e., our removal efficiency) was tested by resorting $15 \%$ of the samples we processed. Results of resorting indicate that our removal efficiency averaged $95 \%$.

There is no single descriptor of aquatic insect assemblages that is generally accepted as better than all others (i.e., most accurate, most sensitive, most reliable, etc). Thus, the quantitative data were summarized as estimates of density for individual species or groups of species. Nine metrics, which are commonly used in water quality monitoring programs, were also calculated. Each of the variables described below is calculated from the same data set, which results in a certain degree of redundancy among the descriptors. Thus, when meaningful changes in aquatic insect assemblages occur, those changes would be expected to affect more than one descriptor. 


\section{Density}

D

ensities of selected genera/species (i.e., usually those that averaged $>100$ individuals/trap at any station in at least one season) were examined. This included pollution-sensitive taxa [e.g., many Ephemeroptera (mayflies), Plecoptera (stoneflies), Trichoptera (caddisflies)] and pollution-tolerant taxa [e.g., many Diptera (true flies), Odonata (dragonflies, damselflies), and Coleoptera (beetles)]. In response to moderate exposure to pollution, a decrease in the density of pollution-sensitive taxa accompanied by an increase in density of pollution-tolerant species would be predicted. In some cases, species densities were pooled together (i.e., to estimate densities of genera, families, orders, etc.) because densities were low and/or pooled groups provided a statistical resolution that was not available otherwise. Densities of Ephemeroptera, Plecoptera, and Trichoptera are commonly pooled together and analyzed as a group (EPT density) to assess changes in water/habitat quality in streams and rivers. Species in this group are generally more pollution-sensitive than other taxa; thus, a decrease in EPT density would be predicted in response to moderate exposure to pollution. All density data were In transformed, a standard procedure to correct for the clumped spatial dispersion of invertebrate populations in rivers (Elliott 1977).

\section{Total Richness}

otal Richness summarizes species responses (as pres-
ence/absence but not abundance) of all taxa, includ-
ing pollution-sensitive and pollution-tolerant taxa. It is reported as the mean number of aquatic insect taxa found in each subsample. Total Richness generally decreases in response to moderate to severe pollution. Total Richness is often split into EPT Richness and Chironomid Richness. Total Richness calculations, as with other calculations of richness, were conservative for all groups except chironomids. This means that a genus (family) was not included in counts of richness if one or more species (genera) within that genus (family) had already been counted. In addition, an order was not included in richness counts if one or more genera or families within the order had already been counted. In contrast, all taxa were included in chironomid richness counts (e.g., both 
Cricotopus spp. and Cricotopus bicinctus grp. were included in richness counts).

\section{EPT Richness}

7 PT Richness is reported as the mean number of Ephemeroptera, Plecoptera, and Trichoptera species found in each subsample. These three insect orders contain many pollution-sensitive taxa; thus, this metric summarizes responses of mostly pollution-sensitive taxa. EPT Richness generally decreases in response to moderate to severe pollution, and can be somewhat more responsive to environmental change than Total Richness.

\section{Chironomid Richness}

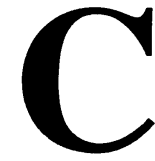
hironomid Richness is reported as the mean number of chironomid midge genera/species found in each subsample. In terms of richness and abundance, the family Chironomidae is generally the most dominant family of aquatic insects in streams and rivers. In the Savannah River, chironomid midges represent about $30 \%$ of Total Richness and about $50 \%$ of density. Pollution tolerances among the species range from sensitive (e.g., similar to many Ephemeroptera, Plecoptera, or Trichoptera) to very tolerant, and are similar to the range generally observed across all non-chironomid species of aquatic insect species. Chironomid Richness generally decreases in response to moderate to severe pollution, as more sensitive species are no longer able to survive at a site. Because some species are very tolerant, Chironomid Richness often represents most of Total Species Richness in cases of severe pollution.

\section{Species Diversity}

$\mathbf{S}$ pecies diversity (Shannon-Wiener Index) integrates both Total Richness and evenness (i.e., how individuals are apportioned across taxa); all taxa are included. Species diversity is estimated with data from each sample, and summarized as a mean. Species Diversity generally decreases in response to moderate to severe pollution. 


\section{\% Chironomidae}

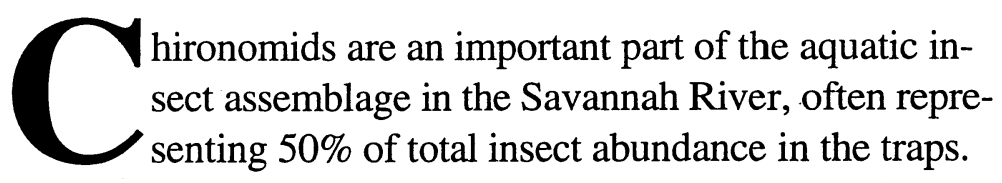

While some chironomid species are sensitive to pollution (see Chironomid Richness above), other chironomid species are very tolerant of pollution (more than any Ephemeroptera, Plecoptera, or Trichoptera) and actually increase in abundance in response to moderate to severe pollution. Thus, while Chironomid Richness may decrease as more sensitive species are lost, \% Chironomidae (i.e., \% of total insect density) often increases in response to moderate to severe pollution. As with other percentage based metrics (see \% Dominance-1, and $\%$ Dominance-5 below), percent Chironomid data were arc sine square root transformed before statistical analyses, a standard procedure for percentage data (Elliott 1977).

\section{$\%$ Dominance-1}

ercent Dominance- 1 is the percent contribution (\% of
total density) of the taxon with the greatest abundance
in a given sample. Percent Dominance often increases in response to moderate to severe pollution, similar to \% Chironomidae.

\section{$\%$ Dominance-5}

ercent Dominance- 5 is the percent contribution (\% of
total density) of the five taxa (rather than a single
taxon, see above) with the greatest abundance in a given sample. Percent Dominance-5 often increases in response to moderate to severe pollution, similar to \% Chironomidae. This metric was recently found to be more informative than \% Dominance-1 using data from over 450 sites in Maryland, Pennsylvania, Virginia and West Virginia (Smith and Voshell 1997).

\section{Hilsenhoff Biotic Index}

$$
\begin{aligned}
& \text { nalyses involving abundance (i.e., density) or pres- } \\
& \text { ence/absence (richness) are only able to incorporate } \\
& \text { pollution tolerance information indirectly, through }
\end{aligned}
$$


the interpretation of results for individual taxa or groups of taxa. Biotic indices combine abundance data and pollution tolerance values for each taxon to form a weighted average for the aquatic insects at that site. A biotic index is estimated with data from each sample, and summarized as a mean per sample. Tolerance values (values range from 0 to 10 , with 10 being most tolerant and 0 being least tolerant of pollution) for the Hilsenhoff Biotic Index (HBI) were obtained from Hilsenhoff (1987) and Plafkin et al. (1989). These tolerance values generally address only genera; thus, family values were derived from generic identifications.

\section{NC Biotic Index}

$\mathbf{S}$ imilar to the Hilsenhoff Biotic Index, the North Carolina Biotic Index (NCBI) combines abundance data and pollution tolerance values for each taxon to form a weighted average for the aquatic insects at that site. Tolerance values for this analysis were obtained during intensive studies by David Lenat and his colleagues (Lenat 1993, personal communication) in numerous streams and rivers throughout North Carolina. Thus, the data may be more applicable to the Savannah River than tolerance values derived by Hilsenhoff (1987) or Plafkin et al. (1989). Tolerance values are estimated for species when possible (values range from 0 to 10 , with 10 being most tolerant and 0 being least tolerant to pollution). The variation among species within some genera illustrate the value of species identifications, and contribute to the differences often observed between HBI and NCBI.

\section{Statistical Analysis of Abundance and Community Structure Data}

The primary objective of our quantitative data analysis of the 2000 data was to examine two principal questions: (1) How did the aquatic insect assemblages at the individual stations compare with each other in 2000, and (2) How did the aquatic insect assemblages in April and September compare with each other in 2000. More specifically, we sought to determine whether the aquatic insect assemblage (as described by abundance of certain species or groups of species, or summary indices) at Stations 2B, 5 and 6 (three 
stations potentially affected by SRS) differed significantly from Station 1 (the reference station), if the aquatic insect assemblages differed among Stations 2B, 5 and 6, or if aquatic insect assemblages differed among seasons. Our primary approach to addressing these questions involved using all of the data collected in 2000. Variation among stations and seasons was examined using a two-way fixed effects analysis of variance (ANOVA; station, season, station-season interaction), with a Tukey's multiple range test to determine the significance of station or season differences. The null hypothesis was that the aquatic insect assemblages did not differ significantly among stations or between seasons in 2000. All analyses employed the General Linear Models procedure of the SAS (1985) Statistical Analysis System. If differences between stations were observed for any variable, we attempted to determine whether these differences could be attributed to an effect of effluent or runoff from SRS by comparing the differences with responses predicted $a$ priori for that variable, and with responses observed for other variables. Differences that did not conform or appeared to be contradictions (e.g., Total Richness increases while EPT Richness decreases) with respect to $a$ priori predictions were considered inconsistent with a SRS effect. Differences found for only one variable (e.g., for one sensitive species but not several other sensitive species) were interpreted cautiously as differences among stations can also result from natural variability that is not related to SRS. Means and standard errors presented in this report were calculated with untransformed data.

In addition to our primary objective (see above), we sought to determine if a reduction in the size of the mesh used during field processing (see qualitative sampling method section for details of this change) affected density estimates for common taxa and groups of taxa (Total Density, EPT Density, and Chironomidae Density). We also sought to determine if this change affected estimates of selected community structure indices (Total Richness, EPT Richness, Chironomidae Richness, \% Dominance-5 taxa, \% Chironomidae, ShannonWiener Diversity, and NCBI). This evaluation included comparisons of stations and seasons based on both density and community structure. Results based on pooled collections, which consisted of individuals caught by the coarse sieve (1.8 $\mathrm{x} 1.4 \mathrm{~mm}$ ) combined with individuals that passed through the coarse sieve but were caught by the fine sieve $(0.5 \times 0.5 \mathrm{~mm})$, 
were compared to those based on the coarse-sieve collections. The results needed for these comparisons were obtained using ANOVAs and Tukey's tests as described in the preceding paragraph. Prior to comparisons of community structure (but not density), all samples and fractions were standardized because the pooled collections retained more insects than the coarse-sieve collections. Standardization was necessary because some measures of community structure (those based on richness) generally increase as the number of individuals examined increase. Therefore, richness measures would be expected to be higher in the pooled collections than in the coarse-sieve collections due to the presence of more individuals in the pooled collections. To compensate for this potential bias, we used a computer program that employed a resampling without replacement routine, to standardize samples to a preset number of individuals. In this case, 92 was selected because $\geq 92$ individuals were found in all subsamples examined. Because we were able to standardize samples (i.e., eliminate the bias resulting from the retention of more individuals by the small mesh than by the large mesh), the effect of a reduction in mesh size on estimates of community structure could reliably be assessed.

\section{Results}

\section{Qualitative Collections at Station 1}

\section{April 2000}

total of 89 taxa including 29 EPT taxa was collected
in April 2000 from Station 1 (Tables D-2 and D-3).
Of these EPT taxa one mayfly (Baetis intercalaris), one stonefly (Perlesta spp.), and three caddisflies (Hydropsyche mississippiensis, Hydropsyche rossi, and Ceraclea maculata) were abundant. The mayfly Baetis intercalaris and the hydropsychid caddisflies were most abundant among woody debris in moderate to fast current. The corixid Trichocorixa calva and the dytiscid beetles (mainly Neoporus venustus and Coptotomus nr. loticus) were abundant in backwater areas. Another beetle, Stenelmis hungerfordi, was also abundant. A number of rare taxa [i.e., those taxa represented by a com- 
Table D-2. List of aquatic insects collected from the Savannah River at Stations 1, 2B, 5 and 6 in the vicinity of the SRS in April and September 2000. Qualitative columns represent hand collections from all available habitats at each station. Quantitative columns are data from traps suspended on the river's surface. $\mathrm{X}$ indicates presence of a taxon; - indicates none was collected at that station.

\begin{tabular}{|c|c|c|c|c|c|c|c|c|c|c|c|c|c|c|c|c|}
\hline & \multicolumn{8}{|c|}{ Qualitative } & \multicolumn{8}{|c|}{ Quantitative } \\
\hline & \multicolumn{4}{|c|}{ April } & \multicolumn{4}{|c|}{ September } & \multicolumn{4}{|c|}{ April } & \multicolumn{4}{|c|}{ September } \\
\hline & 1 & $2 \mathrm{~B}$ & 5 & 6 & 1 & $2 \mathbf{B}$ & 5 & 6 & 1 & 2B & 5 & 6 & 1 & 2B & 5 & 6 \\
\hline \multicolumn{17}{|l|}{ Phylum Arthropoda } \\
\hline \multicolumn{17}{|l|}{ Class Insecta } \\
\hline \multicolumn{17}{|l|}{ Order Odonata } \\
\hline \multicolumn{17}{|l|}{ Suborder Anisoptera } \\
\hline \multicolumn{17}{|l|}{ Family Aeshnidae } \\
\hline Boyeria vinosa & $\mathrm{x}$ & 一 & $\mathrm{X}$ & - & - & - & $\mathrm{x}$ & $\mathrm{x}$ & 一 & - & - & - & - & - & - & - \\
\hline Nasiaeschna pentacantha & 一 & $\mathrm{x}$ & - & $\mathrm{x}$ & - & - & - & - & - & 一 & - & - & - & 一 & - & - \\
\hline Family Corduliidae & - & - & - & - & $\mathrm{x}$ & $\mathbf{x}$ & $\mathbf{x}$ & - & - & - & - & - & $\mathrm{x}$ & $\mathrm{x}$ & $\mathbf{x}$ & $\mathrm{x}$ \\
\hline \multicolumn{17}{|l|}{ Subfamily Corduliinae } \\
\hline Epitheca (=Epicordulia) princeps & $\mathrm{x}$ & - & - & 一 & $\mathrm{x}$ & $\mathbf{x}$ & - & - & - & - & 一 & - & - & - & 一 & - \\
\hline Neurocordulia spp. & - & - & - & - & $\mathrm{x}$ & - & $\mathbf{x}$ & - & - & - & - & - & - & - & - & - \\
\hline Neurocordulia alabamensis & - & - & $\mathrm{x}$ & 一 & - & - & - & - & - & - & - & - & - & - & - & - \\
\hline Neurocordulia molesta & $\mathrm{x}$ & 一 & - & - & - & $\mathrm{x}$ & - & - & 一 & - & 一 & - & - & 一 & - & - \\
\hline Subfamily Macromiinae & - & - & - & $\mathrm{x}$ & - & - & 一 & - & - & - & - & - & - & - & - & - \\
\hline Didymops transversa & - & $\mathrm{x}$ & $\mathrm{x}$ & $\mathrm{x}$ & $\mathrm{x}$ & 一 & $\mathrm{x}$ & $\mathrm{x}$ & $\mathrm{x}$ & - & $\mathrm{x}$ & - & - & 一 & $\mathrm{x}$ & $\mathrm{x}$ \\
\hline Macromia spp. & $\mathrm{x}$ & $\mathrm{x}$ & $\mathrm{x}$ & 一 & $\mathrm{x}$ & $\mathrm{x}$ & $\mathrm{x}$ & 一 & - & 一 & - & 一 & - & - & - & - \\
\hline Macromia illinoiensis georgina & $\mathrm{x}$ & $\mathrm{x}$ & $\mathbf{x}$ & $\mathrm{x}$ & $\mathrm{x}$ & $\mathrm{x}$ & $\mathrm{x}$ & $\mathrm{x}$ & - & - & - & - & - & - & - & - \\
\hline Family Gomphidae & 一 & $\mathrm{x}$ & - & - & - & - & - & - & - & - & - & - & - & - & - & - \\
\hline Dromogomphus spinosus & $\mathrm{x}$ & - & - & - & 一 & $\mathrm{x}$ & $\mathrm{x}$ & - & - & - & 一 & - & - & - & - & - \\
\hline Gomphus sp. & - & - & $\mathrm{x}$ & - & 一 & - & 一 & - & - & 一 & - & - & - & - & $\longrightarrow$ & - \\
\hline Gomphus lividus & $\mathrm{x}$ & - & - & - & - & - & - & - & - & - & - & - & - & 一 & - & - \\
\hline Gomphus parvidens & - & - & - & $\mathrm{x}$ & - & - & - & - & - & - & - & - & - & - & - & - \\
\hline Gomphus vastus & $\mathrm{x}$ & $\mathrm{x}$ & $\mathrm{x}$ & $\mathrm{x}$ & $\mathrm{x}$ & - & 一 & - & - & - & - & - & - & - & - & - \\
\hline Hagenius brevistylus & - & - & - & $\mathrm{x}$ & - & - & - & - & $\mathbf{x}$ & $\mathrm{x}$ & - & $\mathrm{x}$ & - & - & - & - \\
\hline Promogomphus sp. & 一 & - & - & - & 一 & - & $\mathbf{x}$ & - & - & - & - & - & - & - & - & - \\
\hline Stylurus sp. & - & - & - & - & - & - & $\dot{-}$ & $\mathbf{x}$ & - & - & - & - & - & - & - & - \\
\hline Stylurus & - & - & - & $\mathbf{x}$ & - & - & - & - & - & - & - & - & - & - & - & - \\
\hline Stylurus nr. notatus & $\mathrm{x}$ & $\mathrm{x}$ & $\mathrm{x}$ & $\mathrm{x}$ & $\mathrm{x}$ & 一 & $\mathrm{x}$ & $\mathrm{x}$ & - & - & - & - & - & - & - & - \\
\hline \multicolumn{17}{|l|}{ Family Libellulidae } \\
\hline Libellula sp. & - & - & - & - & $\mathrm{x}$ & - & 一 & - & 一 & 一 & - & - & - & - & - & - \\
\hline \multicolumn{17}{|l|}{ Suborder Zygoptera } \\
\hline Family Calopterygidae & 一 & - & - & - & 一 & $\mathrm{x}$ & - & 一 & - & 一 & 一 & - & - & 一 & - & - \\
\hline Calopter & - & - & $\mathrm{x}$ & - & 一 & - & 一 & $\mathrm{x}$ & - & - & 一 & - & - & - & - & - \\
\hline Hetaerina americana & - & - & - & - & 一 & $\mathbf{x}$ & 一 & $\mathrm{x}$ & - & - & - & - & - & - & - & - \\
\hline Hetaerina titia & - & - & - & - & - & - & $\mathbf{x}$ & $\mathbf{x}$ & - & - & - & - & - & - & $\mathbf{x}$ & 一 \\
\hline Tamily Coenagrionidae & 一 & - & - & - & 一 & $\mathbf{x}$ & - & - & 一 & - & - & - & - & $\mathrm{x}$ & $\mathrm{x}$ & $\mathrm{x}$ \\
\hline Argia spp. & $\mathrm{x}$ & $\mathrm{x}$ & $\mathrm{x}$ & $\mathrm{x}$ & $\mathrm{x}$ & 一 & $\mathbf{x}$ & - & - & - & - & - & $\mathrm{x}$ & $\mathrm{x}$ & $\mathbf{x}$ & $\mathrm{x}$ \\
\hline Argia apicalis & $\mathbf{x}$ & 一 & - & $\mathrm{x}$ & - & - & - & - & 一 & - & 一 & - & - & 一 & - & - \\
\hline Argia moesta/translata & - & - & - & - & - & - & - & - & - & - & - & - & 一 & $\mathrm{x}$ & - & - \\
\hline Argia sedula & - & - & $\mathrm{x}$ & $\mathrm{x}$ & - & 一 & $\mathbf{x}$ & $\mathbf{x}$ & - & - & 一 & - & - & - & - & - \\
\hline Argia tibialis & $\mathrm{x}$ & $\mathrm{x}$ & $\mathrm{x}$ & $\mathrm{x}$ & $\mathrm{x}$ & $\mathbf{x}$ & - & - & - & - & - & - & - & $\mathrm{X}$ & $\mathrm{x}$ & - \\
\hline Argia translata & - & $\mathrm{x}$ & $\mathbf{x}$ & 一 & $\mathrm{x}$ & - & $\longrightarrow$ & $\mathrm{x}$ & - & - & - & - & - & - & $\mathbf{x}$ & - \\
\hline Enallagma spp. & - & $\mathrm{x}$ & $\mathbf{x}$ & $\mathrm{x}$ & $\mathrm{x}$ & - & $\mathrm{x}$ & $\mathrm{x}$ & - & $\mathbf{X}$ & - & - & $\mathbf{X}$ & $\mathbf{x}$ & $\mathbf{x}$ & $\mathrm{x}$ \\
\hline Enallagma basidens & $\mathrm{x}$ & 一 & 一 & - & $\mathrm{x}$ & $\mathrm{x}$ & - & 一 & - & - & 一 & - & - & - & - & - \\
\hline Enallagma nr. divagans & $\mathbf{x}$ & $\mathrm{x}$ & $\mathrm{x}$ & $\mathrm{x}$ & - & - & - & - & - & - & - & - & - & - & - & - \\
\hline Enallagma signatum & - & 一 & $\mathrm{x}$ & - & - & 一 & - & - & - & - & - & - & - & - & $\mathbf{x}$ & - \\
\hline Ischnura pesita & $\mathbf{X}$ & - & - & - & - & - & - & - & - & - & - & - & - & - & - & - \\
\hline
\end{tabular}


Table D-2 (continued). List of aquatic insects collected from the Savannah River at Stations 1, 2B, 5, and 6 in the vicinity of the Savannah River Site in April and September 2000. Qualitative columns represent hand collections from all available habitats at each station. Qualitative columns are data from traps suspended on the river's surface. $\mathrm{X}$ indicates presence of a taxon; - indicates none was collected at that station.

\begin{tabular}{|c|c|c|c|c|c|c|c|c|c|c|c|c|c|c|c|c|}
\hline & \multicolumn{8}{|c|}{ Qualitative } & \multicolumn{8}{|c|}{ Quantitative } \\
\hline & \multicolumn{4}{|c|}{ April } & \multicolumn{4}{|c|}{ September } & \multicolumn{4}{|c|}{ April } & \multicolumn{4}{|c|}{ September } \\
\hline & 1 & $2 \mathrm{~B}$ & 5 & 6 & 1 & $2 \mathrm{~B}$ & 5 & 6 & 1 & $2 \mathbf{B}$ & 5 & 6 & 1 & $2 B$ & 5 & 6 \\
\hline Order Ephemeroptera & 一 & - & - & $\mathrm{x}$ & - & - & - & - & $\mathrm{x}$ & - & $\mathbf{x}$ & - & 一 & $\mathbf{x}$ & 一 & 一 \\
\hline Family Baetidae & 一 & $x$ & - & - & - & - & $\mathrm{x}$ & - & $\mathrm{x}$ & $\mathrm{x}$ & $\mathrm{x}$ & $\mathrm{x}$ & $\mathrm{x}$ & - & $\mathbf{x}$ & $\mathrm{x}$ \\
\hline Acerpenna pygmaea & - & - & - & - & - & - & $\mathrm{x}$ & - & - & 一 & - & - & - & 一 & - & - \\
\hline Baetis spp. & 一 & - & $\mathrm{x}$ & $\mathrm{x}$ & - & - & - & - & $\mathrm{x}$ & $\mathrm{x}$ & $\mathrm{x}$ & - & $\mathrm{x}$ & $\mathbf{x}$ & - & $\mathbf{x}$ \\
\hline Baetis intercalaris & $\mathrm{x}$ & $\mathrm{x}$ & $\mathrm{x}$ & $\mathrm{x}$ & $\mathrm{x}$ & $x$ & $\mathrm{x}$ & $\mathrm{x}$ & $\mathrm{x}$ & $\mathrm{x}$ & $\mathrm{x}$ & $\mathbf{x}$ & $\mathrm{x}$ & $\mathrm{x}$ & $\mathrm{x}$ & $\mathrm{x}$ \\
\hline Callibaetis spp. & 一 & - & - & - & $\mathrm{x}$ & $\mathrm{x}$ & - & - & - & - & - & - & 一 & - & 一 & - \\
\hline Centroptilum/Procloeon spp. & $\mathrm{x}$ & $\mathrm{x}$ & $\mathrm{x}$ & $\mathbf{x}$ & $\mathrm{x}$ & $\mathrm{x}$ & $\mathrm{x}$ & $\mathrm{x}$ & - & $\mathrm{x}$ & - & 一 & $\mathrm{x}$ & - & - & - \\
\hline Labiobaetis propinquus grp. & - & $\mathrm{x}$ & $\mathrm{x}$ & $\mathrm{x}$ & $\mathrm{x}$ & $\mathrm{x}$ & $\mathbf{x}$ & $\mathbf{x}$ & $\mathrm{x}$ & $\mathrm{x}$ & $\mathrm{x}$ & $\mathrm{x}$ & $\mathrm{x}$ & $\mathbf{x}$ & $\mathrm{x}$ & $\mathrm{x}$ \\
\hline Plauditus spp. & - & $\mathrm{x}$ & $\mathrm{x}$ & $\mathrm{x}$ & - & $-\quad x$ & - & - & $\mathrm{X}$ & - & - & 一 & - & - & - & - \\
\hline Family Caenidae & - & 一 & - & - & - & - & - & - & $\mathrm{x}$ & $\mathrm{x}$ & $\mathbf{x}$ & - & - & - & - & $\mathrm{x}$ \\
\hline Amercaenis ridens & 一 & - & 一 & - & - & - & - & $\mathrm{x}$ & 一 & - & - & - & - & 一 & - & $\mathrm{x}$ \\
\hline Caenis spp. & - & - & $\mathrm{x}$ & $\mathrm{x}$ & - & - & 一 & - & - & - & - & - & $\mathrm{x}$ & $\mathbf{x}$ & $\mathrm{x}$ & - \\
\hline Caenis diminuta & - & 一 & - & - & $\mathrm{x}$ & - & - & - & $\mathrm{x}$ & - & - & 一 & - & 一 & 一 & - \\
\hline Caenis diminutalamica & $\mathrm{x}$ & 一 & 一 & - & - & $\mathrm{x}$ & 一 & $\mathrm{x}$ & - & - & - & - & - & 一 & - & - \\
\hline Caenis nr. hilaris & - & $\mathrm{x}$ & 一 & - & $\mathrm{x}$ & $\mathrm{x}$ & $\mathrm{x}$ & $\mathrm{x}$ & 一 & - & 一 & - & $\mathrm{x}$ & $\mathrm{x}$ & $\mathbf{x}$ & $\mathrm{x}$ \\
\hline Family Ephemerellidae & - & 一 & 一 & - & 一 & - & 一 & - & 一 & $\mathrm{x}$ & $\mathbf{x}$ & $\mathrm{x}$ & - & - & - & - \\
\hline Ephemerella spp. & - & $\mathrm{x}$ & $\mathbf{x}$ & - & - & - & - & - & - & - & $\mathrm{x}$ & 一 & - & - & - & - \\
\hline Ephemerella argo & $\mathbf{x}$ & $\mathrm{x}$ & $\mathbf{x}$ & $\mathrm{x}$ & - & - & 一 & 一 & - & $\mathrm{x}$ & $\mathbf{x}$ & - & - & 一 & - & - \\
\hline Ephemerella dorothea & $\mathrm{x}$ & $\mathrm{x}$ & $\mathrm{x}$ & $\mathrm{x}$ & 一 & 一 & - & - & - & $\mathrm{x}$ & $\mathrm{x}$ & $\mathrm{x}$ & - & 一 & - & - \\
\hline Eurylophella doris & $\mathrm{x}$ & $\mathrm{x}$ & $\mathrm{x}$ & $\mathrm{x}$ & - & - & - & - & - & $\mathrm{x}$ & $\mathrm{x}$ & 一 & - & - & - & - \\
\hline Serratella sp. & - & - & - & $\mathbf{x}$ & 一 & - & 一 & - & - & 一 & $\mathrm{x}$ & 一 & - & - & - & - \\
\hline Serratella deficiens & - & $\mathrm{x}$ & - & - & 一 & - & $\mathrm{x}$ & 一 & - & - & - & - & - & - & - & 一 \\
\hline \multicolumn{17}{|l|}{ Family Ephemeridae } \\
\hline Hexagenia spp. & $\mathrm{x}$ & $\mathrm{x}$ & 一 & - & 一 & - & - & $\mathrm{x}$ & - & - & - & 一 & 一 & 一 & 一 & - \\
\hline Family Heptageniidae & - & $\mathrm{x}$ & 一 & $\mathbf{x}$ & - & - & - & - & $\mathrm{x}$ & $\mathrm{x}$ & $\mathrm{x}$ & $\mathrm{x}$ & $\mathrm{x}$ & $\mathrm{x}$ & $\mathbf{x}$ & $\mathbf{x}$ \\
\hline Heptagenia spp. & $\mathbf{x}$ & $\mathrm{x}$ & $\mathbf{x}$ & - & - & - & - & - & - & - & - & - & - & - & 一 & - \\
\hline Heptagenia diabasia & $\mathrm{x}$ & - & - & - & - & - & - & - & - & 一 & 一 & - & - & - & - & - \\
\hline Heptagenia flavescens & 一 & $\mathbf{x}$ & $\mathrm{x}$ & $\mathbf{x}$ & 一 & - & - & - & - & $\mathbf{x}$ & - & - & - & - & 一 & 一 \\
\hline Macdunnoa sp. & 一 & - & $\mathrm{x}$ & $\mathbf{x}$ & - & - & - & - & - & $\mathbf{x}$ & - & - & - & - & 一 & 一 \\
\hline Stenonema spp. & 一 & $\mathrm{x}$ & $\mathrm{x}$ & 一 & - & - & 一 & - & $\mathrm{x}$ & $\mathrm{x}$ & $\mathbf{x}$ & $\mathrm{x}$ & $\mathrm{x}$ & $\mathrm{x}$ & $\mathrm{x}$ & $\mathrm{x}$ \\
\hline Stenonema exiguum & $\mathrm{x}$ & $\mathrm{x}$ & $\mathbf{x}$ & $\mathbf{x}$ & - & - & $\mathbf{x}$ & $\mathbf{x}$ & - & $\mathrm{x}$ & 一 & $\mathrm{x}$ & 一 & - & 一 & $\mathbf{x}$ \\
\hline Stenonema mexicanum integrum & $\mathbf{x}$ & $\mathrm{x}$ & $\mathrm{x}$ & $\mathbf{x}$ & - & $\mathrm{x}$ & $\mathbf{x}$ & $\mathrm{x}$ & - & $\mathrm{x}$ & $\mathrm{x}$ & $\mathbf{x}$ & $\mathbf{x}$ & $\mathbf{x}$ & $\mathbf{x}$ & $\mathbf{x}$ \\
\hline Stenonema modestum & $\mathbf{x}$ & $\mathrm{x}$ & $\mathrm{x}$ & $\mathbf{x}$ & - & $\mathrm{x}$ & $\mathrm{x}$ & $\mathbf{x}$ & - & $\mathbf{x}$ & $\mathrm{x}$ & - & $\mathrm{x}$ & $\mathrm{x}$ & $\mathrm{x}$ & $\mathrm{x}$ \\
\hline Stenonema terminatum & $\mathrm{x}$ & $\mathrm{x}$ & $\mathrm{x}$ & $\mathrm{x}$ & - & $\mathbf{x}$ & $\mathbf{x}$ & $\mathbf{x}$ & - & 一 & - & $\mathrm{x}$ & $\mathrm{x}$ & $\mathrm{x}$ & $\mathrm{x}$ & $\mathbf{x}$ \\
\hline Family Leptophlebiidae & - & - & - & - & - & - & - & - & - & - & - & $\mathrm{x}$ & - & - & - & - \\
\hline Leptophlebia spp. & - & - & $\mathbf{x}$ & - & - & - & - & - & - & - & - & - & - & - & - & - \\
\hline Paraleptophlebia spp. & $\mathrm{x}$ & - & - & $\mathbf{x}$ & - & - & - & - & - & - & - & - & - & - & - & - \\
\hline Family Isonychiidae & & & & & & & & & & & & & & & & \\
\hline Isonychia spp. & - & - & - & $\mathrm{X}$ & - & - & $\mathbf{x}$ & $\mathrm{x}$ & - & - & $\mathbf{x}$ & $\mathbf{x}$ & 一 & $\mathrm{x}$ & $\mathrm{x}$ & $\mathbf{X}$ \\
\hline Family Neoephemeridae & & & & & & & & & & & & & & & & \\
\hline $\begin{array}{l}\text { Neoephemera youngi } \\
\text { amily Tricorythidae }\end{array}$ & - & - & $\mathrm{x}$ & 一 & - & - & 一 & - & - & - & - & - & - & - & - & - \\
\hline Tricorythodes spp. & $\mathrm{x}$ & 一 & $\mathrm{x}$ & - & $\mathbf{x}$ & $\mathrm{x}$ & $\mathrm{x}$ & $\mathbf{x}$ & $\mathrm{x}$ & - & $\mathrm{x}$ & $\mathbf{x}$ & $\mathbf{X}$ & $\mathrm{x}$ & $\mathrm{x}$ & $\mathbf{x}$ \\
\hline Prder Plec & - & - & - & - & - & - & - & 一 & - & - & 一 & $\mathbf{x}$ & - & 一 & - & - \\
\hline amily Perlidae & - & $\mathrm{x}$ & - & - & - & - & 一 & $\mathbf{x}$ & $\mathbf{x}$ & $\mathbf{x}$ & $\mathbf{x}$ & $\mathbf{x}$ & - & - & - & $\mathrm{x}$ \\
\hline Acroneuria mela & - & - & 一 & - & - & - & - & - & - & - & - & 一 & - & - & $\mathbf{x}$ & - \\
\hline $\begin{array}{l}\text { Neoperla spp. } \\
\text { Paragnetina kans }\end{array}$ & - & - & $\overline{\mathbf{y}}$ & - & - & 一 & 一 & - & - & - & - & $\mathrm{x}$ & - & - & - & $\bar{y}$ \\
\hline & & - & $\mathrm{X}$ & $\mathbf{X}$ & & - & $\mathrm{x}$ & $\mathrm{X}$ & . & - & - & $\mathrm{X}$ & - & - & - & $\mathrm{X}$ \\
\hline
\end{tabular}


Table D-2 (continued). List of aquatic insects collected from the Savannah River at Stations 1, 2B, 5 , and 6 in the vicinity of the Savannah River Site in April and September 2000. Qualitative columns represent hand collections from all available habitats at each station. Qualitative columns are data from traps suspended on the river's surface. $X$ indicates presence of a taxon; - indicates none was collected at that station.

\begin{tabular}{|c|c|c|c|c|c|c|c|c|c|c|c|c|c|c|c|c|}
\hline & \multicolumn{8}{|c|}{ Qualitative } & \multicolumn{8}{|c|}{ Quantitative } \\
\hline & \multicolumn{4}{|c|}{ April } & \multicolumn{4}{|c|}{ September } & \multicolumn{4}{|c|}{ April } & \multicolumn{4}{|c|}{ September } \\
\hline & 1 & $2 B$ & 5 & 6 & 1 & $2 B$ & 5 & 6 & 1 & 2B & 5 & 6 & 1 & $2 B$ & 5 & 6 \\
\hline Perlesta spp. complex & $\mathrm{x}$ & $\mathrm{x}$ & $\mathrm{x}$ & $\mathrm{x}$ & 一 & - & - & - & $\mathbf{x}$ & $\mathrm{x}$ & $\mathrm{x}$ & $\mathrm{x}$ & - & - & 一 & - \\
\hline \multicolumn{17}{|l|}{ Family Pteronarcyidae } \\
\hline Pteronarcys dorsata & - & $\mathrm{x}$ & $\mathrm{x}$ & $\mathrm{x}$ & 一 & $\mathbf{x}$ & $\mathrm{x}$ & $\mathrm{x}$ & $\mathrm{x}$ & $\mathrm{x}$ & $\mathrm{x}$ & - & - & - & - & $\mathbf{x}$ \\
\hline \multicolumn{17}{|l|}{ Order Heteroptera } \\
\hline \multicolumn{17}{|l|}{ Family Belostomatidae } \\
\hline Belostoma spp. & - & - & 一 & - & $\mathbf{x}$ & - & - & 一 & - & - & - & - & 一 & - & - & - \\
\hline Belostoma lutarium & $\mathrm{x}$ & - & 一 & - & - & 一 & - & - & 一 & - & - & - & - & - & - & - \\
\hline Family Corixidae & $\mathrm{x}$ & 一 & - & $\mathrm{X}$ & $\mathrm{X}$ & $\mathrm{x}$ & $\mathrm{X}$ & - & 一 & - & 一 & - & 一 & 一 & 一 & 一 \\
\hline Palmacorixa spp. & - & - & $\mathrm{x}$ & - & $\mathrm{x}$ & - & - & - & 一 & - & - & - & - & - & - & - \\
\hline Palmacorixa nana/buenoi & $\mathbf{x}$ & - & - & $\mathrm{x}$ & $\mathrm{x}$ & 一 & - & - & - & - & - & - & - & - & - & - \\
\hline Trichocorixa spp. & 一 & - & - & - & $\mathrm{x}$ & - & - & - & 一 & - & - & - & 一 & 一 & 一 & - \\
\hline Trichocorixa calva & $\mathrm{x}$ & - & $\mathrm{x}$ & $\mathrm{x}$ & 一 & - & - & - & 一 & - & - & - & - & 一 & - & - \\
\hline Trichocorixa louisianae & 一 & - & - & $\mathbf{x}$ & 一 & - & - & - & - & - & - & - & - & 一 & - & - \\
\hline \multicolumn{17}{|l|}{ Family Gerridae } \\
\hline Metrobates spp. & 一 & - & - & - & $\mathbf{X}$ & - & $\mathbf{x}$ & $\mathbf{x}$ & - & - & 一 & - & 一 & - & 一 & - \\
\hline Metrobates hesperius & - & - & - & - & - & $\mathbf{x}$ & 一 & 一 & - & - & - & - & 一 & 一 & - & - \\
\hline Rheumatobates spp. & $\mathbf{x}$ & - & $\mathrm{x}$ & $\mathbf{x}$ & $\mathbf{x}$ & 一 & $\mathrm{x}$ & $\mathbf{x}$ & - & - & - & - & 一 & - & - & - \\
\hline Rheumatobates palosi & 一 & - & - & - & $\mathrm{x}$ & - & - & - & - & - & - & - & - & 一 & - & - \\
\hline Rheumatobates tenuipes & - & - & - & - & $\mathrm{x}$ & - & $\mathbf{x}$ & - & - & - & - & - & 一 & 一 & - & - \\
\hline Rheumatobates trulliger & - & - & - & - & - & - & $\mathrm{x}$ & 一 & - & - & - & 一 & 一 & 一 & - & - \\
\hline Trepobates spp. & - & - & - & - & $\mathrm{x}$ & $\mathrm{x}$ & - & - & - & - & - & - & - & 一 & 一 & - \\
\hline \multicolumn{17}{|l|}{ Family Naucoridae } \\
\hline Pelocoris femoratus & - & - & - & $\mathrm{x}$ & 一 & - & 一 & - & - & - & - & 一 & 一 & - & - & - \\
\hline \multicolumn{17}{|l|}{ Order Megaloptera } \\
\hline Family Corydalidae & - & 一 & - & - & - & - & - & - & - & - & 一 & - & $\mathrm{x}$ & 一 & - & - \\
\hline Chauliodes rastricornis & - & - & - & - & $\mathbf{x}$ & 一 & 一 & - & - & - & - & - & - & - & 一 & 一 \\
\hline Corydalus cornutus & - & - & - & - & $\mathbf{x}$ & $\mathrm{x}$ & $\mathbf{x}$ & 一 & 一 & - & - & - & 一 & $\mathrm{x}$ & $\mathbf{x}$ & $\mathrm{x}$ \\
\hline \multicolumn{17}{|l|}{ Order Lepidoptera } \\
\hline Family Pyralidae & - & - & - & - & $\mathbf{x}$ & - & - & $\mathbf{x}$ & - & - & - & - & 一 & 一 & - & $\mathbf{x}$ \\
\hline Parapoynx spp. & $\mathrm{x}$ & - & - & - & $\mathrm{x}$ & $\mathrm{x}$ & - & - & 一 & - & 一 & - & 一 & $\mathbf{x}$ & - & $\mathrm{x}$ \\
\hline Order Trichoptera & - & - & - & $\mathrm{x}$ & 一 & 一 & - & - & $\mathrm{x}$ & - & - & - & - & - & 一 & - \\
\hline \multicolumn{17}{|l|}{ Family Brachycentridae } \\
\hline Brachycentrus numerosus & - & - & - & $\mathbf{x}$ & - & $\mathbf{x}$ & $\mathbf{x}$ & $\mathbf{x}$ & - & 一 & 一 & - & 一 & - & 一 & 一 \\
\hline Micrasema spp. & - & $\mathrm{x}$ & 一 & $\mathbf{x}$ & - & - & - & - & 一 & - & - & 一 & 一 & 一 & 一 & - \\
\hline Family Hydropsychidae & $\mathrm{x}$ & $\mathrm{x}$ & - & $\mathbf{x}$ & - & - & $\mathbf{x}$ & - & $\mathbf{x}$ & $\mathrm{x}$ & $\mathrm{x}$ & $\mathrm{x}$ & $\mathbf{x}$ & $\mathrm{x}$ & $\mathbf{x}$ & $\mathrm{x}$ \\
\hline Cheumatopsyche spp. & - & $\mathbf{x}$ & $\mathrm{x}$ & $\mathrm{x}$ & $\mathrm{x}$ & $\mathrm{x}$ & $\mathrm{x}$ & $\mathrm{x}$ & $\mathrm{x}$ & $\mathrm{x}$ & $\mathrm{x}$ & $\mathbf{x}$ & $\mathrm{x}$ & $\mathrm{x}$ & $\mathbf{x}$ & $\mathbf{x}$ \\
\hline Hydropsyche spp. & 一 & - & - & - & 一 & - & - & - & - & 一 & $\mathbf{x}$ & $\mathbf{x}$ & $\mathbf{x}$ & 一 & - & $\mathrm{x}$ \\
\hline Hydropsyche mississippiensis & $\mathrm{x}$ & - & - & $\mathrm{x}$ & - & - & - & $\mathrm{x}$ & - & - & 一 & - & - & 一 & - & 一 \\
\hline Hydropsyche rossi & $\mathrm{x}$ & $\mathbf{x}$ & $\mathrm{x}$ & $\mathrm{x}$ & $\mathbf{x}$ & $\mathbf{x}$ & $\mathbf{x}$ & $\mathrm{x}$ & $\mathbf{x}$ & $\mathbf{x}$ & $\mathbf{x}$ & - & $\mathbf{x}$ & 一 & 一 & - \\
\hline Hydropsyche simulans & - & $\mathbf{x}$ & - & $\mathbf{x}$ & - & - & 一 & - & - & - & - & $\mathbf{x}$ & - & - & 一 & - \\
\hline Macrostemum spp. & - & - & $\mathbf{x}$ & - & - & - & - & - & - & - & - & - & 一 & 一 & - & $\mathrm{x}$ \\
\hline Macrostemum carolina & - & $\mathbf{x}$ & $\mathbf{x}$ & $\mathbf{x}$ & - & $\mathbf{x}$ & $\mathrm{x}$ & $\mathbf{x}$ & 一 & - & - & - & - & $\mathrm{x}$ & $\mathbf{x}$ & $\mathrm{x}$ \\
\hline Family Hydroptilidae & - & - & - & 一 & $\mathrm{x}$ & - & - & - & - & - & 一 & $\mathbf{x}$ & - & - & - & - \\
\hline Hydroptila spp. & $\mathrm{X}$ & $\mathbf{X}$ & $\mathrm{X}$ & $\mathrm{x}$ & $\mathrm{X}$ & $\mathrm{x}$ & $\mathbf{x}$ & - & $\mathbf{X}$ & $\mathbf{X}$ & $\mathbf{x}$ & $\mathbf{x}$ & $\mathbf{x}$ & $\mathbf{x}$ & $\mathbf{x}$ & $\mathrm{x}$ \\
\hline
\end{tabular}


Table D-2 (continued). List of aquatic insects collected from the Savannah River at Stations 1, 2B, 5 , and 6 in the vicinity of the Savannah River Site in June and September 1998. Qualitative columns represent hand collections from all available habitats at each station. Qualitative columns are data from traps suspended on the river's surface. $X$ indicates presence of a taxon; - indicates none was collected at that station.

\begin{tabular}{|c|c|c|c|c|c|c|c|c|c|c|c|c|c|c|c|c|}
\hline & \multicolumn{8}{|c|}{ Qualitative } & \multicolumn{8}{|c|}{ Quantitative } \\
\hline & \multicolumn{4}{|c|}{ April } & \multicolumn{4}{|c|}{ September } & \multicolumn{4}{|c|}{ April } & \multicolumn{4}{|c|}{ September } \\
\hline & 1 & $2 \mathbf{B}$ & 5 & 6 & 1 & 2B & 5 & 6 & 1 & $2 \mathbf{B}$ & 5 & 6 & 1 & $2 \mathbf{B}$ & 5 & 6 \\
\hline Family Leptoceridae & - & - & $\mathrm{x}$ & - & - & - & 一 & - & $\mathrm{x}$ & $\mathrm{x}$ & $\mathrm{x}$ & - & - & $\mathrm{x}$ & $\mathrm{x}$ & $\mathrm{x}$ \\
\hline Ceraclea spp. & $\mathrm{x}$ & $\mathrm{x}$ & $\mathrm{x}$ & $\mathrm{x}$ & - & $\mathrm{x}$ & $\mathrm{x}$ & - & $\mathrm{x}$ & $\mathrm{x}$ & $\mathrm{x}$ & $\mathrm{x}$ & 一 & 一 & - & - \\
\hline Ceraclea alagma & $\mathrm{x}$ & - & 一 & 一 & - & - & 一 & - & - & - & $\mathrm{x}$ & 一 & - & - & - & - \\
\hline Ceraclea cancellata & $\mathrm{x}$ & - & $\mathrm{x}$ & - & - & - & 一 & - & - & - & - & - & - & - & - & - \\
\hline Ceraclea maculata & $\mathrm{x}$ & $\mathrm{x}$ & $x$ & $\mathrm{x}$ & 一 & - & 一 & - & 一 & - & $\mathrm{x}$ & - & - & 一 & - & - \\
\hline Ceraclea nr. punctata & $\mathrm{x}$ & $\mathrm{x}$ & $\mathrm{x}$ & $\mathrm{x}$ & 一 & - & $\mathrm{x}$ & - & - & - & - & - & - & 一 & 一 & - \\
\hline Ceraclea slossonae/menteia & - & - & 一 & - & - & - & - & - & - & - & - & $\mathrm{x}$ & 一 & 一 & 一 & - \\
\hline Ceraclea submaculata/punctata & 一 & 一 & 一 & - & $\mathrm{x}$ & 一 & - & - & 一 & - & - & - & - & 一 & - & - \\
\hline Ceraclea tarsipunctata & $\mathbf{x}$ & $\mathbf{x}$ & $\mathbf{x}$ & - & 一 & - & 一 & - & - & $\mathbf{x}$ & - & - & 一 & - & - & 一 \\
\hline Ceraclea transversa & $\mathrm{x}$ & $\mathrm{x}$ & $\mathrm{x}$ & - & 一 & - & - & 一 & - & - & - & $\mathrm{x}$ & - & - & - & - \\
\hline Oecetis $\mathrm{s}$ & $\mathrm{x}$ & $\mathrm{x}$ & $\mathrm{x}$ & $\mathrm{x}$ & $\mathbf{x}$ & $\mathbf{x}$ & $\mathbf{x}$ & $\mathrm{x}$ & 一 & - & - & - & $\mathrm{x}$ & $\mathbf{X}$ & $\mathbf{x}$ & $\mathbf{x}$ \\
\hline che spp. & 一 & $\mathrm{x}$ & - & - & 一 & $\mathrm{x}$ & $\mathrm{x}$ & $\mathrm{x}$ & - & $\mathbf{x}$ & - & $\mathrm{x}$ & $\mathrm{x}$ & $\mathbf{x}$ & $\mathrm{x}$ & $\mathbf{x}$ \\
\hline Nectopsyche candida & $\mathrm{x}$ & $\mathbf{x}$ & $\mathrm{x}$ & $\mathbf{x}$ & $\mathrm{x}$ & $\mathrm{x}$ & $\mathrm{x}$ & $\mathrm{x}$ & - & $\mathrm{x}$ & $\mathrm{x}$ & $\mathrm{x}$ & $\mathrm{x}$ & $\mathbf{x}$ & $\mathrm{x}$ & $\mathrm{x}$ \\
\hline Nectopsyche exquisita & 一 & - & $\mathrm{x}$ & $\mathrm{X}$ & $\mathrm{x}$ & $\mathrm{x}$ & $\mathrm{x}$ & $\mathrm{x}$ & - & $\mathrm{x}$ & - & - & 一 & 一 & $\mathrm{x}$ & 一 \\
\hline Triaenodes $\mathrm{sp}$ & - & $\mathrm{x}$ & - & - & - & 一 & 一 & $\mathrm{x}$ & - & $\mathrm{x}$ & - & - & - & 一 & 一 & 一 \\
\hline Triaenodes $\mathrm{n}$ & 一 & - & - & 一 & - & - & - & - & - & - & $\mathrm{x}$ & - & - & 一 & 一 & 一 \\
\hline Triaenodes $i$ & - & - & $\mathrm{x}$ & - & 一 & $\mathrm{x}$ & 一 & 一 & 一 & - & - & - & - & 一 & - & - \\
\hline Triae & $\mathrm{x}$ & $\mathrm{x}$ & $\mathrm{x}$ & $\mathrm{x}$ & - & $\mathrm{x}$ & $\mathrm{x}$ & $\mathrm{x}$ & 一 & $\mathrm{x}$ & - & - & - & $\mathbf{x}$ & $\mathbf{x}$ & $\mathrm{x}$ \\
\hline Family Limnephilidae & - & - & 一 & - & 一 & - & 一 & 一 & 一 & - & - & - & - & $\mathrm{x}$ & $\mathbf{x}$ & $\mathrm{x}$ \\
\hline Pycnopsyche sp. & - & - & $\mathrm{x}$ & $\mathrm{x}$ & 一 & - & - & - & - & - & 一 & - & 一 & - & 一 & - \\
\hline \multicolumn{17}{|l|}{ Family Philopotamidae } \\
\hline Chimarra spp. & $\mathbf{X}$ & $\mathbf{X}$ & $\mathbf{x}$ & $\mathrm{X}$ & - & 一 & - & 一 & - & - & $\mathbf{X}$ & $\mathbf{x}$ & $\mathrm{x}$ & $\mathbf{X}$ & - & $\mathrm{x}$ \\
\hline rrima & - & - & - & - & $\mathrm{x}$ & $\mathrm{x}$ & $\mathbf{x}$ & $\mathrm{x}$ & - & - & - & - & $\mathrm{x}$ & $\mathbf{x}$ & $\mathbf{x}$ & $\mathrm{X}$ \\
\hline Family Polycentropodidae & - & - & - & - & - & - & - & 一 & - & - & - & - & - & - & $\mathbf{x}$ & - \\
\hline ellus $\mathrm{s}$ & - & - & - & $\mathrm{x}$ & - & 一 & 一 & 一 & - & 一 & - & - & - & 一 & 一 & - \\
\hline ellus fraternus & - & $\mathrm{x}$ & - & - & - & 一 & 一 & - & - & - & - & - & $\mathrm{x}$ & $\mathbf{x}$ & $\mathbf{x}$ & - \\
\hline Neureclipsis crepuscularis & $\mathrm{x}$ & $\mathbf{x}$ & $\mathrm{x}$ & $\mathrm{x}$ & - & $\mathrm{x}$ & $\mathbf{x}$ & $\mathbf{x}$ & - & - & - & - & $\mathrm{x}$ & $\mathrm{x}$ & $\mathrm{x}$ & 一 \\
\hline Polycentrop & - & - & $\mathrm{x}$ & - & - & - & - & - & - & - & 一 & - & - & 一 & - & - \\
\hline Polycentropus remotus & - & - & - & 一 & $\mathrm{x}$ & 一 & 一 & - & 一 & - & - & - & - & - & - & - \\
\hline \multicolumn{17}{|l|}{ Family Dipseudopsidae } \\
\hline Phylocentropus spp. & 一 & - & $\mathrm{x}$ & $\mathrm{x}$ & $\mathrm{x}$ & 一 & 一 & 一 & - & - & - & - & 一 & 一 & - & - \\
\hline \multicolumn{17}{|l|}{ Order Coleoptera } \\
\hline Family Curculionidae & - & - & 一 & - & - & 一 & 一 & - & - & $\mathrm{x}$ & - & - & - & $\mathbf{X}$ & - & - \\
\hline Family Dytiscidae & - & - & - & - & - & - & 一 & - & - & 一 & - & $\mathbf{x}$ & - & 一 & - & - \\
\hline & 一 & - & $\mathbf{x}$ & $\mathbf{x}$ & 一 & 一 & - & - & - & - & 一 & - & - & - & - & - \\
\hline Bidessonotus inconspicuus/pulicarius & - & - & $\mathbf{x}$ & $\mathrm{x}$ & 一 & $\mathbf{x}$ & - & - & 一 & - & 一 & - & 一 & - & - & - \\
\hline Coptotomus spp. & - & - & - & - & $\mathrm{x}$ & $\mathbf{x}$ & - & $\mathbf{x}$ & - & - & - & - & 一 & 一 & - & 一 \\
\hline nr. loticus & $\mathrm{x}$ & $\mathrm{x}$ & $\mathbf{x}$ & $\mathrm{x}$ & $\mathrm{x}$ & $\mathbf{x}$ & $\mathrm{X}$ & $\mathbf{x}$ & 一 & 一 & 一 & - & 一 & 一 & 一 & - \\
\hline Liodessus sf & 一 & 一 & 一 & 一 & $\mathrm{x}$ & 一 & 一 & - & - & - & 一 & 一 & 一 & 一 & - & - \\
\hline Neoporus (=Hydroporus) spp. & $\mathrm{x}$ & $\mathrm{x}$ & $\mathrm{x}$ & - & - & - & - & $\mathrm{x}$ & $\mathrm{x}$ & $\mathrm{x}$ & - & - & $\mathrm{x}$ & 一 & 一 & - \\
\hline Neoporus c & $\mathrm{x}$ & $\mathrm{x}$ & $\mathbf{x}$ & 一 & - & $\mathrm{x}$ & - & - & - & $\mathrm{x}$ & $\mathrm{x}$ & - & - & 一 & - & 一 \\
\hline Neoporus $h$ & - & - & - & $\mathrm{x}$ & - & - & 一 & 一 & - & - & 一 & - & 一 & - & $\mathrm{x}$ & - \\
\hline Neoporus nr. carolinus & 一 & - & - & - & - & - & - & $\mathrm{x}$ & - & - & - & - & 一 & - & - & - \\
\hline dixianus & - & - & $\mathbf{x}$ & - & 一 & - & - & - & 一 & - & 一 & - & 一 & - & 一 & - \\
\hline Neoporus undulatus & - & - & - & $\mathrm{x}$ & 一 & - & 一 & 一 & - & - & 一 & 一 & - & 一 & 一 & - \\
\hline Neoporus venustus & $\mathrm{X}$ & - & $\mathbf{x}$ & - & - & - & - & - & - & - & - & - & - & 一 & - & \\
\hline Ancyronyx variegata & $\mathbf{x}$ & $\mathbf{X}$ & $\mathbf{X}$ & $\mathbf{X}$ & $\mathbf{X}$ & $\mathrm{x}$ & $\mathrm{x}$ & $\mathrm{x}$ & 一 & - & - & 一 & 一 & $\mathbf{x}$ & 一 & \\
\hline
\end{tabular}


Table D-2 (continued). List of aquatic insects collected from the Savannah River at Stations 1, 2B, 5 , and 6 in the vicinity of the Savannah River Site in April and September 2000. Qualitative columns represent hand collections from all available habitats at each station. Qualitative columns are data from traps suspended on the river's surface. $\mathrm{X}$ indicates presence of a taxon; - indicates none was collected at that station.

\begin{tabular}{|c|c|c|c|c|c|c|c|c|c|c|c|c|c|c|c|c|}
\hline & \multicolumn{8}{|c|}{ Qualitative } & \multicolumn{8}{|c|}{ Quantitative } \\
\hline & \multicolumn{4}{|c|}{ April } & \multicolumn{4}{|c|}{ September } & \multicolumn{4}{|c|}{ April } & \multicolumn{4}{|c|}{ September } \\
\hline & 1 & 2B & 5 & 6 & 1 & 2B & 5 & 6 & 1 & $2 B$ & 5 & 6 & 1 & 2B & 5 & 6 \\
\hline Dubiraphia spp. & 一 & - & - & $\mathrm{x}$ & $\mathrm{X}$ & - & - & - & - & - & - & - & 一 & - & - & 一 \\
\hline Dubiraphia vittata & $\mathrm{x}$ & - & - & - & - & - & 一 & - & - & - & - & - & - & 一 & - & - \\
\hline Macronychus glabratus & $\mathrm{x}$ & $\mathrm{x}$ & $\mathrm{x}$ & $\mathrm{X}$ & $\mathrm{x}$ & $\mathrm{x}$ & $\mathbf{x}$ & $\mathrm{x}$ & - & - & - & $\mathbf{x}$ & $\mathbf{x}$ & $\mathrm{x}$ & $\mathrm{x}$ & 一 \\
\hline Microcylloepus pusillus & 一 & - & $\mathrm{x}$ & - & 一 & - & - & - & - & - & - & - & - & 一 & - & - \\
\hline Optioservus sp. & - & $\mathrm{x}$ & - & - & 一 & - & - & - & - & - & - & - & 一 & - & - & - \\
\hline Stenelmis spp. & 一 & $\mathrm{x}$ & $\mathbf{x}$ & $\mathrm{x}$ & - & $\mathrm{x}$ & - & $\mathrm{x}$ & - & $\mathrm{x}$ & - & $\mathrm{x}$ & - & $\mathrm{x}$ & $\mathrm{x}$ & $\mathrm{x}$ \\
\hline Stenelmis antennalis & - & - & - & $\mathrm{x}$ & $\mathrm{x}$ & $\mathbf{x}$ & $\mathbf{x}$ & $\mathrm{x}$ & 一 & - & - & 一 & 一 & - & - & - \\
\hline Stenelmis hungerfordi & $\mathrm{x}$ & $\mathrm{x}$ & $\mathbf{x}$ & $\mathrm{x}$ & $\mathrm{x}$ & $\mathrm{x}$ & $\mathrm{x}$ & $\mathbf{x}$ & - & $\mathbf{x}$ & $\mathrm{x}$ & - & $\mathrm{x}$ & $\mathbf{x}$ & $\mathrm{x}$ & $\mathrm{x}$ \\
\hline \multicolumn{17}{|l|}{ Family Gyrinidae } \\
\hline Dineutus spp. & $\mathrm{X}$ & $\mathrm{x}$ & $\mathrm{x}$ & - & $\mathrm{x}$ & $\mathbf{x}$ & $\mathrm{x}$ & - & - & - & 一 & - & 一 & $\mathbf{X}$ & 一 & 一 \\
\hline Dineutus assimilis & - & - & - & - & $\mathrm{x}$ & - & $\mathrm{x}$ & - & 一 & - & - & - & - & 一 & - & - \\
\hline Dineutus discolor & $\mathbf{x}$ & $\mathbf{x}$ & 一 & $\mathbf{x}$ & $\mathrm{x}$ & $\mathbf{x}$ & $\mathbf{x}$ & $\mathrm{x}$ & 一 & - & - & 一 & - & - & 一 & - \\
\hline Gyrinus spp. & 一 & - & 一 & - & - & - & $\mathrm{x}$ & - & - & - & 一 & - & - & - & - & - \\
\hline Gyrinus analis/lugens & $\mathrm{x}$ & $\mathrm{x}$ & 一 & - & $\mathrm{x}$ & $\mathbf{x}$ & $\mathrm{x}$ & $\mathbf{x}$ & - & - & - & - & 一 & 一 & 一 & - \\
\hline \multicolumn{17}{|l|}{ Family Haliplidae } \\
\hline Haliplus fasciatus & 一 & - & - & $\mathrm{x}$ & 一 & - & - & - & 一 & - & - & 一 & 一 & - & - & 一 \\
\hline Haliplus triopsis & 一 & - & - & $\mathrm{x}$ & - & - & - & 一 & - & - & - & - & 一 & 一 & 一 & 一 \\
\hline Peltodytes spp. & 一 & - & - & $\mathbf{x}$ & $\mathbf{x}$ & $\mathbf{x}$ & $\mathbf{x}$ & $\mathrm{x}$ & - & 一 & - & - & - & - & 一 & 一 \\
\hline Peltodytes bradleyi & $\mathrm{x}$ & - & - & - & $\mathbf{x}$ & $\mathrm{x}$ & 一 & 一 & 一 & - & - & - & - & - & - & - \\
\hline Peltodytes dietrichi & 一 & - & - & - & - & $\mathbf{x}$ & - & - & - & - & - & - & - & 一 & - & 一 \\
\hline Peltodytes dunavani & 一 & - & - & $\mathrm{x}$ & $\mathrm{x}$ & $\mathbf{x}$ & 一 & $\mathbf{x}$ & - & - & - & - & 一 & - & 一 & 一 \\
\hline Peltodytes muticus & $\mathbf{x}$ & - & - & $\mathrm{x}$ & 一 & - & - & - & 一 & - & - & - & - & - & - & - \\
\hline Peltodytes ses & $\mathbf{x}$ & $\mathrm{x}$ & $\mathrm{x}$ & $\mathbf{x}$ & $\mathbf{x}$ & $\mathbf{x}$ & $\mathbf{x}$ & $\mathrm{x}$ & 一 & - & - & - & - & - & - & 一 \\
\hline Hydrophilidae & - & - & - & - & - & - & 一 & - & 一 & - & $\mathrm{X}$ & - & - & - & 一 & 一 \\
\hline Berosus peregrinus & - & - & - & - & 一 & - & $\mathbf{x}$ & - & - & - & - & - & 一 & - & - & - \\
\hline Enochrus blatchleyi & - & - & - & - & 一 & $\mathbf{x}$ & - & 一 & - & - & - & $一$ & 一 & 一 & - & - \\
\hline Hydrochus inaequalis & - & - & - & - & - & 一 & - & - & 一 & - & - & $\mathrm{x}$ & 一 & - & - & 一 \\
\hline Hydrochus squamifer & 一 & - & - & - & - & - & - & - & - & $\mathrm{x}$ & - & - & - & 一 & 一 & 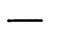 \\
\hline Hydrochus nr. squamifer & - & - & $\mathrm{x}$ & 一 & - & - & 一 & - & 一 & 一 & - & - & - & - & - & - \\
\hline Phaenonotum exstriatum & - & - & - & $\mathrm{x}$ & 一 & - & - & - & - & - & - & - & 一 & - & - & - \\
\hline Sperchopsis sp. & 一 & - & $\mathrm{x}$ & - & - & - & - & - & - & - & - & - & - & - & 一 & - \\
\hline Sperchopsis tessellatus & - & - & - & - & - & - & - & - & 一 & - & - & - & $一$ & $\mathrm{x}$ & 一 & 一 \\
\hline Tropisternus sp. & - & - & - & - & - & 一 & - & $\mathrm{x}$ & - & - & - & - & - & - & - & 一 \\
\hline us blatchleyi blatchleyi & - & - & - & $\mathrm{x}$ & $\mathrm{x}$ & - & - & - & - & - & - & - & - & - & - & - \\
\hline Tropisternus collaris striolatus & $\mathbf{x}$ & - & - & $\mathrm{x}$ & 一 & - & - & - & - & - & - & - & 一 & - & - & 一 \\
\hline \multicolumn{17}{|l|}{ Noteridae } \\
\hline Hydrocanthus sp. & - & - & - & $\mathbf{x}$ & - & - & - & - & - & $\mathrm{x}$ & - & - & - & - & 一 & - \\
\hline Suphisellus bicolor punctipennis & $\mathbf{x}$ & - & - & - & - & - & - & - & - & 一 & - & 一 & - & - & 一 & 一 \\
\hline Suphisellus gibbulus & - & - & $\mathbf{x}$ & - & 一 & 一 & - & - & - & $\mathrm{x}$ & - & - & 一 & - & - & - \\
\hline Suphisellus puncticollis & - & - & $\mathrm{x}$ & - & - & - & - & - & - & - & - & - & - & - & 一 & - \\
\hline \multicolumn{17}{|l|}{ Scirtidae } \\
\hline Cyphon sp. & - & - & $\mathrm{x}$ & - & - & - & - & - & - & 一 & - & - & - & - & - & 一 \\
\hline & $\mathbf{x}$ & - & - & - & - & - & - & - & 一 & 一 & - & - & $\mathbf{x}$ & 一 & - & 一 \\
\hline Family Ceratopogonidae & - & - & - & $\mathbf{x}$ & 一 & $\mathbf{x}$ & - & - & - & $\mathrm{x}$ & - & - & 一 & - & - & - \\
\hline Dasyhelea sp. & - & - & - & - & $\mathbf{x}$ & - & - & - & 一 & 一 & - & - & 一 & - & - & - \\
\hline Palpomyia/Bezzia spp. complex & $\mathbf{x}$ & $\mathbf{x}$ & $\mathbf{x}$ & - & $\mathrm{x}$ & $\mathbf{x}$ & $\mathbf{x}$ & $\mathbf{x}$ & $\mathbf{x}$ & $\mathbf{x}$ & - & - & - & $\mathrm{X}$ & - & \\
\hline amily Chaoboridae & & & & & & & & & & & & & & & & \\
\hline & & - & & & $\mathrm{x}$ & & & - & & & & & & & & \\
\hline
\end{tabular}


Table D-2 (continued). List of aquatic insects collected from the Savannah River at Stations 1, 2B, 5, and 6 in the vicinity of the Savannah River Site in April and September 2000. Qualitative columns represent hand collections from all available habitats at each station. Qualitative columns are data from traps suspended on the river's surface. $\mathrm{X}$ indicates presence of a taxon; - indicates none was collected at that station.

\begin{tabular}{|c|c|c|c|c|c|c|c|c|c|c|c|c|c|c|c|c|}
\hline & \multicolumn{8}{|c|}{ Qualitative } & \multicolumn{8}{|c|}{ Quantitative } \\
\hline & \multicolumn{4}{|c|}{ April } & \multicolumn{4}{|c|}{ September } & \multicolumn{4}{|c|}{ April } & \multicolumn{4}{|c|}{ September } \\
\hline & 1 & $2 B$ & 5 & 6 & 1 & $2 B$ & 5 & 6 & 1 & $2 B$ & 5 & 6 & 1 & $2 B$ & 5 & 6 \\
\hline \multicolumn{17}{|l|}{ Family Culicidae } \\
\hline Culex sp. & - & - & - & - & $\mathbf{x}$ & - & - & - & - & - & - & 一 & 一 & - & 一 & $\longrightarrow$ \\
\hline Family Empididae & - & - & - & - & - & - & 一 & 一 & - & - & - & - & $\mathrm{x}$ & $\mathbf{x}$ & $\mathbf{x}$ & $\mathrm{X}$ \\
\hline Hemerodromia spp. & - & - & - & - & - & $\mathrm{x}$ & - & - & - & 一 & - & - & $\mathrm{x}$ & $\mathrm{x}$ & $\mathrm{x}$ & $\mathrm{x}$ \\
\hline Family Simuliidae & - & - & - & - & - & - & 一 & 一 & - & - & - & - & $\mathrm{x}$ & - & $\mathbf{x}$ & - \\
\hline Simulium spp. & $\mathrm{x}$ & 一 & - & - & $\mathrm{x}$ & $\mathrm{x}$ & $\mathrm{x}$ & $\mathrm{x}$ & $\mathrm{x}$ & - & - & $\mathbf{x}$ & $\mathrm{x}$ & $\mathrm{x}$ & $\mathrm{x}$ & $\mathrm{x}$ \\
\hline \multicolumn{17}{|l|}{ Family Stratiomyidae } \\
\hline Stratiomys sp. & - & - & - & $\mathrm{x}$ & - & - & 一 & - & - & 一 & 一 & - & 一 & - & - & - \\
\hline \multicolumn{17}{|l|}{ Family Tabanidae } \\
\hline nr. Chlorotabanus & 一 & - - & - & - & - & $\mathrm{x}$ & - & - & 一 & - & 一 & - & - & - & - & - \\
\hline Chrysops spp. & - & - & 一 & - & - & - & - & - & - & - & - & - & 一 & $\mathbf{x}$ & - & - \\
\hline Family Tipulidae & - & - & - & - & - & - & - & - & - & - & $\mathbf{x}$ & - & - & 一 & - & - \\
\hline Cryptolabis sp. & - & - & - & - & $\mathrm{x}$ & - & 一 & - & - & - & - & - & 一 & 一 & - & - \\
\hline Tipula spp. & - & $\mathrm{x}$ & $\mathrm{x}$ & - & - & 一 & 一 & $\mathrm{x}$ & - & - & - & - & - & - & - & - \\
\hline Family: Chironomidae & 一 & - & - & - & - & 一 & - & - & - & - & - & - & $\mathrm{x}$ & $\mathrm{x}$ & $\mathrm{x}$ & $\mathbf{x}$ \\
\hline \multicolumn{17}{|l|}{ Subfamily: Diamesinae } \\
\hline Potthastia longimana grp. & $\mathrm{x}$ & - & 一 & 一 & - & 一 & 一 & - & $\mathrm{x}$ & $\mathbf{x}$ & $\mathrm{x}$ & - & - & - & - & - \\
\hline Subfamily: Tanypodinae & - & - & - & - & - & 一 & 一 & - & $\mathrm{x}$ & 一 & - & - & $\mathrm{x}$ & $\mathrm{x}$ & $\mathrm{x}$ & $\mathrm{x}$ \\
\hline Ablabesmyia spp. & - & - & - & 一 & - & 一 & 一 & - & $\mathrm{x}$ & $\mathrm{x}$ & $\mathrm{x}$ & $\mathbf{x}$ & $\mathrm{x}$ & $\mathrm{x}$ & $\mathrm{x}$ & $\mathrm{x}$ \\
\hline Ablabesmyia mallochi & $\mathrm{x}$ & $\mathbf{x}$ & $\mathrm{x}$ & $\mathrm{x}$ & $\mathrm{x}$ & $\mathbf{x}$ & $\mathbf{x}$ & 一 & - & - & - & - & - & - & 一 & - \\
\hline Ablabesmyia ramphe grp. & $\mathrm{x}$ & $\mathrm{x}$ & $\mathbf{x}$ & $\mathrm{x}$ & $\mathrm{x}$ & $\mathbf{x}$ & $\mathbf{x}$ & $\mathbf{x}$ & - & - & - & - & - & - & - & - \\
\hline Clinotanypus sp. & - & - & - & - & $\mathrm{x}$ & - & 一 & - & - & - & - & - & - & - & - & 一 \\
\hline Coelotanypus sp. & - & - & 一 & $\mathrm{x}$ & $\mathbf{x}$ & 一 & - & $\mathrm{x}$ & - & - & - & 一 & - & - & - & - \\
\hline Labrundinia sp. & - & - & $\mathrm{x}$ & - & - & $\mathrm{x}$ & - & - & $\mathrm{x}$ & $\mathrm{x}$ & $\mathrm{x}$ & $\mathbf{x}$ & $\mathrm{x}$ & $\mathbf{x}$ & $\mathrm{x}$ & $\mathrm{x}$ \\
\hline Labrundinia pilosella & - & - & 一 & - & $\mathrm{x}$ & - & - & - & - & 一 & - & - & 一 & 一 & - & - \\
\hline Nilotanypus spp. & 一 & - & - & - & - & - & 一 & - & $\mathrm{x}$ & $\mathbf{x}$ & $\mathrm{x}$ & $\mathrm{x}$ & $\mathrm{x}$ & - & $\mathrm{x}$ & $\mathrm{x}$ \\
\hline Nilotanypus fimbriatus & - & - & - & - & - & - & $\mathrm{x}$ & - & - & - & - & - & - & - & - & - \\
\hline Pentaneura nr. inconspicua & 一 & - & - & $\mathbf{x}$ & 一 & - & 一 & - & - & - & - & - & 一 & - & - & 一 \\
\hline Procladius sp. & $\mathrm{x}$ & $\mathrm{x}$ & - & $\mathrm{x}$ & $\mathrm{x}$ & - & - & $\mathrm{x}$ & - & - & 一 & 一 & - & - & - & - \\
\hline Rheopelopia sp. & - & $\mathbf{x}$ & - & - & $\mathrm{x}$ & $\mathrm{x}$ & $\mathrm{x}$ & $\mathrm{x}$ & $\mathrm{x}$ & $\mathbf{x}$ & $\mathbf{x}$ & $\mathbf{x}$ & $\mathrm{x}$ & $\mathrm{x}$ & $\mathrm{x}$ & $\mathrm{x}$ \\
\hline elopia spp. & - & - & - & - & - & - & 一 & - & - & - & 一 & - & - & $\mathbf{x}$ & 一 & - \\
\hline Subfamily: Orthocladiinae & 一 & - & - & - & - & - & - & - & - & 一 & - & - & $\mathrm{x}$ & $\mathbf{x}$ & - & $\mathrm{x}$ \\
\hline Corynoneura spp & - & - & - & - & - & 一 & - & - & $\mathrm{x}$ & $\mathrm{x}$ & $\mathrm{x}$ & $\mathbf{x}$ & $\mathrm{x}$ & - & - & 一 \\
\hline Cricotopus spp. & $\mathrm{x}$ & $\mathrm{x}$ & $\mathbf{x}$ & $\mathrm{x}$ & $\mathrm{x}$ & $\mathrm{x}$ & 一 & - & $\mathrm{x}$ & $\mathbf{x}$ & $\mathrm{x}$ & $\mathrm{x}$ & $\mathbf{x}$ & - & $\mathrm{x}$ & 一 \\
\hline Cricotopus bicinctus grp. & $\mathrm{x}$ & $\mathbf{x}$ & $\mathrm{x}$ & $\mathrm{x}$ & $\mathrm{x}$ & 一 & $\mathbf{x}$ & - & - & $\mathbf{x}$ & 一 & - & - & 一 & - & - \\
\hline Cricotopus/Orthocladius spp. & $\mathbf{x}$ & $\mathrm{x}$ & $\mathrm{x}$ & $\mathrm{x}$ & $\mathrm{x}$ & $\mathbf{x}$ & $\mathrm{x}$ & $\mathbf{x}$ & $\mathrm{x}$ & $\mathbf{x}$ & 一 & $\mathrm{x}$ & $\mathbf{x}$ & - & $\mathrm{x}$ & - \\
\hline Mesomittia sp. & 一 & - & - & - & - & - & - & $\mathbf{x}$ & - & 一 & - & $\mathrm{x}$ & - & - & - & - \\
\hline Nanocladius spp. & 一 & $\mathbf{x}$ & $\mathbf{X}$ & $\mathbf{x}$ & - & $\mathbf{x}$ & - & $\mathbf{x}$ & $\mathrm{x}$ & $\mathbf{x}$ & $\mathrm{x}$ & $\mathbf{x}$ & $\mathrm{x}$ & $\mathbf{x}$ & - & $\mathrm{x}$ \\
\hline Orthocladius sp. & 一 & - & - & - & $\mathrm{x}$ & $\mathbf{x}$ & - & - & - & - & - & - & - & - & - & - \\
\hline Parakiefferiella sp. & - & $\mathrm{x}$ & - & - & - & - & - & - & $\mathrm{x}$ & $\mathbf{x}$ & - & - & - & - & - & - \\
\hline Psectrocladius sp. & $\mathrm{x}$ & $\mathrm{x}$ & $\mathrm{x}$ & - & - & - & 一 & - & - & 一 & - & - & - & - & - & 一 \\
\hline Rheocricotopus spp. & - & - & - & - & - & - & - & 一 & - & 一 & - & - & $\mathrm{x}$ & - & $\mathrm{x}$ & - \\
\hline Rheocricotopus $\mathrm{nr}$. robacki & - & $\mathbf{x}$ & $\mathbf{x}$ & - & - & - & 一 & - & $\mathrm{x}$ & $\mathbf{x}$ & $\mathrm{x}$ & $\mathbf{x}$ & 一 & - & - & - \\
\hline Thienemanniella spp. & - & - & - & - & 一 & - & - & - & $\mathrm{X}$ & - & - & $\mathrm{x}$ & $\mathbf{x}$ & 一 & 一 & $\mathbf{x}$ \\
\hline Thienemanniella sp. 2 & - & $\mathbf{x}$ & $\mathbf{x}$ & - & - & - & $\mathbf{x}$ & - & - & - & - & - & - & - & - & - \\
\hline Tvetenia spp. & - & - & - & - & - & - & - & - & - & - & - & - & $\mathrm{x}$ & $\mathbf{x}$ & $\mathbf{x}$ & $\mathbf{x}$ \\
\hline Tvetenia discoloripes grp. spp. & $\mathrm{x}$ & $\mathrm{x}$ & $\mathbf{x}$ & $\mathrm{x}$ & $\mathrm{X}$ & $\mathbf{x}$ & $\mathrm{x}$ & $\mathrm{x}$ & $\mathbf{x}$ & $\mathbf{x}$ & $\mathrm{x}$ & $\mathbf{X}$ & - & - & - & - \\
\hline Xylotopus par & - & $\mathbf{x}$ & - & - & - & - & 一 & - & - & - & - & - & - & - & 一 & - \\
\hline
\end{tabular}


Table D-2 (continued). List of aquatic insects collected from the Savannah River at Stations 1, 2B, 5 , and 6 in the vicinity of the Savannah River Site in April and September 2000. Qualitative columns represent hand collections from all available habitats at each station. Qualitative columns are data from traps suspended on the river's surface. $X$ indicates presence of a taxon; - indicates none was collected at that station.

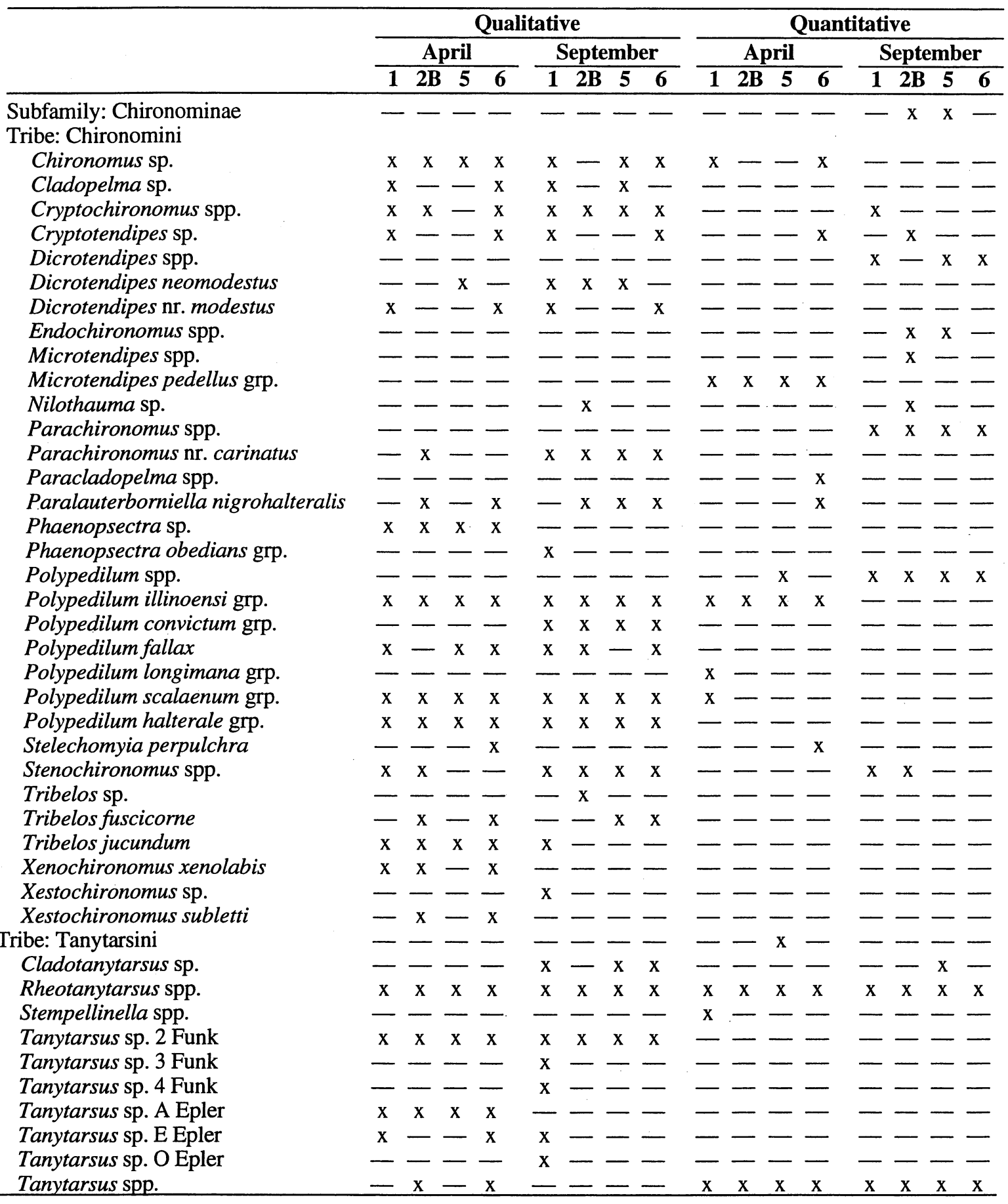


Table D-3. Total number of insect taxa, number of EPT (Ephemeroptera, Plecoptera, and Trichoptera) taxa, and number of insect taxa by order ( $\mathrm{O}=$ Odonata, $E=$ Ephemeroptera, $\mathrm{P}=$ Plecoptera, $\quad \mathrm{H}=$ Hemiptera, $\quad \mathrm{M}=$ Megaloptera, $\quad \mathrm{L}=$ Lepidoptera, $\quad \mathrm{T}=$ Trichoptera, $C=$ Coleoptera, $D=$ Diptera) collected in Spring (April) and Fall (September) 2000 from the Savannah River in the vicinity of the Savannah River Site. Numbers are for qualitative samples, only.

\begin{tabular}{|c|c|c|c|c|c|c|c|c|c|c|c|}
\hline \multirow[b]{2}{*}{ Order } & \multicolumn{5}{|c|}{ Spring } & \multicolumn{5}{|c|}{ Fall } & \multirow{2}{*}{$\begin{array}{l}\text { All Stations } \\
\text { and Seasons }\end{array}$} \\
\hline & 1 & $2 B$ & 5 & 6 & All & 1 & 2B & 5 & 6 & All & \\
\hline $\mathrm{O}$ & 13 & 8 & 12 & 12 & 23 & 10 & 7 & 10 & 10 & 17 & 27 \\
\hline E & 14 & 15 & 17 & 17 & 23 & 7 & 11 & 12 & 13 & 17 & 26 \\
\hline $\mathrm{P}$ & 1 & 2 & 3 & 3 & 3 & 0 & 1 & 2 & 2 & 2 & 3 \\
\hline $\mathrm{H}$ & 4 & 0 & 3 & 5 & 6 & 7 & 3 & 4 & 2 & 8 & 10 \\
\hline $\mathbf{M}$ & 0 & 0 & 0 & 0 & 0 & 2 & 1 & 1 & 0 & 2 & 2 \\
\hline L & 1 & 0 & 0 & 0 & 1 & 1 & 1 & 0 & 1 & 1 & 1 \\
\hline $\mathrm{T}$ & 14 & 16 & 19 & 19 & 26 & 10 & 13 & 12 & 11 & 16 & 26 \\
\hline C & 14 & 9 & 17 & 20 & 33 & 14 & 14 & 10 & 11 & 20 & 39 \\
\hline D & 28 & 32 & 24 & 32 & 45 & 41 & 27 & 25 & 27 & 51 & 61 \\
\hline EPT & 29 & 33 & 39 & 39 & 52 & 17 & 25 & 26 & 26 & 35 & 55 \\
\hline Total & 89 & 82 & 95 & 108 & 160 & 92 & 78 & 76 & 77 & 134 & 195 \\
\hline
\end{tabular}

bined total of three or fewer specimens during recent (19982000) surveys] were collected including the mayfly Heptagenia diabasia, the dragonfly Gomphus lividus, the damselfly Ischnura pesita, the beetle Suphisellus bicolor punctipennis, and the chironomid midge Potthastia longimana grp. Although chironomid densities were high in backwater areas, chironomid taxa richness was only moderate (26 taxa collected), with most (72\%) of the individuals belonging to 3 taxa (Chironomus sp., Tvetenia discoloripes grp., and Polypedilum illinoensi grp.). Dicrotendipes nr. modestus was the only other abundant chironomid at Station 1.

Although a large number of taxa was collected from Station 1 (many of which were EPT taxa), most stoneflies including Paragnetina, Acroneuria, and Pteronarcys, two mayflies (Isonychia and Labiobaetis), two caddisflies (Cheumatopsyche and Macrostemum) a beetle (Stenelmis antennalis), and a damselfly (Argia sedula) were missing from Station 1 collections in April. In addition to the absence of these taxa, most mayfly taxa were uncommon at Station 1 . This was particularly true of Stenonema mexicanum integrum, which was represented in the April collection at Station 1 by one individual. 


\section{September 2000}

total of 92 taxa including 17 EPT taxa were col-
lected in September 2000 from Station 1 (Tables D-
2 and D-3). Five mayfly taxa (Baetis intercalaris, Labiobaetis propinquus grp., Centroptilum/Procloeon, Caenis diminuta, and Tricorythodes spp.), one caddisfly taxa (Hydropsyche rossi), two gerrids (Metrobates and Rheumatobates), and two beetle taxa (Ancyronyx variegata and Gyrinus analis/lugens) were abundant at Station 1. Four of these taxa were primarily collected among woody debris (Baetis intercalaris, Labiobaetis propinquus grp, and Hydropsyche rossi in moderate to fast current and Ancyronyx variegata in slow to no current) while two others (Caenis diminuta and Centroptilum/Procloeon) were abundant in backwater areas. Another taxon (Tricorythodes spp.) was abundant in slow current root masses. A number of rare taxa were collected in September 2000 including the mayfly Callibaetis sp., the caddisfly Polycentropus remotus, the beetle Tropisternus blatchleyi blatchleyi, the dragonfly Libellula sp., the hemipteran Rheumatobates palosi, the megalopteran Chauliodes rastricornis, and the dipterans Dasyhelea sp., Culex sp., Cryptolabis sp., and Tanytarsus sp. O Epler. Although chironomid abundance and richness (35 taxa collected) were high and many taxa (7) were abundant, no individual taxon dominated chironomid collections. The three most common chironomid taxa, which comprised $46 \%$ of the individuals collected, were Polypedilum illinoensi grp., Polypedilum halterale grp., and Ablabesmyia ramphe grp.

Similar to April collections, some EPT groups were missing from September collections. The most obvious group was the stoneflies, which were absent. Additional EPT taxa including the mayflies Isonychia and Stenonema, and the caddisflies Macrostemum, Triaenodes, and Neureclipsis were also absent. In addition, the beetle Stenelmis antennalis and the caddisfly Chimarra were uncommon at Station 1 (one individual of each taxon collected).

\section{Similarities Between Seasons}

lthough the total number of taxa collected was high
for both sampling seasons ( 89 in April and 92 in Sep-
tember), only 5 taxa were abundant across seasons at 
Station 1. These taxa are the caddisfly Hydropsyche rossi, the beetle Gyrinus analis/lugens, the mayfly Baetis intercalaris, the chironomid Dicrotendipes (although the abundant species in April was not the same as the abundant species in September), and chironomid Polypedilum illinoensi grp. In contrast, most stoneflies (except Perlesta spp.), the mayfly Isonychia spp., the caddisfly Macrostemum, and the elmid beetle Stenelmis antennalis were absent or very uncommon at Station 1 during April and September collections. For both seasons, a total of at least five rare taxa including at least one mayfly, one dragonfly, one beetle, and one chironomid taxa were collected at Station 1.

\section{Qualitative Collections at Station 2B}

\section{April 2000}

D espite less than ideal habitat compared with the other stations (i.e., backwater and submerged willow root habitats were absent), 82 taxa including 33 EPT taxa were collected from Station 2B in April (Tables D-2 and D3). A number of EPT taxa including the mayflies Eurylophella doris, Ephemerella dorothea, and Baetis intercalaris, the stonefly Perlesta spp., and the caddisflies Cheumatopsyche spp., Nectopsyche candida, and Chimarra spp. were abundant. Eurylophella doris was found largely among shoreline roots in slow to no current while Ephemerella dorothea was collected primarily among pilings and large woody debris in fast current. Baetis intercalaris, Chimarra spp., and Cheumatopsyche spp. were found in several habitat types that included woody debris of all sizes in moderate to fast current. Additional taxa including the beetles Ancyronyx variegata (found principally among woody debris in slow to no current) and Gyrinus analis/lugens and a number of chironomids including Cricotopus spp., Tvetenia discoloripes grp., Cryptochironomus spp., Polypedilum illinoensi grp., Rheotanytarsus spp., and Tanytarsus spp. were abundant at Station 2B. Many rare taxa were collected from Station $2 \mathrm{~B}$ including the caddisflies Micrasema spp. and Cyrnellus fraternus, the beetle $O p$ tioservus sp., and the dipterans Tipula sp., Parakiefferiella sp., and Xylotopus par. Chironomid richness was high (30 taxa), but 3 taxa (Tvetenia discoloripes grp., Rheotanytarsus 
spp., and Tanytarsus spp.) comprised $54 \%$ of the individuals collected.

A number of groups were absent from Station 2B but present at Station 5 and/or Station 6 including the mayfly Isonychia spp., the beetle Stenelmis antennalis, and all hemipteran groups (probably due to the absence of backwater habitat). Other groups including most stoneflies (Perlesta spp. was abundant but only three other stonefly specimens were collected) and Chiromomus spp. were relatively scarce at Station 2B compared to the other stations. The relative scarcity of Chironomus spp. was probably due to differences in backwater habitat at Station 2B compared to the other stations.

\section{September 2000}

total of 78 taxa including 25 EPT taxa was collected
from Station 2B in September (Tables D-2 and D-3).
Some EPT taxa were abundant including several baetid mayflies (Baetis intercalaris, Labiobaetis propinquus grp., and Centroptilum/Procloeon spp.) and two caddisflies (Cheumatopsyche spp. and Chimarra spp.). Additional abundant taxa included two hemipterans (Metrobates hesperius and Trepobates spp.), several beetles (Ancyronyx variegata, Stenelmis hungerfordi, Dineutus discolor, and Gyrinus analis/lugens), and several chironomids (Tanytarsus sp. 2 Funk, Polypedilum illinoensi grp., Polypedilum convictum grp., Ablabesmyia ramphe grp., and Polypedilum halterale grp.). Two of the beetles (Ancyronyx variegata and Stenelmis hungerfordi) were found primarily on woody debris in slow to no current. Corydalus cornutus. was much more abundant than in previous collections (i.e., 17 individuals were collected from Station 2B in September 2000 whereas the previous record for a collection at any station was 7 individuals) and was found primarily (along with Chimarra spp.) among woody debris and pilings in moderate to fast current. Numerous rare taxa were collected from Station 2B in September including the mayfly Callibaetis sp., the beetles Bidessonotus inconspicuus/pulicarius and Enochrus blatchleyi, and dipterans Tabanidae and Nilothauma sp. Twenty-three chironomid taxa were collected with $55 \%$ belonging to three taxa (Tanytarsus sp. 2 Funk, Polypedilum illinoensi grp., and Polypedilum convictum grp.). 
Although a number of EPT taxa were abundant (see above) others were absent or scarce. For example, the mayfly Isonychia spp. was absent and stoneflies in general along with the caddisflies Macrostemum and Triaenodes were scarce. (i.e., only one or two specimens were collected). In addition, hemipterans other than gerrids were uncommon (one total individual collected) and the chironomid Chironomus spp. was absent (probably due to the scarcity of backwater habitat).

\section{Similarities Between Seasons}

cross sampling periods, Total Richness, EPT Rich-
ness, and the abundances of Baetis intercalaris,
Cheumatopsyche spp., Chimarra spp., Ancyronyx variegata, Gyrinus analis/lugens, and Polypedilum illinoensi grp. were high. In contrast, Isonychia spp. were absent and hemipterans other than gerrids were uncommon (one specimen collected) at Station 2B in April and September. In addition, Chironomus was absent or uncommon (probably due to the lack of backwater habitat) and stoneflies other than Perlesta spp. were uncommon. In both April and September, the three most abundant chironomids accounted for about $50 \%$ of the midges collected; although the most abundant taxa in April were not the same as those in September. At least one rare beetle and two rare dipteran taxa were collected.

\section{Qualitative Collections at Station 5}

\section{April 2000}

total of 95 taxa including 39 EPT taxa was collected
from Station 5 in April (Tables D-2 and D-3). Many
of these taxa including the mayflies Baetis intercalaris, Ephemerella dorothea, and Heptagenia flavescens, the stoneflies Perlesta spp. and Pteronarcys dorsata, the caddisflies Cheumatopsyche spp. Macrostemum carolina, Ceraclea nr. punctata, and Nectopsyche candida, the beetle Stenelmis hungerfordi, and the chironomids Tvetenia discoloripes grp., Chironomus sp., and Polypedilum illinoensi grp. were abundant. Of the abundant mayflies, stoneflies, caddisflies, and beetles listed above all except Nectopsyche candida were primarily collected from willow roots and woody debris in moderate to fast current. In contrast, Nectopsyche candida was 
collected mostly from willow roots in slow to no current. Many rare taxa were collected including two mayflies (Macdunnoa and Neoephemera), two caddisflies (Ceraclea cancellata and Polycentropus sp.), one dragonfly (Neurocordulia alabamensis), and seven beetles (Bidessonotus inconspicuus/pulicarius, Neoporus nr. dixianus, Microcylloepus pusillus, Hydrochus nr. squamifer, Sperchopsis sp., Suphisellus puncticollis and Cyphon sp.). Chironomid richness was moderate (22 taxa) with the 3 most abundant taxa (Tvetenia discoloripes grp., Chironomus sp., and Polypedilum illinoensi grp.) comprising most of the chironomids collected (85\%).

Although richness (both Total and EPT) was high and a large number of taxa were abundant, two taxa (the mayfly Isonychia spp. and the beetle Stenelmis antennalis) were absent from April collections at Station 5.

\section{September 2000}

total of 76 taxa including 26 EPT taxa was collected
from Station 5 in September (Tables D-2 and D-3).
A number of EPT taxa including three mayflies (Labiobaetis propinquus grp., Isonychia spp., and Tricorythodes spp.) and four caddisflies (Nectopsyche canida, Chimarra, Cheumatopsyche, and Macrostemum carolina) were abundant. Additional taxa including the hemipteran Rheumatobates, the coleopterans Stenelmis hungerfordi, Stenelmis antennalis, Dineutus discolor, and Gyrinus analis/lugens, and the dipterans Simulium, Polypedilum illinoensi grp., Tanytarsus sp. 2 Funk, Ablabesmyia ramphe grp., Rheotanytarsus, and Polypedilum halterale grp. were abundant. Several of these taxa including Labiobaetis propinquus grp., Stenelmis hungerfordi, and Stenelmis antennalis were predominantly found among pilings and associated woody debris (Labiobaetis propinquus grp. in slow current and Stenelmis in moderate to fast current). Several other taxa were collected mainly among willow root masses (Tricorythodes spp. in slow current and Chimarra, Simulium, and Isonychia in fast current). A number of rare taxa (to the study sites) including the dragonfly Promogomphus sp., the mayfly Acerpenna pygmaea, the beetles Dineutus assimilis and Berosus peregrinus, and the chironomid Nilotanypus fimbriatus were collected from Station 5 in September. The chironomid fauna was moderately rich ( 23 taxa were collected) with the 3 most 
abundant taxa (Tanytarsus sp. 2 Funk, Rheotanytarsus, and Polypedilum halterale grp.) comprising $48 \%$ of the chironomids collected.

Although many taxa were abundant, two groups including the plecopterans (two specimens collected) and most hemipterans (gerrids were the exception) were uncommon in September collections at Station 5.

\section{Similarities Between Seasons}

The caddisflies Cheumatopsyche, Nectopsyche candida, and Macrostemum carolina, the beetle Stenelmis hungerfordi, and the chironomid Polypedilum illinoensi grp. were abundant across sampling periods. Furthermore, chironomid richness was nearly constant across sampling periods (22 chironomid taxa were collected in April and 23 in September). In addition, at least one rare mayfly taxa and two rare beetle taxa were collected during each season.

\section{Qualitative Collections at Station 6}

\section{April 2000}

total of 108 insect taxa including 39 EPT taxa was
collected from Station 6 in April (Tables D-2 and D-
3). Of the 108 taxa collected, a large number (20) were abundant including the mayflies Baetis intercalaris, Centroptilum/Procloeon, Ephemerella dorothea, Eurylophella doris, and Heptagenia flavescens, the stoneflies Perlesta spp. and Pteronarcys dorsata, the hemipterans Trichocorixa calva and Rheumatobates spp., the caddisflies Cheumatopsyche spp., Macrostemum carolina, Ceraclea nr. punctata, and Nectopsyche candida, the beetles Stenelmis hungerfordi and Stenelmis antennalis, and the dipterans Ceratopogonidae, Procladius sp., Tvetenia discoloripes grp., Chironomus spp., and Tanytarsus spp. Of the taxa listed above, all the hemipterans and two of the dipterans (Ceratopogonidae, and Chironomus spp.) were collected mainly from backwater areas and the mayflies Baetis intercalaris and Ephemerella dorothea and caddisfly Nectopsyche candida were collected predominantly from willow roots in moderate current. Other taxa were abun- 
dant among pilings and associated woody debris in moderate to fast current including Cheumatopsyche spp., Macrostemum carolina, and Ceraclea nr. punctata. Still other taxa were abundant in both willow roots and pilings/woody debris in moderate to fast current including the mayfly Heptagenia flavescens, the stoneflies Perlesta spp. and Pteronarcys dorsata, and the beetles Stenelmis hungerfordi and Stenelmis antennalis. Seventeen rare taxa were collected from Station 6 in April: the mayfly Macdunnoa sp. (also rare across its range), the caddisfly Micrasema spp., the dragonflies Gomphus parvidens, Nasiaeschna pentacantha, and Stylurus ivae, the hemipteran Pelocoris femoratus, the beetles Bidessonatus inconspicuus pulicarius, Neoporus undulatus, Neoporus hybridus, Haliplus triopsis, Peltodytes muticus, Tropisternus blatchleyi blatchleyi, Phaenonotum exstriatum, and Hydrocanthus sp., and the dipterans Stratiomys sp., Pentaneura nr. inconspicua, and Stelechomyia perpulchra. A large number of chironomids (both in terms of number of individuals and taxa) were collected from Station 6 in April with the three most abundant chironomids (Chironomus sp., Tvetenia discoloripes grp., and Tanytarsus spp.) comprising $66 \%$ of the individuals collected.

\section{September 2000}

total of 77 taxa including 26 EPT taxa was collected
from Station 6 in September (Tables D-2 and D-3).
A number of taxa including the mayflies Baetis intercalaris, Labiobaetis propinquus, Stenonema mexicanum integrum, and Isonychia spp., the caddisflies Nectopsyche candida and Chimarra, the beetles Stenelmis hungerfordi and Stenelmis antennalis, and the dipterans Polypedilum halterale grp., Tanytarsus sp. 2 Funk, and Polypedilum illinoensi grp. were abundant at Station 6 in September. Of the taxa listed above the baetid mayflies (Baetis intercalaris and Labiobaetis propinquus) were collected primarily from pilings and associated woody debris in moderate to fast current while the beetles were collected mainly from willow roots in moderate to fast current. Other abundant taxa including Isonychia, Nectopsyche candida, and Chimarra were abundant among both willow roots and woody debris in moderate to fast current. In contrast to the April collections, which included many rare taxa, only one rare taxon (the chironomid Mesosmittia sp.) 
was collected from Station 6 in September. Chironomid collections also differed from April with fewer individuals and taxa collected and the three most abundant taxa (Tanytarsus sp. 2 Funk, Polypedilum illinoensi grp., and Polypedilum halterale grp.) comprising fewer of the chironomids collected (only $46 \%$ in September compared to $66 \%$ in April). Except for the collection of two gerrid taxa, other hemipteran taxa were absent from Station 6 collections in September.

\section{Similarities Between Seasons}

ommunity composition differed greatly between sea-
sons in 2000 with much higher richness and abun-
dance in April compared to September for most groups. Thus there were few similarities across seasons. The exceptions included the mayfly Baetis intercalaris, the caddisfly Nectopsyche candida, and the beetles Stenelmis hungerfordi and Stenelmis antennalis, which were abundant across seasons.

\section{Station Comparisons for 2000 Based on Qualitative Collections}

\section{Comparison of Stations 1 and 2B in April 2000}

lthough fewer individuals and taxa (all groups
pooled) were collected at Station $2 \mathrm{~B}$ compared to
Station 1, EPT Richness and the abundance of several groups including the mayflies, stoneflies, and some caddisflies were higher at Station 2B than Station 1. Most mayfly families including the baetids (particularly Labiobaetis propinquus grp. and Baetis intercalaris), the ephemerellids (particularly Eurylophella doris and Ephemerella dorothea), and the heptageniids (particularly Stenonema mexicanum integrum) were more abundant at Station $2 \mathrm{~B}$ than at Station 1. Differences in the stonefly fauna, which consisted primarily of Perlesta spp. at both stations, included higher overall abundance at Station 2B than at Station 1 and the presence of Pteronarcys dorsata at Station 2B but not Station 1. Although overall caddisfly abundance was higher at Station 1, two genera (Cheumatopsyche and Macrostemum) were collected from Station 2B but not Station 1 and another genus 
(Chimarra) was more abundant at Station 2B than Station 1. Other taxa, including the beetles Ancyronyx variegata and Dineutus discolor and the dipterans Nanocladius spp., Polypedilum halterale grp., Rheotanytarsus spp., Cryptochironomus spp., and Tanytarsus spp. were also more abundant at Station 2B than at Station 1.

A number of other groups (mainly non-EPT taxa) including the dragonflies (especially Corduliidae), damselflies, hemipterans, four beetles (Dytiscidae, Haliplidae, Hydrophilidae, and Dubiraphia), two caddisflies (Hydropsyche and Ceraclea), two mayflies (Centroptilum/Procloeon and Caenis), and five dipterans (Simulium spp. and the chironomids Procladius sp., Chironomus spp., Dicrotendipes nr. modestus and Tanytarsus sp. 2 Funk) were more abundant at Station 1 than at Station 2B. Some of these differences were large and included the complete absence of some taxa from Station 2B (Hemiptera, Corduliidae, Hydrophilidae, Dubiraphia, Simulium, and Dicrotendipes nr. modestus) and order of magnitude higher abundances at Station 1 compared to Station 2B for another taxon (Chironomus spp.). The abundances of Argia apicalis, Enallagma basidens and Enallagma nr. divagans in slow-current, backwater habitats at Station 1 was responsible for most of the difference in damselfly abundance between stations. The abundance of the dytiscid beetles Neoporus and Coptotomus, the haliplid beetle Peltodytes, and the hemipteran Corixidae in backwater areas resulted in elevated dytiscid, haliplid, and hemipteran abundances at Station 1 compared to Station 2B. Similarly, Chironomus spp. was more abundant at Station 1 than at Station 2B due to its abundance in backwater areas at Station 1. Generally, differences in slow current habitat between Stations 1 and 2B appeared to contribute to most of the abundance differences described above (i.e., extensive backwater areas were present at Station 1 but not Station 2B, possibly resulting in higher abundances of backwater taxa at Station 1 compared to Station 2B).

\section{Comparison of Stations 1 and 2B in September 2000}

s in April, fewer individuals and taxa (all insect
groups pooled) were collected at Station $2 \mathrm{~B}$ com-
pared to Station 1 in September, but EPT Richness 
Station 2B was higher mainly due to the higher number of mayfly and caddisfly taxa collected at Station 2B compared to Station 1. In addition to higher EPT Richness, the abundances of several taxa including the dobsonfly Corydalus cornutus, the caddisfly Chimarra, the beetles Stenelmis, Dineutus, and Ancyronyx and the chironomids Tanytarsus sp. 2 Funk and Rheotanytarsus spp. were higher at Station 2B than at Station 1. The mayfly Stenonema (mainly Stenonema mexicanum integrum) was collected in moderate numbers from Station 2B, but was absent from Station 1. Additional taxa including the stonefly Pteronarcys dorsata and the caddisflies Triaenodes and Macrostemum and the chironomid Nanocladius were collected in low numbers from Station $2 \mathrm{~B}$ but were absent from Station 1.

A number of other groups including the dragonflies and damselflies (especially the dragonfly Corduliidae and the damselfly Enallagma), the mayflies (especially Centroptilum/ Procloeon, Caenis, and Tricorythodes spp.) the hemipteran Corixidae, the caddisfly Hydropsyche and Oecetis, the beetle Dubiraphia and Peltodytes, and the chironomids Ablabesmyia, Procladius, Chironomus, Dicrotendipes nr. modestus, Polypedilum illinoensi grp., and Polypedilum halterale grp. were more abundant at Station 1 than at Station 2B. Some of these differences were large with the complete absence of Dubiraphia, Procladius, Dicrotendipes nr. modestus, and Chironomus spp. from Station 2B. The association of many of these taxa with backwater areas (Caenis, Corixidae, Dubiraphia, Peltodytes, Chironomus, Centroptilum/Procloeon, Corduliidae, and Enallagma) or willow root masses (Tricorythodes), both of which were absent from Station 2B may have been responsible for the abundance differences described above. Chironomid richness was greater at Station 1 than at Station 2B (again possibly due to the presence of large quantities of backwater habitat at Station 1 but not Station 2B) and rare taxa were more frequently collected from Station 1 than from Station 2B (10 rare taxa were collected at Station 1 compared to 5 at Station $2 \mathrm{~B})$. 


\section{Comparison of Stations 1 and 2B Across Seasons in 2000}

$\mathbf{T}$

The following differences were consistent across both sampling periods. EPT Richness and the abundances

of the mayfly Stenonema (especially Stenonema mexicanum integrum), the caddisflies Macrostemum and Chimarra, the beetles Ancyronyx and Dineutus, and the chironomids Nanocladius, Rheotanytarsus, and Tanytarsus were higher at Station 2B than at Station 1. Differences between stations were particularly large for Nanocladius (20 individuals collected from Station 2B, but none from Station 1). Similarly, the stonefly Pteronarcys dorsata and the caddisfly Macrostemum were collected from Station 2B (although in low numbers), but were absent from Station 1. Higher EPT Richness and the abundance of the previously mentioned taxa at Station 2B (compared to Station 1) did not appear to be due to greater habitat quality or quantity at Station $2 B$. In fact, habitat quality and quantity generally appeared to be higher at Station 1 than at Station 2B (i.e., backwater areas and willow root masses were present at Station 1, but absent at Station 2B).

Overall abundance and richness (all groups pooled) and the abundances of several groups including the damselflies (especially Enallagma), dragonflies (especially Corduliidae), the mayflies Centroptilum/Procloeon and Caenis, the hemipteran Corixidae, the caddisfly Hydropsyche, the beetles Dubiraphia and Peltodytes, and the chironomids Procladius, Chironomus, and Dicrotendipes nr. modestus were higher at Station 1 than at Station 2B across seasons. Differences between stations were particularly large for Dubiraphia (16 individuals were collected from Station 1, but none from Station 2B), Corixidae (154 individuals were collected from Station 1, but only 1 from Station 2B), Procladius (46 individuals were collected from Station 1, but only 1 from Station 2B), Chironomus (279 individuals were collected from Station 1, but only 17 from Station 2B), and Dicrotendipes nr. modestus (26 individuals were collected from Station 1, but none from Station 2B). Habitat differences (i.e., extensive backwater areas were present at Station 1, but not Station 2B) may have contributed to greater damselfly, dragonfly, corixid, Centroptilum/Procloeon, Caenis, Dubiraphia, Peltodytes, and Chironomus abundances at Station 1 compared to Station $2 \mathrm{~B}$ because 
these groups are generally abundant in slow current backwater areas but uncommon elsewhere. Differences in the abundance of Hydropsyche, Procladius, and Dicrotendipes nr. modestus probably did not result from habitat differences between stations.

\title{
Comparison of Station 1 with Stations 5 and 6 in April of 2000
}

\author{
Total Richness, EPT Richness, and the abundance of a \\ number of groups including the mayflies and the \\ stoneflies were higher at downstream Stations 5 and
} 6 than at Station 1. Elevated mayfly abundance at Stations 5 and 6 was mainly due to the much higher abundances of three genera (Baetis, Ephemerella, and Heptagenia) at Stations 5 and 6 compared to Station 1. A few individuals of another mayfly (Isonychia) were collected from Station 6, but not Stations 1 or 5. All three of the stonefly taxa collected in April (Perlesta, Paragnetina, and Pteronarcys) were more abundant at Stations 5 and 6 than at Station 1. A number of caddisflies including Cheumatopsyche, Macrostemum, Nectopsyche and Ceraclea nr. punctata were much more abundant at Stations 5 and 6 than at Station 1. Low numbers of two other caddisflies (Pycnopsyche and Phylocentropus) were collected from Stations 5 and 6, but not Station 1. The damselfly Argia sedula was absent from Station 1 but moderate numbers were collected from Stations 5 and 6. Two beetles (Ancyronyx and Macronychus) were also much more abundant at Stations 5 and 6 than at Station 1. Another beetle (Stenelmis antennalis) was abundant at Station 6, but absent from Stations 1 and 5. Differences among stations (see above) were particularly large for Heptagenia (35 individuals were collected from Station 5 and 37 individuals from Station 6 but only 2 individuals were collected from Station 1), Pteronarcys dorsata (25 individuals were collected from Station 5 and 23 from Station 6 but none was collected from Station 1), Cheumatopysche (46 individuals were collected from Station 5 and 29 from Station 6 but none was collected from Station 1), and Macrostemum (21 individuals were collected from Station 5 and 22 from Station 6 but none was collected from Station 1). Rare taxa were collected more frequently from Stations 5 and 6 (12 and 17 taxa, respectively) than Station 1 ( 5 taxa) with rare beetles exhibiting the greatest difference (only 1 rare beetle 
taxa was collected from Station 1 compared to 7 and 8 for Stations 5 and 6 , respectively).

Several groups including the dragonfly Corduliidae, hemipteran Corixidae, the caddisflies Hydropsyche and Ceraclea maculata, the beetle Gyrinus analis/lugens and several chironomids including Psectrocladius, Dicrotendipes nr. modestus, and Tanytarsus sp. 2 Funk were more abundant at Station 1 than at Stations 5 and 6. An additional beetle, Peltodytes, was more abundant at Station 1 than Station 5 but not Station 6.

\section{Comparison of Station 1 with Stations 5 and 6 in September 2000}

$\mathbf{E}$

PT Richness was higher at downstream Stations 5 and 6 than at Station 1. This was mainly due to higher mayfly richness at Stations 5 and 6 than at Station 1 (i.e., 12 and 13 mayfly taxa at Stations 5 and 6, respectively but only 7 mayfly taxa at Station 1 ). Stoneflies were absent from Station 1, but low numbers of two stonefly taxa (Paragnetina kansensis and Pteronarcys dorsata) were collected from both Station 5 and Station 6. The abundances of a number of additional taxa including three mayflies (Labiobaetis propinquus grp. Stenonema, and Isonychia), several caddisflies (Macrostemum, Nectopsyche, Triaenodes, and Chimarra), and the beetles (mainly Stenelmis hungerfordi, Stenelmis antennalis, and Dineutus discolor) were higher at Stations 5 and 6 than at Station 1. Another taxon, the damselfly Argia sedula, was collected in low numbers from Stations 5 and 6 but was absent from Station 1. Differences among stations (see above) were particularly large for Stenonema (27 individuals were collected from Station 5 and 30 from Station 6 but none was collected from Station 1), Isonychia spp. (44 individuals were collected from Station 5 and 33 from Station 6 but none was collected from Station 1), Macrostemum (21 individuals were collected from Station 5 and 16 from Station 6 but none was collected from Station 1), Chimarra (44 individuals collected from Station 5 and 31 from Station 6 but only 1 was collected from Station 1), Stenelmis antennalis (25 individuals were collected from Station 5 and 44 from Station 6 but only 1 was collected from Station 1), and Dineutus discolor (83 individuals were collected from Station 5 and 25 individuals from Station 6 but only 1 was collected from 
Station 1). Rare taxa were more frequently collected from Station 1 (10) than from Stations 5 (5) or 6 (1). Higher EPT Richness, mayfly richness, and abundance of the previously mentioned taxa at Stations 5 and 6 (compared to Station 1) could have been due to the availability of willow root masses in medium to fast current at Stations 5 and 6 but not Station 1.

Total Richness (all groups pooled) was higher at Station 1 than at Stations 5 and 6 (mainly due to the collection of 35 chironomid taxa at Station 1 compared to 23 and 24 chironomid taxa at Stations 5 and 6, respectively). Chironomid abundance was also much higher at Station 1 than at Stations 5 or 6 . Several additional groups including the dragonfly Corduliidae, two mayflies (Centroptilum/Procloeon and Caenis), the hemipteran Corixidae, the caddisfly Hydropsyche, the beetle Peltodytes, and the several chironomids including Ablabesmyia, Procladius, Polypedilum and Dicrotendipes nr. modestus were more abundant at Station 1 than at Stations 5 and 6. Differences were particularly large for Hydropsyche [52 individuals were collected from Station 1 but only 2 individuals were collected from Station 5 and 3 from Station 6] and Procladius (30 individuals were collected from Station 1 but none was collected from Station 5 and only 2 from Station 6).

\section{Comparison of Station 1 with Stations 5 and 6 Across Seasons in 2000}

he following differences were consistent across sam-
pling periods. EPT Richness was much higher at
downstream stations 5 and 6 than at Station 1 ( 9 more EPT taxa were collected at each of the downstream stations in April than at Station 1 and 10 more EPT taxa at each of the downstream stations in September than at Station 1). Furthermore, several taxa were collected from Stations 5 and 6 but were absent from Station 1 including the stoneflies Paragnetina kansensis and Pteronarcys dorsata, the damselfly Argia sedula, and the caddisfly Macrostemum. Other taxa including the caddisfly Nectopsyche and the mayfly

Stenonema mexicanum integrum were more abundant at Stations 5 and 6 than at Station 1. Differences among stations were particularly large for Stenonema mexicanum integrum (i.e., one individual was collected in April and none in September at Station 1 but moderate to large numbers were col- 
lected at Stations 5 and 6 during both seasons). The beetles Stenelmis antennalis and Dineutus were also uncommon at Station 1 but large numbers were collected at Station 6 during each sampling period. Stenelmis antennalis was particularly uncommon at Station 1 with one individual collected in September but none in April. Similarly, the mayfly Isonychia was absent at Station 1 but collected at Station 6 during each sampling period. There were no obvious differences in quality or quantity of habitat among Stations 1,5 and 6 that could explain the differences described above.

Several groups were more abundant at Station 1 than at the Stations 5 and 6 during both sampling periods including the hemipteran Corixidae, the dragonfly Corduliidae, the caddisfly Hydropsyche, and the dipteran Dicrotendipes nr. modestus. In addition, the beetle Peltodytes was more abundant at Station 1 than at one downstream station (5) across seasons. Differences in the abundance of backwater habitat (it was more common at Station 1 compared to Station 5 during both sampling periods) may have contributed to higher Peltodytes, Corixidae, and Corduliidae abundances at Station 1 compared to Station 5. In contrast, other differences between the upstream and downstream stations (see above) could not consistently be attributed to differences in habitat among stations.

\section{Differences Among Stations Based on Recent Qualitative Collections}

\footnotetext{
ome differences among stations have been observed repeatedly during recent (1998-2000) qualitative surveys. These include the lower abundance of most stoneflies at Station 1 compared to Stations 2B, 5 and 6 (except Perlesta spp., which has been abundant at all the sampling stations during recent spring surveys). Stoneflies have been absent from Station 1 during all recent fall surveys except 1998 (one individual collected), but have been collected from each of the downstream stations (2B, 5 and 6) during all recent fall surveys. Additionally, other than Perlesta spp., the stonefly Perlidae has been absent from Station 1 during most recent surveys (the exception was the collection of several immature specimens from Station 1 in Spring 1998) but has been collected from Stations 5 and 6 during all recent surveys and Station 2B from all but one recent survey. As with the
} 
perlids, the caddisfly Macrostemum has been absent from Station 1 during most recent surveys (the exception was the collection of one individual from Station 1 in May 1999), but has been collected from Stations 2B, 5 and 6 during all recent surveys. Other taxa, including the mayflies Ephemerellidae and Heptagenia, were much less abundant at Station 1 than at the downstream stations during most recent spring surveys. The difference in Ephemerellidae and Heptagenia abundance was not evident in 1998, possibly because most individuals emerged prior to sampling (sampling was delayed until late June in 1998 due to high water). Additionally, the damselfly Argia sedula was always absent from Stations 1 and 2B, but was sometimes collected from Station 5 and always collected from Station 6 during recent surveys. Similarly, the mayfly Isonychia was usually absent from Stations 1 and 2B (a few individuals were collected in Spring 1998), but was moderately abundant to abundant at Station 5 during all recent fall surveys and abundant at Station 6 during most spring and fall surveys.

Other consistent differences among stations included lower abundance of Chironomus and the hemipteran Corixidae and lower abundance and richness of the Odonata (damselflies and dragonflies) at Station 2B compared to most other stations during many of the recent surveys. The preference of these taxa for backwater, no-current areas, which have been uncommon at Station 2B during recent surveys, may explain their scarcity at Station 2B.

\section{Long-term Trends in Taxa Richness Based on Qualitative Collections}

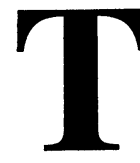

1965 at Stations 1, 5 and 6 (spring-summer long-term data are not available from Station 2B) (see Figs. D-1 to D-8). The exception to this pattern was high Total Richness in 1989 compared to 1988 and 1990. High Total Richness in 1989 was mainly due to the collection of large numbers of Coleoptera and Odonata taxa, many of which may have been present at the sampling stations in 1989 due to the pronounced rise and subsequent fall in water level during the six days proceeding 


\section{Total Richness in}

\section{Late-Spring/Summer}

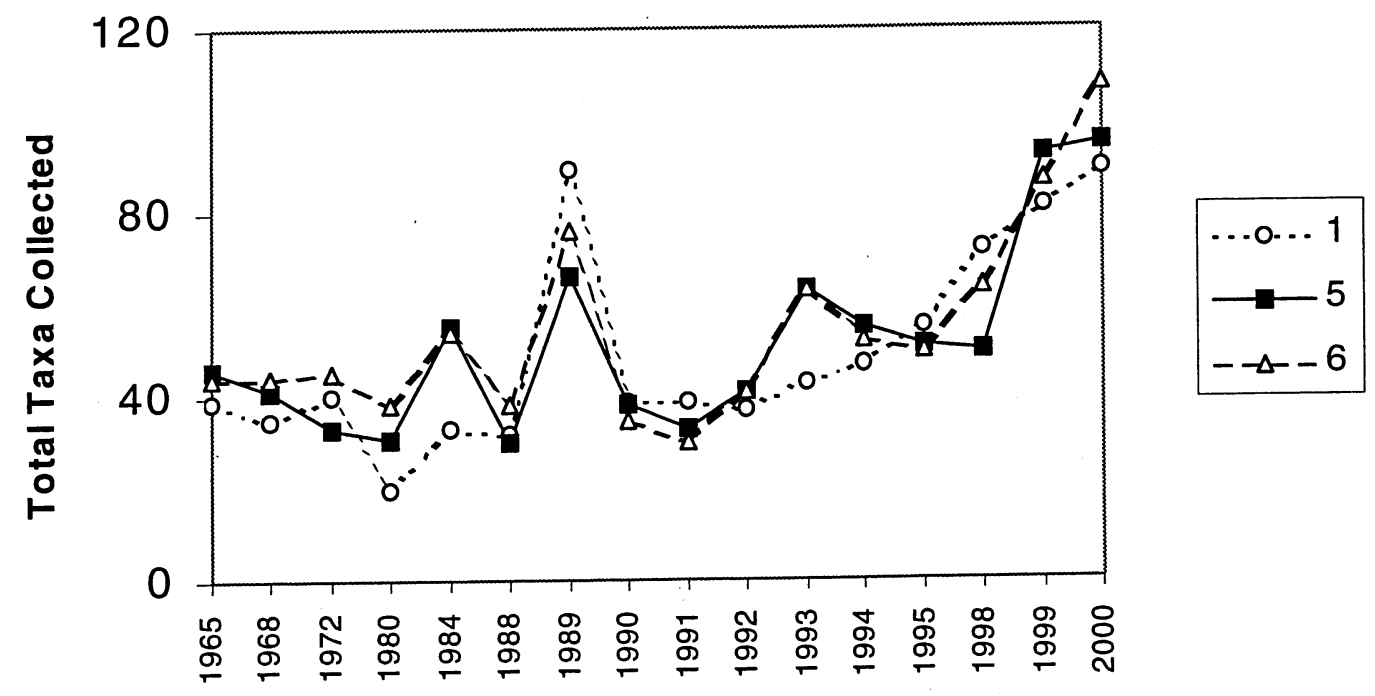

Figure D-1. Total number of insect taxa qualitatively collected (total richness) at each station during late spring-summer surveys of the Savannah River in the vicinity of the Savannah River Site (1965-2000).

EPT Richness in

Late-Spring/S u m mer

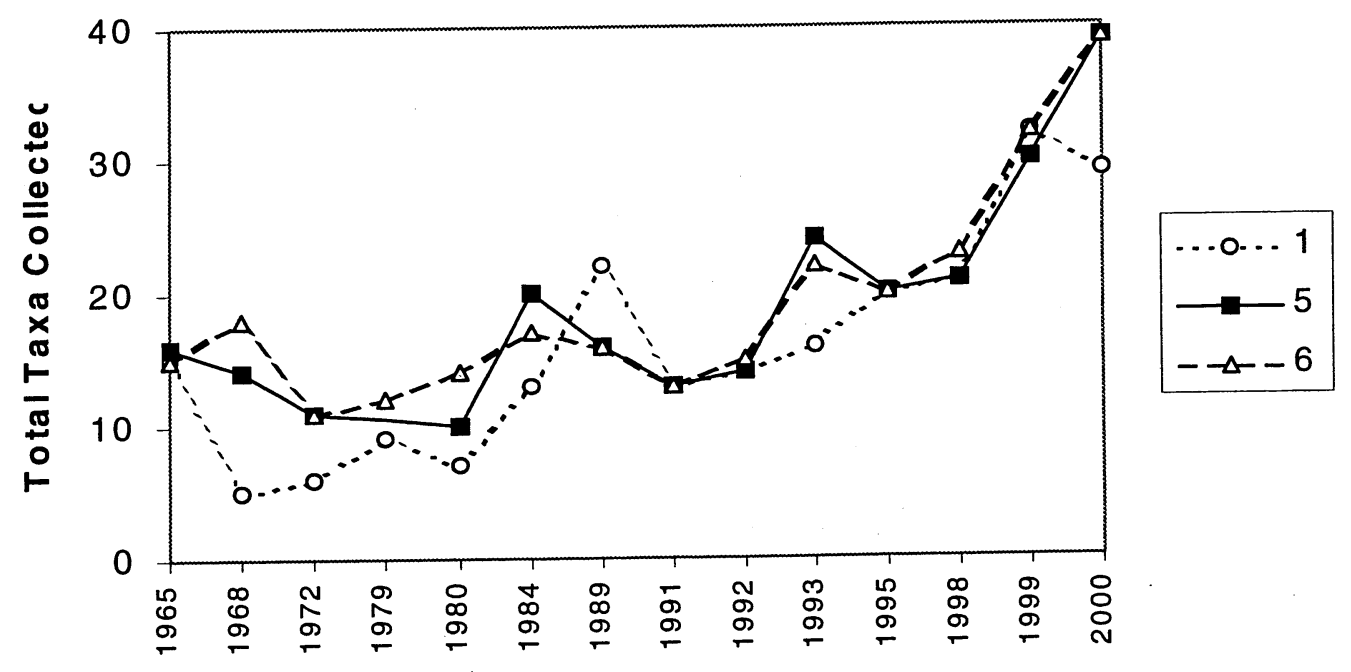

Figure D-2. Total number of EPT (Ephemeroptera, Plecoptera, and Trichoptera) taxa (EPT richness) qualitatively collected at each station during late spring-summer surveys of the Savannah River in the vicinity of the Savannah River Site (1965-2000). 


\section{Ephemeroptera Richness in Late-S pring/S u m mer}

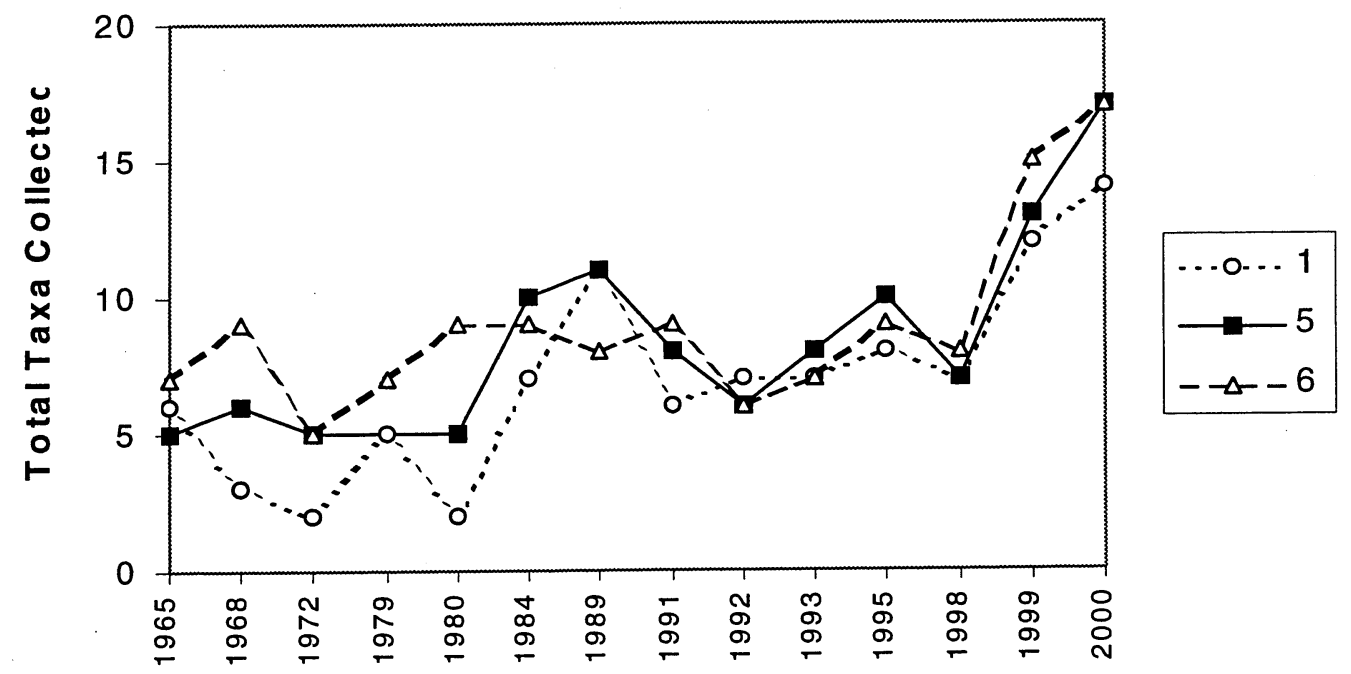

Figure D-3. Total number of Ephemeroptera taxa (Ephemeroptera richness) qualitatively collected at each station during late spring-summer surveys of the Savannah River in the vicinity of the Savannah River Site (1965-2000).

\section{Plecoptera Richness in \\ Late-Spring/Su m mer}

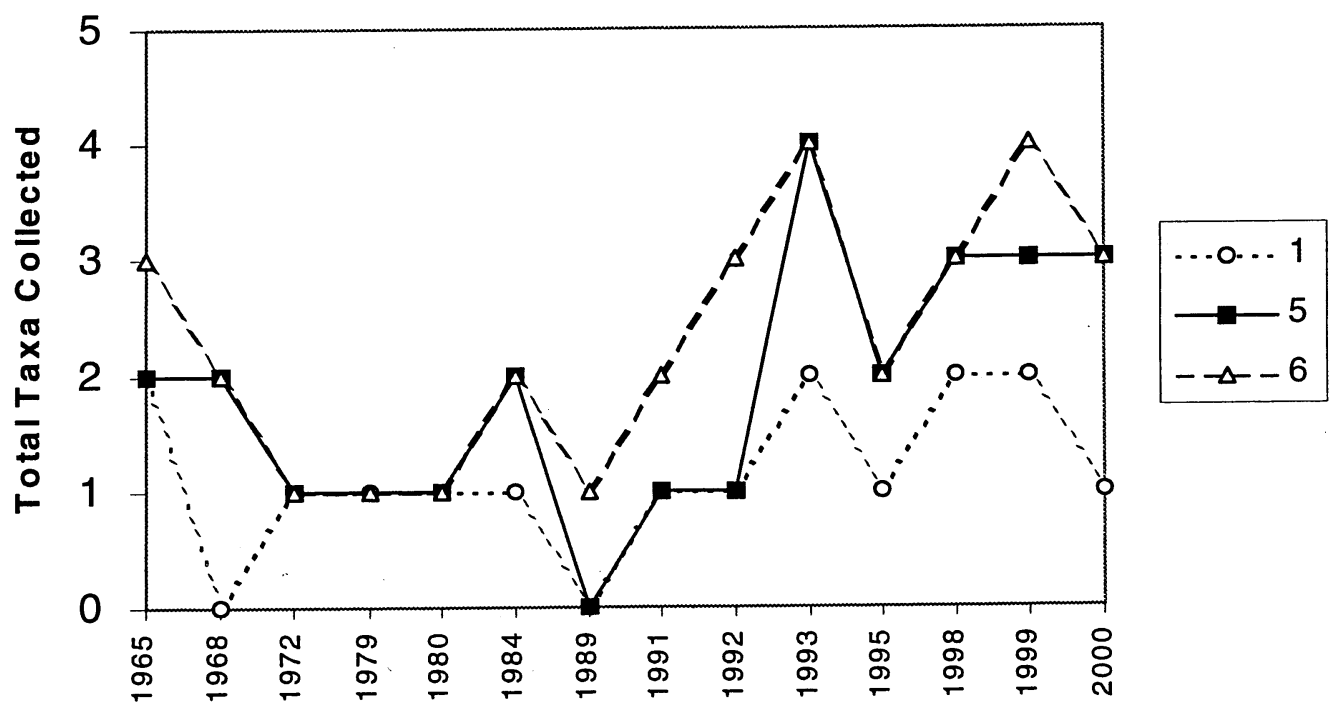

Figure D-4. Total number of Plecoptera taxa (Plecoptera richness) qualitatively collected at each station during late spring-summer surveys of the Savannah River in the vicinity of the Savannah River Site (1965-2000). 


\section{Trichoptera Richness in}

Late-Spring/Summer

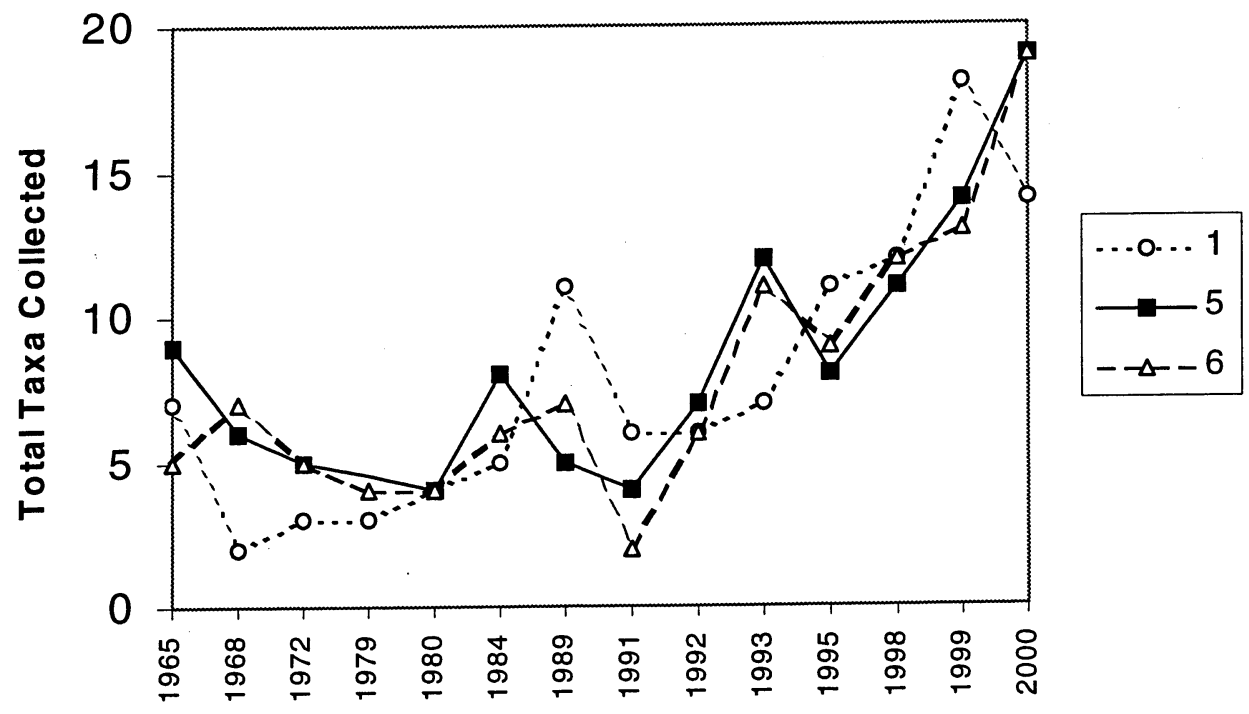

Figure D-5. Total number of Trichoptera taxa (Trichoptera richness) qualitatively collected at each station during late spring-summer surveys of the Savannah River in the vicinity of the Savannah River Site (1965-2000).

\section{Odonate Richness in}

\section{Late-S pring/S u m mer}

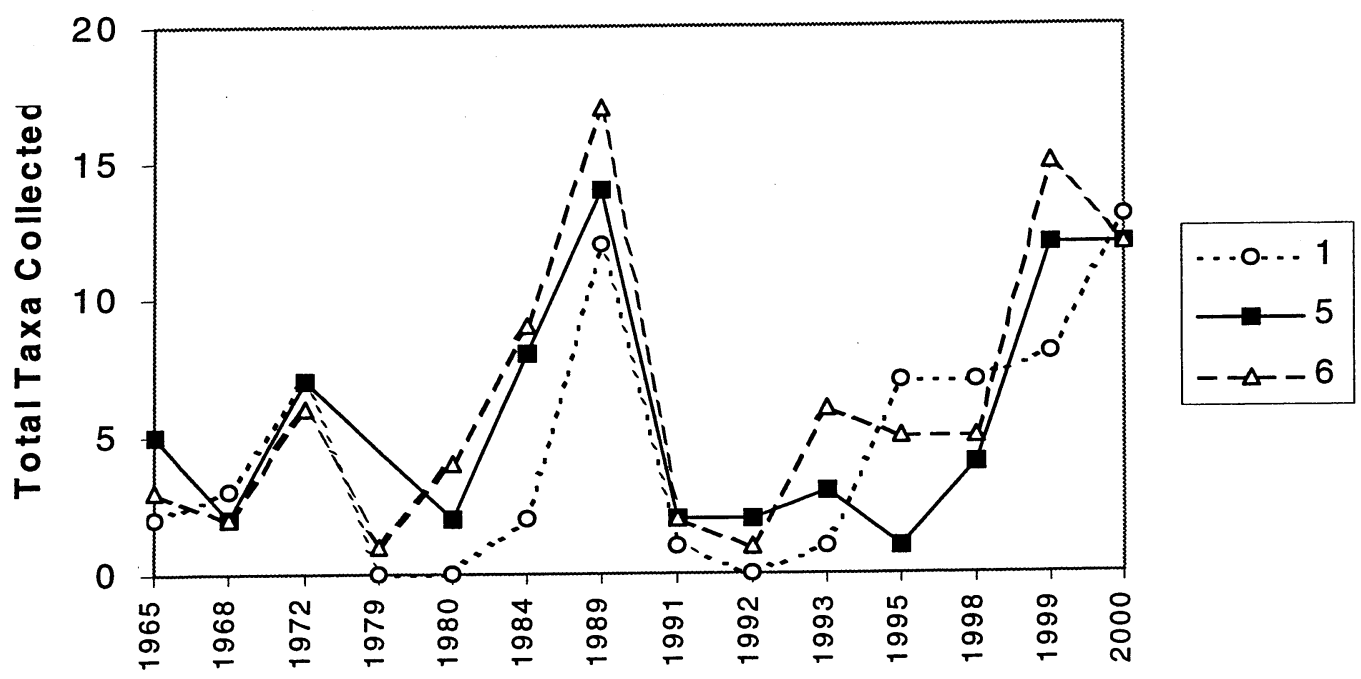

Figure D-6. Total number of Odonate taxa qualitatively collected (Odonate richness) at each station during late spring-summer surveys of the Savannah River in the vicinity of the Savannah River Site (1965-2000). 


\section{Coleoptera Richness in \\ Late-Spring/Summer}

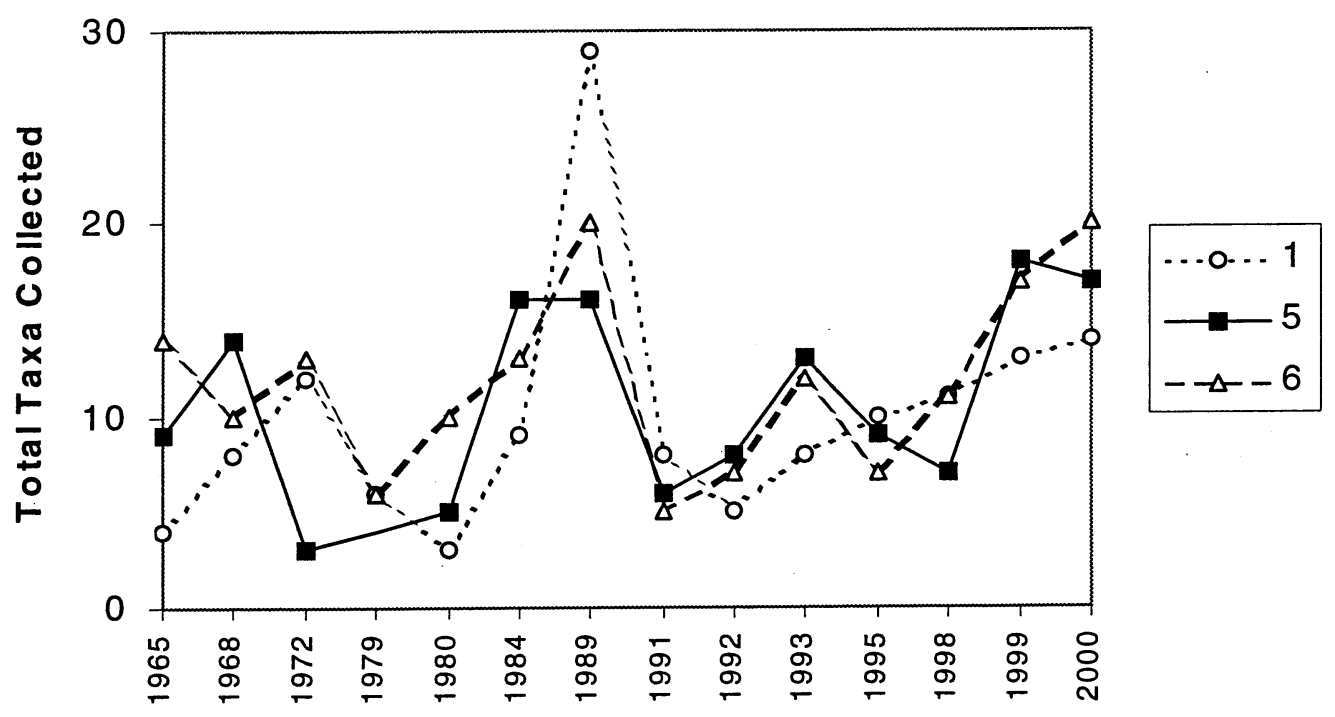

Figure D-7. Total number of Coleoptera taxa qualitatively collected (Coleoptera richness) at each station during late spring-summer surveys of the Savannah River in the vicinity of the Savannah River Site (1965-2000).

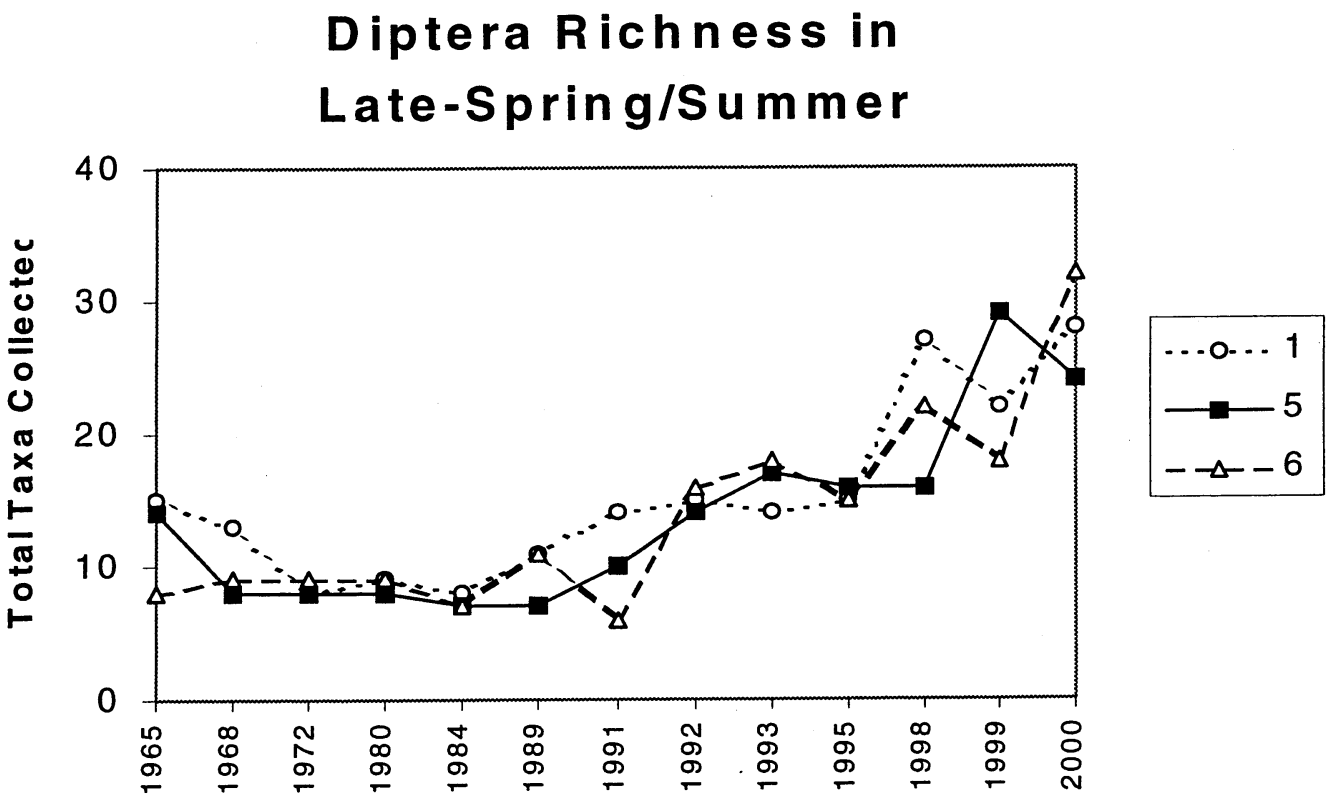

Figure D-8. Total number of Diptera taxa (Diptera richness) qualitatively collected at each station during late spring-summer surveys of the Savannah River in the vicinity of the Savannah River Site (1965-2000). 
sampling (see ANSP 1991 for additional details concerning water level fluctuations in 1989). Richness of other aquatic insect orders including Plecoptera, Odonata, and Coleoptera has generally increased since the early 1990s (see Figs. D-1 to D-8). For many orders, richness in April 2000 was high compared to past spring-summer surveys. For example, a record number of Ephemeroptera taxa were collected at Stations 1, 5 and 6 in April 2000 relative to previous spring-summer surveys (data available from 1965 to present). Also in April 2000, Total, EPT, and Trichoptera Richness at Stations 5 and 6, Odonata Richness at Station 1, and Diptera Richness at Stations 1 and 6 were the highest recorded. Except for 1989, Total Richness at Station 1 and Coleoptera Richness at Station 6 in April 2000 were the highest on record. Similarly, except for 1999, Diptera Richness at Station 5 in April 2000 was the highest on record.

The results of late summer-fall surveys indicate that Total Richness and richness within most major orders of aquatic insects have generally increased since the late 1980s/early 1990s (Figs. D-9 to D-16). Richness in September 2000 was especially high at Stations 1 and 2B compared to past surveys. For example, a record number of total (all groups pooled) and Diptera taxa were collected at Stations 1 and 2B relative to previous summer-fall surveys (data available from 1955 to present for Station 1 and 1985 to present for Station 2B). Also in September 2000, Trichoptera, and Coleoptera Richness at Station 2B, was the highest recorded. Odonata Richness at Stations 1 and 5 was nearly the highest on record in September 2000 (at Station 1 Odonata Richness was higher in 2000 than in all years except 1976 and at Station 5 it was higher in 2000 than in all years except 1955). Diptera Richness at Stations 5 and 6 was also nearly the highest on record in 2000 (at Station 5 Diptera Richness was higher in 2000 than in all years except 1999 and at Station 6 it was higher in 2000 than in all years except 1998).

\section{April and September 2000 Quantitative Collections}

7 otal insect densities (all taxa pooled) among the 4 stations averaged 3,148-17,067 insects/trap in April and 3,670-7,043 insects/trap in September (Table D-4a). 


\section{Total Richness in}

\section{Late-Summer/Fall}

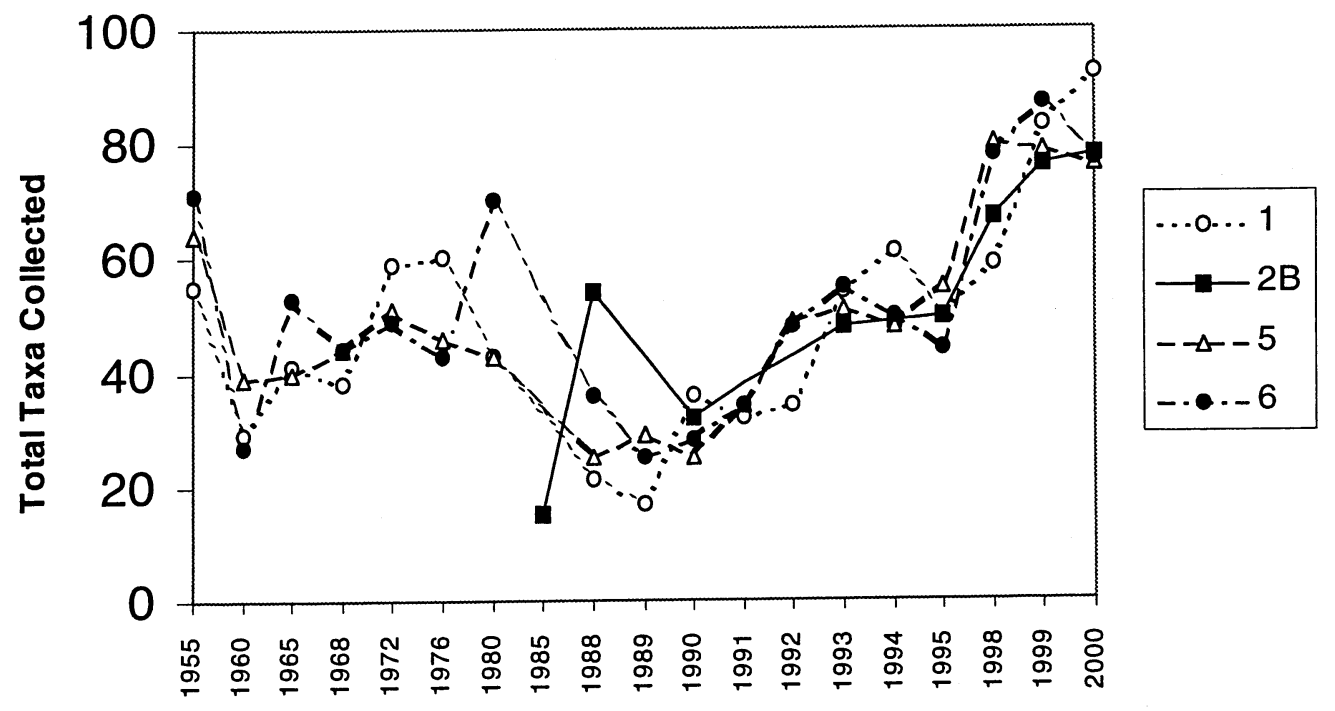

Figure D-9. Total number of insect taxa qualitatively collected (total richness) at each station during late summer-fall surveys of the Savannah River in the vicinity of the Savannah River Site (1955-2000).

\section{EPT Richness in}

\section{Late-Summer/Fall}

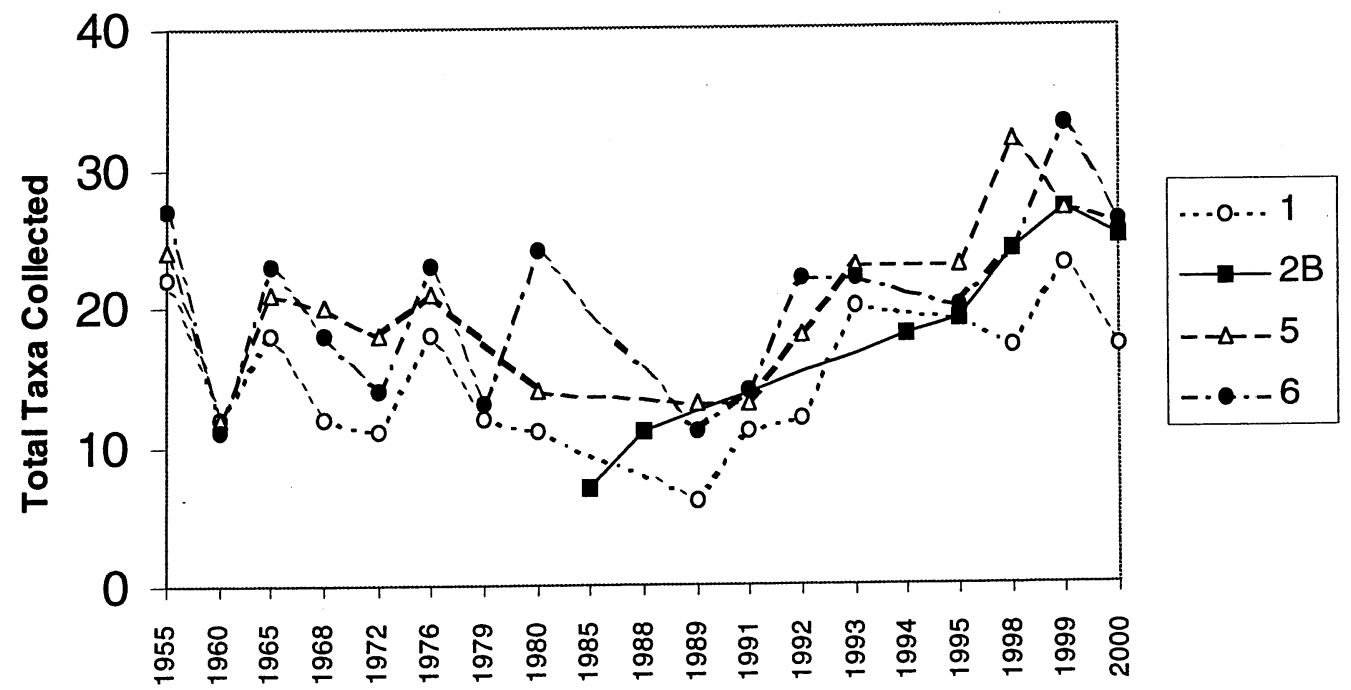

Figure D-10. Total number of EPT (Ephemeroptera, Trichoptera, and Plecoptera) taxa (EPT richness) qualitatively collected at each station during late summer-fall surveys of the Savannah River in the vicinity of the Savannah River Site (1955-2000). 


\section{Ephemeroptera Richness in \\ Late-Summer/Fall}

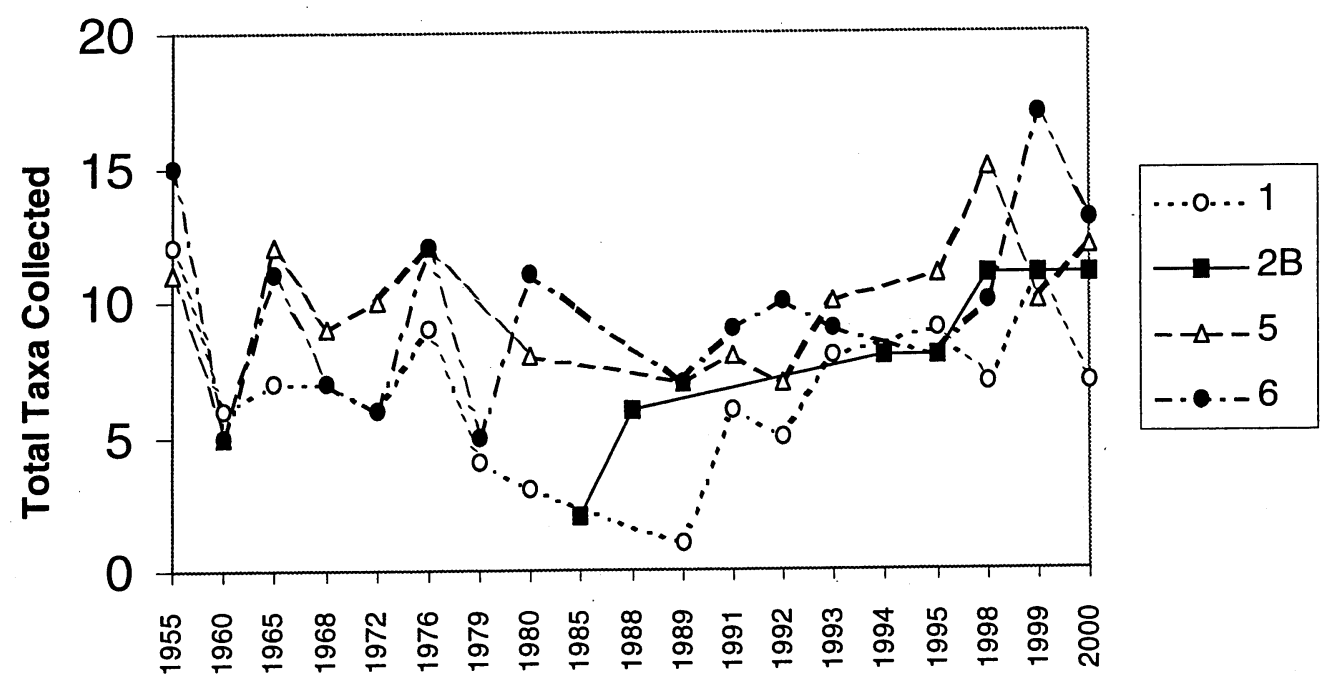

Figure D-11. Total number of Ephemeroptera taxa (Ephemeroptera richness) qualitatively collected at each station during late summer-fall surveys of the Savannah River in the vicinity of the Savannah River Site (1955-2000).

\section{Plecoptera Richness in}

\section{Late-Summer/Fall}

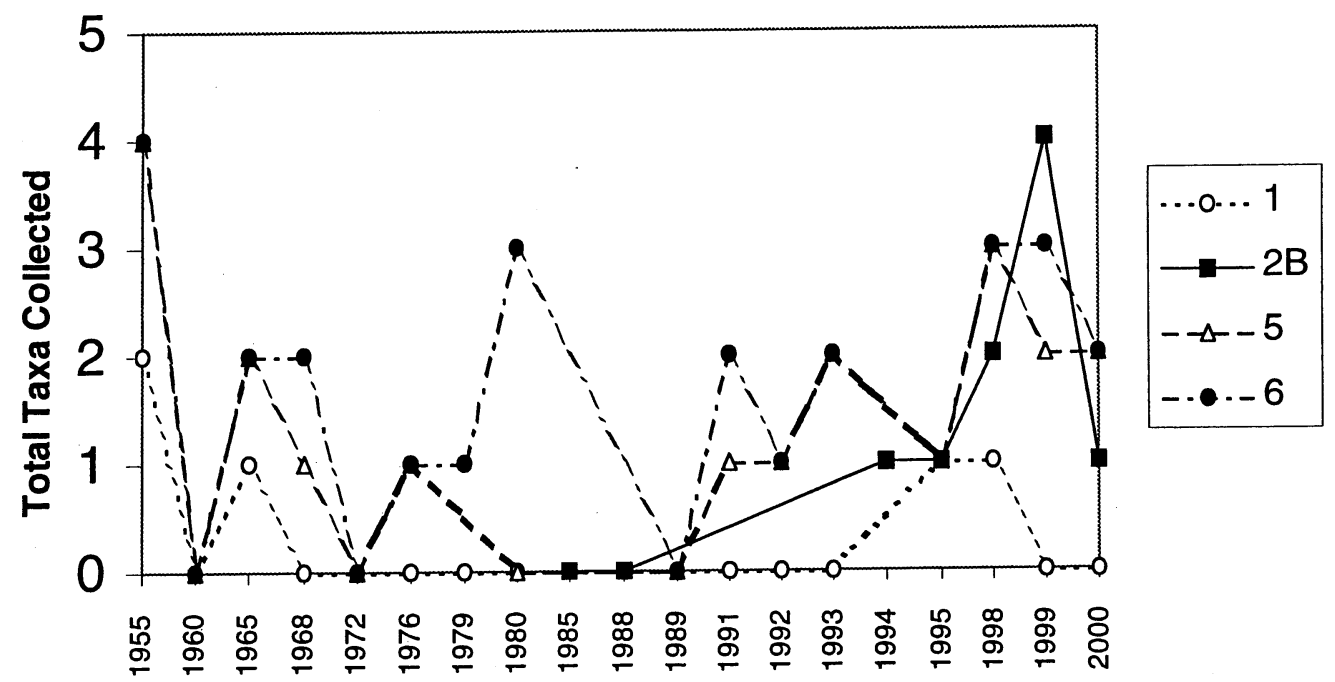

Figure D-12. Total number of Plecoptera taxa (Plecoptera richness) qualitatively collected at each station during late summer-fall surveys of the Savannah River in the vicinity of the Savannah River Site (1955-2000). 


\section{Trichoptera Richness in \\ Late-Summer/Fall}

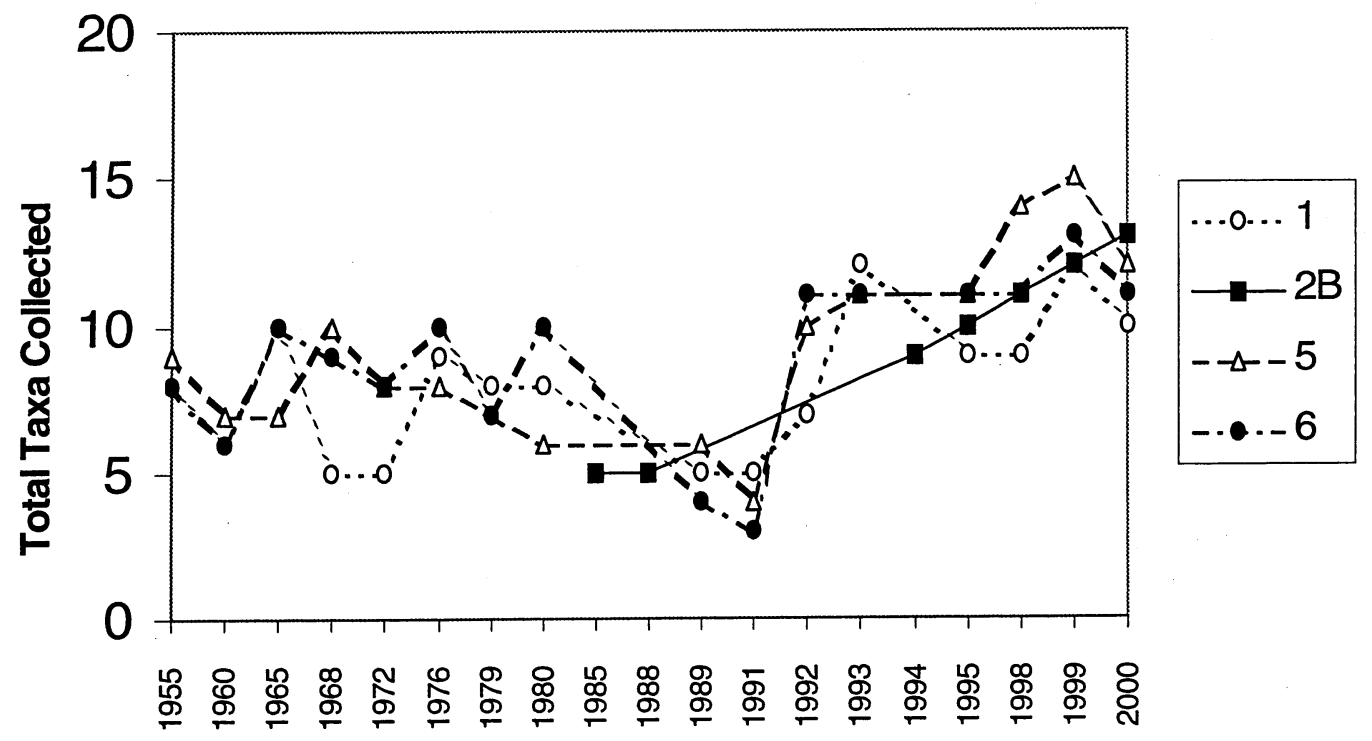

Figure D-13. Total number of Trichoptera taxa (Trichoptera richness) qualitatively collected at each station during late summer-fall surveys of the Savannah River in the vicinity of the Savannah River Site (1955-2000).

\section{Odonate Richness in}

\section{Late-Summer/Fall}

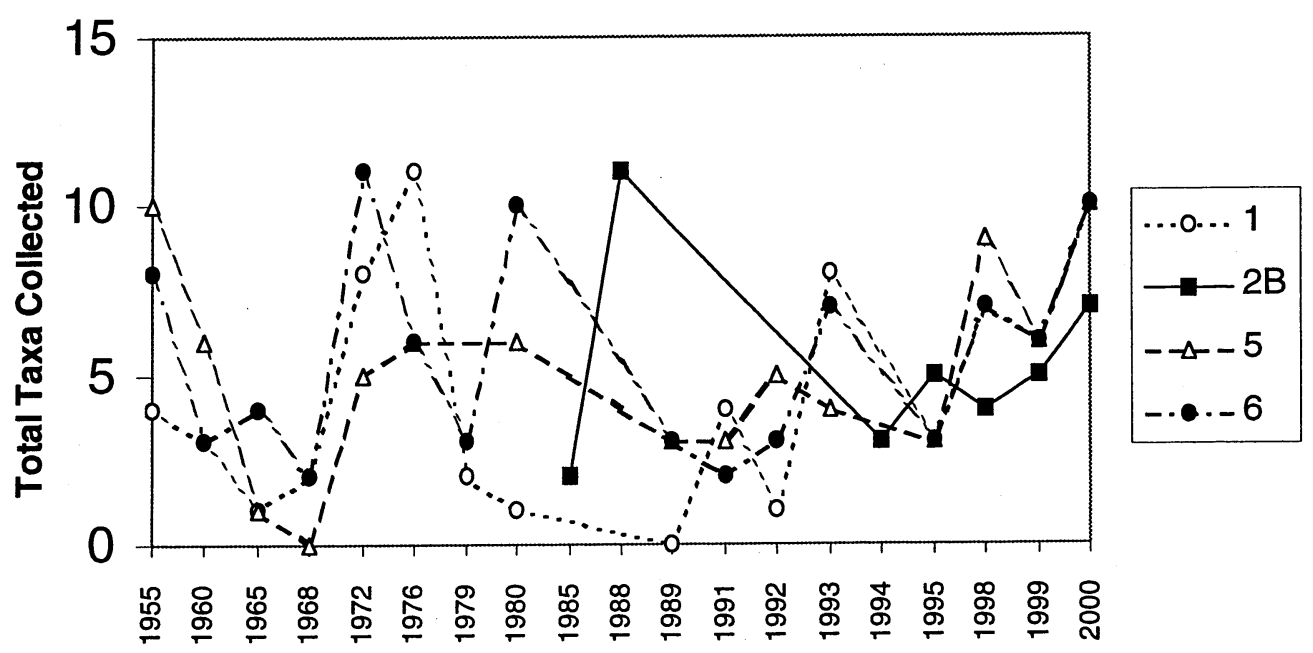

Figure D-14. Total number of Odonate taxa qualitatively collected (Odonate richness) at each station during late summer-fall surveys of the Savannah River in the vicinity of the Savannah River Site (1955-2000). 


\section{Coleoptera Richness in}

\section{Late-Summer/Fall}

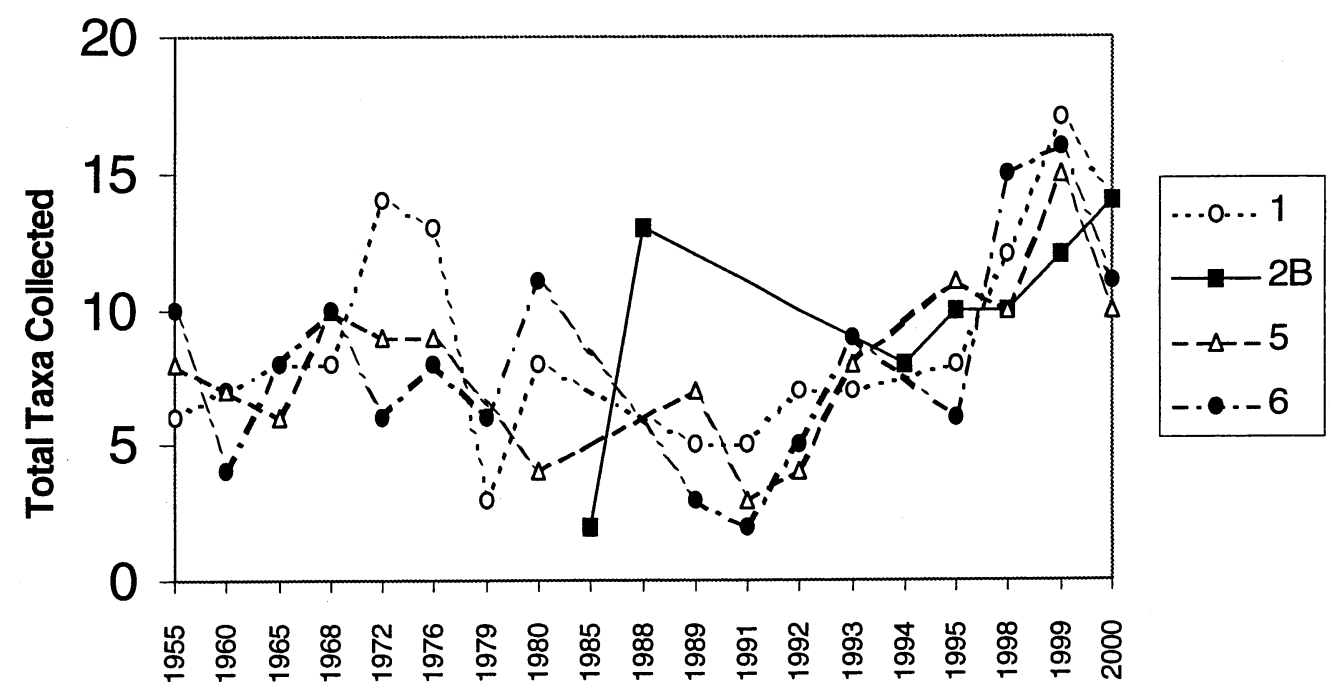

Figure D-15. Total number of Coleoptera taxa qualitatively collected (Coleoptera richness) at each station during late summer-fall surveys of the Savannah River in the vicinity of the Savannah River Site (1955-2000).

\section{Diptera Richness in}

\section{Late-Summer/Fall}

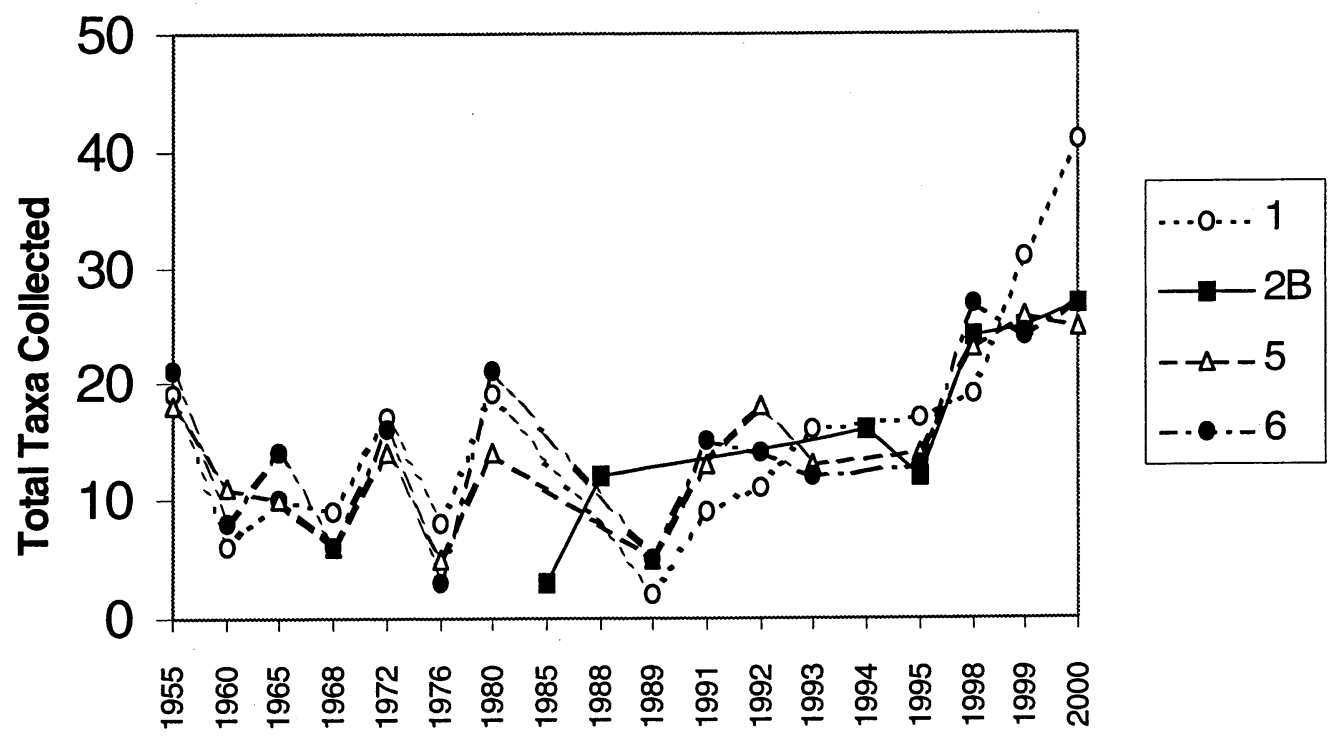

Figure D-16. Total number of Diptera taxa (Diptera richness) qualitatively collected at each station during late summer-fall surveys of the Savannah River in the vicinity of the Savannah River Site (1955-2000). 


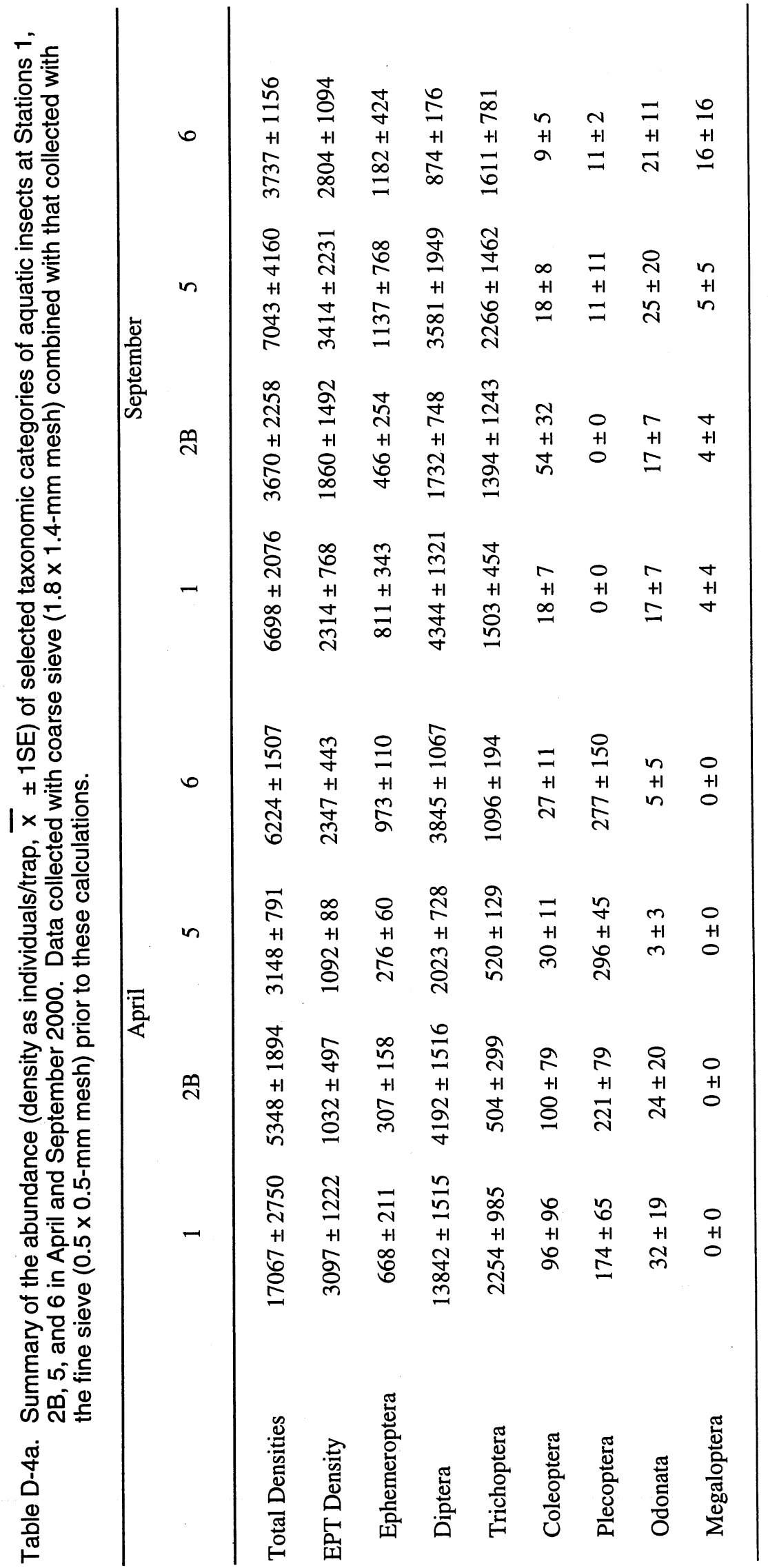


Table D-4b. Summary of the results of statistical tests (2-way ANOVA with station $x$ season interaction (inter.)) used to evaluate station (Stations 1, 2B, 5, 6) and season ( $A=$ April, $S=$ September) differences $(p<0.05)$ for selected taxonomic categories of aquatic insects in 2000. Data collected with the coarse sieve $(1.8 \times .4-\mathrm{mm}$ mesh) combined with that collected with the fine sieve $(0.5 \times 0.5-\mathrm{mm}$ mesh) prior to these analyses. NA indicates that statistical analyses were not applied because densities were too low. Blanks for season or station comparisons indicate no significant difference $(p>0.05)$.

\begin{tabular}{|c|c|c|c|c|c|c|c|c|c|}
\hline & & $\mathbf{P}$ & Season & 1 vs $2 B$ & 1 vs 5 & 1 vs 6 & 2B vs 5 & 2B vs 6 & 5 vs 6 \\
\hline \multirow[t]{3}{*}{ Total Density } & Station & 0.106 & & & & & & & \\
\hline & Season & 0.147 & & & & & & & \\
\hline & Inter. & 0.742 & & & & & & & \\
\hline \multirow{3}{*}{ EPT Density } & Station & 0.706 & & & & & & & \\
\hline & Season & 0.415 & & & & & & & \\
\hline & Inter. & 0.643 & & & & & & & \\
\hline \multirow[t]{3}{*}{ Ephemeroptera } & Station & 0.078 & & & & & & & \\
\hline & Season & 0.373 & & & & & & & \\
\hline & Inter. & 0.789 & & & & & & & \\
\hline \multirow[t]{3}{*}{ Diptera } & Station & $0.026^{\mathrm{a}}$ & & & & & & & \\
\hline & Season & 0.016 & $\mathrm{~A}>\mathrm{S}$ & & & & & & \\
\hline & Inter. & 0.622 & & & & & & & \\
\hline \multirow[t]{3}{*}{ Trichoptera } & Station & 0.248 & & & & & & & \\
\hline & Season & 0.945 & & & & & & & \\
\hline & Inter. & 0.982 & & & & & & & \\
\hline \multirow[t]{3}{*}{ Coleoptera } & Station & 0.662 & & & & & & & \\
\hline & Season & 0.700 & & & & & & & \\
\hline & Inter. & 0.771 & & & & & & & \\
\hline \multirow[t]{3}{*}{ Plecoptera } & Station & 0.022 & & & & $6>1$ & & $6>2 B$ & \\
\hline & Season & $<0.001$ & $A>S$ & & & & & & \\
\hline & Inter. & 0.095 & & & & & & & \\
\hline \multirow[t]{3}{*}{ Odonata } & Station & 0.746 & & & & & & & \\
\hline & Season & 0.327 & & & & & & & \\
\hline & Inter. & 0.784 & & & & & & & \\
\hline \multirow[t]{2}{*}{ Megaloptera } & Station & NA & & & & & & & \\
\hline & $\begin{array}{l}\text { Season } \\
\text { Inter. }\end{array}$ & & & & & & & & \\
\hline \multirow[t]{2}{*}{ Lepidoptera } & Station & NA & & & & & & & \\
\hline & $\begin{array}{l}\text { Season } \\
\text { Inter. }\end{array}$ & & & & & & & & \\
\hline
\end{tabular}

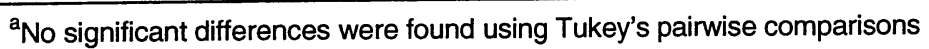


Diptera (predominantly chironomid midges) were the most abundant group in April and September samples (62-81\% of total insect density in April and 23-65\% in September) followed by Trichoptera (9-18\% of total insect density in April and $22-43 \%$ in September) (Table D-4a). Diptera collections were composed primarily of chironomid midges while Trichoptera collections were composed primarily of filterfeeding hydropsychids and philopotomatids. Ephemeroptera were also common in quantitative collections at some stations and represented 4-16\% of total insect density in April and 12$32 \%$ of total insect density in September (Table D-4a). Plecoptera (mostly perlids) were present in most April trap samples (1-9\% of total insect density) but were absent from most September samples (0-0.3\% of total insect density) (Table D-4a).

A total of 104 aquatic insect taxa was collected in the insect traps across the 4 stations in 2000, 77 in April and 68 in September (Table D-2). Most of the taxa collected belonged to four orders (Diptera, Trichoptera, Ephemeroptera, and Coleoptera). These orders accounted for 30, 14, 18 and 8 taxa, respectively in April and 28, 12, 11 and 7 taxa, respectively in September. Other groups (orders) accounted for less than six taxa per season. All but 10 of the taxa found in the traps were also collected in the qualitative sampling program. None of these "unique" taxa was common in the trap samples. Taxa collected in traps were clumped into various taxonomic groups that could be analyzed statistically (i.e., species were often pooled together to increase the number of individuals per sample). Overall, we were able to examine eight higher taxonomic groups. These groups are Total Density (all insects pooled), EPT density (Ephemeroptera, Plecoptera, and Trichoptera pooled), and the densities of six common orders including Ephemeroptera, Plecoptera, Trichoptera, Coleoptera, Diptera, and Odonata (Table D-4b). A total of 31 lower taxonomic groups (7 families, 24 genera/species) of Ephemeroptera, Plecoptera, Trichoptera, and Diptera and 9 metrics summarizing community structure were also analyzed (Tables D-5b to D-8b). Some Megaloptera and Lepidoptera were collected, but were not common enough to analyze statistically (Table D-4b). Likewise, none of the lower taxonomic groups of Coleoptera and Odonata was common enough to analyze statistically. 


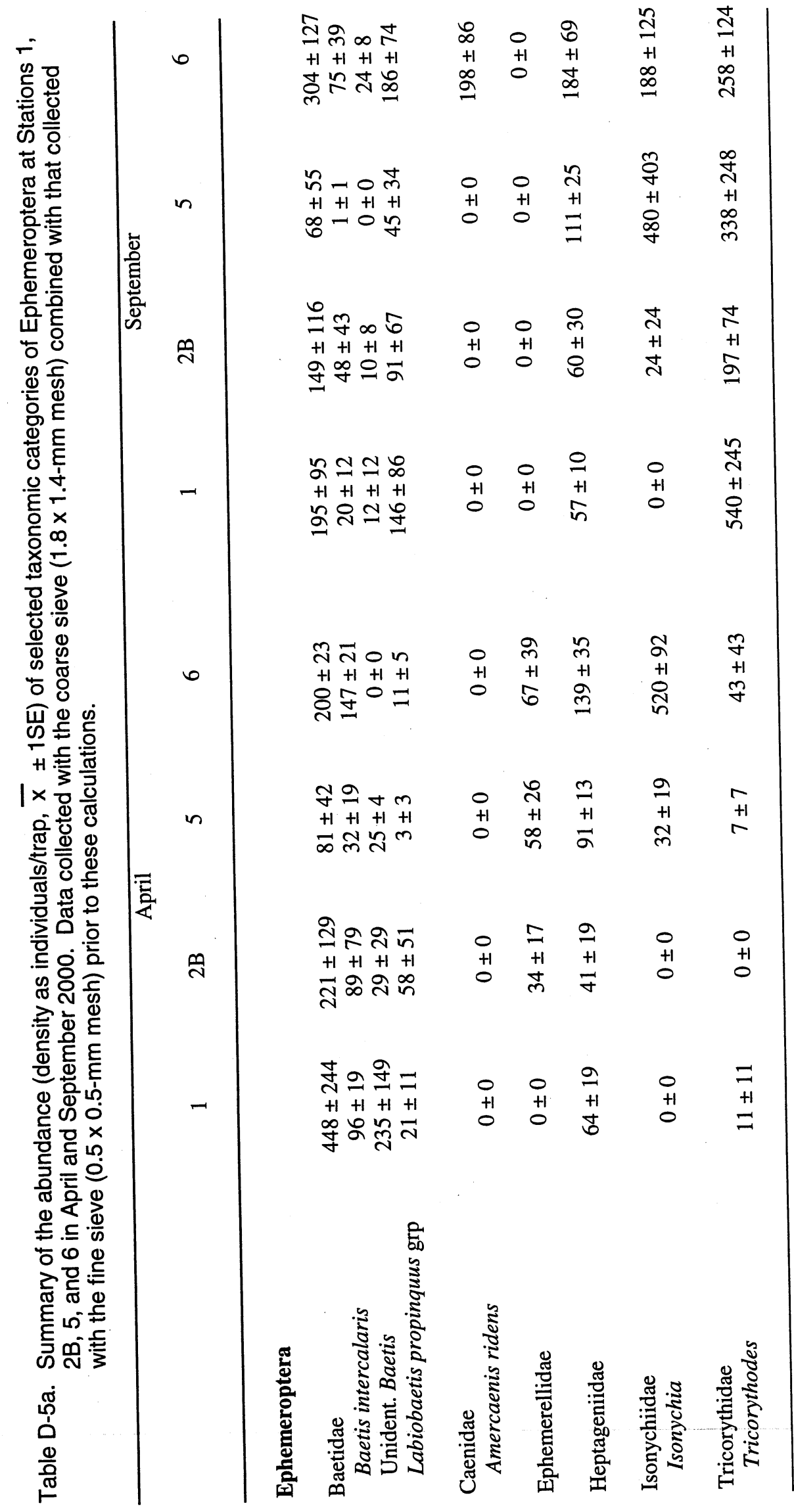


Table D-5b. Summary of the results of statistical tests (2-way ANOVA with station $x$ season interaction (inter.)) used to evaluate station (Stations 1, 2B, 5, 6) and season ( $A=$ April, $S=$ September) differences $(p<0.05)$ for Ephemeroptera. Data collected with the coarse sieve (1.8 $\times .4-\mathrm{mm}$ mesh) combined with that collected with the fine sieve $(0.5 \mathrm{x}$ $0.5-\mathrm{mm}$ mesh) prior to these analyses. Blanks for season or station comparisons indicate no significant difference ( $p>0.05$ ).

\begin{tabular}{|c|c|c|c|c|c|c|c|c|c|}
\hline & & $\mathbf{P}$ & Season & 1 vs $2 B$ & 1 vs 5 & 1 vs 6 & $2 B$ vs 5 & 2B vs 6 & 5 vs 6 \\
\hline \multicolumn{10}{|l|}{ Ephemeroptera } \\
\hline \multirow[t]{3}{*}{ Baetidae } & Station & 0.096 & & & & & & & \\
\hline & Season & 0.226 & & & & & & & \\
\hline & Inter. & 0.873 & & & & & & & \\
\hline \multirow[t]{3}{*}{ Baetis intercalaris } & Station & 0.161 & & & & & & & \\
\hline & Season & $0.017^{\mathrm{a}}$ & & & & & & & \\
\hline & Inter. & 0.926 & & & & & & & \\
\hline \multirow[t]{3}{*}{ Unidentified Baetidae } & Station & 0.750 & & & & & & & \\
\hline & Season & 0.287 & & & & & & & \\
\hline & Inter. & $0.022^{\mathrm{a}}$ & & & & & & & \\
\hline \multirow[t]{3}{*}{ Labiobaetis propinquus grp. } & Station & $0.359 \mathrm{a}$ & & & & & & & \\
\hline & Season & $0.019^{\mathrm{a}}$ & & & & & & & \\
\hline & Inter. & 0.692 & & & & & & & \\
\hline \multicolumn{10}{|l|}{ Caenidae } \\
\hline \multirow{3}{*}{ Americaenis ridens } & Station & $<0.001$ & & & & $6>1$ & & $6>2 B$ & $6>5$ \\
\hline & Season & $<0.001$ & $\mathrm{~S}>\mathrm{A}$ & & & & & & \\
\hline & Inter. & $<0.001$ & & & & & & & \\
\hline \multirow[t]{3}{*}{ Ephemerellidae } & Station & 0.005 & & & $5>1$ & $6>1$ & & & \\
\hline & Season & $<0.001$ & $A>S$ & & & & & & \\
\hline & Inter. & 0.005 & & & & & & & \\
\hline \multirow[t]{3}{*}{ Heptageniidae } & & & & & & & & & \\
\hline & $\begin{array}{l}\text { Station } \\
\text { Season }\end{array}$ & $\begin{array}{l}0.013^{\prime \prime} \\
0.532\end{array}$ & & & & & & & \\
\hline & Inter. & 0.942 & & & & & & & \\
\hline \multirow{4}{*}{$\begin{array}{l}\text { Isonychiidae } \\
\text { Isonychia }\end{array}$} & & & & & & & & & \\
\hline & Station & $<0.001$ & & & $5>1$ & $6>1$ & & $6>2 B$ & \\
\hline & Season & 0.711 & & & & & & & \\
\hline & Inter. & 0.441 & & & & & & & \\
\hline \multicolumn{10}{|l|}{ Tricorythidae } \\
\hline \multirow[t]{2}{*}{ Tricorythodes } & Station & $\begin{array}{r}0.564 \\
<0.001\end{array}$ & & & & & & & \\
\hline & $\begin{array}{l}\text { Season } \\
\text { Inter. }\end{array}$ & $\begin{array}{r}<0.001 \\
0.854\end{array}$ & $S>A$ & & & & & & \\
\hline
\end{tabular}

${ }^{a}$ Primary model not significant $([>0.05)$. 


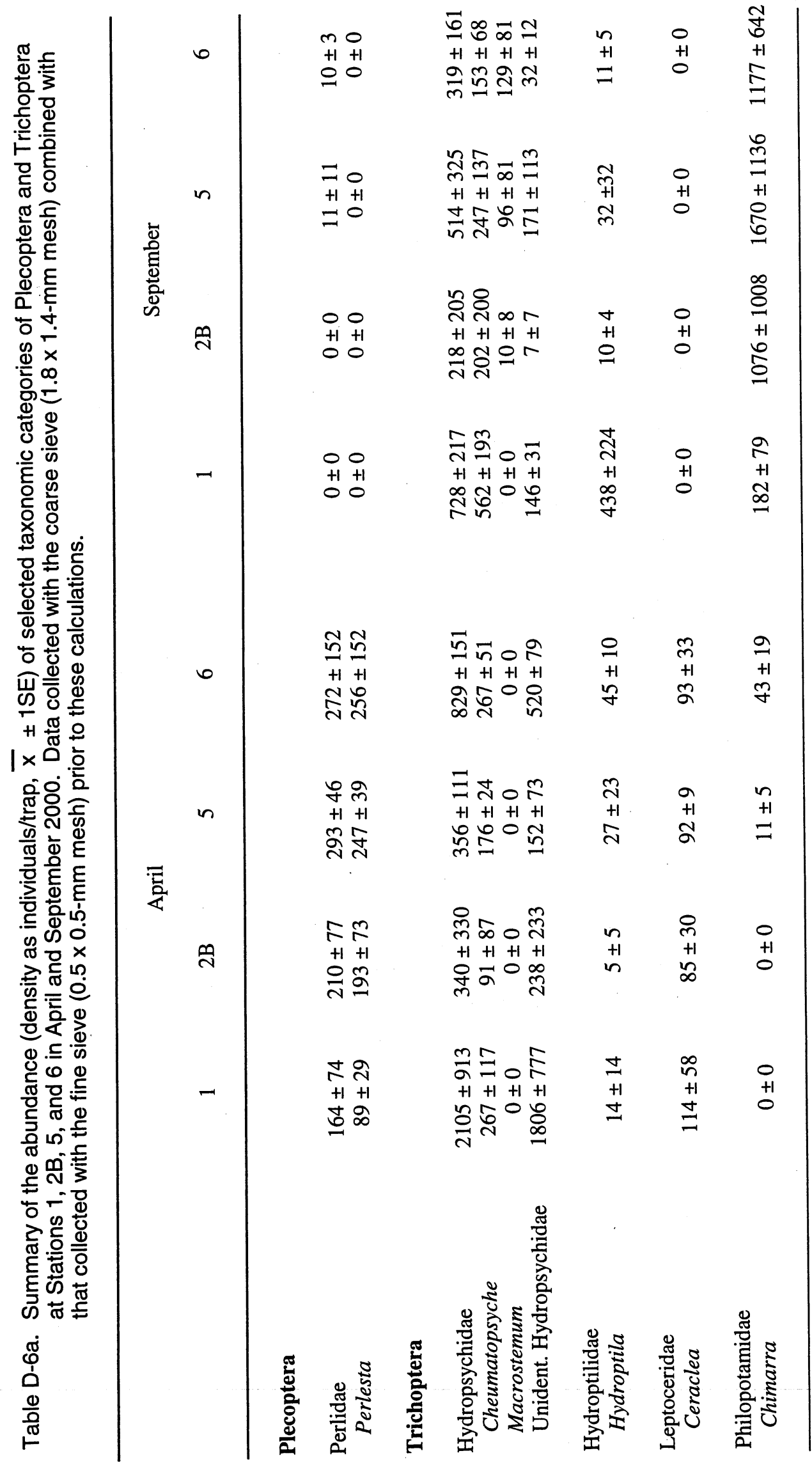


Table D-6b. Summary of the results of statistical tests (2-way ANOVA with station $x$ season interaction (inter.)) used to evaluate station (Stations $1,2 B, 5,6)$ and season ( $A=A$ pril, $S=$ September) differences $(p<0.05)$ for selected taxonomic categories of Plecoptera and Trichoptera. Data collected with the coarse sieve $(1.8 \times .4-\mathrm{mm}$ mesh) combined with that collected with the fine sieve $(0.5 \times 0.5-\mathrm{mm}$ mesh) prior to these analyses. Blanks for season or station comparisons indicate no significant difference $(p>0.05)$.

P $\quad$ Season 1 vs 2B 1 1 vs 5 1 vs 6 2B vs 5 2B vs $6 \quad 5$ vs 6

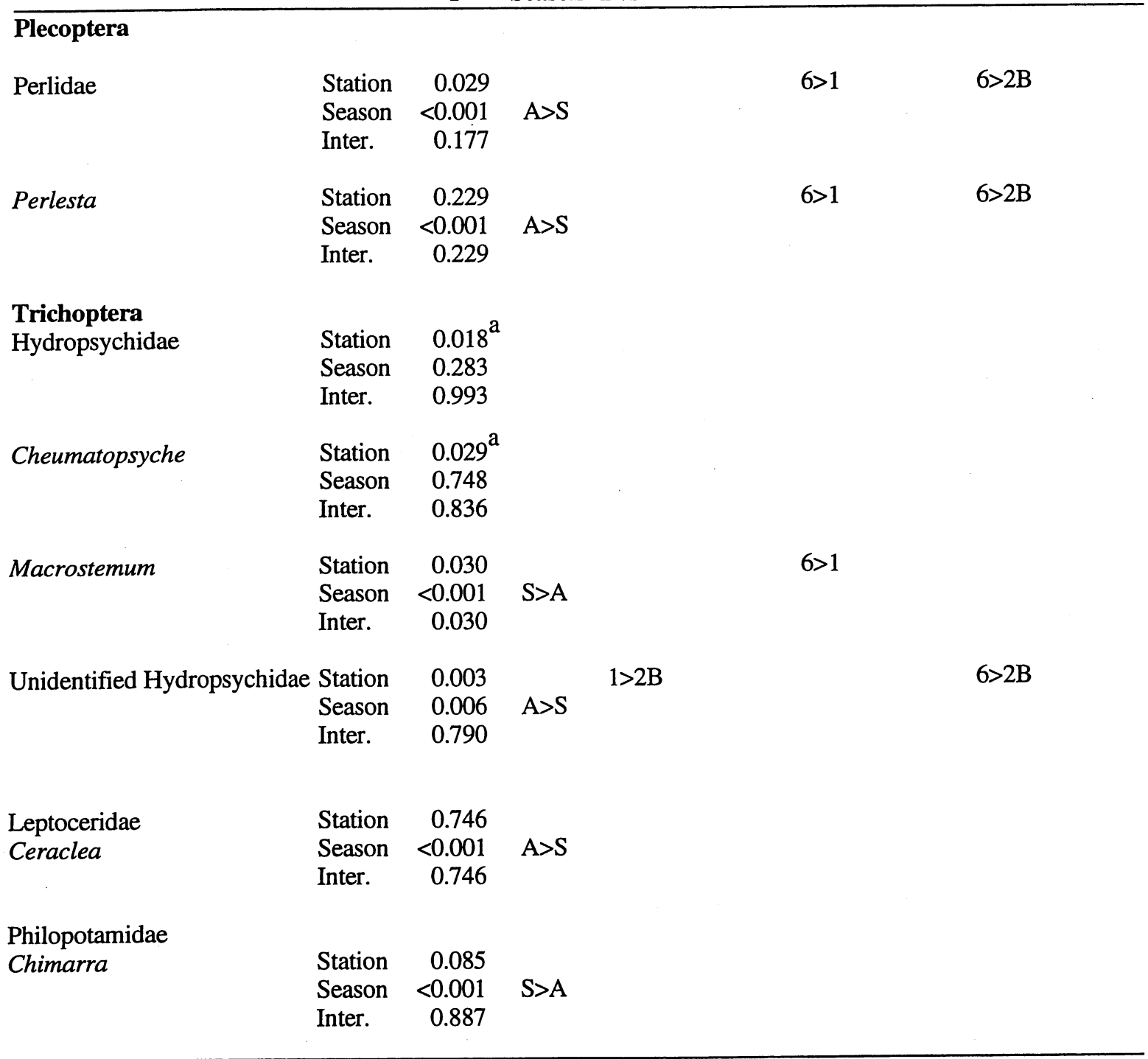

aPrimary model not significant $(p>0.05)$. 


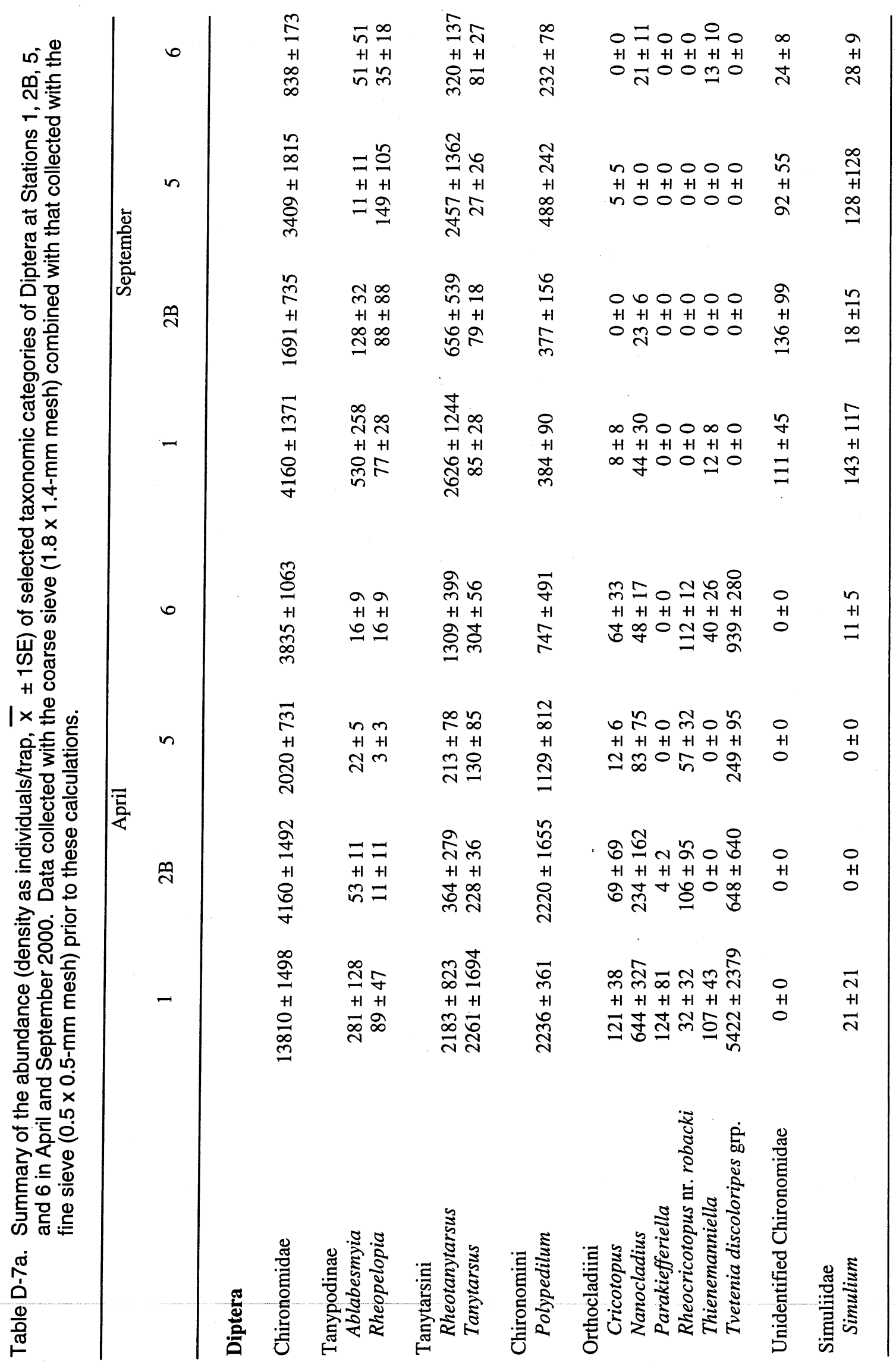


Table D-7b. Summary of the results of statistical tests (2-way ANOVA with station $x$ season interaction (inter.)) used to evaluate station (Stations 1, 2B, 5, 6) and season ( $A=$ April, $S=$ September) differences $(p<0.05)$ for selected taxonomic categories of Diptera. Data collected with the coarse sieve $(1.8 \times .4-\mathrm{mm}$ mesh) combined with that collected with the fine sieve $(0.5 \times 0.5-\mathrm{mm}$ mesh) prior to these analyses. Blanks for season or station comparisons indicate no significant difference $(p>0.05)$.

\begin{tabular}{|c|c|c|c|c|c|c|c|c|c|}
\hline & & $\mathbf{P}$ & Season & 1 vs $2 B$ & 1 vs 5 & 1 vs 6 & $2 B$ vs 5 & $2 B$ vs 6 & 5 vs 6 \\
\hline $\begin{array}{l}\text { Diptera } \\
\text { Chironomidae }\end{array}$ & $\begin{array}{l}\text { Station } \\
\text { Season } \\
\text { Inter. }\end{array}$ & $\begin{array}{l}0.028^{a} \\
0.013 \\
0.611\end{array}$ & $\mathrm{~A}>\mathrm{S}$ & & & & & & \\
\hline $\begin{array}{l}\text { Tanypodinae } \\
\text { Ablabesmyia }\end{array}$ & $\begin{array}{l}\text { Station } \\
\text { Season } \\
\text { Inter. }\end{array}$ & $\begin{array}{l}0.002 \\
0.665 \\
0.433\end{array}$ & & & $1>5$ & $1>6$ & & $2 \mathrm{~B}>6$ & \\
\hline Rheopelopia & $\begin{array}{l}\text { Station } \\
\text { Season } \\
\text { Inter. }\end{array}$ & $\begin{array}{l}0.379 \\
0.269 \\
0.772\end{array}$ & & & & & & & \\
\hline $\begin{array}{l}\text { Tanytarsini } \\
\text { Rheotanytarsus }\end{array}$ & $\begin{array}{l}\text { Station } \\
\text { Season } \\
\text { Inter. }\end{array}$ & $\begin{array}{l}0.054 \\
0.947 \\
0.404\end{array}$ & & 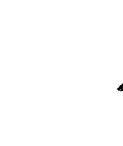 & & & & & 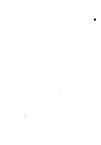 \\
\hline Tanytarsus & $\begin{array}{l}\text { Station } \\
\text { Season } \\
\text { Inter. }\end{array}$ & $\begin{array}{r}0.005 \\
<0.001 \\
0.488\end{array}$ & $A>S$ & & $1>5$ & & & & $6>5$ \\
\hline $\begin{array}{l}\text { Chironomini } \\
\text { Polypedilum }\end{array}$ & $\begin{array}{l}\text { Station } \\
\text { Season } \\
\text { Inter. }\end{array}$ & $\begin{array}{l}0.405 \mathrm{~b} \\
0.011 \\
0.925\end{array}$ & & & & & & & \\
\hline $\begin{array}{l}\text { Orthocladiini } \\
\text { Cricotopus }\end{array}$ & $\begin{array}{l}\text { Station } \\
\text { Season } \\
\text { Inter. }\end{array}$ & $\begin{array}{l}0.258 \\
0.002 \\
0.489\end{array}$ & $A>S$ & & & & & & \\
\hline Nanocladius & $\begin{array}{l}\text { Station } \\
\text { Season } \\
\text { Inter. }\end{array}$ & $\begin{array}{l}0.051 \\
0.003 \\
0.621\end{array}$ & $A>S$ & & & & & & \\
\hline Parakiefferiella & $\begin{array}{l}\text { Station } \\
\text { Season } \\
\text { Inter. }\end{array}$ & $\begin{array}{l}0.031^{a} \\
0.013 \\
0.031\end{array}$ & $A>S$ & & & & & & \\
\hline Rheocricotopus $\mathrm{nr}$ robacki & $\begin{array}{l}\text { Station } \\
\text { Season } \\
\text { Inter. }\end{array}$ & $\begin{array}{r}0.365 \\
<0.001 \\
0.365\end{array}$ & $\mathrm{~A}>\mathrm{S}$ & & & & & & \\
\hline Thienemanniella & $\begin{array}{l}\text { Station } \\
\text { Season } \\
\text { Inter. }\end{array}$ & $\begin{array}{r}<0.001 \\
0.078 \\
0.139\end{array}$ & & $\begin{array}{l}1>2 B \\
1>2 B\end{array}$ & 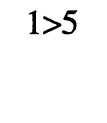 & & & $6>2 B$ & $6>5$ \\
\hline Tvetenia discoloripes grp. & $\begin{array}{l}\text { Station } \\
\text { Season } \\
\text { Inter. }\end{array}$ & $\begin{array}{r}0.019 \\
<0.001 \\
0.019\end{array}$ & $A>S$ & & & & & & \\
\hline Unidentified Chironomidae & $\begin{array}{l}\text { Station } \\
\text { Season } \\
\text { Inter. }\end{array}$ & $\begin{array}{r}0.924 \\
<0.001 \\
0.924\end{array}$ & $\mathrm{~S}>\mathrm{A}$ & & & & & & \\
\hline Simuliidae & $\begin{array}{l}\text { Station } \\
\text { Season } \\
\text { Inter. }\end{array}$ & $\begin{array}{l}0.323 \mathrm{~b} \\
0.033 \\
0.974 \\
\end{array}$ & & & & & . & & \\
\hline
\end{tabular}

${ }^{a}$ No significant differences were found using Tukey's pariwise comparisons. ${ }^{b}$ Primary model not significant $(p>0.05)$. 


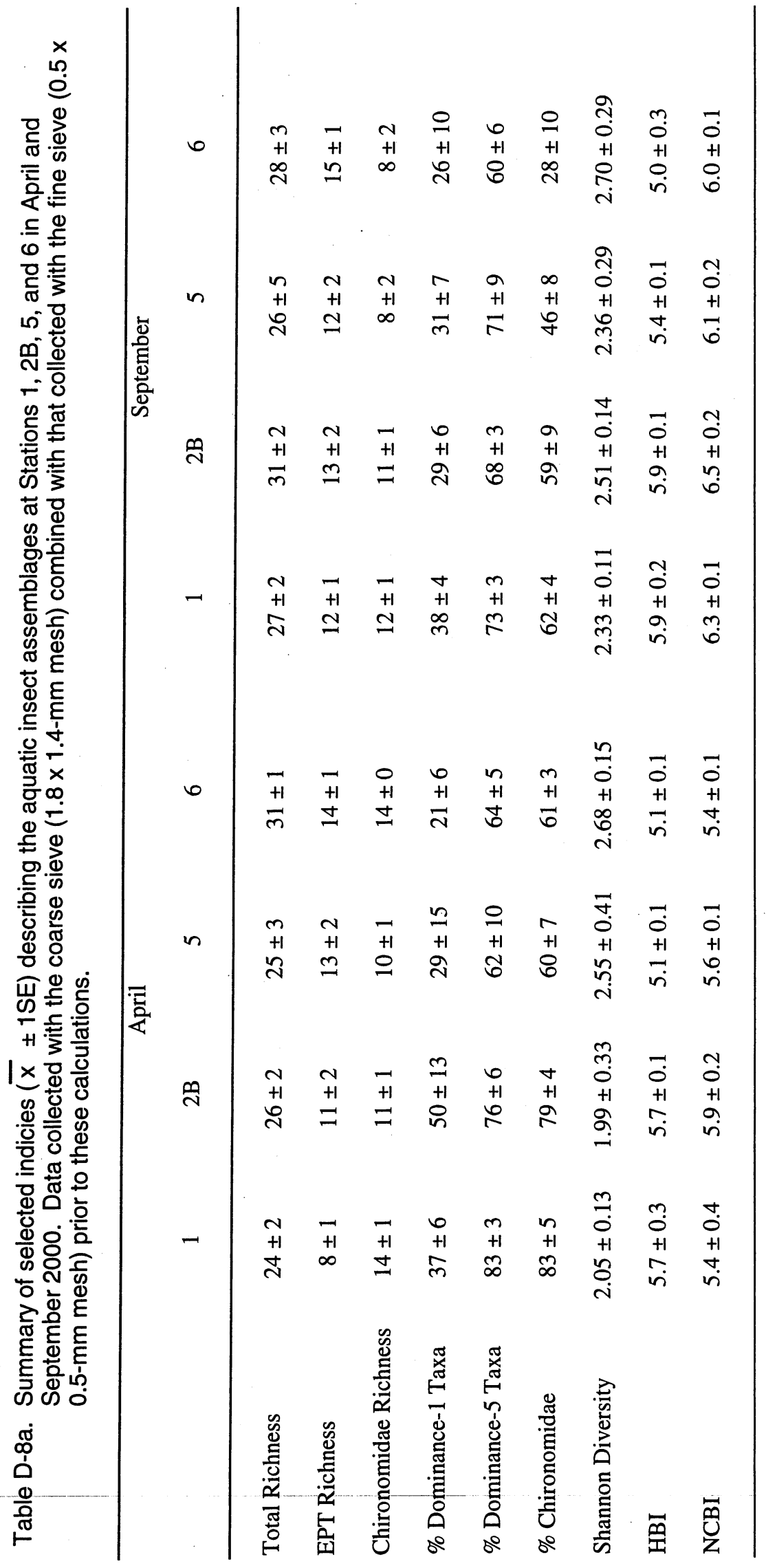


Table D-8b. Summary of the results of statistical tests (2-way ANOVA with station $x$ season interaction (inter.)) used to evaluate station (Stations $1,2 B, 5,6)$ and season ( $A=$ April, $S=$ September) differences $(p<0.05)$ for selected indices describing the aquatic insect assemblages at Stations 1, 2B, 5 and 6 in spring and fall 2000. Data collected with the coarse sieve (1.8 $\times .4-\mathrm{mm}$ mesh) combined with that collected with the fine sieve $(0.5 \mathrm{x}$ $0.5-\mathrm{mm}$ mesh) prior to these analyses. Blanks for season or station comparisons indicate no significant difference $(p>0.05)$.

\begin{tabular}{|c|c|c|c|c|c|c|c|c|c|}
\hline & & $\mathbf{P}$ & Season & 1 vs $2 B$ & 1 vs 5 & 1 vs 6 & $2 B$ vs 5 & $2 B$ vs 6 & 5 vs 6 \\
\hline \multirow[t]{3}{*}{ Total Richness } & Station & 0.322 & & & & & & & \\
\hline & Season & 0.368 & & & & & & & \\
\hline & Inter. & 0.539 & & & & & & & \\
\hline \multirow{3}{*}{ EPT Richness } & Station & $0.022^{\mathrm{a}}$ & & & & & & & \\
\hline & Season & 0.156 & & & & & & & \\
\hline & Inter. & 0.471 & & & & & & & \\
\hline \multirow[t]{3}{*}{ Chironomidae Richness } & Station & 0.065 & & & & & & & \\
\hline & Season & 0.007 & $\mathrm{~A}>\mathrm{S}$ & & & & & & \\
\hline & Inter. & 0.299 & & & & & & & \\
\hline \multirow[t]{3}{*}{$\%$ Dominance-1 Taxa } & Station & 0.288 & & & & & & & \\
\hline & Season & 0.578 & & & & & & & \\
\hline & Inter. & 0.421 & & & & & & & \\
\hline \multirow[t]{3}{*}{$\%$ Dominance-5 Taxa } & Station & 0.057 & & & & & & & \\
\hline & Season & 0.484 & & & & & & & \\
\hline & Inter. & 0.351 & & & & & & & \\
\hline \multirow[t]{3}{*}{$\%$ Chironomidae } & Station & 0.002 & & & & $1>6$ & & $2 B>6$ & \\
\hline & Season & $<0.001$ & $A>S$ & & & & & & \\
\hline & Inter. & 0.602 & & & & & & & \\
\hline \multirow[t]{3}{*}{ Shannon Diversity } & Station & 0.191 & & & & & & & \\
\hline & Season & 0.376 & & & & & & & \\
\hline & Inter. & 0.497 & & & & & & & \\
\hline \multirow[t]{3}{*}{ HBI } & Station & 0.001 & & & & $1>6$ & $2 B>5$ & $2 B>6$ & \\
\hline & Season & 0.218 & & & & & & & \\
\hline & Inter. & 0.847 & & & & & & & \\
\hline \multirow[t]{2}{*}{ NCBI } & Station & 0.088 & & & & & & & \\
\hline & $\begin{array}{l}\text { Season } \\
\text { Inter. }\end{array}$ & $\begin{array}{r}<0.001 \\
0.588\end{array}$ & $S>A$ & & & & & & \\
\hline
\end{tabular}

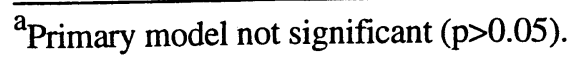




\section{Reference Conditions Upstream of SRS}

Q tation 1 was used to describe reference conditions upstream of SRS because it was not exposed to effluent or runoff from SRS. Mean total insect density at Station 1 was 17,067 individuals/trap in April and 6,698 individuals/trap in September (Table D-4a). In April, Diptera (mainly chironomids) averaged $>13,000$ individuals/trap and accounted for $81 \%$ of the individuals found at Station 1 (Table D-4a). Most of these individuals were Tvetenia discoloripes grp. (5,422 individuals/trap), Tanytarsus (2,261 individuals/trap), Polypedilum (2,236 individuals/trap), and Rheotanytarsus (2,183 individuals/trap) (Table D-7a). Trichoptera were also common at Station 1 in April (2,254 individuals/trap, $13 \%$ of total insect density) and consisted principally of unidentified, early-instar Hydropsychidae (1,806 individuals/trap), Cheumatopsyche (267 individuals/trap), and Ceraclea (114 individuals/trap) (Tables D-4a and D-6a). Although Ephemeroptera (mainly Baetidae) were often encountered in trap samples at Station 1 in April (668 individuals/trap, $4 \%$ of total insect density) (Table D-5a), they were much less abundant than Diptera or Trichoptera. Other groups including Plecoptera, Coleoptera, and Odonata were present, but were encountered infrequently at Station 1 in . April ( $<200$ individuals/trap) (Table D-4a). These groups collectively accounted for $<2 \%$ of the individuals found in Station 1 traps in April. Despite the scarcity of Plecoptera, the presence of large numbers of Trichoptera (see above) resulted in EPT densities of 3,097 individuals/trap (18\% of total insect density) at Station 1 in April (Table D-4a).

In September, Diptera (mainly Chironomidae) remained the dominant order at Station 1 (4,344 individuals/trap, $65 \%$ of total insect density) followed by Trichoptera (1,503 individuals/trap, $22 \%$ of total insect density) (Table D-4a). Although Diptera and Trichoptera were dominant in both April and September at Station 1, there were large differences between seasons in the importance of specific taxa within these orders (Tables D-6a and D-7a). For example, the most common dipteran in April (the chironomid midge Tvetenia discoloripes grp., 5,422 individuals/trap) was not collected in September (Table D-7a). Similarly, the densities of two other common 
dipterans (also chironomid midges) were lower in September than in April: Tanytarsus (2,261 individuals/trap in April compared to 85 individuals/trap in September) and Polypedilum (2,236 individuals/trap in April compared to 384 individuals/trap in September) (Table D-7a). In contrast, Rheotanytarsus densities were similar in April and September (2,183 individuals/trap in April and 2,626 individuals/trap in September) (Table D-7a). As with dipterans, the most dominant trichopteran in April (unidentified Hydropsychidae) was not the most dominant trichopteran in September $(1,806$ individuals/trap in April compared to 146 individuals/trap in September) (Table D-6a). Ceraclea densities were also markedly lower in September than in April (114 individuals/trap in April but absent in September) (Table D-6a). In contrast, densities of other trichopterans were higher in September than in April including Cheumatopsyche (267 individuals/trap in April compared to 562 individuals/trap in September), $\mathrm{Hy}$ droptila (14 individuals/trap in April compared to 438 individuals/trap in September), and Chimarra (absent from trap collections in April compared to 182 individuals/trap in September) (Table 6a). Although Ephemeroptera (mainly Tricorythodes) accounted for $12 \%$ of total density ( 811 individuals/trap) in September (Table D-5a), they remained less abundant than Diptera or Trichoptera. Coleoptera and Odonata were collected from Station 1, but were again uncommon (only 35 individuals/trap collectively) and accounted for $<1 \%$ of the individuals found in Station 1 traps in September (Table D-4a). Despite the absence of Plecoptera, moderate densities of Ephemeroptera and Trichoptera resulted in EPT densities of 2,314 individuals/trap (35\% of total insect density) at Station 1 in September (Table D-4a).

Total Richness, which accounts for both common (mentioned previously) and uncommon taxa, averaged 24 taxa/subsample in April and 27 taxa/subsample in September at Station 1 (Table D-8a). Ephemeroptera, Plecoptera, and Trichoptera (EPT) Richness averaged 8 taxa in April (33\% of Total Richness) and 12 taxa in September (44\% of Total Richness) at Station 1 (Table D-8a). Chironomidae Richness also accounted for a large part of Total Richness in both seasons (i.e., 58\% in April and 44\% in September) (Table D-8a). No single taxon dominated aquatic insect traps at Station 1 in either season (\% Dominance-1 taxa averaged 37\% in April and $38 \%$ in September) but when the five most common taxa 
were pooled together ( $\%$ Dominance- 5 taxa), they accounted for most of total insect density (83\% in April and 73\% in September) at Station 1 (Table D-8a). Many of these common taxa were chironomids, which comprised $83 \%$ of total density in April and $62 \%$ of total density in September at Station 1 (Table D-8a). The dominance of Chironomidae may have affected community structure at Station 1 . For example, because diversity has an evenness component, chironomid dominance probably reduced Shannon Diversity at Station 1 in April (Shannon Diversity averaged 2.05 and was near the low end of the range measured at the sampling stations in 2000) (Table D-8a). Lower relative abundance of Chironomidae in September may have contributed to higher diversity in September (Shannon Diversity averaged 2.33 in September compared to 2.05 in April) (Table D-8a). The abundance of Chironomidae, which are generally pollution tolerant, probably also contributed to elevated HBI scores at Station 1 (HBI scores averaged 5.7 in April and 5.9 in September and were near the high end of the range measured at the sampling stations in 2000) (Table D-8a). HBI scores indicate that water quality at Station 1 was fair in April and September based on ranges provided in Hilsenhoff (1987). NCBI scores averaged 5.4 in April and 6.3 in September indicating that water quality was good in April and good-fair in September (Table D-8a) (Lenat 1993).

\section{Comparison of Reference and Downstream Conditions}

I $\mathrm{n}$ order to assess changes potentially associated with SRS, Station 1 (i.e., the reference site consisting of aquatic insects that had not been exposed to effluent or runoff from the SRS) was compared with Stations $2 \mathrm{~B}, 5$, and 6 (i.e., sites where insects were potentially exposed to effluent or runoff from the SRS). A negative impact was defined $a$ priori as lower densities of pollution-sensitive taxa (e.g., mayflies) downstream of Station 1, potentially accompanied by higher densities of pollution-tolerant taxa (e.g. some chironomid species). Lower Total Richness, the richness of pollution-sensitive groups (i.e., EPT Richness), and the richness of large groups containing sensitive and tolerant species (i.e., Chironomidae) downstream of Station 1 were also designated 
a priori as evidence of a negative impact. Meaningful differences in relative abundance and richness (as described above) would be expected to result in lower species diversity and higher \% Chironomidae, \% Dominance-1, \% Dominance-5, HBI, or NCBI. Because Stations 2B, 5 and 6 each represent different conditions, the above differences could be apparent at any one or all of the downstream stations.

Of the eight higher taxonomic groups analyzed (Total Insect Density, EPT Density, Ephemeroptera Density, Diptera Density, Trichoptera Density, Coleoptera Density, Plecoptera Density, and Odonata Density) only Plecoptera Density differed among stations with higher densities at Station 6 than at Stations 1 and 2B (Table D-4b). Indices that describe the collective response of aquatic insects (community level responses) also showed few differences among stations.

Chironomids comprised a larger fraction of total density (i.e., $\%$ Chironomidae) at Stations 1 and 2B than at Station 6 (Table $\mathrm{D}-8 \mathrm{~b}$ ). The presence of large numbers of generally intolerant chironomids at Stations 1 and $2 \mathrm{~B}$ may have contributed to higher HBI scores at Stations 1 and 2B than at Station 6 and higher HBI scores at Station 2B than Station 5 (Table $8 b)$. None of these differences conformed to our a priori hypotheses concerning a negative response to exposure to effluent or runoff from SRS. For example, \% Chironomidae and HBI scores, which are expected to increase in response to pollution, were lower at one or more potential impact Stations $(2 \mathrm{~B}, 5$, and 6$)$ than at the reference Station (1). Furthermore, Plecoptera Density, which is expected to decrease in response to pollution, was higher at one or more potential impact stations than at the reference station.

Important responses are sometimes more easily observed or interpreted when examined using individual taxa or small groups of taxa (i.e., lower taxa). Ten (Amercaenis ridens, Ephemerellidae, Isonychia, Perlidae, Macrostemum, Unidentified Hydropsychidae, Ablabesmyia, Tanytarsus, Thienemanniella, and Tvetenia discoloripes grp.) of the 31 lower taxa examined in 2000 exhibited a significant difference between the reference station (1) and one or more potential impact stations (2B, 5, and 6) (Tables D-5b to D-7b). Additionally, significant differences between potential impact stations were found for all but three of these taxa (Ephemerellidae, Macrostemum, and Tvetenia discoloripes grp.) (Tables D-5b to D-7b). Densities of several EPT taxa including the may- 
flies Ephemerellidae, Amercaenis ridens, and Isonychia, the stonefly Perlidae, and the caddisfly Macrostemum were higher at Stations 5 and/or 6 than at Station 1 (Tables D-5b and D-6b). Densities of the majority of these taxa (Isonychia, Perlidae, and Amercaenis ridens) were also higher at Station 6 than at Station 2B (Tables D-5b and D-6b). In contrast to the above EPT taxa, densities of a number of chironomid taxa were higher at Station 1 than at one or more of the potential impact stations including Tanytarsus (Station $1>$ Station 5), Ablabesmyia (Station $1>$ Stations 5 and 6), and Thienemanniella (Station $1>$ Stations $2 \mathrm{~B}$ and 5) (Table D-7b). Densities of Unidentified Hydropsychidae were also higher at Station 1 than at one of the potential impact stations (2B) (Table D-6b). For several of the above taxa (Ephemerellidae, Amercaenis ridens, Macrostemum, and Tvetenia discoloripes grp.), the interaction factor (station $\mathrm{x}$ season) was significant, indicating that differences among stations varied seasonally (Tables D-5b to D-7b). For example, station differences were apparent during April for Tvetenia discoloripes grp. and Ephemerellidae whereas these taxa were absent at all stations in September. Conversely, station differences were apparent in September for Amercaenis ridens and Macrostemum whereas these taxa were absent in April at all stations. Seasonal changes in abundance are expected because the life cycles of many aquatic insects involve time periods where eggs, very small larva, and adults are present (these stages occur following emergence and are not collected by traps).

None of the differences in lower taxa conformed to our a priori hypotheses concerning a negative response to exposure to effluent/runoff from the SRS. For example, the densities of the mayflies Ephemerellidae, Amercaenis ridens, and Isonychia, the caddisflies Macrostemum, and the stonefly Perlidae were higher and the densities of the chironomids Tanytarsus, Ablabesmyia, and Thienemanniella were lower at one or more of the potential impact stations than at the reference station. These differences do not confirm to our a priori hypotheses because mayfly, caddisfly, and stonefly densities are expected to decrease and chironomid densities are expected to increase in response to pollution.

These results do not reveal a common pattern among indices, higher taxa, or lower taxa that conformed to our a priori hypotheses concerning a negative response to exposure to effluent or runoff from SRS. In fact, these results indicate that 
conditions at the potential impact stations (downstream of SRS inputs) are generally superior to those at the upstream reference station. Thus, there was no evidence that suggests a general response to environmental disturbance in the Savannah River near the SRS. Rather, the differences that we observed among stations in 2000 presumably reflect the differences that occur naturally among spatially separate sites (i.e., natural spatial variation).

\section{Seasonal Differences in 2000}

D ifferences among stations near SRS are evaluated at different times of the year primarily because (1) the volume and concentration of effluent and runoff from the SRS can change throughout the year and (2) the composition of the aquatic insect assemblage (presence/absence and abundance) can change throughout the year. The aquatic insect assemblage in the river changes throughout the year in response to biological phenomena (e.g., life history characteristics, food quality or quantity, interactions with predators or competitors) and physicochemical phenomena (e.g., floods, droughts, temperature extremes). This has been observed in warm and cold environments, in mountains and coastal plains, in small streams and large rivers.

The aquatic insect community of the Savannah River is also temporally variable (i.e., April samples were different from those collected in September). For example, densities of two higher taxa (Diptera and Plecoptera) and twelve lower taxa (Ephemerellidae, Perlidae, Perlesta, Ceraclea, Unidentified Hydropsychidae, Chironomidae, Tanytarsus, Cricotopus, Nanocladius, Parakiefferiella, Rheocricotopus nr. robacki, and Tvetenia discoloripes grp.) were higher in April than September while densities of five additional lower taxa (Tricorythodes, Amercaenis ridens, Macrostemum, Chimarra, and Unidentified Chironomidae) were higher in September than April (Tables D-4b to D-7b). Seasonal differences in a few of the indices that describe the collective response of aquatic insects (community level responses) were also found with higher Chironomidae Richness and \% Chironomidae in April than September and higher NCBI scores in September than in April (Table D-8b). 
Although there were seasonal differences in the aquatic insect community of the Savannah River, these differences were expected (i.e., caused by differences in life history patterns such as emergence times) and there was no indication that they were caused by exposure to effluent or runoff from the SRS. Together, the station and season analyses provide no evidence that would suggest that there was a general negative response indicative of environmental disturbance in the Savannah River near the SRS. Rather, the station and seasonal differences observed in 2000 presumably reflect the differences that occur naturally among sites and seasons in streams and rivers (i.e., natural spatial and temporal variation).

\section{Effects of a Reduction in Mesh Size on Quantitative Collections}

$\mathbf{P}$ rior to 1998 , samples were cleaned in the field by passing them through a coarse sieve with $1.8 \times 1.4-$ mm mesh. Starting in 1998 the coarse sieve was replaced by a sieve that is commonly used in benthic studies (referred to as the fine sieve). Although the switch to a more standard mesh size will facilitate compariśons between the SRS data and data collected elsewhere, direct comparisons between long-term SRS data (that collected prior to 1998) and more recent data (that collected from 1998-1999) are currently not possible due to the reduction in mesh size. One of the objectives of the 2000 sampling program was to determine if switching to a smaller mesh size affected quantitative collections. This was accomplished by separating each sample into a coarse-mesh fraction (material retained by the coarse sieve) and a fine-mesh fraction (material that passed through the coarse sieve but was retained by the fine sieve). The combination of the coarse-mesh and fine-mesh fractions represent the material that would have been retained if it had not first been passed through the coarse-mesh sieve. Comparisons of the coarse-mesh data with the combined (pooled) data provided estimates of the effect of the switch to the fine mesh. Prior to discussing comparisons involving mesh size, it is important to note that station and season comparisons discussed in previous sections and in previous reports (1998 and 1999) reflect the analysis of pooled data. 
The use of a smaller mesh generally resulted in density estimates that were much higher than those provided by the coarse mesh indicating that many of the individuals collected in the traps passed through the coarse mesh but were retained by the fine mesh. This was evident for groups of taxa (Total Density, EPT Density and Chironomidae Density) and individual taxa (Table D-9a). For example, the total number of individuals (Total Density) retained by the fine mesh was 2.1 (Station 2B in April) to 3.6 (Station 6 in April) times higher than for the coarse mesh (these calculations completed by dividing 'pooled Total Density' by 'coarse mesh Total Density', Table D-9a). In other words, in April at Station 2B about the same number of individuals passed through the coarse mesh as were retained by it and in April at Station 6 about 2.5 times more individuals passed through the coarse mesh than were retained. Similar results were observed for other higher taxonomic groups including EPT and Chironomidae, and for a number of individual taxa including Cheumatopsyche, Chimarra, Unident. Polypedilum, Tvetenia discoloripes grp., and Rheotanytarsus (i.e., pooled densities were usually about 2-4 times higher than coarse-mesh densities) (Table 9a). Differences between densities were even more dramatic for a number of other taxa. For example, most of the Isonychia, Tanytarsus, Tricorythodes, and Unident. Hydropsychidae that were present in trap collections in April were too small to be retained by the coarse mesh. Consequently, pooled densities were generally about 4-15 times higher than coarse-mesh densities for these taxa in April (Table 9a). Similarly most of the Tricorythodes, Ablabesmyia, and Unident. Hydropsychidae present in September trap collections passed through the coarse mesh resulting in pooled densities that were usually about 5-21 times higher than coarse-mesh densities (Table 9a). In contrast, many Perlesta and Polypedilum illinoensi grp. were too large to pass through the coarse mesh, which usually resulted in higher densities in the coarse-mesh fraction than in the fine-mesh fraction (Table D-9a).

Although mesh size had a major effect on density estimates, many measures of community structure (Total Richness, EPT Richness, \% Chironomidae, and NCBI) were basically unchanged by the switch to a smaller mesh size (see Table D10a). Those measures that were affected by the switch to a smaller mesh size showed smaller changes than were ob- 


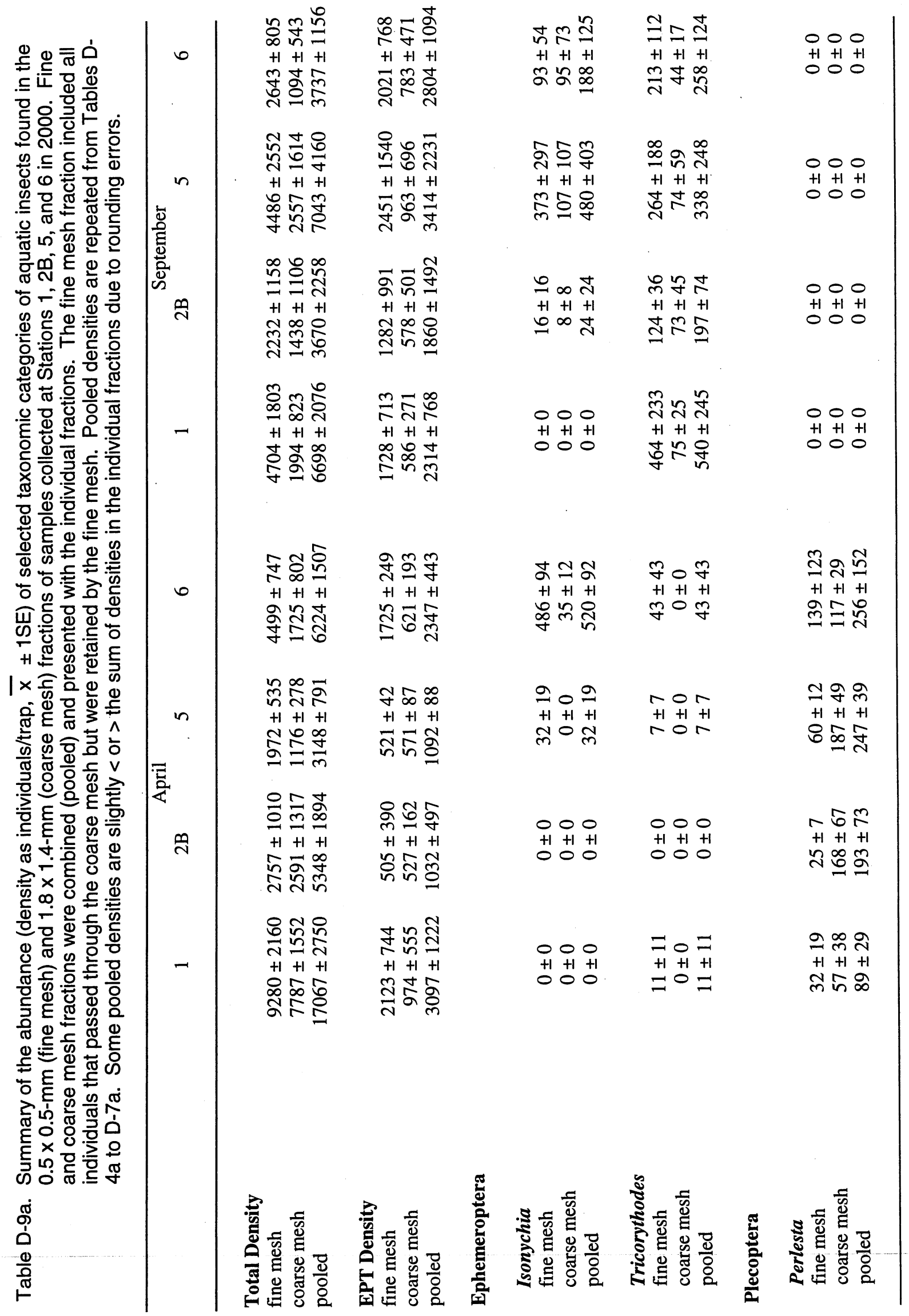




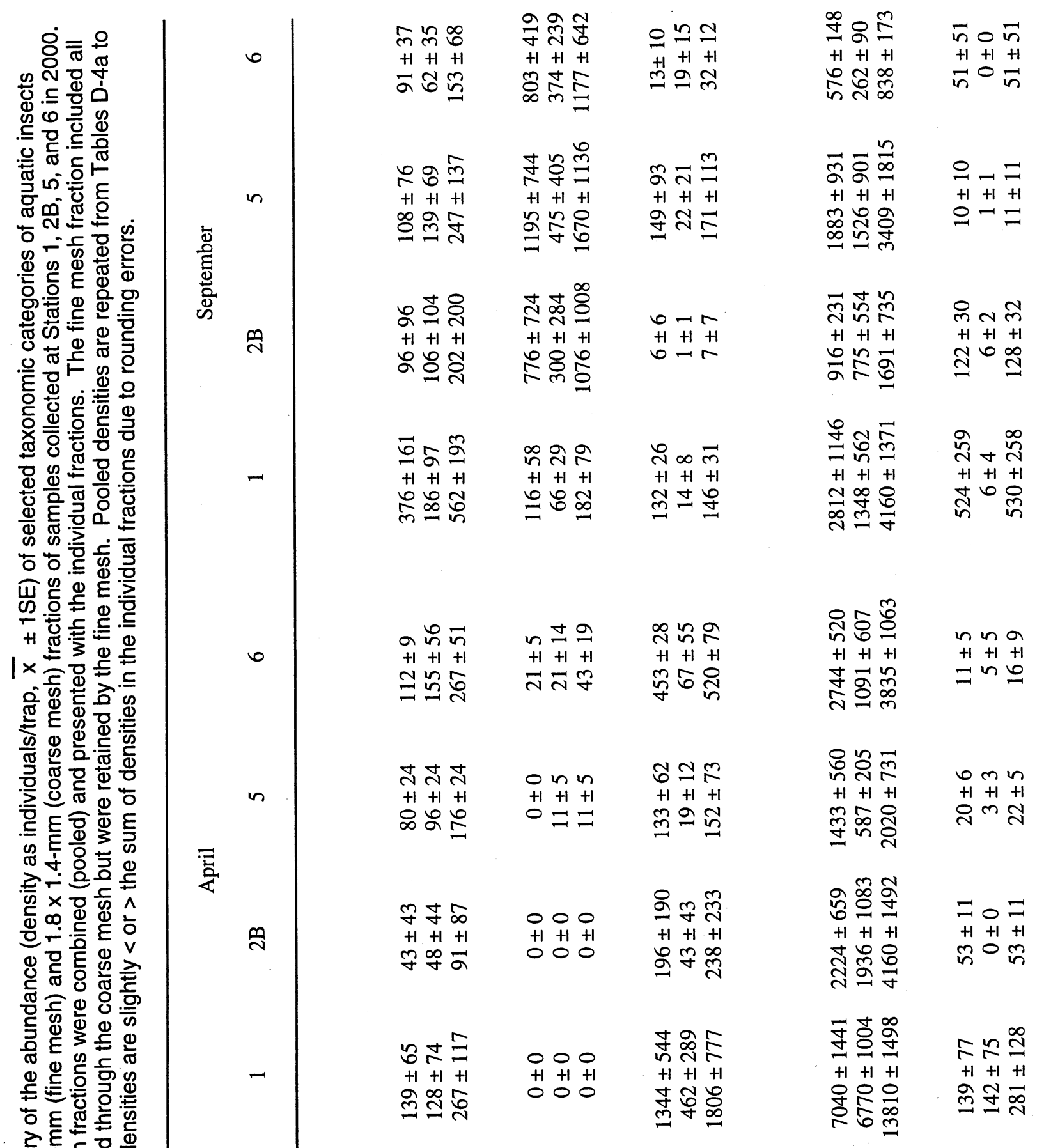

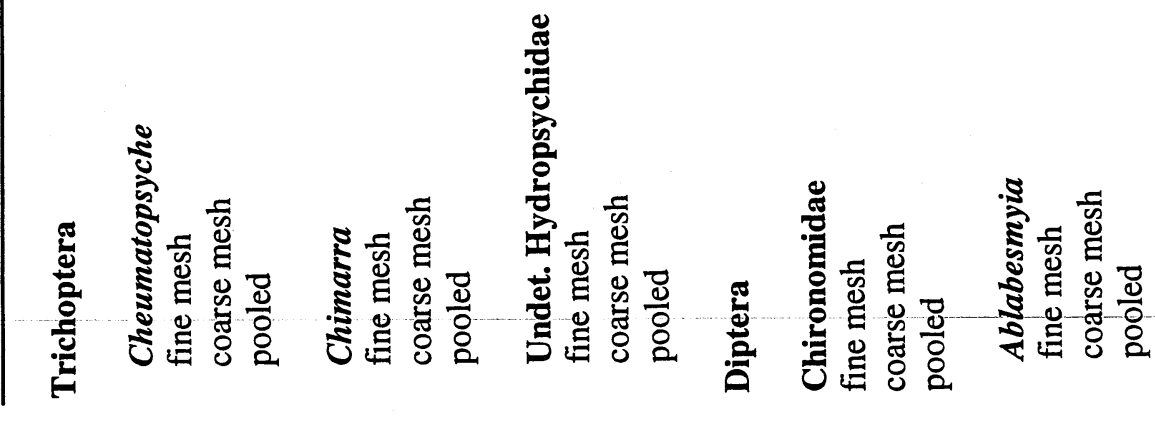




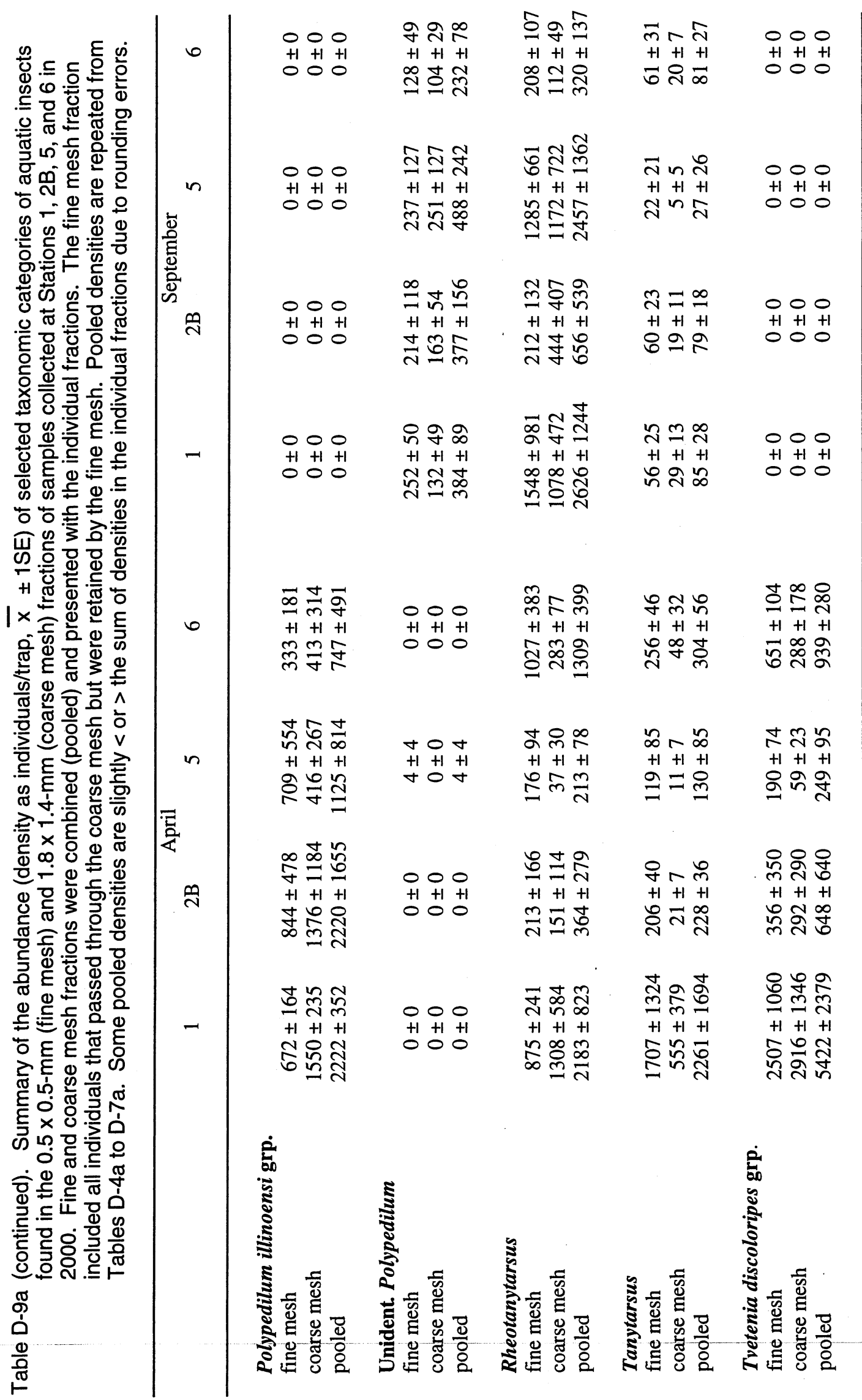


Table D-9b. Summary of the results of statistical tests (2-way ANOVA with station $x$ season interaction (inter.)) used to evaluate station (Stations $1,2 B, 5,6)$ and season ( $A=$ April, $S=$ September) differences $(p<0.05)$ for selected taxonomic categories of aquatic insects in 2000. Statistical tests were completed for the fine sieve $(0.5 \times 0.5-\mathrm{mm}$ mesh) and coarse sieve (1.8 $\times .4-\mathrm{mm}$ mesh) fractions individually and for the fine and coarse mesh fractions combined (pooled). The results of statistical tests on the pooled data are repeated from Tables D-4b to D-7b.

\begin{tabular}{|c|c|c|c|c|c|c|c|c|}
\hline & & $\mathbf{P}$ & Season 1 vs 2B & 1 vs 5 & 1 vs 6 & $2 B$ vs 5 & 2B vs 6 & 5 vs 6 \\
\hline $\begin{array}{l}\text { Total Density } \\
\text { fine mesh }\end{array}$ & $\begin{array}{l}\text { Station } \\
\text { Season } \\
\text { Inter. }\end{array}$ & $\begin{array}{l}0.035^{a} \\
0.322 \\
0.179\end{array}$ & & & & & & \\
\hline coarse mesh & $\begin{array}{l}\text { Station } \\
\text { Season } \\
\text { Inter. }\end{array}$ & $\begin{array}{l}0.018^{\mathrm{a}} \\
0.061 \\
0.026\end{array}$ & & & & & & \\
\hline pooled & $\begin{array}{l}\text { Station } \\
\text { Season } \\
\text { Inter. }\end{array}$ & $\begin{array}{l}0.106 \\
0.147 \\
0.742\end{array}$ & & & & & & \\
\hline $\begin{array}{l}\text { EPT Richness } \\
\text { fine mesh }\end{array}$ & $\begin{array}{l}\text { Station } \\
\text { Season } \\
\text { Inter. }\end{array}$ & $\begin{array}{l}0.575 \\
0.285 \\
0.578\end{array}$ & & & & & & \\
\hline coarse mesh & $\begin{array}{l}\text { Station } \\
\text { Season } \\
\text { Inter. }\end{array}$ & $\begin{array}{l}0.943 \\
0.858 \\
0.824\end{array}$ & & & & & & \\
\hline pooled & $\begin{array}{l}\text { Station } \\
\text { Season } \\
\text { Inter. }\end{array}$ & $\begin{array}{l}0.706 \\
0.415 \\
0.643\end{array}$ & & & & & & \\
\hline $\begin{array}{l}\text { Ephemeropters } \\
\text { Isonychia } \\
\text { fine mesh }\end{array}$ & $\begin{array}{l}\text { Station } \\
\text { Season } \\
\text { Inter. }\end{array}$ & $\begin{array}{l}0.025 \\
0.906 \\
0.024\end{array}$ & & & $6>1$ & & & \\
\hline coarse mesh & $\begin{array}{l}\text { Station } \\
\text { Season } \\
\text { Inter. }\end{array}$ & $\begin{array}{l}0.319 \\
0.158 \\
0.567\end{array}$ & & & & & & \\
\hline pooled & $\begin{array}{l}\text { Station } \\
\text { Season } \\
\text { Inter. }\end{array}$ & $\begin{array}{r}<0.001 \\
0.711 \\
0.441\end{array}$ & & $5>1$ & $6>1$ & & $6>2 B$ & \\
\hline
\end{tabular}


Table D-9b (continued). Summary of the results of statistical tests (2-way ANOVA with station $x$ season interaction (inter.)) used to evaluate station (Stations $1,2 B, 5,6)$ and season $(A=$ April, $S=$ September) differences $(p<0.05)$ for selected taxonomic categories of aquatic insects in 2000. Statistical tests were completed for the fine sieve $(0.5 \times 0.5-\mathrm{mm}$ mesh) and coarse sieve (1.8 $\times .4-\mathrm{mm}$ mesh) fractions individually and for the fine and coarse mesh fractions combined (pooled). The results of statistical tests on the pooled data are repeated from Tables D-4b to D-7b.

\begin{tabular}{|c|c|c|c|c|c|c|c|c|c|}
\hline & & $\mathbf{P}$ & Season & 1 vs $2 B$ & 1 vs 5 & 1 vs 6 & $2 B$ vs 5 & 2B vs 6 & 5 vs 6 \\
\hline \multicolumn{10}{|l|}{ Tricorythodes } \\
\hline \multirow[t]{3}{*}{ fine mesh } & Station & $0.582{ }^{a}$ & & & & & & & \\
\hline & Season & $0.013^{\mathrm{a}}$ & & & & & & & \\
\hline & Inter. & 0.583 & & & & & & & \\
\hline \multirow[t]{3}{*}{ coarse mesh } & Station & $0.951 \mathrm{a}$ & & & & & & & \\
\hline & Season & $0.007^{\mathrm{a}}$ & & & & & & & \\
\hline & Inter. & 0.951 & & & & & & & \\
\hline \multirow[t]{3}{*}{ pooled } & Station & 0.564 & & & & & & & \\
\hline & Season & $<0.001$ & $\mathrm{~S}>\mathrm{A}$ & & & & & & \\
\hline & Inter. & 0.854 & & & & & & & \\
\hline \multicolumn{10}{|l|}{ Plecoptera } \\
\hline \multirow{3}{*}{$\begin{array}{l}\text { Perlesta } \\
\text { fine mesh }\end{array}$} & & & & & & & & & \\
\hline & $\begin{array}{l}\text { Station } \\
\text { Season }\end{array}$ & $0.504 \mathrm{a}$ & & & & & & & \\
\hline & $\begin{array}{l}\text { Season } \\
\text { Inter. }\end{array}$ & 0.504 & & & & & & & \\
\hline \multirow[t]{3}{*}{ coarse mesh } & Station & 0.178 & & & & & & & \\
\hline & Season & $<0.001$ & $\mathrm{~A}>\mathrm{S}$ & & & & & & \\
\hline & Inter. & 0.178 & & & & & & & \\
\hline \multirow[t]{3}{*}{ pooled } & Station & 0.229 & & & & & & & \\
\hline & Season & $<0.001$ & $A>S$ & & & & & & \\
\hline & Inter. & 0.229 & & & & & & & \\
\hline \multirow{2}{*}{\multicolumn{10}{|c|}{$\begin{array}{l}\text { Trichoptera } \\
\text { Cheumatopysche }\end{array}$}} \\
\hline & & & & & & & & & \\
\hline \multirow[t]{2}{*}{ fine mesh } & Station & 0.188 & & & & & & & \\
\hline & $\begin{array}{l}\text { Season } \\
\text { Inter. }\end{array}$ & $\begin{array}{l}0.276 \\
0.535\end{array}$ & & & & & & & \\
\hline \multirow[t]{3}{*}{ coarse mesh } & Station & 0.761 & & & & & & & \\
\hline & Season & 0.766 & & & & & & & \\
\hline & Inter. & 0.732 & & & & & & & \\
\hline \multirow[t]{3}{*}{ pooled } & Station & $0.029^{\mathrm{a}}$ & & & & & & & \\
\hline & Season & 0.748 & & & & & & & \\
\hline & Inter. & 0.836 & & & & & & & \\
\hline
\end{tabular}


Table D-9b (continued). Summary of the results of statistical tests (2-way ANOVA with station $x$ season interaction (inter.)) used to evaluate station (Stations 1, 2B, 5, 6) and season ( $A=$ April, $S=$ September) differences $(p<0.05)$ for selected taxonomic categories of aquatic insects in 2000. Statistical tests were completed for the fine sieve $(0.5 \times 0.5-\mathrm{mm}$ mesh) and coarse sieve (1.8 $\times .4-\mathrm{mm}$ mesh) fractions individually and for the fine and coarse mesh fractions combined (pooled). The results of statistical tests on the pooled data are repeated from Tables $D-4 b$ to $D-7 b$.

\begin{tabular}{|c|c|c|c|c|c|c|c|c|c|}
\hline & & $\mathbf{P}$ & Season & 1 vs $2 B$ & 1 vs 5 & 1 vs 6 & $2 B$ vs 5 & $2 B$ vs 6 & 5 vs 6 \\
\hline $\begin{array}{l}\text { Chimarra } \\
\text { fine mesh }\end{array}$ & $\begin{array}{l}\text { Station } \\
\text { Season } \\
\text { Inter. }\end{array}$ & $\begin{array}{l}0.653 \\
0.030^{a} \\
0.658\end{array}$ & & & & & & & \\
\hline coarse mesh & $\begin{array}{l}\text { Station } \\
\text { Season } \\
\text { Inter. }\end{array}$ & $\begin{array}{l}0.744 \\
0.051 \\
0.783\end{array}$ & & & & & & & \\
\hline pooled & $\begin{array}{l}\text { Station } \\
\text { Season } \\
\text { Inter. }\end{array}$ & $\begin{array}{r}0.085 \\
<0.001 \\
0.887\end{array}$ & $\mathrm{~S}>\mathrm{A}$ & & & & & & \\
\hline $\begin{array}{l}\text { Unidentified Hydropsychidae } \\
\text { fine mesh }\end{array}$ & $\begin{array}{l}\text { Station } \\
\text { Season } \\
\text { Inter. }\end{array}$ & $\begin{array}{l}0.010 \\
0.003 \\
0.022\end{array}$ & $A>S$ & $1>2 B$ & & & & & \\
\hline coarse mesh & $\begin{array}{l}\text { Station } \\
\text { Season } \\
\text { Inter. }\end{array}$ & $\begin{array}{l}0.091 \\
0.066 \\
0.093\end{array}$ & & & & & & & \\
\hline pooled & $\begin{array}{l}\text { Station } \\
\text { Season } \\
\text { Inter. }\end{array}$ & $\begin{array}{l}0.003 \\
0.006 \\
0.790\end{array}$ & $\mathrm{~A}>\mathrm{S}$ & $1>2 B$ & & & & $6>2 B$ & \\
\hline $\begin{array}{l}\text { Diptera } \\
\text { Chironomidae } \\
\text { fine mesh }\end{array}$ & $\begin{array}{l}\text { Station } \\
\text { Season } \\
\text { Inter. }\end{array}$ & $\begin{array}{l}0.001 \\
0.007 \\
0.075\end{array}$ & $\mathrm{~A}>\mathrm{S}$ & $1>2 B$ & $1>5$ & $1>6$ & & & \\
\hline coarse mesh & $\begin{array}{l}\text { Station } \\
\text { Season } \\
\text { Inter. }\end{array}$ & $\begin{array}{r}<0.001 \\
0.004 \\
0.002\end{array}$ & $\mathrm{~A}>\mathrm{S}$ & $1>2 B$ & $1>5$ & $1>6$ & & & \\
\hline pooled & $\begin{array}{l}\text { Station } \\
\text { Season } \\
\text { Inter. }\end{array}$ & $\begin{array}{l}0.028^{b} \\
0.013 \\
0.611\end{array}$ & $A>S$ & & & & & & \\
\hline
\end{tabular}


Table D-9b (continued). Summary of the results of statistical tests (2-way ANOVA with station $x$ season interaction (inter.)) used to evaluate station (Stations $1,2 B, 5,6)$ and season $(A=$ April, $S=$ September) differences $(p<0.05)$ for selected taxonomic categories of aquatic insects in 2000. Statistical tests were completed for the fine sieve $(0.5 \times 0.5-\mathrm{mm}$ mesh) and coarse sieve (1.8 $\times .4-\mathrm{mm}$ mesh) fractions individually and for the fine and coarse mesh fractions combined (pooled). The results of statistical tests on the pooled data are repeated from Tables $D-4 b$ to $D-7 b$.

\begin{tabular}{|c|c|c|c|c|c|c|c|c|c|}
\hline & & $\mathbf{P}$ & Season & 1 vs $2 B$ & 1 vs 5 & 1 vs 6 & $2 B$ vs 5 & 2B vs 6 & 5 vs 6 \\
\hline $\begin{array}{l}\text { Ablabesmyia } \\
\text { fine mesh }\end{array}$ & $\begin{array}{l}\text { Station } \\
\text { Season } \\
\text { Inter. }\end{array}$ & $\begin{array}{l}0.060 \\
0.179 \\
0.373\end{array}$ & & & & & & & \\
\hline coarse mesh & $\begin{array}{l}\text { Station } \\
\text { Season } \\
\text { Inter. }\end{array}$ & $\begin{array}{l}0.016^{b} \\
0.062 \\
0.023\end{array}$ & & & & & & & \\
\hline pooled & $\begin{array}{l}\text { Station } \\
\text { Season } \\
\text { Inter. }\end{array}$ & $\begin{array}{l}0.002 \\
0.665 \\
0.433\end{array}$ & & & $1>5$ & $1>6$ & & $2 B>6$ & \\
\hline $\begin{array}{l}\text { Polypedilum illinoensi grp. } \\
\text { fine mesh }\end{array}$ & $\begin{array}{l}\text { Station } \\
\text { Season } \\
\text { Inter. }\end{array}$ & $\begin{array}{l}0.774{ }^{a} \\
0.002 \\
0.774\end{array}$ & & & & & & & \\
\hline coarse mesh & $\begin{array}{l}\text { Station } \\
\text { Season } \\
\text { Inter. }\end{array}$ & $\begin{array}{l}0.376 \\
0.005^{a} \\
0.376\end{array}$ & & & & & & & \\
\hline pooled & $\begin{array}{l}\text { Station } \\
\text { Season } \\
\text { Inter. }\end{array}$ & $\begin{array}{r}0.311 \\
<0.001 \\
0.311\end{array}$ & $\mathrm{~A}>\mathrm{S}$ & & & & & & \\
\hline $\begin{array}{l}\text { Unidentified Polypedilum } \\
\text { fine mesh }\end{array}$ & $\begin{array}{l}\text { Station } \\
\text { Season } \\
\text { Inter. }\end{array}$ & $\begin{array}{r}0.836 \\
<0.001 \\
0.844\end{array}$ & $\mathrm{~S}>\mathrm{A}$ & & & & & & \\
\hline coarse mesh & $\begin{array}{l}\text { Station } \\
\text { Season } \\
\text { Inter. }\end{array}$ & $\begin{array}{r}0.583 \\
<0.001 \\
0.583\end{array}$ & $\mathrm{~S}>\mathrm{A}$ & & & & & & \\
\hline pooled & $\begin{array}{l}\text { Station } \\
\text { Season } \\
\text { Inter. }\end{array}$ & $\begin{array}{r}0.946 \\
<0.001 \\
0.617\end{array}$ & $\mathrm{~S}>\mathrm{A}$ & & & & & & \\
\hline
\end{tabular}


Table D-9b (continued). Summary of the results of statistical tests (2-way ANOVA with station $x$ season interaction (inter.)) used to evaluate station (Stations $1,2 B, 5,6)$ and season $(A=$ April, $S=$ September) differences $(p<0.05)$ for selected taxonomic categories of aquatic insects in 2000. Statistical tests were completed for the fine sieve $(0.5 \times 0.5-\mathrm{mm}$ mesh) and coarse sieve ( $1.8 \times .4-\mathrm{mm}$ mesh) fractions individually and for the fine and coarse mesh fractions combined (pooled). The results of statistical tests on the pooled data are repeated from Tables D-4b to D-7b.

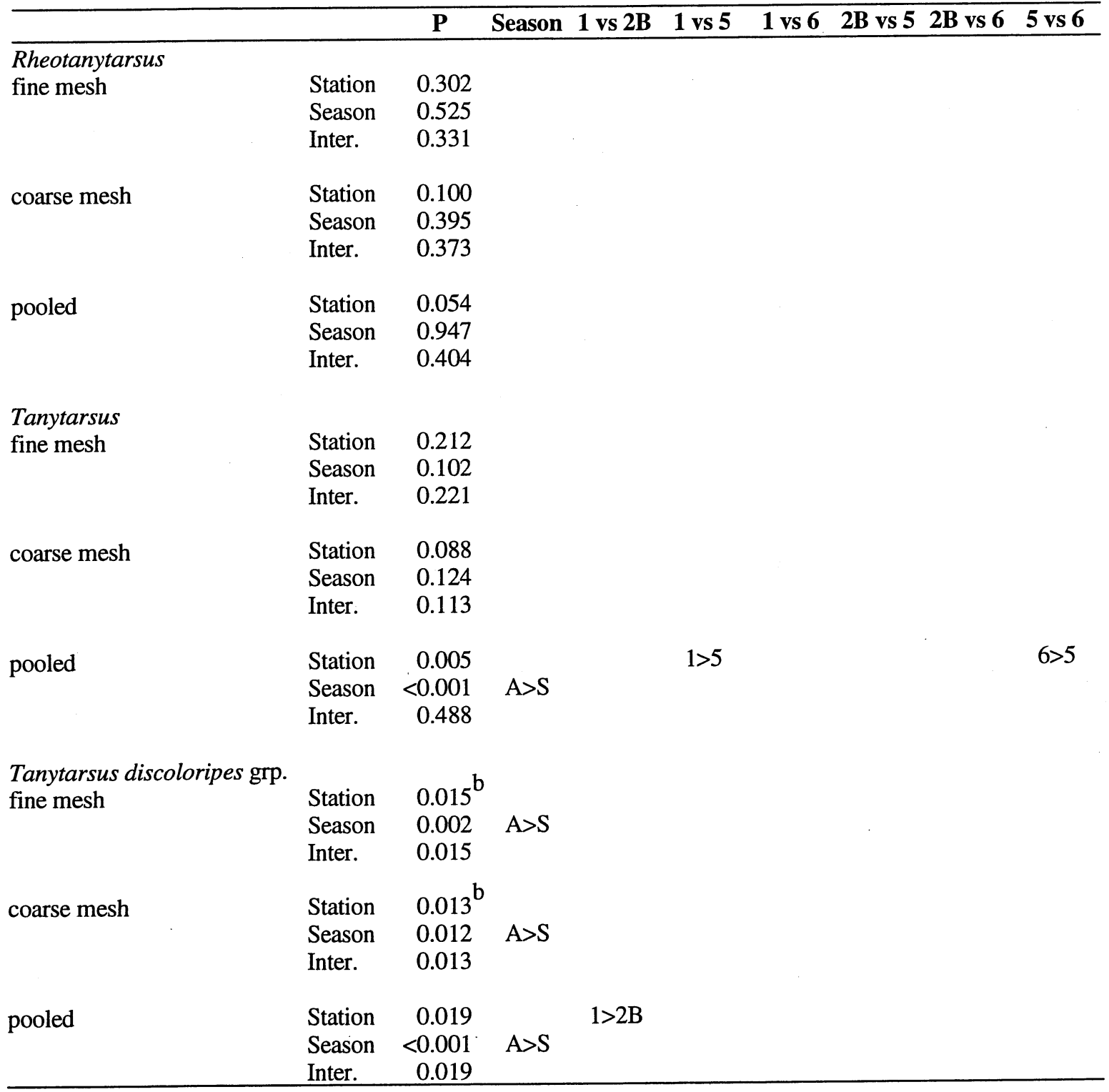

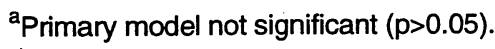

bNo significant differences were found using Tukey's pairwise comparisons. 
served for density. For example, fine-mesh fractions usually resulted in samples that contained $20-60 \%$ more chironomid taxa, were somewhat more diverse (as shown by Shannon Diversity), and slightly less dominated by the five most abundant taxa than the coarse-mesh fractions. In contrast, fine-mesh fractions usually contained 30-50\% fewer EPT taxa in the spring than coarse-mesh fractions (Table D-10a).

In an attempt to determine if the change to a smaller mesh size altered comparisons among stations and between seasons for individual taxa and groups of taxa, statistical results based on coarse-mesh data were compared to those based on pooled data. These comparisons indicate that a number of differences among stations and between seasons were only significant with pooled data. For example, based on the coarsemesh data there were no differences in Isonychia density among stations. In contrast, the pooled data indicate that Isonychia density was higher at Station 6 than at Stations 1 and $2 \mathrm{~B}$ and that Isonychia density was also higher at Station 5 than at Station 1 (Table D-9b). Similar results were obtained for Unident. Hydropsychidae, Ablabesmyia, Tanytarsus, and Tvetenia discoloripes grp. For each of these taxa pooled data indicate station differences that were not significant with the coarse-mesh data (Table D-9b). As with the station differences, a number of seasonal differences were significant with the pooled data but not the coarse-mesh data. For example, based on coarse-mesh data Tricorythodes density was the same in April and September. In contrast, pooled data indicate that Tricorythodes density was higher in September than April (Table D-9b). Similar results were obtained for Chimarra, Polypedilum illinoensi grp., and Tanytarsus. Again, the standard sieve data indicate significant seasonal differences that were not indicated with the coarse-mesh data (Table D-9b). Only Chironomidae exhibited a difference based on coarse-mesh data but not pooled data - density was higher at Station 1 than at Stations 2B, 5, and 6 based on coarsemesh data but not pooled data) (Table D-9b). Overall, $12 \%$ of the 90 station comparisons involving density ( 15 measures $\mathrm{x} 6$ pairwise comparisons for each) were significant based on pooled data while only $3 \%$ were significant based on coarsemesh data. Similarly, seasonal comparisons involving density were more often significant when based on pooled $(60 \%)$ than coarse-mesh $(27 \%)$ data. 


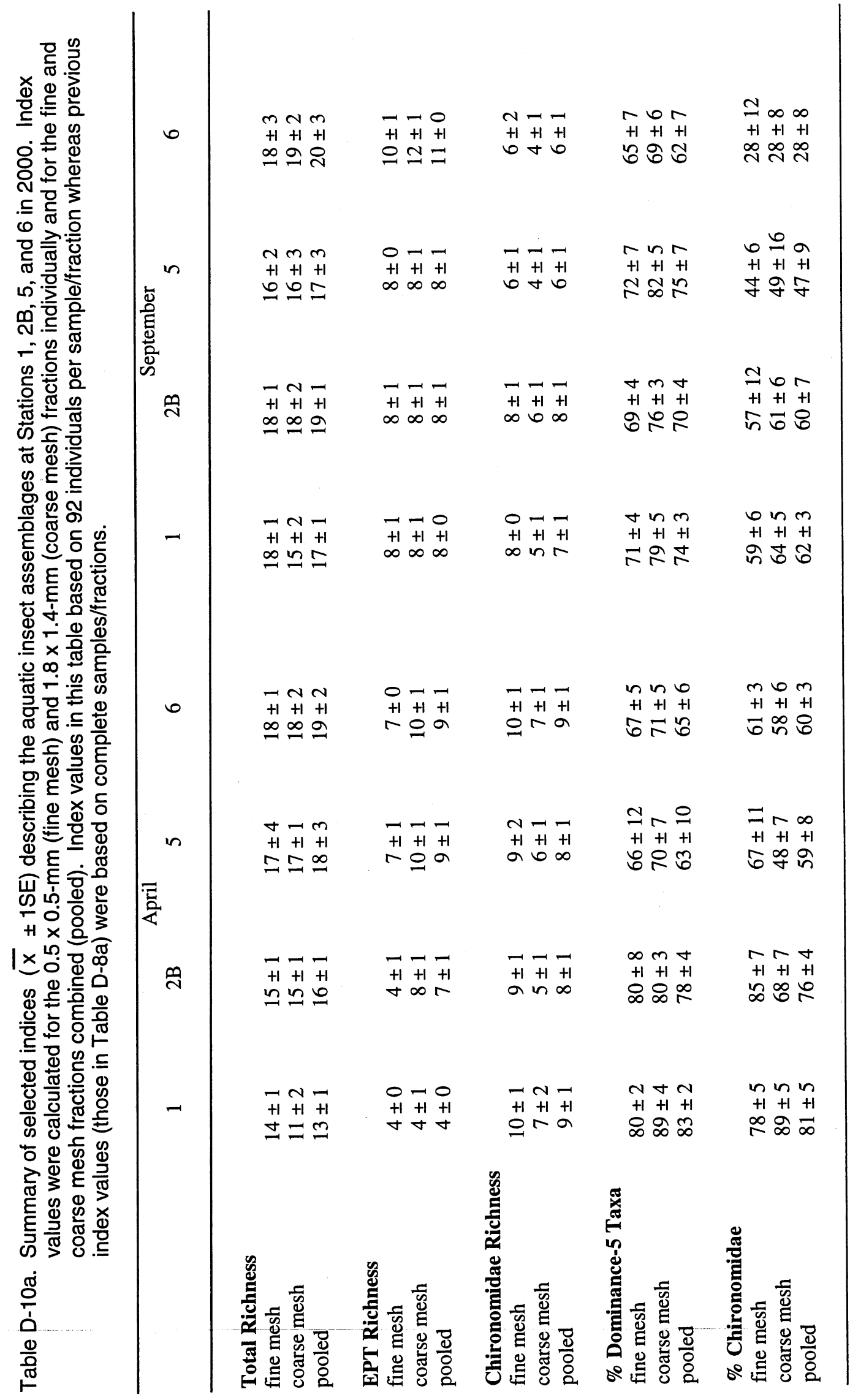




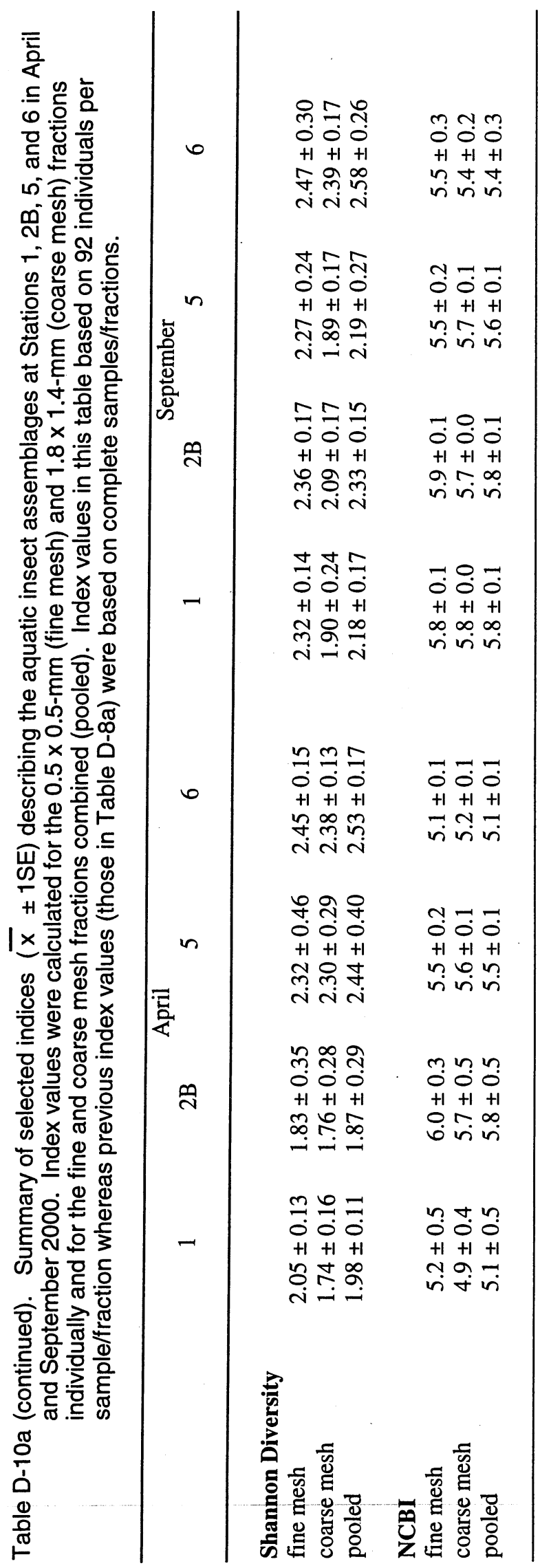


Table D-10b. Summary of the results of statistical tests (2-way ANOVA with station $\mathrm{x}$ season interaction (inter.)) used to evaluate station (Stations 1, 2B, 5, 6) and season ( $A=A$ pril, $S=$ September) differences $(p<0.05)$ for selected indices describing the aquatic insect assemblages at Stations 1,2B, 5, and 6 in 2000. Statistical tests were completed for the fine sieve $(0.5 \times 0.5-\mathrm{mm}$ mesh) and coarse sieve (1.8 $\times .4-\mathrm{mm}$ mesh) fractions individually and for the fine and coarse mesh fractions combined (pooled). Analyses were based on 92 individuals per sample/fraction whereas previous analyses (those in Table D-8b) were based on complete samples/fractions.

\begin{tabular}{|c|c|c|c|c|c|c|c|c|c|}
\hline & & $\mathbf{P}$ & Season & 1 vs $2 B$ & 1 vs 5 & 1 vs 6 & 2B vs 5 & $2 B$ vs 6 & 5 vs 6 \\
\hline \multicolumn{10}{|c|}{ Total Richness } \\
\hline \multirow[t]{3}{*}{ fine mesh } & Station & 0.795 & & & & & & & \\
\hline & Season & 0.214 & & & & & & & \\
\hline & Inter. & 0.518 & & & & & & & \\
\hline \multirow[t]{3}{*}{ coarse mesh } & Station & $0.050^{\mathrm{a}}$ & & & & & & & \\
\hline & Season & 0.271 & & & & & & & \\
\hline & Inter. & 0.654 & & & & & & & \\
\hline \multirow[t]{3}{*}{ pooled } & Station & 0.170 & & & & & & & \\
\hline & Season & 0.248 & & & & & & & \\
\hline & Inter. & 0.458 & & & & & & & \\
\hline \multicolumn{10}{|l|}{ EPT Richness } \\
\hline \multirow[t]{3}{*}{ fine mesh } & Station & 0.002 & & & & $6>1$ & & $6>2 B$ & \\
\hline & Season & $<0.001$ & $\mathrm{~S}>\mathrm{A}$ & & & & & & \\
\hline & Inter. & 0.081 & & & & & & & \\
\hline \multirow[t]{3}{*}{ coarse mesh } & Station & 0.001 & & & & $6>1$ & & $6>2 B$ & \\
\hline & Season & 0.300 & & & & & & & \\
\hline & Inter. & 0.021 & & & & & & & \\
\hline \multirow[t]{3}{*}{ pooled } & Station & $<0.001$ & & & $5>1$ & $6>1$ & & $6>2 B$ & \\
\hline & Season & 0.009 & $\mathrm{~S}>\mathrm{A}$ & & & & & & \\
\hline & Inter. & 0.027 & & & & & & & \\
\hline \multicolumn{10}{|c|}{$\begin{array}{l}\text { Chironomidae Richness } \\
\text { fine mesh }\end{array}$} \\
\hline \multirow{2}{*}{ fine mesh } & $\begin{array}{l}\text { Station } \\
\text { Season }\end{array}$ & $\begin{array}{l}0.408 \\
0.010^{a}\end{array}$ & & & & & & & \\
\hline & Inter. & 0.662 & & & & & & & \\
\hline \multirow[t]{3}{*}{ coarse mesh } & Station & 0.669 & & & & & & & \\
\hline & Season & $0.043^{\mathrm{a}}$ & & & & & & & \\
\hline & Inter. & 0.267 & & & & & & & \\
\hline \multirow[t]{2}{*}{ pooled } & Station & $0.462 a$ & & & & & & & \\
\hline & $\begin{array}{l}\text { Season } \\
\text { Inter. }\end{array}$ & $\begin{array}{l}0.008^{\mathrm{a}} \\
0.395\end{array}$ & & & & & & & \\
\hline
\end{tabular}


Table D-10b (continued). Summary of the results of statistical tests (2-way ANOVA with station $x$ season interaction (inter.)) used to evaluate station (Stations 1, 2B, 5, 6) and season (A $=$ April, $S=$ September) differences $(p<0.05)$ for selected indices describing the aquatic insect assemblages at Stations 1,2B, 5, and 6 in 2000. Statistical tests were completed for the fine sieve $(0.5 \times 0.5-\mathrm{mm}$ mesh) and coarse sieve $(1.8 \times .4-\mathrm{mm}$ mesh) fractions individually and for the fine and coarse mesh fractions combined (pooled). Analyses were based on 92 individuals per sample/fraction whereas previous analyses (those in Table D-8b) were based on complete samples/fractions.

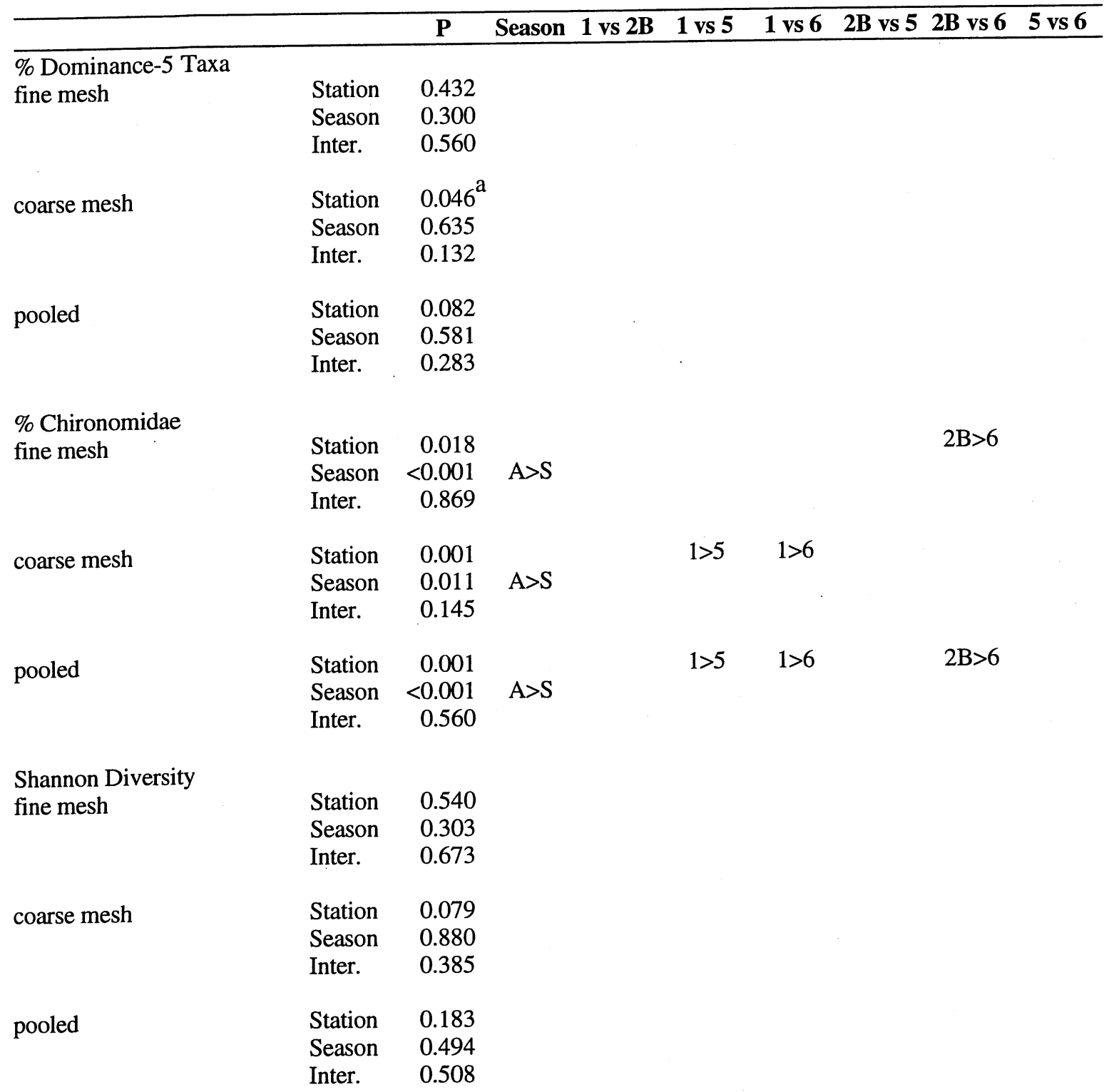


Table D-10b (continued). Summary of the results of statistical tests (2-way ANOVA with station $x$ season interaction (inter.)) used to evaluate station (Stations 1, 2B, 5, 6) and season (A $=$ April, $S=$ September) differences $(p<0.05)$ for selected indices describing the aquatic insect assemblages at Stations 1, 2B, 5, and 6 in 2000. Statistical tests were completed for the fine sieve $(0.5 \times 0.5-\mathrm{mm}$ mesh) and coarse sieve $(1.8 \times .4-\mathrm{mm}$ mesh) fractions individually and for the fine and coarse mesh fractions combined (pooled). Analyses were based on 92 individuals per sample/fraction whereas previous analyses (those in Table D-8b) were based on complete samples/fractions.

\begin{tabular}{|c|c|c|c|c|c|c|c|c|}
\hline & & $\mathbf{P}$ & Season & 1 vs $2 B$ & 1 vs 5 & 1 vs 6 & $2 \mathrm{~B}$ vs $52 \mathrm{~B}$ vs 6 & 5 vs 6 \\
\hline \multicolumn{9}{|l|}{ NCBI } \\
\hline \multirow[t]{3}{*}{ fine mesh } & Station & 0.055 & & & & & & \\
\hline & Season & 0.212 & & & & & & \\
\hline & Inter. & 0.433 & & & & & & \\
\hline \multirow[t]{3}{*}{ coarse mesh } & Station & 0.243 & & & & & & \\
\hline & Season & 0.067 & & & & & & \\
\hline & Inter. & 0.233 & & & & & & \\
\hline \multirow[t]{3}{*}{ pooled } & Station & 0.167 & & & & & & \\
\hline & Season & 0.116 & & & & & & \\
\hline & Inter. & 0.453 & & & & & & \\
\hline
\end{tabular}

aPrimary model not significant $(p>0.05)$.

Although mesh size had a major effect on comparisons of density among stations and between seasons, it had a much smaller effect on comparisons involving community structure (see Table D-10b). For example, mesh size did not affect station or season comparisons for five of the measures of community structure examined and only resulted in minor differences for two others (Table D-10b). EPT Richness was higher at Station 5 than at Station 1 based on pooled but not coarse-mesh data (Table D-10b). Pooled data also indicate that EPT Richness was greater in September than April but based on coarse-mesh data there was no significant difference between seasons (Table D-10b). In addition, based on pooled (but not coarse mesh) data, \% Chironomidae was higher at Station 2B than at Station 6 (Table D-10b). These results indicate that although the fine and coarse-mesh fractions differed with regard to some measures of community structure (i.e., EPT Richness in April and Chironomidae Richness, Shannon Diversity, \% Dominance-5 taxa in both seasons), analyses based on pooled data usually provided the same results as those based on individual fractions. Overall, of the 42 station comparisons involving community structure (7 measures of community structure $\mathrm{x} 6$ comparisons for each), a similar number were significant based on the pooled and 
coarse-mesh data ( 6 for the pooled and 4 for the coarse mesh). Likewise, a similar number of seasonal comparisons were significant based on the pooled and coarse-mesh data (two for the pooled and one for the coarse mesh).

\section{Discussion}

The primary objective of the 2000 study was to describe qualitatively and quantitatively the assemblage of aquatic insects inhabiting the Savannah River upstream (Station 1) and downstream (Stations 2B, 5 and 6) of effluent/runoff from the SRS. Observed similarities and differences between the upstream and downstream sites were used to evaluate the effect of SRS on the Savannah River ecosystem in 2000 . For the qualitative analysis, lower species richness at Stations 2B, 5 and/or 6 relative to Station 1 would suggest a loss of species in response to exposure to effluent and runoff from the SRS. This decrease in richness would reflect the absence of species (or species groups), especially those known to be pollution sensitive (Hilsenhoff 1987, Lenat 1993). Concurrently, the relative abundance of pollution-tolerant species (or species groups) may increase. Personal judgment was used to evaluate the significance of differences in richness or relative abundance observed in the qualitative data.

A parallel approach was used in the quantitative analysis of the aquatic insects at the four stations. Lower species richness, species diversity, densities of pollution-sensitive species (or species groups) and/or increases in densities or relative abundance (dominance) of pollution-tolerant species (or species groups) at Stations 2B, 5 and/or 6 relative to Station 1 would have suggested that differences among stations were attributable to effluent or runoff from the SRS. The significance of these differences was determined statistically; the probability of erroneously identifying a difference was $\leq 5 \%$. 


\section{Environmental Conditions in 2000 as Indicated by Aquatic Insect Collections}

wide variety of species, many of which were abun1 dant, was found in both qualitative and quantitative tions in 2000. The qualitative and quantitative assessments of the aquatic insect assemblages did not indicate that inputs from SRS had a negative effect on aquatic insects in the Savannah River. Conditions (as indicated by aquatic insect communities) at the potential impact stations (downstream of SRS inputs) were as good as or better than those at an upstream reference station. Likewise, species composition at all four stations in 2000 was generally similar to observations from previous surveys.

The qualitative collections provide a thorough description of the overall composition of the insect fauna at each of the four stations because all habitats are sampled. Forty-six taxa were unique to the qualitative collections (not found in trap samples), whereas only ten taxa were unique to the trap samples. This difference primarily represents the greater number of habitats included in the qualitative samples relative to the trap samples. The insect faunas in the qualitative collections from April and September 2000 were generally similar to those found in earlier studies; a total of 195 taxa was collected across the two dates (160 taxa in April and 134 taxa in September) and 4 stations in 2000 . This includes 27 dragonfly and damselfly taxa, 26 mayfly taxa, 26 caddisfly taxa, 10 true bug taxa, 3 stonefly taxa, 39 beetle taxa, and 61 Diptera (primarily Chironomidae) taxa. Total Richness estimated in both April and September 2000 was higher than in most previous surveys; this reflects the highest recorded numbers of mayfly, caddisfly, beetle, Odonata, and Diptera species at one or more stations and in one or both seasons. Most of these additional taxa were not common; thus, the dominant species were similar across the four stations and similar to those found at these stations in previous surveys. The 2000 data continue a longterm trend of increasing Taxa Richness across these sites on the Savannah River that has been observed over the last several years. There were some differences in the insect faunas 
of the four stations, but these differences did not conform to our $a$ priori hypotheses regarding negative responses to exposure to effluent and runoff from the SRS (i.e., conditions were generally better downstream of SRS inputs than at an upstream site). Therefore, the qualitative aquatic insect data do not appear to indicate significant environmental degradation in the Savannah River in the vicinity of SRS. When 2000 qualitative data were combined with data collected as part of previous surveys, we found no evidence that long-term exposure to effluent or runoff from the SRS had an adverse effect on the taxonomic composition of the insect assemblages downstream of SRS in 2000.

The trap samples are quantitative examinations of the many species that inhabit snag and debris habitats. Most of these species are also in the qualitative samples (only 10 species were unique to the quantitative samples, and all were rare), but the quantitative data can be examined using rigorous statistical techniques that cannot be applied to the qualitative data. Quantitative examination of the aquatic insects (i.e., as measures of population density of individual species, and overall community structure) found no evidence that effluent or runoff from the SRS resulted in changes in the aquatic insect assemblages downstream of the SRS. Some differences were observed among stations and between seasons, but these differences do not appear indicative of environmental degradation downstream of the SRS. Rather, these results indicate that conditions at the potential impact stations (downstream of SRS inputs) are generally superior to those at the upstream reference station. The quantitative data show that there were seasonal differences in the aquatic insect community of the Savannah River, but these differences were expected (i.e., caused by differences in life history patterns such as emergence times) and there was no indication that they were caused by exposure to effluent or runoff from the SRS. The available data suggest that the differences among sites and between seasons reflect natural spatial and temporal variation that is characteristic of all streams and rivers.

In summary, Stations 1, 2B, 5 and 6 supported aquatic assemblages in 2000 that contained numerous species, many of which were quite numerous and pollution sensitive. Differences were observed among stations, both between upstream and downstream stations and among downstream stations. However, aquatic insect composition and abundance at the 
downstream stations were generally similar to the upstream (reference) station. Thus, exposure to effluent and runoff from the SRS did not appear to have a measurable effect on the aquatic insect assemblage.

\section{Consequences of a Reduction in Mesh Size}

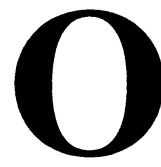

ne of the objectives of the 2000 sampling program was to determine if a reduction in the size of the mesh used during field processing (see qualitative sampling method section for details of this change) affected density estimates for common taxa and groups of taxa (Total Density, EPT Density, and Chironomidae Density). We also sought to determine if this change affected estimates of selected community structure indices (Total Richness, EPT Richness, Chironomidae Richness, \% Dominance-5 taxa, $\%$ Chironomidae, Shannon-Wiener Diversity, and NCBI). This evaluation included comparisons of stations and seasons based on both density and community structure. This was accomplished by separating each sample into a coarse-mesh fraction (material retained by the coarse sieve) and a finemesh fraction (material that passed through the coarse sieve but was retained by the fine sieve). The combination of the coarse mesh and fine-mesh fractions represent the material that would have been retained if it had not first been passed through the coarse-mesh sieve. This method was used in 1998 and 1999 whereas pre-1998 data represent only material retained in the coarse mesh. Comparisons of the coarse-mesh data with the combined (pooled) data provided estimates of the effect of the switch to the fine mesh.

Density estimates based on the fine-mesh data were generally much greater (usually 2-4 times, but up to 21 times greater for some taxa) than those based on the coarse-mesh data. This was evident when taxa were grouped and when they were examined individually. Differences between the mesh sizes were particularly large for Isonychia and Tanytarsus in April, Ablabesmyia in September, and Unident. Hydropsychidae across seasons. This indicates that most of the Isonychia, Tanytarsus, Tricorythodes, and Unident. Hydropsychidae collected in the April 2000 trap samples and most of the Ablabesmyia, Tricorythodes, and Unident. Hydropsychidae 
collected in the September 2000 trap samples were too small to be retained by the wire screen. In contrast, most measures of community structure were little changed by the switch to a smaller mesh size and those measures that were affected (Chironomidae Richness, Shannon Diversity, and \% Dominance-5 taxa) were not changed dramatically based on the 2000 data.

As with the density estimates themselves, the change to a smaller mesh size had a major effect on comparisons based on density. For 8 of the 13 taxa analyzed, differences in station and/or season were significant with the pooled data but not the coarse-mesh data. This was particularly true for Isonychia, Unident. Hydropsychidae, Ablabesmyia, and Tanytarsus. These results suggest that although densities are consistently higher in fine-mesh fractions than in coarse-mesh fractions, the magnitude of these density increases was not consistent across stations or seasons for many taxa. In contrast to the major effect of mesh size on comparisons of density among stations and between seasons, the effect of mesh size on comparisons involving community structure was relatively minor. For example, mesh size did not affect station or season comparisons for five of the seven measures of community structure analyzed and differences between mesh sizes were relatively minor for the other two measures of community structure.

In conclusion, it appears that based on the 2000 data the switch to a fine sieve with smaller mesh had a major effect on density estimates and the station and season comparisons based on these estimates. The fine sieve provided density estimates that were commonly 2-4 fold higher than those estimated using the coarse sieve. Furthermore, a number of differences among stations and/or between seasons were detected with the fine sieve that were not detected with the coarse sieve suggesting that the magnitude of density increases was not consistent across stations or seasons. In contrast, the switch to a fine sieve appeared to have a minimal effect on community structure. Because year to year fluctuations in density and community structure are common for riverine insect assemblages efforts will be made to repeat these mesh size analyses in subsequent years. 


\section{E. FISH}

\section{Introduction}

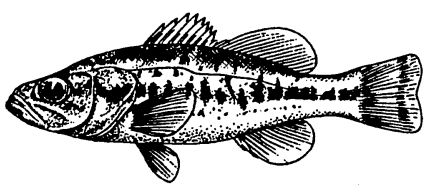

The Academy has studied the fish of the Savannah

River for almost 50 years, and this information is useful in determining the long-term effects of the Savannah River Site operations, on the health of the river.
The structure and dynamics of fish assemblages are commonly used to assess the health of aquatic systems. Fishes are good indicators of overall system integrity because assemblages include a diversity of species that occupy a variety of trophic levels whose presence or absence can be indicative of local conditions. The presence or absence of fishes intolerant to pollution or tolerant to physical and chemical habitat degradation, and the presence of introduced species and various life stages of fishes and their population dynamics have also been used to measure the health of aquatic systems. The study of fish assemblages and the changes in these assemblages over time are important elements in the monitoring and evaluation of human impacts upon aquatic ecosystems. Monitoring the structure of fish assemblages in Savannah River has been an integral part of environmental assessments of the Savannah River Site by The Academy of Natural Sciences of Philadelphia (ANSP) since 1951.

Until 1997 these assessments included comprehensive studies, cursory studies and independent monitoring of locations near Plant Vogtle. Comprehensive studies included a twice per year assessment every 4-5 years at four stations. The cursory studies were annual assessments at three of the four stations. The Vogtle study was an annual assessment of two stations, upstream and downstream of Plant Vogtle, both upstream from the SRS. The last cursory and Vogtle studies were conducted in 1996 and the last comprehensive study was conducted in 1993.

The current study design is an annual, early fall assessment, which has been conducted since 1997 . This report documents the 2000 study. Sampling is done in representative river and 
backwater habitats at four stations, using walkalong electroshocking in shallow backwater areas, boat electroshocking in channels and deeper backwaters, and seining along shores of the main channel. Three of the stations, Stations 1, 5 and 6, have been sampled in previous years in both cursory and comprehensive surveys. The fourth station, 2B, was sampled prior to 1997 as the downstream Vogtle station (V-2) and reported as part of the Plant Vogtle studies. There are historical data from each of these four stations that can be used to examine changes in occurrence of fish species over time. The examination of temporal variation in fish assemblage structure is necessary for the detection of any perturbations that may be related to SRS because there are few reliable data from Savannah River that document fish assemblage dynamics prior to plant construction.

The main objectives of the 2000 survey were to: 1) evaluate possible effects of the SRS through comparison of fish species richness, abundance, and occurrence at stations upstream and downstream of the plant; and 2) compare results with those of the 1997-1999 surveys and previous comprehensive surveys to identify temporal variation in fish assemblage structure related to SRS.

\section{Methods}

F ishes were sampled at four stations in the Savannah River on 8-12 September 2000. Station 1 is the most upstream station and Station 6, the most downstream. Stations 1, 2B, and 5 are on the river adjacent to the SRS and Station 6 is downstream from the site. All stations have been sampled in previous Academy surveys. Seining, walk-along electrofishing in backwaters, and boat electrofishing in the main channel were the primary collection techniques used in the 2000 survey. Additional fish specimens were collected with dip nets and from traps during macroinvertebrate and insect sampling and were incorporated into the fisheries results. Singularly, each of the primary methods was more efficient for the assessment of specific habitats and the collection of particular species than other methods. Together, the techniques were complementary and resulted in an adequate assessment of species occurrences and distributions throughout the river reach. 
Changes in sampling methods among surveys must be considered in any comparisons of these data among years. Sampling methods used in 1997-2000 are most comparable to those used in previous comprehensive surveys (at Stations 1, 5 and 6) and previous Vogtle surveys (at Station 2B; ANSP 1990a, 1994a). The comprehensive surveys were conducted twice each year, while the current program includes only one survey per year. More seine samples were taken in the 19972000 surveys than in previous cursory surveys (no seining was done in most cursory surveys), but fewer compared to comprehensive surveys. In 1995, walk-along electrofishing sampling replaced rotenone sampling in backwater areas in all surveys. Boat electrofishing was employed in 1995 to collect fishes from the main channel at Station 1 during a cursory study, in 1996 for Vogtle stations and used extensively in the 1997-2000 studies at all stations. The boat electroshocking sampling provides valuable data on fish populations inhabiting the main river channels, replacing gill netting and trapping, which were used in previous comprehensive surveys.

\section{Seine Samples}

S eine samples were taken along both river banks using a $6.1-\mathrm{m} \times 1.2-\mathrm{m}(20-\mathrm{x} 4-\mathrm{ft})$ bag seine with $0.318-\mathrm{cm}$ (1/8-in) mesh and extra chain on the lead line. Seine hauls were taken in the direction of river flow in lengths varying from 24-45 m (median $28 \mathrm{~m}$ ) depending on available habitat. The area seined was calculated for each haul for standardization of fish densities. In samples where the seine was not opened to its full extent, the area of the sample was adjusted accordingly. Habitat variables were measured within the area seined, and these data were used in statistical analyses to investigate differences among stations. Fishes from each seine sample were preserved separately for subsequent identification and enumeration.

\section{Habitat Variables}

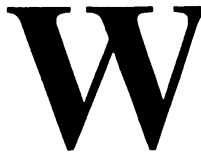

ithin each seine sampling area, water depth (m), water current velocity $(\mathrm{m} / \mathrm{s})$, and most prevalent substrate material were measured at three points within each seine sampling area: the upstream outer corner, the midpoint and the downstream outer corner. Water depth 
was measured with a metal meter stick. Velocity was measured with a Swoffer model 201 digital current meter according to Patrick Center Standard Operating Procedure No. P-13-14. Current velocity was measured at 0.6 of depth in water less than 1-m deep and at 0.2 and 0.8 of depth in water deeper than $1 \mathrm{~m}$. Dissolved oxygen, conductivity and water temperature were measured at one location with the sample area. Dissolved oxygen $(\mathrm{mg} / \mathrm{L})$ and water temperature $\left({ }^{\circ} \mathrm{C}\right)$ were measured with a YSI (Yellow Springs Instrument Co., Model 58E) meter. Conductivity ( $\mu$ mhos) was measured with a YSI model 33 SCT meter or a TDS Tester Conductivity Pen.

Dominant substrate types in the area (i.e., in a 15-cm diameter circle) around each measurement point in seine sample areas were recorded as gravel, sand, silt, or organic detritus. Substrates were categorized by referring to a scale of particle sizes. Where a mix of substrate sizes was present, two types were noted in order of decreasing dominance. Substrate composition was coded for use in statistical analyses by assigning a value of seven to gravel, nine to sand, and ten to silt, and eleven to organic detritus. In areas where two substrates occurred together, a weighted average of the two numbers was taken with the dominant substrate weighted at $75 \%$.

The average of the three point measurements in each station was used as an index of habitat conditions. Since the sampling points are on the middle and outside of the sampling area, these averages are indices of habitat condition, but are not unbiased estimates of averages over the entire sampling area. In particular, average depth over the site will usually be less than the average over the three measurement points.

Water temperature, dissolved oxygen and conductivity were also measured in walk-along shocking samples using the same equipment as at the seine sampling sites.

\section{Walk-Along Shocking}

$\mathbf{U}$ sing a walk-along electroshocker, depletion sampling was done at one location within each station $(1,5$ and 6$)$ in backwater areas along the South Carolina bank. Prior to 1993, these sites had been sampled using rotenone. The electroshocking used a Honda EG5000X gener- 
ator and a Coffelt VVP-15 controller that generated 500 volts and output current of 2-7 amps. Positive electrodes were hoops covered with $0.32-\mathrm{cm}$ mesh netting and mounted on fiberglass poles carried by two collectors. The negative electrode was a single stainless steel cable that was submerged into the sampling area. Block seines with mesh size of 0.32$\mathrm{cm}$ were installed around the sampling area, providing an obstructed perimeter from which fish presumably could not escape. Operators wading with anodes and $0.32-\mathrm{cm}$ mesh dip nets shocked the blocked area and collected effected fishes. The stunned fishes were held in river water during each pass until they were identified, measured and released, or preserved. Three successive electrofishing passes were made in each blocked area, until depletion of the fish population residing within that area was apparent. Each pass sample was preserved as a separate distinct sample. Fishes were either removed from the perimeter block nets after each pass and tabulated with fish from that pass, or were removed from the block nets only at the end of sampling. Where fish were removed from block nets only after all passes, the catches in the block nets were mathematically apportioned to the catch from each of the passes for analysis of catch rates (see below). Each area was mapped and distances between various boundary points were measured using a Leitz metric tape measure, a Bushnell Laser rangefinder, or a Sonin laser rangefinder. The size of the area was calculated as the sum of the areas of polygons (triangles and parallelograms) drawn on a scale map of the site. The number of fishes in each successive electrofishing pass was used to calculate a depletion estimate (see below) of the total number and density of those species present in the samples.

Walkalong shocking is done at consistent sites within each station. These sites are given individual numbers consistent over different surveys. Depending on water level, sampling may only be possible at some sites during each survey. For example, no appropriate habitat was present at Station 2B, as in many previous surveys.

Several types of backwater habitats are present and sampled at the different stations. Differences in the topography and hydrology of these sites may affect fish use. Major types include:

- Small pools off the main channel, connected to the main channel by inlets and outlets which may be shallow or dry 
at low water levels. These sites fill during high water levels and shrink in area and volume as water levels fall. These area and volume changes create a potential for concentration of fish, although fish may be able to leave the sites when inlets and outlets are open. These pools are typically lentic, with little current velocity even at high water levels. Examples of this type occur at Station 1 (site 2 not sampled in 2000, but routinely sampled in higher water years) and Station 5 (the "levee" sites, 2 and 3, not sampled in 2000). These particular pools may be partly artificial in origin, created by deposition below pilings or shore dumping of dredge spoils.

- Small inlets between the shoreline and bar deposits, e.g., behind sand/mud bars which build up below pilings. The bars are typically covered at high water levels, so that the sites are part of the main channel at high flows. At low flows, they are broadly connected to the main channel at the bottom, and may have input flows at the top. Thus, these sites have less potential for concentration of fish at low water levels. The sites may have some current, so may provide habitat for fish preferring lotic habitats as well as more lentic species. Examples of this type occur at Station 1 (site 1 sampled in 2000) and Station 6 (site 1 not sampled in 2000).

- Portions of side channels. These channels divert a portion of the channel's flow at high water levels, but may dry up at lower levels. These areas have a potential for concentration of fish. They may be lotic at high flows, although they become more lentic as the lower portions dry up. As a result, they may be favorable to riverine and backwater species at different times. An example of this type is the top of Wild Horse Slough at Station 5 (site 1 sampled in 2000).

- Coves. These are the lower part of current or historical side channels, abandoned meander bends, etc. These sites may have inflow from the top at high flows, but these typically dry up at low flows. They remain broadly connected to the main channel at the lower end. Because of this downstream connection, these sites probably have less potential for concentration of fish as water levels fall. They probably also contain water for longer periods than some of the other types. These sites tend to be lentic, with 
little current velocity and soft substrates. Ring Jaw Cove at Station 6 is an example of this type of habitat. Portions of this cove (site 2, which is routinely sampled, including the 2000 surveyat the upper part of the cove) are routinely sampled.

\section{Boat Electrofishing Samples}

B oat electroshocking was done using an 18-ft Coffelt electroshocking boat with the same generator and VVP unit used for walk-along shocking. Shocking was done using a 40-in Wisconsin ring with droppers. The voltage ranged from 190-250 volts to maintain a current of 56 amps. Samples were taken following Patrick Center Standard Operating Procedure No. P-14-02. One crew member operated the boat while one or two technicians used long handled dip nets with $0.32-\mathrm{cm}$ square mesh to collect fishes. Sampling was done in a variety of bank habitats, including debris dams and areas with downed trees, swift currents and undercut banks along the fringes of the main river channel. Sampling was also done in the deeper, lower parts of backwaters (e.g., Ring Jaw Cove at Station 6 and Devil's Elbow at Station 5), as well as along the main channel. The distance traversed during the sample was measured to the nearest meter using a Bushnell Yardage Pro 400 laser rangefinder, using piling sets or overhanging trees as target marks. Three samples were taken at each station ranging in length from $80-180 \mathrm{~m}$ (median $142 \mathrm{~m}$ ), and in duration from 15 to $16.2 \mathrm{~min}$.

\section{Hand Collections}

S mall fish specimens (particularly catfishes) were turned over to fisheries personnel by the Academy macroinvertebrate crew for subsequent laboratory identification. The fish were mainly collected by hand dip nets with fine mesh. Only a few, notable specimens were recorded from these samples. 


\section{Specimens}

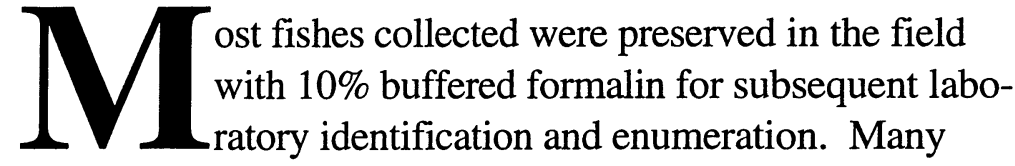
large fish were identified, measured and released in the field. In the laboratory, fishes were transferred to $50 \%$ ethanol after a two-day water rinse and, subsequently to $70 \%$ ethanol for storage and long-term curation. All fishes were identified to the species level using standard references, including Blair et al. (1968), Miller and Robinson (1973), Bennett and McFarlane (1983), Menhinick (1991) and Jenkins and Burkhead (1994). We used nomenclature from Robins et al. (1991), except that Elassoma zonatum was placed in Elassomatidae rather than Centrarchidae. Selected fish specimens will be accessioned into the permanent Ichthyology fish collection at the Academy. A number of young-of-year (YOY) minnows of the genus Cyprinella (either C. nivea or C. leedsi, both of which are common in the river) were collected which were too small to be identified by external characters. Selected individuals were identified to species, but a number of specimens are reported as Cyprinella species. Some cyprinids were not identifiable to genus and are listed as cyprinid species; many or all of these are probably Cyprinella as well, based on the frequency of various small cyprinids at the time of sampling.

\section{Analyses}

\section{Diversity Measures}

$\mathbf{S}$ pecies richness (the number of species present) was determined for all individual samples taken by each technique. Shannon-Wiener Diversity index values were calculated for each quantitative seine sample. The ShannonWiener Diversity index incorporates the number of taxa present and the evenness of the distribution of taxa in a sample to provide an assessment of the structure of the assemblage. Thus, if a sample has a large number of taxa and the taxa are evenly proportionate across the sample, the diversity index value for the sample will be high. 


\section{Depletion Estimates}

Total populations and densities of fish species in backwater sample sites were estimated. These estimates 1 are comparable to the rotenone sample densities, since rotenone sampling was considered to collect virtually all fish in the sample area. The total population sizes of each species in the electrofishing samples were calculated using MicroFish 3.0 (Van Deventer and Platts 1989; 1983), which provides maximum likelihood estimates (MLE) of density from successive removal data. This technique is analogous to the linear regression method based on Seber (1973) which was used for the 1996 and 1997 analyses. MicroFish also provides confidence intervals of population estimates. Both methods are based on the following assumptions of the removal-depletion method: the population is closed, all organisms within each group (each species in this case) have the same probability of being captured and that probability is constant for each pass, and sampling effort is constant. The accuracy of the estimate is dependent upon how strictly these assumptions are met. Reliable MLEs cannot be calculated in several cases: 1) all fish of a species are caught on the first pass; 2) only one individual of a taxon is caught over all passes; 3) the pattern of catches on successive passes does not form a decreasing trend. For the first two cases, the total number of fish caught was used as the population estimate, which is reasonable given the conditions when these cases occur. The third condition is analogous to the requirement of a negative slope for the regression method. Non-decreasing trends can arise from violation of the assumptions, or from sampling error (for rare species). In these cases, MicroFish arbitrarily assigns an estimate of 1.5 times the total catch. In past years, groups of similar species were grouped together in order to provide reliable estimates of population sizes. This was not necessary for the 1998-2000 data.

For two of the three samples, fish were recovered from the block nets at the end of sampling (i.e., block nets were kept in place throughout sampling to avoid escape of fish). These fish could have been chased into the nets during any of the passes. These fish were apportioned among the sample passes in the proportion that each species occurred in the passes. For example, if $60 \%$ of the specimens caught in four passes were caught in the first pass, $25 \%$ in the second pass, $15 \%$ in the 
third pass, and none in the fourth pass, then $60 \%$ of the net fish would be added to the first pass results, etc. Apportioning net fish among samples results in fractional numbers of fish caught, which were rounded to integers as required by the depletion estimation procedure. Because of the rounding, the total number of fish after apportionment for net fish can sometimes be one more or less than the total number actually caught. In these cases, the population estimates and confidence bounds are increased (where the adjusted number was less than the actual number caught) or decreased by one. These cases are indicated by mle+net and mle-net in the table of depletion estimates (e.g., in the 1998 study). Occasionally, the only specimens of a species may be recovered from the net (this occurred for one species in one sample in 2000). In these cases, it is assumed that these were the only fish of those species in the sample site, i.e., the total number caught is used as the total population estimate.

Densities of fish in the backwater sampling areas were estimated from the total population estimates for each species and the calculated sample areas. Fish densities from seine samples were standardized to number of fish per $100 \mathrm{~m}^{2}$ as a measure of catch-per-unit-effort (CPUE).

\section{Statistical Analysis Of Seine Data}

$\mathbf{F}$ ish densities from seine samples were standardized to number of fish per $100 \mathrm{~m}^{2}$ as a measure of CPUE. Two types of analyses of seine data were used. The first, analysis of variance/analysis of covariance (ANOVA/ANCOVA) was used to test differences in abundances of species among stations. The second, canonical correlation analysis (CANOCO), was used to investigate differences in overall community structure among stations across several surveys.

The fish densities were transformed to $\ln (\mathrm{CPUE}+1)$ for the ANOVA/ANCOVA statistical analyses. Statistical Analysis Systems (SAS 1990) was used for all analyses. Catch-perunit-effort of fishes present in at least $10 \%$ of the samples, mean species richness, and mean diversity of fishes at each station were compared using a general linear model (PROC GLM) analysis of covariance (ANCOVA) and least squares means to identify differences among stations. Species rich- 
ness was transformed to square root of richness. An ANCOVA was the most appropriate analysis because it adjusts for differences in microhabitat among stations and focuses on differences among densities of species. The habitat covariables used were average depth, current velocity and substrate composition. Habitat variables were also compared among stations in an ANOVA (PROC GLM). Probability values for all statistical tests were considered significant at a level determined by a Bonferroni correction ( $0.05 /$ number of tests run) which reduces the likelihood of erroneously rejecting a true hypothesis.

CANOCO was performed using the CANOCO software (ter Braak and Smilauer 1998). This technique finds suites of correlated biological and environmental data. This enables detection of patterns of occurrence among groups of species, including uncommon species. CANOCO positions species along dominant environmental gradients, i.e., it assumes species have unimodal responds to one or more gradients, and iteratively finds optimal gradients and species' positions along these gradients. Tests of significance of relationships are performed by permutations of species/environmental scores.

For CANOCO, the ln-transformed densities of individual species were used. Very rare species were not included in the analysis, and greater weight was given to more common species. Two types of environmental data were used:

- the measured microhabitat variables, including average depth, velocity, and substrate types, and dissolved oxygen, conductivity, water temperature, and $\mathrm{pH}$;

- ordinal variables representing position along the river; one variable indexed longitudinal position along the river to look for community differences related to consistent upstream-downstream patterns; the second variable indexed position relative to SRP (minimum value at Station 1, maximum value at Station 5 and intermediate values at Stations $2 B$ and 6 ). 


\section{Site and Sampling Descriptions and Conditions}

lthough ANSP collections on the Savannah River
have been made at the same stations over time, the
precise sampling locations and volume of areas sampled have varied with changes in water level and floodplain morphology. In 2000, the water levels during the sampling period (early September) had increased to a low level from a very low level experienced during late August (at the time of the Patrick Center mussel collection survey). The partial flooding of grasses, wild rice and other terrestrial macrophytes along river banks and sand bars was evidence that summer water levels were relatively low allowing growth of these grasses to the river's edge. Most of the areas sampled by seining and boat shocking in 2000 progressed along these recently flooded shorelines. The water level change affected inundation of side channels and pools, which are sampled by backwater sampling. For example, the river edge pool site at Station 1 was quite low during the mussel survey, but became filled when water levels increased in early September. The increase in level permitted more complete sampling of this area and its associated fauna. The water levels were typical of the levels experienced in the previous surveys, but much lower than the higher levels experienced during the 1995 and 1996 surveys.

\section{Station 1}
O
eine samples at this station were collected along a long sand-gravel beach on the right bank (facing down- stream) and between and below pilings in silt-sand ar- eas with high organic detritus and flooded terrestrial grasses along the left bank. One walk-along electrofishing sample, site, last sampled in 1999, was a river connected side pool area, downstream of piling set \#78. The site was bordered by a grass-covered sand spit (an island at higher water levels) on the river side. The shoreline consisted of a moderately high, 
terrestrial grass-covered mud bank with submerged logs and brush and a group of willow trees. The fringes of the area contained recently flooded terrestrial grasses. The substrate consisted of sand/gravel in the middle of the sample area and silt/sand along the shoreline. The maximum depth of this area was $1.2 \mathrm{~m}$. No submerged aquatic vegetation was present at this site. Boat electrofishing samples were taken along both banks. One location sampled along the left bank included the shoreline downstream of piling set \#78, which contained submerged tree/brush snags and flooded terrestrial grasses with moderate flow. Another location between the pilings along the left bank was also sampled. The area contained backeddy currents with debris jams along pilings and flooded shoreline grasses. The right bank was sampled by boat shocking from the vicinity of an intermittent creek at the lower end of the station to the upper sand beach across the river from the piling sets. Some rock rip-rap was present at the lower end of the station, forming the upstream mouth of the creek. The areas sampled contained swift water with deeply cut banks, snag piles, submerged trees and flooded grasses.

\section{Station 2B}

L ocations seined at this station included two locations along the right bank in silt/sand areas between and below piling sets; these areas had soft to moderately firm substrates and negative (upstream) to low, positive current velocities. A firm sand beach with flooded terrestrial grasses along the left bank downstream of piling set \#68 was also sampled. No adequate backwater habitat was present at the station for walk-along shocking. Boat electroshocking samples were taken along both banks. Two samples were collected on each side of the river between the piling sets. The areas collected included mud beaches with areas of flooded terrestrial vegetation, debris jams between and on the piling sets and the outer edges of the pilings in deeper swift water. Two additional boat shock samples were taken in moderately flowing water, one above the pilings on the left bank along moderate cut banks with tree and brush snags and another downstream of the piling set on the right bank along moderate to steeply sloping banks with submerged tree and brush snags. 


\section{Station 5}

small beach was seined on the right bank $150 \mathrm{~m}$
downstream of piling set $\# 55$. The area contained a
firm sand substrate with a moderately sloping shoreline and flooded terrestrial vegetation and willow roots hanging into the water. A seine sample was also taken on the right bank in a back eddy (minimal to low upstream flow) depositional area with flooded terrestrial vegetation between piling set \#55 and the next upstream set. An additional seine sample was taken on the left bank along a beach at the levee with flooded terrestrial vegetation on moderately soft silt/sand substrate.

The walk-along electrofishing sample was taken in a side channel at Wild Horse Slough. The Slough contained large submerged logs and branches with steep, soft mud banks and shallow sloping sand shoreline with brush piles at the inner end. The maximum depth of this area was $0.9 \mathrm{~m}$ and the substrate varied between very soft mud and firm sand at the outlet to the main river. Boat electroshocking was conducted in areas on both banks. The areas sampled on the left bank included the cut banks and submerged logs and willow tree branches just upstream of Wild Horse Slough. The right bank shocking was done between the pilings along the main river upstream of Devil's Elbow. The areas shocked included debris dams along the pilings, swifter outer edges of pilings, and submerged tree and woody debris, and flooded terrestrial grasses. Two boat shock samples were collected into the backwater area at Devil's Elbow on the right bank. Areas sampled included open shorelines with flooded terrestrial vegetation and alligator weed, and submerged logs/trees and brush piles along both banks of this backwater.

\section{Station 6}

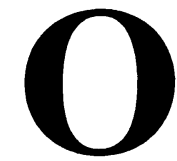

ne depositional, back-eddy (minimal to no flow) area with flooded terrestrial grasses was seined at the pilings along the left bank. The substrates in this depositional site were variable from firm sand to soft silt. The large open beach area along the right bank at the upstream end of the station was also sampled. The substrate consisted of firm sand with flooded terrestrial grasses along the shore- 
line. An additional area along the left bank $200 \mathrm{~m}$ upstream of Ring Jaw Cove was also seined. This area was an open firm sand beach with some flooded terrestrial grasses and overhanging willow trees. One walk-along electroshocking site was sampled in Ring Jaw Cove at Station 6. The historically sampled inner area of this cove was unavailable for sampling because of low water. An area along the north shore towards the mouth of the cove was sampled. This area contained flooded shoreline grasses and groups of overhanging willow trees and a large open area offshore. The maximum depth of the sample site was $1.0 \mathrm{~m}$. The area contained moderate to soft silt substrate, with no aquatic vegetation. Submerged log/snags and brush piles were present along the shoreline of the sampling area. Boat shocking samples were taken along both banks. The piling area on the left bank was sampled and the adjacent moderately cut bank area along the right bank was sampled. Both areas contained brush piles, overhanging trees, and open areas with flooded terrestrial grasses and woody debris jams. Additionally, the area just downstream and into the mouth of Ring Jaw Cove was also shocked. This area contained steep to gradual sloping banks with snag piles, exposed root masses and stumps, open water areas with no cover, and shallow muddy areas with flooded terrestrial grasses. The large cove area along the right bank downstream of the upper sand beach was also boat shocked. The area contained submerged trees/logs and brush piles with flooded grasses along mud covered shorelines.

\section{Results}

total of 4,599 individuals of 50 species of fish was captured in the 2000 ANSP Savannah River survey
(Table E-1). The spottail shiner (Notropis hudsonius) was the most abundant species followed by the bannerfin shiner (Cyprinella leedsi). The bluegill (Lepomis macrochirus), brook silverside (Labidesthes sicculus) and whitefin shiner (C. nivea) were also common. Together, $74 \%$ of the total catch was comprised of these five species (assuming that unidentified minnows were Cyprinella). These patterns are very similar to those in the 1999 survey, where the spottail shiner was also the most common species, and $77 \%$ of the total catch was comprised of the same five species. 
Table E-1. Total number of fish caught at each station by all techniques in the 2000 ANSP Savannah River survey.

\begin{tabular}{|c|c|c|c|c|c|c|c|}
\hline \multirow[b]{2}{*}{ Scientific Name } & \multirow[b]{2}{*}{ Common Name } & \multicolumn{4}{|c|}{ Station } & \multirow[b]{2}{*}{ Total } & \multirow{2}{*}{$\begin{array}{l}\% \text { of } \\
\text { Total }\end{array}$} \\
\hline & & 1 & 2B & 5 & 6 & & \\
\hline Lepisosteidae & & & & & & & \\
\hline Lepisosteus osseus & longnose gar & 2 & & 1 & & 3 & 0.07 \\
\hline $\begin{array}{c}\text { Lepisosteus platyrhincus } \\
\text { Amiidae }\end{array}$ & Florida gar & & & 1 & 1 & 2 & 0.04 \\
\hline $\begin{array}{l}\text { Amia calva } \\
\quad \text { Anguillidae }\end{array}$ & bowfin & 4 & 2 & 4 & 2 & 12 & 0.26 \\
\hline $\begin{array}{l}\text { Anguilla rostrata } \\
\text { Clupeidae }\end{array}$ & American eel & 4 & & 5 & 14 & 23 & 0.50 \\
\hline Alosa aestivalis & blueback herring & & & 1 & 2 & 3 & 0.07 \\
\hline Alosa sapidissima & American shad & & & 3 & & 3 & 0.07 \\
\hline Dorosoma cepedianum & gizzard shad & 5 & 3 & 3 & 11 & 22 & 0.48 \\
\hline $\begin{array}{r}\text { Dorosoma petenense } \\
\text { Cyprinidae }\end{array}$ & threadfin shad & & & 1 & & 1 & 0.02 \\
\hline Cyprinella leedsi & bannerfin shiner & 84 & 106 & 144 & 205 & 539 & 11.72 \\
\hline Cyprinella nivea & whitefin shiner & 136 & 69 & 53 & 43 & 301 & 6.54 \\
\hline Cyprinella species & shiner species & 1 & & & 61 & 62 & 1.35 \\
\hline Cyprinidae species & minnow & & 1 & 17 & 96 & 114 & 2.48 \\
\hline Hybognathus regius & Eastern silvery minnow & & & & 4 & 4 & 0.09 \\
\hline Nocomis leptocephalus & bluehead chub & & & 1 & & 1 & 0.02 \\
\hline Notemigonus crysoleucas & golden shiner & 1 & & 4 & 2 & 7 & 0.15 \\
\hline Notropis chalybaeus & ironcolor shiner & 1 & 2 & & 1 & 4 & 0.09 \\
\hline Notropis cummingsae & dusky shiner & & 8 & 2 & 5 & 15 & 0.33 \\
\hline Notropis hudsonius & spottail shiner & 154 & 684 & 401 & 441 & 1680 & 36.53 \\
\hline Notropis lutipinnis & yellowfin shiner & & 3 & 1 & & 4 & 0.09 \\
\hline Notropis maculatus & taillight shiner & & & 4 & 11 & 15 & 0.33 \\
\hline Notropis petersoni & coastal shiner & 4 & 50 & 3 & 31 & 88 & 1.92 \\
\hline Notropis rubescens & rosyface chub & 40 & 96 & 2 & 2 & 140 & 3.04 \\
\hline $\begin{array}{r}\text { Opsopoeodus emiliae } \\
\text { Catostomidae }\end{array}$ & pugnose shiner & 10 & 12 & 12 & 24 & 58 & 1.26 \\
\hline $\begin{array}{l}\text { Minytrema melanops } \\
\text { Ictaluridae }\end{array}$ & spotted sucker & 6 & 5 & 13 & 49 & 73 & 1.59 \\
\hline Ameiurus catus & white catfish & 4 & & 2 & 2 & 8 & 0.17 \\
\hline Ameiurus platycephalus & flat bullhead & & 3 & 3 & & 6 & 0.13 \\
\hline Ictalurus punctatus & channel catfish & 1 & 2 & 1 & & 4 & 0.09 \\
\hline Noturus gyrinus & tadpole madtom & & 1 & & & 1 & 0.02 \\
\hline $\begin{array}{r}\text { Noturus leptacanthus } \\
\text { Esocidae }\end{array}$ & speckled madtom & & 5 & 5 & 5 & 15 & 0.33 \\
\hline Esox americanus & redfin pickerel & 2 & & 3 & & 5 & 0.11 \\
\hline $\begin{array}{l}\text { Esox niger } \\
\text { Aphredoderidae }\end{array}$ & chain pickerel & 3 & 1 & 2 & 1 & 7 & 0.15 \\
\hline $\begin{array}{l}\text { Aphredoderidae } \\
\text { Aphredoderus sayanus } \\
\text { Cyprinodontidae }\end{array}$ & pirate perch & 1 & 1 & 2 & & 4 & 0.09 \\
\hline $\begin{array}{l}\text { Fundulus lineolatus } \\
\text { Poeciliidae }\end{array}$ & lineated topminnow & 8 & & & 4 & 12 & 0.26 \\
\hline $\begin{array}{r}\text { Gambusia holbrooki } \\
\text { Atherinidae }\end{array}$ & eastern mosquitofish & 16 & 1 & 5 & 6 & 28 & 0.61 \\
\hline Labidesthes sicculus & brook silverside & 8 & 12 & 98 & 189 & 307 & 6.68 \\
\hline
\end{tabular}


Table E-1 (continued). Total number of fish caught at each station by all techniques in the 2000 ANSP Savannah River survey.

\begin{tabular}{|c|c|c|c|c|c|c|c|}
\hline \multirow[b]{2}{*}{ Scientific Name } & \multirow[b]{2}{*}{ Common Name } & \multicolumn{4}{|c|}{ Station } & \multirow[b]{2}{*}{ Total } & \multirow{2}{*}{$\begin{array}{l}\% \text { of } \\
\text { Total } \\
\end{array}$} \\
\hline & & 1 & $2 \mathbf{B}$ & 5 & 6 & & \\
\hline \multicolumn{8}{|l|}{ Centrarchidae } \\
\hline Centrarchus macropterus & flier & & & $\begin{array}{l}2 \\
3\end{array}$ & & $\begin{array}{l}2 \\
6\end{array}$ & 0.04 \\
\hline Enneacanthus gloriosus & bluespotted sunfish & 3 & & 31 & & 0 & 0.13 \\
\hline Lepomis auritus & redbreast sunfish & 38 & 24 & 31 & 39 & 132 & 2.87 \\
\hline Lepomis gibbosus & pumpkinseed & 4 & 1 & 23 & 5 & 33 & 0.72 \\
\hline Lepomis gulosus & warmouth & 6 & 1 & 18 & 7 & 32 & 0.70 \\
\hline Lepomis macrochirus & bluegill & 54 & 22 & 238 & 181 & 495 & 10.76 \\
\hline Lepomis marginatus & dollar sunfish & 5 & & 41 & 33 & 79 & 1.72 \\
\hline Lepomis microlophus & redear sunfish & 1 & 1 & 12 & 10 & 24 & 0.52 \\
\hline Lepomis punctatus & spotted sunfish & 2 & 1 & 5 & & 8 & 0.17 \\
\hline Lepomis species & sunfish species & & & & 2 & 2 & 0.04 \\
\hline Micropterus salmoides & largemouth bass & 15 & 9 & 21 & 21 & 66 & 1.44 \\
\hline $\begin{array}{c}\text { Pomoxis nigromaculatus } \\
\text { Percidae }\end{array}$ & black crappie & 1 & & & 24 & 25 & 0.54 \\
\hline Etheostoma fusiforme & swamp darter & & & & 1 & 1 & 0.02 \\
\hline Etheostoma olmstedi & tesselated darter & 1 & 3 & 5 & 3 & 12 & 0.26 \\
\hline Perca flavescens & yellow perch & 1 & 1 & & 1 & 3 & 0.07 \\
\hline \multicolumn{8}{|l|}{$\begin{array}{r}\text { Percina nigrofasciata } \\
\text { Mugilidae }\end{array}$} \\
\hline $\begin{array}{l}\text { Mugil cephalus } \\
\text { Soleidae }\end{array}$ & striped mullet & & & & 1 & 1 & 0.02 \\
\hline \multirow[t]{3}{*}{ Trinectes maculatus } & hogchoker & 1 & 32 & 41 & 10 & 84 & 1.83 \\
\hline & Total: & 631 & 1178 & 1239 & 1551 & 4599 & 100 \\
\hline & Number of Species: & 36 & 32 & 43 & 40 & & \\
\hline
\end{tabular}

Other species collected are typical of those recorded in recent surveys. Uncommon species collected include bluehead chub (Nocomis leptocephalus) at Station 5, yellow perch (Perca flavescens) at Stations 1, 2B and 6, dusky shiner (Notropis cummingsae) at Stations 2B, 5 and 6, and yellowfin shiner ( $N$. lutipinnis) collected at Stations 2B and 5.

\section{Backwater Electroshocking Samples}

D epletion sampling in backwater and eddy habitats was done using walkalong shocking at one site at each of Stations 1, 5 and 6. As in most years, no appropriate habitat was present at Station 2B. A total of 612 individuals of 28 species was caught (Tables E-2, E-3), with more species at Station 6 (21 species) than at Stations 1 and 5 (15 and 13 species). A variety of sunfishes was caught at each station. Relatively high numbers of minnows, suckers, 
Table E-2. Total numbers of fish collected in walkalong electroshocking samples in the 2000 ANSP Savannah River survey.

\begin{tabular}{|c|c|c|c|c|}
\hline \multirow[b]{2}{*}{ Scientific Name } & \multicolumn{3}{|c|}{ Site } & \multirow[b]{2}{*}{ TOTAL } \\
\hline & 1WS1 & 5WS1 & 6WS1 & \\
\hline Ameiurus platycephalus & & 3 & & 3 \\
\hline Anguilla rostrata & & 1 & 10 & 11 \\
\hline Aphredoderus sayanus & 1 & 1 & & 2 \\
\hline Centrarchus macropterus & & 2 & & 2 \\
\hline Cyprinella leedsi & & & 7 & 7 \\
\hline Cyprinella species & & & 1 & 1 \\
\hline Cyprinidae species & & & 8 & 8 \\
\hline Enneacanthus gloriosus & 3 & 3 & & 6 \\
\hline Esox americanus & 2 & 3 & & 5 \\
\hline Esox niger & 2 & & & 2 \\
\hline Etheostoma fusiforme & & & 1 & 1 \\
\hline Etheostoma olmstedi & & & 1 & 1 \\
\hline Fundulus lineolatus & 5 & & 4 & 9 \\
\hline Gambusia holbrooki & 16 & & 2 & 18 \\
\hline Labidesthes sicculus & & & 136 & 136 \\
\hline Lepomis auritus & 1 & & 17 & 18 \\
\hline Lepomis gibbosus & 1 & 16 & 4 & 21 \\
\hline Lepomis gulosus & 5 & 14 & 6 & 25 \\
\hline Lepomis macrochirus & 15 & 25 & 108 & 148 \\
\hline Lepomis marginatus & 4 & 17 & 25 & 46 \\
\hline Lepomis microlophus & 1 & 3 & 4 & 8 \\
\hline Lepomis punctatus & & 3 & & 3 \\
\hline Lepomis species & & & 1 & 1 \\
\hline Micropterus salmoides & 1 & 1 & 12 & 14 \\
\hline Minytrema melanops & & & 33 & 33 \\
\hline Notemigonus crysoleucas & & & 1 & 1 \\
\hline Notropis hudsonius & & & 51 & 51 \\
\hline Notropis maculatus & & & 11 & 11 \\
\hline Opsopoeodus emiliae & & & 4 & 4 \\
\hline Pomoxis nigromaculatus & 1 & & 12 & 13 \\
\hline Trinectes maculatus & 1 & & 2 & 3 \\
\hline Totals 2 & 59 & 92 & 461 & 612 \\
\hline Sample Areas $\left(m^{2}\right)$ & 176 & 114 & 259 & \\
\hline Min total density (per $100 \mathrm{~m}^{2}$ ) & 33.52 & 80.70 & 177.99 & \\
\hline No. of Passes & 3 & 3 & 3 & \\
\hline No. of Species & 15 & 13 & 21 & \\
\hline
\end{tabular}

and brook silverside were caught at Station 6. Total catches and richness were lower than that in 1999, when two samples were collected at each station.

The total population in each sampling site was estimated by the depletion method (maximum likelihood method). Estimates depend on having a decreasing pattern of catches. In addition, the algorithm cannot estimate populations if only one fish is caught or if all fish of a species are caught on the first 


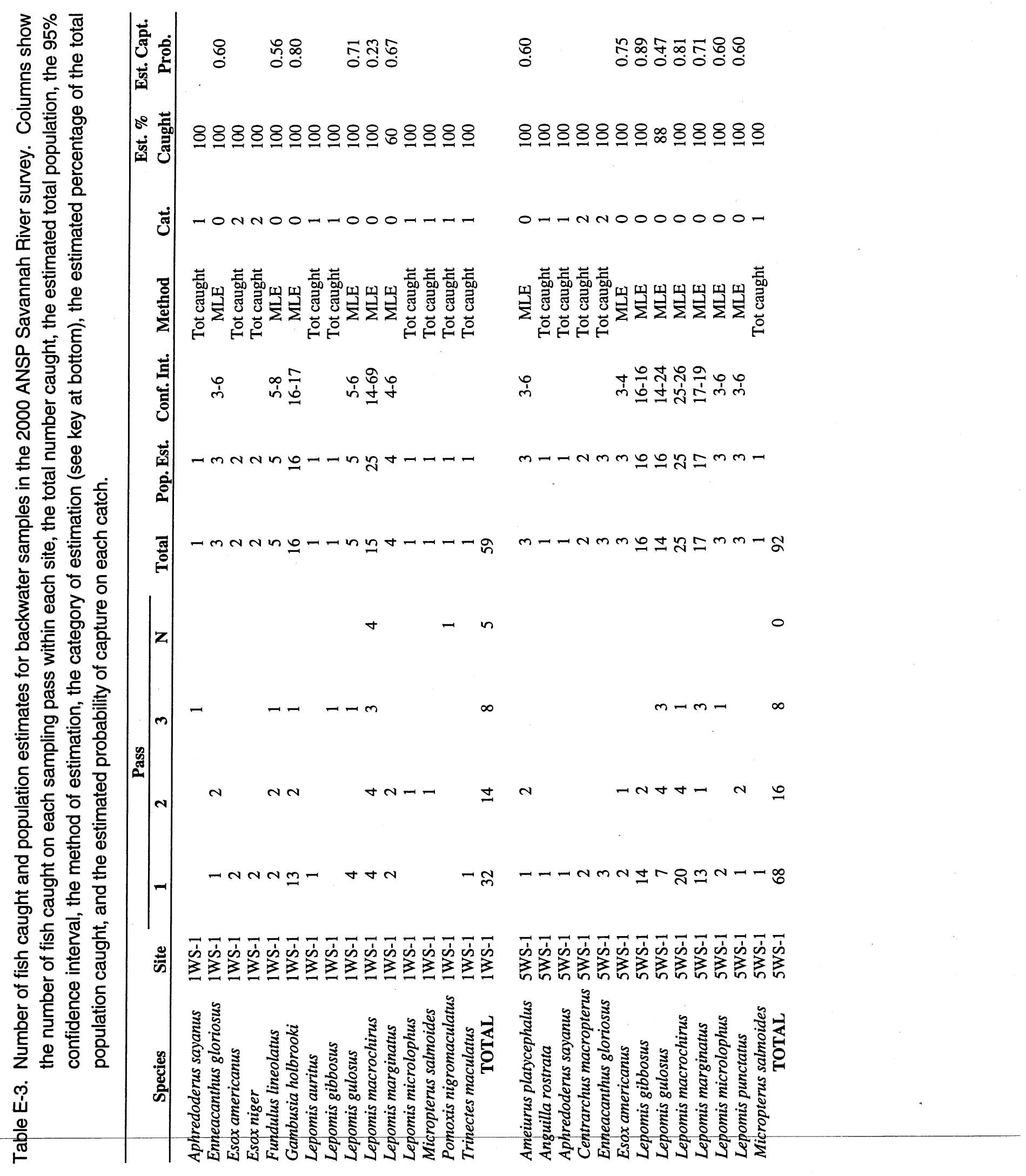




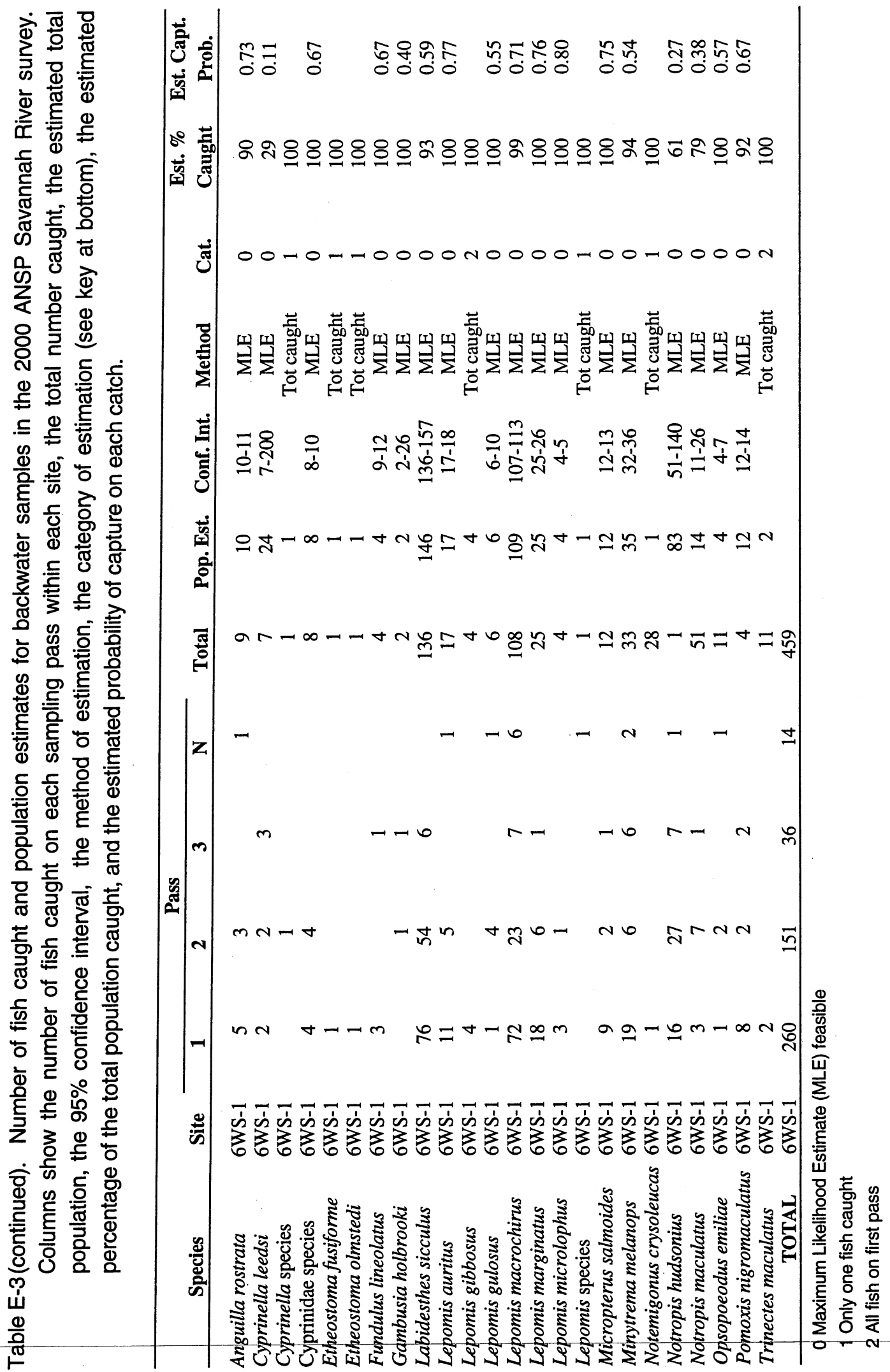


pass. In these cases, the total caught is a reasonable estimate of the total population.

For the 2000 samples, reliable depletion estimates were feasible for common species (Tables E-3, E-4). For a few species (e.g., Lepomis macrochirus at Station 1, L. gulosus at Station 5, and Cyprinella leedsi, Notropis hudsonius and N. maculatus at Station 6), MLE estimates were feasible, but the confidence intervals were relatively large (Table E-3). Except for these species at these sites, collection efficiency appeared high (it was estimated that $90-100 \%$ of the species were caught over the three passes) resulting in low confidence inter-

Table E-4. Estimated densities (no. per $100 \mathrm{~m}^{2}$ ) of fishes in backwater sites in 2000 ANSP Savannah River survey.

\begin{tabular}{|c|c|c|c|}
\hline \multirow[b]{2}{*}{ Scientific Name } & \multicolumn{3}{|c|}{ Station } \\
\hline & 1 & 5 & 6 \\
\hline Ameiurus platycephalus & 0.00 & 2.63 & 0.00 \\
\hline Ameiurus species & 0.00 & 0.00 & 0.00 \\
\hline Anguilla rostrata & 0.00 & 0.88 & 3.86 \\
\hline Aphredoderus sayanus & 0.57 & 0.88 & 0.00 \\
\hline Centrarchus macropterus & 0.00 & 2.63 & 0.00 \\
\hline Cyprinella leedsi & 0.00 & 0.00 & 9.27 \\
\hline Cyprinella species & 0.00 & 0.00 & 0.39 \\
\hline Cyprinidae species & 0.00 & 0.00 & 3.09 \\
\hline Enneacanthus gloriosus & 1.70 & 2.63 & 0.00 \\
\hline Esox americanus & 1.14 & 2.63 & 0.00 \\
\hline Esox niger & 1.14 & 0.00 & 0.00 \\
\hline Etheostoma fusiforme & 0.00 & 0.00 & 0.39 \\
\hline Etheostoma olmstedi & 0.00 & 0.00 & 0.39 \\
\hline Fundulus lineolatus & 2.84 & 0.00 & 1.54 \\
\hline Gambusia holbrooki & 9.09 & 0.00 & 0.77 \\
\hline Labidesthes sicculus & 0.00 & 0.00 & 56.37 \\
\hline Lepomis auritus & 0.57 & 0.00 & 6.56 \\
\hline Lepomis gibbosus & 0.57 & 14.04 & 1.54 \\
\hline Lepomis gulosus & 2.84 & 14.04 & 2.32 \\
\hline Lepomis macrochirus & 14.20 & 21.93 & 42.08 \\
\hline Lepomis marginatus & 2.27 & 14.91 & 9.65 \\
\hline Lepomis microlophus & 0.57 & 2.63 & 1.54 \\
\hline Lepomis punctatus & 0.00 & 2.63 & 0.00 \\
\hline Lepomis species & 0.00 & 0.00 & 0.39 \\
\hline Micropterus salmoides & 0.57 & 0.88 & 4.63 \\
\hline Minytrema melanops & 0.00 & 0.00 & 13.51 \\
\hline Notemigonus crysoleucas & 0.00 & 0.00 & 0.39 \\
\hline Notropis hudsonius & 0.00 & 0.00 & 32.05 \\
\hline Notropis maculatus & 0.00 & 0.00 & 5.41 \\
\hline Opsopoeodus emiliae & 0.00 & 0.00 & 1.54 \\
\hline Pomoxis nigromaculatus & 0.57 & 0.00 & 4.63 \\
\hline Trinectes maculatus & 0.57 & 0.00 & 0.77 \\
\hline $\begin{array}{l}\text { Total } 2 \\
\text { Area }\left(\mathrm{m}^{2}\right)\end{array}$ & $\begin{array}{r}39.20 \\
176.00 \\
\end{array}$ & $\begin{array}{r}83.33 \\
114.00 \\
\end{array}$ & $\begin{array}{l}203.09 \\
259.00 \\
\end{array}$ \\
\hline
\end{tabular}


vals for the total estimate. Overall, it was estimated that collections caught $85 \%, 98 \%$ and $87 \%$ of all fish in each of the three sampling areas (and that almost all of the fish which were not caught were of the species noted above).

Estimates of total density (Table E-4) varied greatly among sites. The lowest densities were found in the most isolated site, the flood plain pool at Station 1, while the highest densities were found in the sample from Ring Jaw Cove in Station 6 , which is in a cove connected to the main river. This is consistent with patterns noted in 1999 and other years. As noted above, sunfishes dominated samples at Stations 1 and 5, while a variety of species was common at the Station 6 site.

\section{Seine Samples: 2000 Samples}

$\mathbf{S}$ eine samples were taken at each of the stations. Seining sites included open sand or sand/gravel beaches, sand-silt areas along the shoreline, and shorelines between pilings. These shoreline areas between pilings are mainly fine sediments (silts and detritus), but some areas had firm sand as well. Many of the beach sites had slow areas of flooded grasses at their edges, because water levels had recently risen to areas where grasses had grown during the summer low flow period. As a result, seine sampling sites were not as clearly divisible into discrete habitat types (unvegetated sand beaches versus vegetated fine substrate areas). Analyses were done using three discrete habitat descriptors, but these were not informative and are not presented here. Relationships between fish occurrence and microhabitat for the 2000 samples were assessed using averages of microhabitat variables (depth, velocity, substrate) measured within each sample site as a continuous measure of microhabitat (used as covariates in analysis of covariance).

A total of 1,456 individuals of 22 species was collected in the seine samples (Table E-5). Minnows (the spottail shiner and/or the whitefin shiner) were the most abundant species in the samples. The bannerfin shiner (Notropis leedsi), pugnose minnow (Opsopoeodus emiliae), brook silverside (Labidesthes sicculus), redbreast sunfish (Lepomis auritus), and bluegill (L. macrochirus) were the only other species collected at every station. 
Table E-5. Average (arithmetic mean) CPUE (number of fish per $100 \mathrm{~m}^{2}$ ) in quantitative seine samples in the 2000 ANSP Savannah River survey.

\begin{tabular}{llrrrr}
\hline & & \multicolumn{5}{c}{ Station } \\
\cline { 3 - 6 } \multicolumn{1}{c}{ Scientific Name } & \multicolumn{1}{c}{ Common Name } & $\mathbf{1}$ & 2B & $\mathbf{5}$ & $\mathbf{6}$ \\
\hline Lepisosteus osseus & longnose gar & 0.24 & 0.00 & 0.00 & 0.00 \\
Cyprinella leedsi & bannerfin shiner & 0.27 & 0.20 & 0.26 & 4.69 \\
Cyprinella nivea & whitefin shiner & 20.16 & 0.78 & 6.61 & 4.15 \\
Cyprinella species & shiner species & 0.27 & 0.00 & 0.00 & 8.30 \\
Cyprinidae species & minnow & 0.00 & 0.00 & 3.30 & 13.04 \\
Nocomis leptocephalus & bluehead chub & 0.00 & 0.00 & 0.19 & 0.00 \\
Notemigonus crysoleucas & golden shiner & 0.24 & 0.00 & 0.00 & 0.00 \\
Notropis chalybaeus & ironcolor shiner & 0.00 & 0.44 & 0.00 & 0.00 \\
Notropis hudsonius & spottail shiner & 18.41 & 98.64 & 40.85 & 16.46 \\
Notropis petersoni & coastal shiner & 0.67 & 1.48 & 0.00 & 0.00 \\
Notropis rubescens & rosyface chub & 0.33 & 4.90 & 0.00 & 0.00 \\
Opsopoeodus emiliae & pugnose shiner & 1.00 & 0.74 & 1.59 & 4.17 \\
Noturus leptacanthus & speckled madtom & 0.00 & 0.00 & 0.26 & 0.00 \\
Esox niger & chain pickerel & 0.33 & 0.00 & 0.26 & 0.00 \\
Fundulus lineolatus & lineated topminnow & 1.00 & 0.00 & 0.00 & 0.00 \\
Gambusia holbrooki & eastern mosquitofish & 0.00 & 0.00 & 0.95 & 0.63 \\
Labidesthes sicculus & brook silverside & 0.33 & 0.20 & 7.63 & 6.60 \\
Lepomis auritus & redbreast sunfish & 0.67 & 1.18 & 0.19 & 1.04 \\
Lepomis gibbosus & pumpkinseed & 0.33 & 0.00 & 0.00 & 0.35 \\
Lepomis macrochirus & bluegill & 2.95 & 0.25 & 1.66 & 2.78 \\
Micropterus salmoides & largemouth bass & 0.67 & 0.39 & 0.19 & 0.00 \\
Etheostoma olmstedi & tesselated darter & 0.00 & 0.20 & 0.83 & 0.17 \\
Percina nigrofasciata & blackbanded darter & 0.54 & 0.48 & 0.19 & 0.00 \\
Trinectes maculatus & hogchoker & 0.00 & 6.69 & 7.11 & 1.33 \\
& & & & & \\
Average No. of Species & & 6 & 6.67 & 9.33 & 5 \\
Aiverage S-W Diversity & & 1.10 & 0.89 & 1.25 & 1.26 \\
\hline & & & & & \\
& & & & &
\end{tabular}

Statistical comparisons of abundance of the four most common taxa (spottail shiner, whitefin shiner, brook silverside and hogchoker) and of species richness (square root transformation) and Shannon-Wiener diversity were done using ANOVA and ANCOVA. These show no significant station difference for any species (using a Bonferroni-adjusted $\mathrm{p}$ level of 0.009), with or without inclusion of microhabitat variables. Whitefin shiner show significant regressions with velocity, maximum velocity or substrate type (more common in higher velocities and coarser substrates). Comparisons of microhabitat variables (Table E-6) shows a marginally significant difference in average depth among station $(p<0.04)$. 
Table E-6. Habitat characteristics within quantitative seine sampling sites in the 2000 ANSP Savannah River survey. Averages, minima and maxima are calculated over the average of three point measurements within each sampling area.

\begin{tabular}{lcrcc}
\hline \multirow{2}{*}{ Habitat Characteristics } & \multicolumn{5}{c}{ Station } \\
\cline { 2 - 5 } & $\mathbf{1}$ & 2B & 5 & 6 \\
\hline Average of ave. Depth (m) & 0.96 & 0.65 & 0.72 & 0.81 \\
Minimum of ave. Depth (m) & 0.87 & 0.60 & 0.60 & 0.70 \\
Maximum of ave. Depth (m) & 1.03 & 0.73 & 0.90 & 0.93 \\
Average of ave. velocity (m/s) & 0.18 & 0.04 & 0.16 & 0.22 \\
Minimum of ave. velocity (m/s) & 0.00 & -0.15 & -0.13 & 0.03 \\
Maximum of ave. velocity (m/s) & 0.48 & 0.17 & 0.34 & 0.39 \\
Average of ave. substrate meas. & 10.00 & 9.67 & 9.53 & 9.25 \\
Minimum of ave. substrate meas. & 9.83 & 9.00 & 9.08 & 9.00 \\
Maximum of ave. substrate meas. & 10.25 & 10.25 & 9.75 & 9.75 \\
\hline
\end{tabular}

\section{Seine Samples: Comparison of 1996-2000 Samples}

S tatistical analyses of the seine data from the 1996-2000 surveys did not provide evidence of significant station differences, although they did show differences among years and relationships between abundance and microhabitat in the seining sites. ANOVA and ANCOVA were used to analyze year differences, station differences and microhabitat relationships for species richness (square root transformation), Shannon-Wiener diversity, and the ln-transformed abundance of the eight most common taxa (spottail shiner, Eastern silvery minnow, whitefin shiner, Eastern mosquitofish, bannerfin shiner, redbreast sunfish, brook silverside and bluegill). These analyses did not show any significant station differences (at the Bonferroni-adjusted p-value of 0.0005). There were highly significant differences among years in the abundances of spottail shiner $(\mathrm{p}<0.0001)$, Eastern silvery minnow $(\mathrm{p}<0.0001)$, redbreast sunfish $(\mathrm{p}<0.0001)$, and bannerfin shiner $(\mathrm{p}<0.001)$. In addition to the year effects, the abundance of redbreast sunfish was correlated with average velocity ( $\mathrm{p}<0.0002)$. Regressions of abundance against microhabitat variables (i.e., with no year or station difference included in the model) resulted in significant relationships between average substrate and abundances of whitefin shiner $(\mathrm{p}<0.0001)$, Eastern mosquitofish $(\mathrm{p}<0.0012)$, redbreast sunfish $(\mathrm{p}<0.0001)$, and bluegill $(\mathrm{p}<0.0001)$, and between aver- 
age velocity and the average abundances of whitefin shiner $(\mathrm{p}<0.0001)$ and redbreast sunfish $(\mathrm{p}<0.0005)$.

In addition, CANOCO was used to investigate associations between fish assemblages, microhabitat variables, and position variables (which could include plant effects) over the 1996-2000 surveys. The CANOCO analysis identifies major axes reflecting the occurrence of various species. These axes are related to the microhabitat variables, showing relationships among different species and among microhabitat and location/year variables, as well as relationships between fish abundance and the microhabitat and location/year variables. For the analysis of 1996-2000 seine samples, two major gradients explained $59.2 \%$ of total assemblage variation. The results are summarized in Figure E-1, which shows locations of peak species abundance along the gradients as points, and arrows representing the microhabitat and location/position variables. The direction of the arrows indicates correlations (axes and variables in the same direction are more positively correlated), and the length indicates the magnitude of the correlation. The first axis was correlated with substrate and velocity, i.e., it reflects the gradient from fine substrates in slow water (e.g., behind pilings) to coarser substrates in areas with greater current velocities (e.g., along beaches). The whitefin shiner (CYNIV in figure), bannerfin shiner (CYLEE), dusky shiner (NOCUM), bluehead chub (NOCLEP) and blackbanded darter (PENIG) are correlated with higher velocities (and coarser substrates). In contrast, the swamp darter (ETFUS), taillight shiner (NOMAC), lineolated killifish (FULIN), pickerels (ESAME and ESNIG), golden shiner (NOCRY), coastal shiner (NOPET), Eastern mosquitofish (GAHOL) and the various species of sunfishes (LEMIC, LEGIB, LEMAC, LEMAR, LEAUR) are more associated with finer substrates. The ANCOVAs of individual species abundance find similar correlations between abundance and substrate and velocity. Although these results parallel those of the ANCOVAs, they provide additional information, since they 1) show relationships for uncommon as well as common species; and 2) fit species abundances to a unimodal curve (i.e., they fit a microhabitat of peak abundance, rather than fitting monotonic relationships between abundance and microhabitat).

The second axis correlates most strongly with year. This axis models species found mainly in single years or groups of 


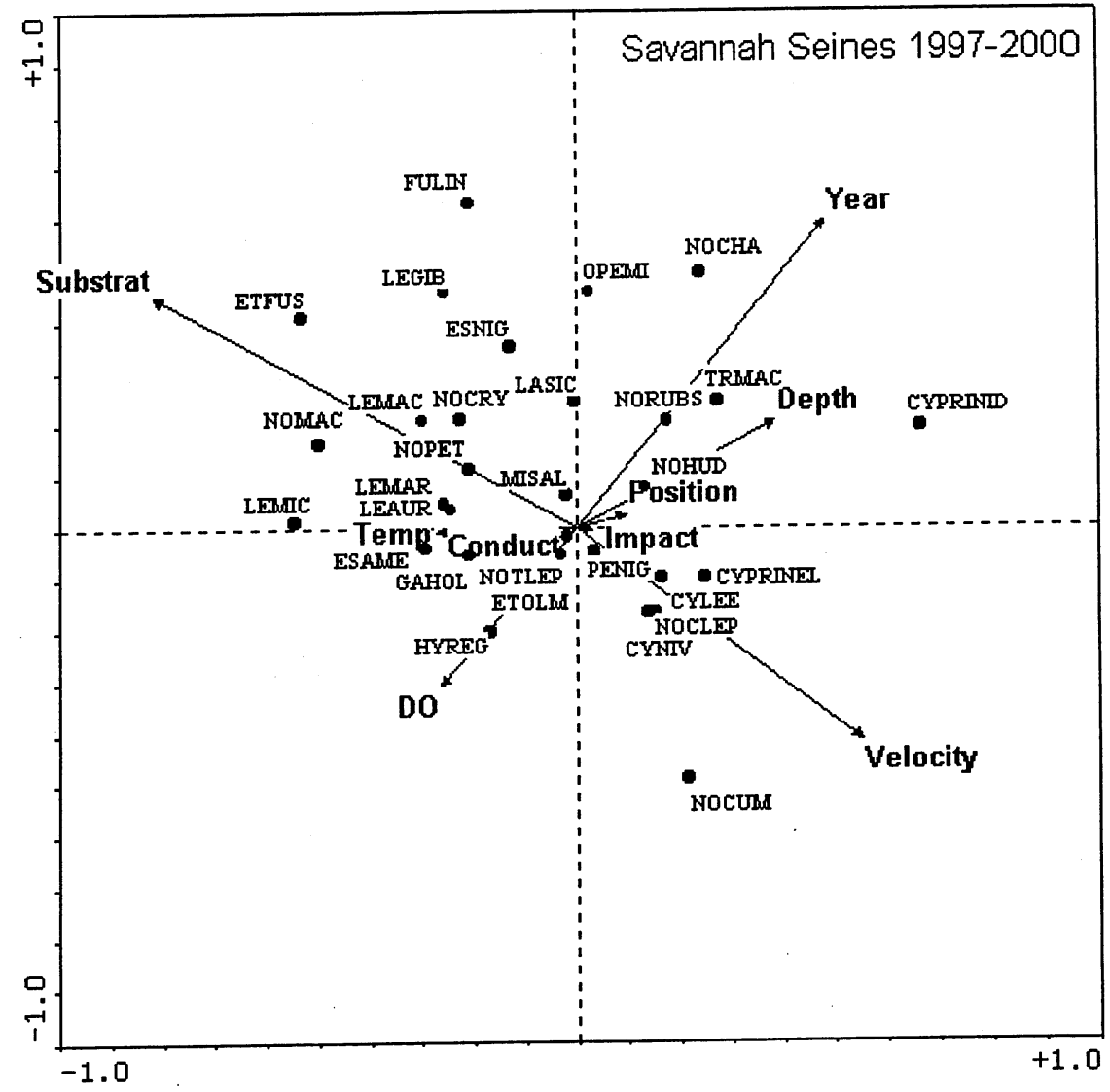

Figure E-1. Relationships between environmental parameters and abundance of fish in seine samples from the 1996-2000 ANSP Savannah River surveys. Relationships are calculated by CANOCO (see text), which positions species on composite environmental gradients. Arrows show the direction and magnitude of correlations between raw environmental parameters and the two most important composite gradients. Species locations show the modeled position of maximum abundance along the environmental gradients.

years, such as the ironcolor shiner, hogchoker, rosyface chub and pugnose minnow.

\section{Boat Electroshocking Samples}

A total of 2,434 individuals of 41 species were caught

$\triangle$ by boat electroshocking (Tables E-7 to E-9). As in

1 previous surveys, several species were recorded mainly or only in the boat electroshocking samples, including American shad (Alosa sapidissima), blueback herring (A. aestivalis), gizzard and threadfin shad (Dorosoma cepedianum and D. petenense), bowfin (Amia calva), Florida gar (Lepisosteus platyrhyncus), bannerfin shiner, channel catfish 
Table E-7. Average CPUEL (In-transformed catch per $100 \mathrm{~m}$ ) in boat electroshocking samples in the 2000 ANSP Savannah River survey.

\begin{tabular}{|c|c|c|c|c|}
\hline \multirow[b]{2}{*}{ Scientific Name } & \multicolumn{4}{|c|}{ Station } \\
\hline & 1 & 2B & 5 & 6 \\
\hline Alosa aestivalis & 0.00 & 0.00 & 0.19 & 0.31 \\
\hline Alosa sapidissima & 0.00 & 0.00 & 0.81 & 0.00 \\
\hline Ameiurus catus & 0.19 & 0.00 & 0.00 & 0.00 \\
\hline Amia calva & 0.63 & 0.33 & 0.73 & 0.32 \\
\hline Anguilla rostrata & 0.72 & 0.00 & 0.75 & 1.25 \\
\hline Aphredoderus sayanus & 0.00 & 0.16 & 0.31 & 0.00 \\
\hline Cyprinella leedsi & 12.83 & 17.58 & 36.17 & 28.96 \\
\hline Cyprinella nivea & 9.34 & 11.46 & 5.10 & 2.53 \\
\hline Cyprinella species & 0.00 & 0.00 & 0.00 & 0.63 \\
\hline Cyprinidae species & 0.00 & 0.16 & 0.00 & 0.00 \\
\hline Dorosoma cepedianum & 0.76 & 0.47 & 0.57 & 2.98 \\
\hline Dorosoma petenense & 0.00 & 0.00 & 0.19 & 0.00 \\
\hline Esox niger & 0.00 & 0.16 & 0.19 & 0.31 \\
\hline Etheostoma olmstedi & 0.14 & 0.16 & 0.17 & 0.16 \\
\hline Gambusia holbrooki & 0.00 & 0.16 & 0.00 & 0.00 \\
\hline Hybognathus regius & 0.00 & 0.00 & 0.00 & 1.25 \\
\hline Ictalurus punctatus & 0.19 & 0.32 & 0.19 & 0.00 \\
\hline Labidesthes sicculus & 1.23 & 1.90 & 11.09 & 7.34 \\
\hline Lepisosteus osseus & 0.19 & 0.00 & 0.19 & 0.00 \\
\hline Lepisosteus platyrhincus & 0.00 & 0.00 & 0.17 & 0.16 \\
\hline Lepomis auritus & 5.90 & 3.13 & 6.61 & 3.30 \\
\hline Lepomis gibbosus & 0.37 & 0.16 & 1.47 & 0.00 \\
\hline Lepomis gulosus & 0.18 & 0.16 & 1.12 & 0.31 \\
\hline Lepomis macrochirus & 5.15 & 3.57 & 41.83 & 14.90 \\
\hline Lepomis marginatus & 0.19 & 0.00 & 5.72 & 2.35 \\
\hline Lepomis microlophus & 0.00 & 0.18 & 1.84 & 1.41 \\
\hline Lepomis punctatus & 0.33 & 0.19 & 0.34 & 0.00 \\
\hline Micropterus salmoides & 1.94 & 1.22 & 3.78 & 1.72 \\
\hline Minytrema melanops & 1.04 & 0.85 & 2.56 & 3.60 \\
\hline Mugil cephalus & 0.00 & 0.00 & 0.00 & 0.16 \\
\hline Notemigonus crysoleucas & 0.00 & 0.00 & 0.76 & 0.42 \\
\hline Notropis chalybaeus & 0.14 & 0.00 & 0.00 & 0.16 \\
\hline Notropis cummingsae & 0.00 & 1.28 & 0.63 & 0.81 \\
\hline Notropis hudsonius & 13.95 & 32.73 & 46.75 & 46.61 \\
\hline Notropis lutipinnis & 0.00 & 0.48 & 0.31 & 0.00 \\
\hline Notropis maculatus & 0.00 & 0.00 & 0.77 & 0.00 \\
\hline Notropis petersoni & 0.30 & 7.20 & 0.94 & 5.67 \\
\hline Notropis rubescens & 2.88 & 3.78 & 0.17 & 0.16 \\
\hline Opsopoeodus emiliae & 1.06 & 1.45 & 0.74 & 1.26 \\
\hline Perca flavescens & 0.19 & 0.18 & 0.00 & 0.31 \\
\hline Percina nigrofasciata & 0.33 & 2.31 & 0.31 & 0.16 \\
\hline Pomoxis nigromaculatus & 0.00 & 0.00 & 0.00 & 3.60 \\
\hline Trinectes maculatus & 0.00 & 0.18 & 0.87 & 0.00 \\
\hline Total & 61.14 & 91.89 & 179.34 & 139.10 \\
\hline Average Sample Length & 155 & 147.5 & 122.5 & 138.75 \\
\hline Average Number of Species & 12.5 & 14.5 & 17 & 15.25 \\
\hline Station Total & 25 & 27 & 34 & 29 \\
\hline Total Number of Individuals & 380 & 545 & 789 & 720 \\
\hline
\end{tabular}


|⿹丁口.

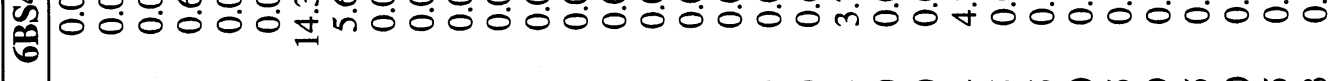

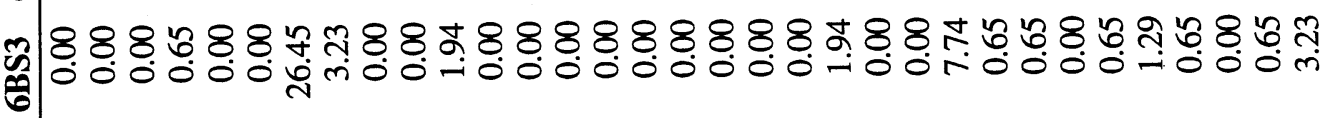

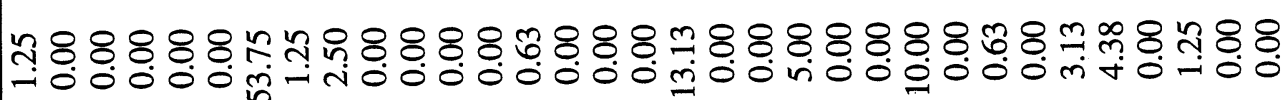

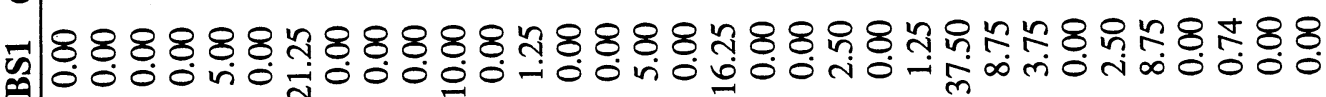

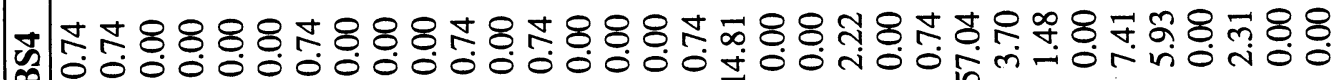

888 药

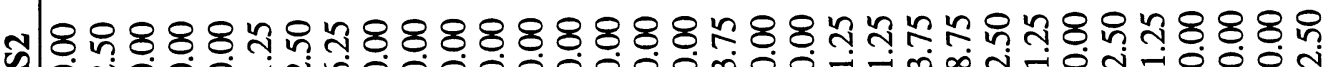
约

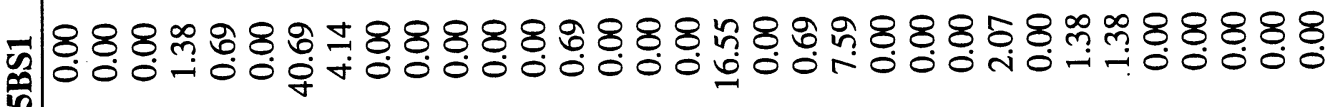

88

m 88 . 8 .

Nิ888888\%

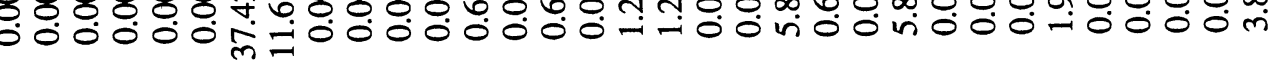

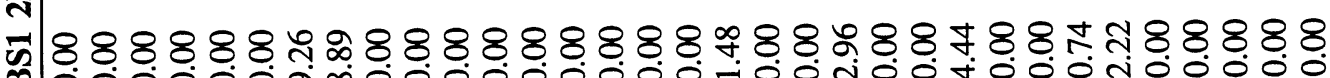

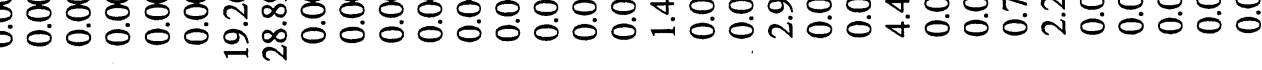

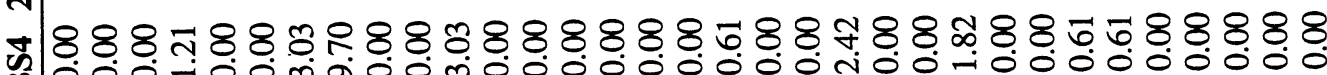
88

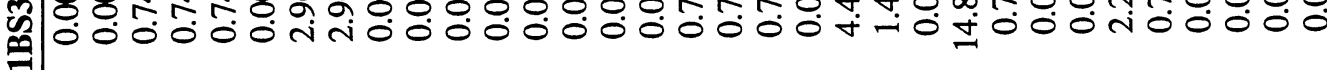

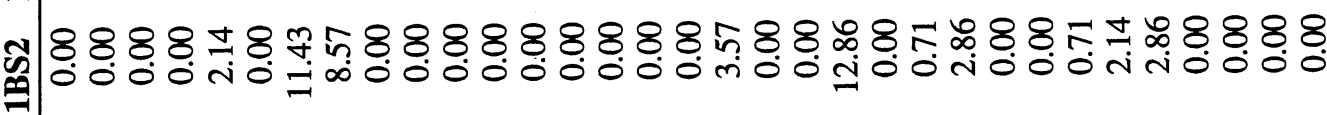

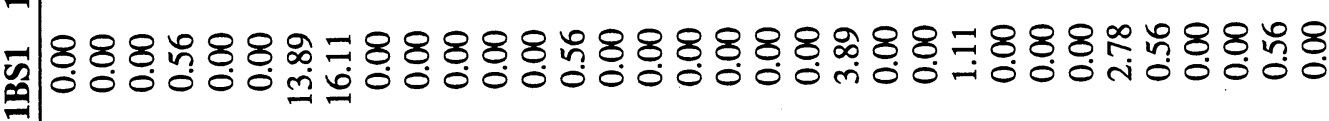




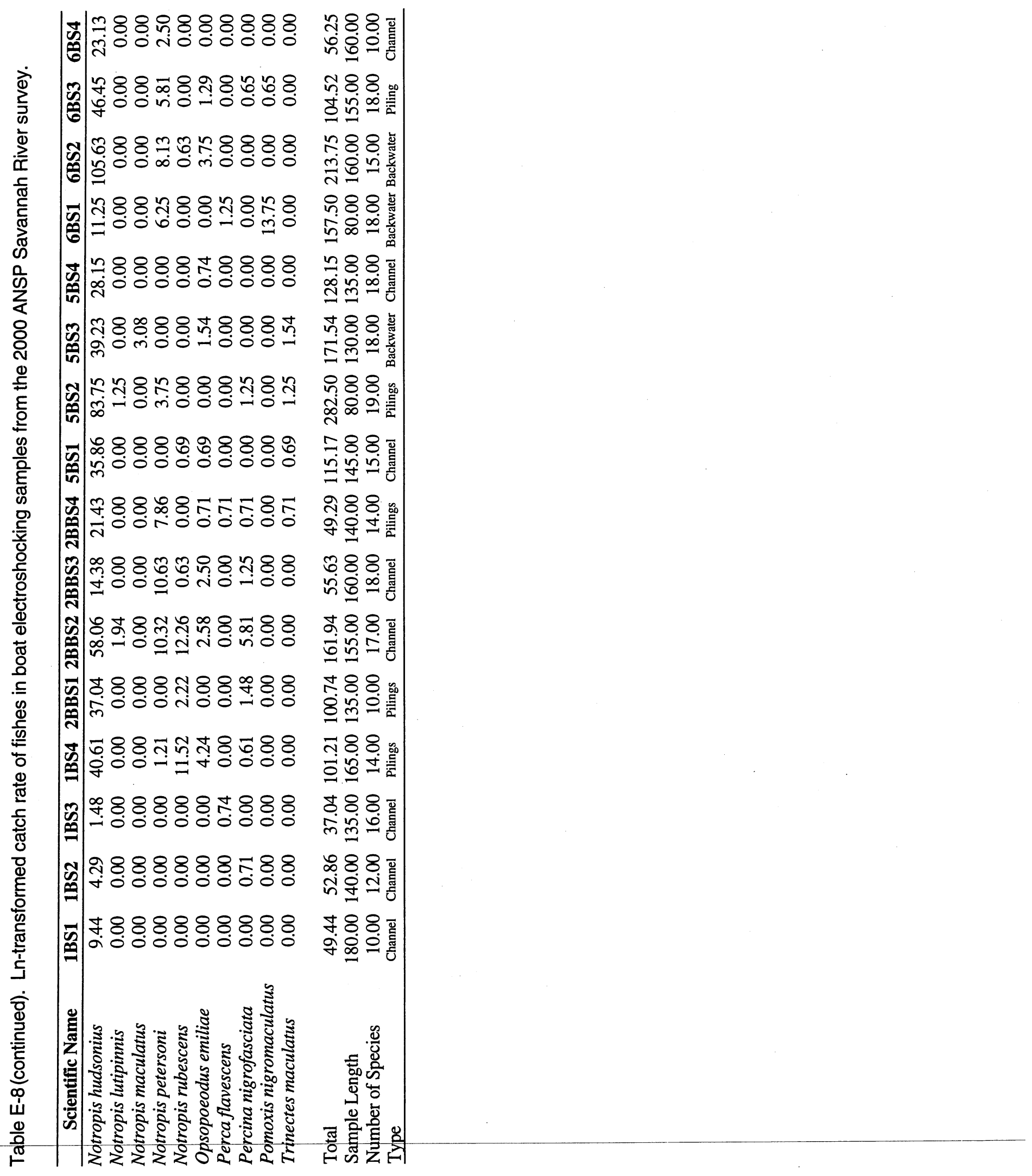


Table E-9. Numbers of fish and catch per sample length (calculated as total catch divided by total length sampled) caught in boat electroshocking samples in 1997-2000 ANSP Savannah River surveys.

\begin{tabular}{|c|c|c|c|c|c|c|c|c|}
\hline \multirow[t]{2}{*}{ Scientific Name } & \multirow[t]{2}{*}{ Common Name } & \multirow{2}{*}{$\begin{array}{c}1997 \\
\#\end{array}$} & \multicolumn{2}{|c|}{1998} & \multicolumn{2}{|c|}{1999} & \multicolumn{2}{|c|}{2000} \\
\hline & & & \# & $\# / 100 \mathrm{~m}$ & \# & \#/100m & \# & $\# / 100 \mathrm{~m}$ \\
\hline Alosa aestivalis & blueback herring & & & & & & 3 & 0.13 \\
\hline Alosa sapidissima & American shad & & & & 5 & 0.30 & 3 & 0.13 \\
\hline Ameiurus brunneus & snail bullhead & 4 & 22 & 0.75 & & & & \\
\hline Ameiurus catus & white catfish & 5 & 3 & 0.10 & 1 & 0.06 & 1 & 0.04 \\
\hline Ameiurus platycephalus & flat bullhead & 2 & 1 & 0.03 & & & & \\
\hline Amia calva & bowfin & 14 & 15 & 0.51 & 17 & 1.01 & 12 & 0.53 \\
\hline Anguilla rostrata & American eel & 6 & 9 & 0.31 & 11 & 0.66 & 12 & 0.53 \\
\hline Aphredoderus sayanus & pirate perch & & 12 & 0.41 & 3 & 0.182 & 0.09 & \\
\hline Cyprinella leedsi & bannerfin shiner & 10 & 25 & 0.86 & 95 & 5.66 & 498 & 22.08 \\
\hline Cyprinella nivea & whitefin shiner & 15 & 38 & 1.30 & 56 & 3.34 & 161 & 7.14 \\
\hline Cyprinella species & shiner species & & & & & & 4 & 0.18 \\
\hline Cyprinidae species & minnow & 2 & & & & & 1 & 0.04 \\
\hline Dorosoma cepedianum & gizzard shad & 5 & 5 & 0.17 & 2 & 0.12 & 22 & 0.98 \\
\hline Dorosoma petenense & threadfin shad & 3 & 1 & 0.03 & & & 1 & 0.04 \\
\hline Elassoma zonatum & banded pygmy sunfish & & 1 & 0.03 & & & & \\
\hline Enneacanthus gloriosus & bluespotted sunfish & 1 & 1 & 0.03 & & & & \\
\hline Erimyzon sucetta & lake chubsucker & & 3 & 0.10 & & & & \\
\hline Esox americanus & redfin pickerel & & 3 & 0.10 & & & & \\
\hline Esox niger & chain pickerel & & 10 & 0.34 & 1 & 0.06 & 3 & 0.13 \\
\hline Etheostoma olmstedi & tesselated darter & & 2 & 0.07 & & & 4 & 0.18 \\
\hline Gambusia holbrooki & eastern mosquitofish & & 12 & 0.41 & 1 & 0.06 & 1 & 0.04 \\
\hline Hybognathus regius & eastern silvery minnow & 11 & 267 & 9.14 & 45 & 2.68 & 4 & 0.18 \\
\hline Ictalurus punctatus & channel catfish & 11 & 2 & 0.07 & 1 & 0.06 & 4 & 0.18 \\
\hline Labidesthes sicculus & brook silverside & 2 & 111 & 3.80 & 119 & 7.10 & 111 & 4.92 \\
\hline Lepisosteus osseus & longnose gar & 4 & & & 3 & 0.18 & 2 & 0.09 \\
\hline Lepisosteus platyrhincus & Florida gar & 1 & & & 3 & 0.18 & 2 & 0.09 \\
\hline Lepisosteus species & gar species & 1 & 0.03 & & & & & \\
\hline Lepomis auritus & redbreast sunfish & 14 & 79 & 2.70 & 116 & 6.92 & 103 & 4.57 \\
\hline Lepomis gibbosus & pumpkinseed & & 4 & 0.14 & 18 & 1.07 & 10 & 0.44 \\
\hline Lepomis gulosus & warmouth & 2 & 58 & 1.98 & 9 & 0.54 & 7 & 0.31 \\
\hline Lepomis macrochirus & bluegill & 6 & 152 & 5.20 & 140 & 8.35 & 321 & 14.24 \\
\hline Lepomis marginatus & dollar sunfish & 1 & 42 & 1.44 & 7 & 0.42 & 33 & 1.46 \\
\hline Lepomis microlophus & redear sunfish & 11 & 24 & 0.82 & 22 & 1.31 & 16 & 0.71 \\
\hline Lepomis punctatus & spotted sunfish & 1 & 17 & 0.58 & 11 & 0.66 & 5 & 0.22 \\
\hline Micropterus salmoides & largemouth bass & 4 & 14 & 0.48 & 31 & 1.85 & 47 & 2.08 \\
\hline Minytrema melanops & spotted sucker & 19 & 19 & 0.65 & 37 & 2.21 & 40 & 1.77 \\
\hline Moxostoma anisurum & silver redhorse & 13 & & & 2 & 0.12 & & \\
\hline Mugil cephalus & striped mullet & 3 & 1 & 0.03 & 9 & 0.54 & 1 & 0.04 \\
\hline Nocomis leptocephalus & bluehead chub & & & & 1 & 0.06 & & \\
\hline Notemigonus crysoleucas & golden shiner & & 11 & 0.38 & & & 5 & 0.22 \\
\hline Notropis chalybaeus & ironcolor shiner & & & & & & 2 & 0.09 \\
\hline Notropis cummingsae & dusky shiner & & 16 & 0.55 & 1 & 0.06 & 15 & 0.67 \\
\hline Notropis hudsonius & spottail shiner & 1 & 5 & 0.17 & 695 & 41.44 & 780 & 34.59 \\
\hline Notropis lutipinnis & yellowfin shiner & & & & & & 4 & 0.18 \\
\hline Notropis maculatus & taillight shiner & & 15 & 0.51 & & & 4 & 0.18 \\
\hline Notropis petersoni & coastal shiner & 3 & 84 & 2.87 & 95 & 5.66 & 80 & 3.55 \\
\hline Notropis rubescens & rosyface chub & & & & 30 & 1.79 & 44 & 1.95 \\
\hline Noturus leptacanthus & speckled madtom & 2 & & & & & & \\
\hline Opsopoeodus emiliae & pugnose shiner & 1 & 17 & 0.58 & 16 & 0.95 & 28 & 1.24 \\
\hline Perca flavescens & yellow perch & 3 & 23 & 0.79 & 3 & 0.18 & 3 & 0.13 \\
\hline
\end{tabular}


Table E-9 (continued). Numbers of fish and catch per sample length (calculated as total catch divided by total length sampled) caught in boat electroshocking samples in 1997-2000 ANSP Savannah River surveys.

\begin{tabular}{|c|c|c|c|c|c|c|c|c|}
\hline \multirow[t]{2}{*}{ Scientific Name } & \multirow[t]{2}{*}{ Common Name } & \multirow{2}{*}{$\begin{array}{c}1997 \\
\#\end{array}$} & \multicolumn{2}{|c|}{1998} & \multicolumn{2}{|c|}{1999} & \multicolumn{2}{|c|}{2000} \\
\hline & & & $\#$ & $\# / 100 \mathrm{~m}$ & $\#$ & $\# / 100 \mathrm{~m}$ & $\#$ & $\# / 100 \mathrm{~m}$ \\
\hline Percina nigrofasciata & blackbanded darter & 3 & 10 & 0.34 & 6 & 0.36 & 1 & 0.80 \\
\hline Pomoxis nigromaculatus & black crappie & 1 & 3 & 0.10 & 1 & 0.06 & 12 & 0.53 \\
\hline Trinectes maculatus & hogchoker & 1 & & & 1 & 0.06 & 5 & 0.22 \\
\hline Total & & 185 & 1138 & 38.94 & 1614 & 96.24 & 2434 & 107.94 \\
\hline Ave number per sample & & 18.5 & 51.7 & & 124.2 & & 152.1 & \\
\hline Number of samples & & 10 & 22 & & 13 & & 16 & \\
\hline Shoreline sampled & & & 2923 & & 1677 & & 2255 & \\
\hline
\end{tabular}

(Ictalurus punctatus), striped mullet (Mugil cephalus) and yellow perch (Perca flavescens). Some uncommon minnows, such as the Eastern silvery minnow (Hybognathus nuchalis), dusky shiner (Notropis cummingsae), yellowfin shiner (N. lutipinnis), were caught only in the boat shocking samples, although these species have been caught in other techniques in other surveys. Several species of minnows, including the spottail shiner, bannerfin shiner, whitefin shiner, and the bluegill were the most abundant species, while several other species of minnows and sunfishes and the brook silverside (Labidesthes sicculus) were also frequent. More species were caught at Stations 5 and 6 (33 and 29) than at Stations 1 and 2B (25 and 27); the average number of species per sample was also higher at Stations 5 and 6 than at Stations 1 and 2B. The catch varied among individual samples, but there were some differences in species composition between the upper stations (1 and $2 \mathrm{~B}$ ) and the lower stations (5 and 6). For example, the whitefin shiner and rosyface chub were more common in samples from the upper stations, while the blueback herring, bannerfin shiner, brook silverside, several sunfishes (redbreast, dollar, redear, and bluegill), and spotted sucker were more common at Stations 5 and 6. The blackbanded darter was most common at Station 2B. There were few clear differences in abundance between main channel (most samples) and backwater samples (three samples from Devil's Elbow and Ring Jaw Cove in Stations 5 and 6), or between channel samples taken around pilings and those on open shoreline. Channel eatfish was, appropriately, caught only in non-piling channel samples. Dusky shiner, yellowfin shiner, taillight shiner, and 
blackbanded darter were caught only in channel samples, and the rosyface chub was most common in channel samples. Gizzard shad, bluegill and redear sunfish were most common in backwater samples.

\section{Hand Samples}
A
few specimens were collected by dip nets during macroinvertebrate sampling (Table E-10). These samples show the widespread occurrence of small catfishes, including speckled madtom (Noturus leptacanthus), white catfish (Ameiurus catus) and flat bullhead (A. platy- cephalus) in the study area.

Table E-10. Numbers of fish collected in hand samples in the 2000 ANSP Savannah River survey.

\begin{tabular}{lccccc}
\hline \multirow{2}{*}{\multicolumn{1}{c}{ Scientific Name }} & \multicolumn{5}{c}{ Station } \\
\cline { 2 - 6 } Ameiurus catus & $\mathbf{1}$ & 2B & $\mathbf{5}$ & $\mathbf{6}$ \\
Ameiurus platycephalus & 1 & - & 1 & 1 \\
Etheostoma olmstedi & - & 1 & - & - \\
Notorus gyrinus & - & 1 & - & - \\
Noturus leptacanthus & - & 5 & 4 & 5 \\
\hline
\end{tabular}

\section{Overall Proportions}

$\mathrm{n}$ index of relative abundance at each station was cal-
culated (Table E-11), based on relative abundance
within each collecting type. Since different techniques are used in different habitats and have different efficiencies on different species, the overall proportions of different species (e.g., Table E-2) are sensitive to the relative effort by each technique. To reduce the dependence on relative effort, the overall index averages the relative proportion of species by each major collecting technique (seining, boat electroshocking, and walkalong electroshocking), giving equal weight to each collecting technique.

The resultant frequencies of occurrence show differences in occurrence across the stations. For a number of species, these show several patterns of occurrence:

- lower relative abundance at Station 2B (e.g., American eel, Eastern mosquitofish, bluegill, dollar and redear 
Table E-11. Average (\%) relative abundances of fish at each station by major sampling techniques (seine, boat shocking, and walkalong shocking) in the 2000 ANSP Savannah River survey.

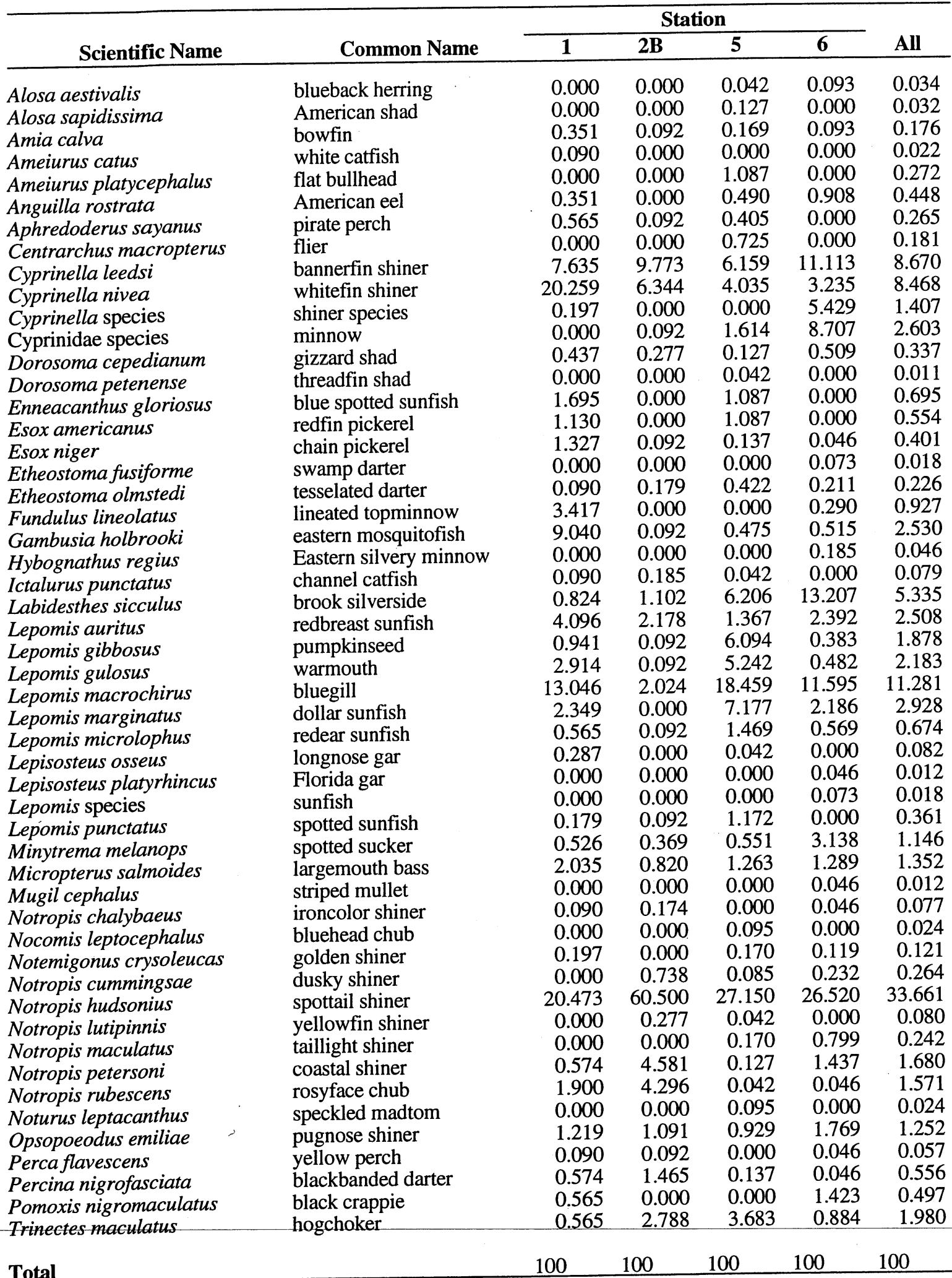


sunfishes); this presumably reflects the absence of backwater habitat at this station;

- higher relative abundance at Station 2B (spottail shiner, coastal shiner Notropis petersoni, rosyface chub $N$. rubescens); this reflects the paucity of backwater habitats and dominance of main channel fishes;

- $\quad$ high relative abundance of whitefin shiner at Station 1; the analysis of seine results indicates relationships between this species and current velocity and substrate; its abundance at Station 1 may reflect abundant habitat, combined with poorer habitat for other species;

- higher relative abundance at Stations 5 and 6 (American shad, blueback herring, taillight shiner, spotted sucker, brook silverside); this may reflect the presence of backwater habitats (taillight shiner) and large cove habitats (other species).

Some of these patterns are explicable by occurrence of backwater habitats at the stations, which were most extensive at Stations 5 and 6, and absent from Station 2B. For example, the differences between Station $2 B$ and the others may reflect absence of backwaters there (with no backwater electroshocking done), and the presence of bars with relatively coarse (sand, gravel) substrates.

\section{Condition Analysis}

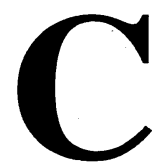
omparisons of length-weight relationships of four common species were done using ANCOVA. Analyses were done on 197 spottail shiner, 186 whitefin shiner, 117 redbreast sunfish, and 249 bluegill. Examination of length-weight regressions (Figs. E-2 to E-5) and statistical analysis indicate that the length-weight relationships were very similar among stations for each of the four species. Examination of the relationships indicates some apparent outlier points. Three clear outliers were corrected (based on reexamination of specimens) and one outlier was deleted. A few other specimens also appear to be outside the main length-weight regressions. These may represent true outliers or erroneous measurements, but were not clearly different enough to warrant exclusion from the analyses. 
Spottail shiner (Notropis hudsonius) Condition Analysis Ln Length (cm) vs. Ln Mass (g)

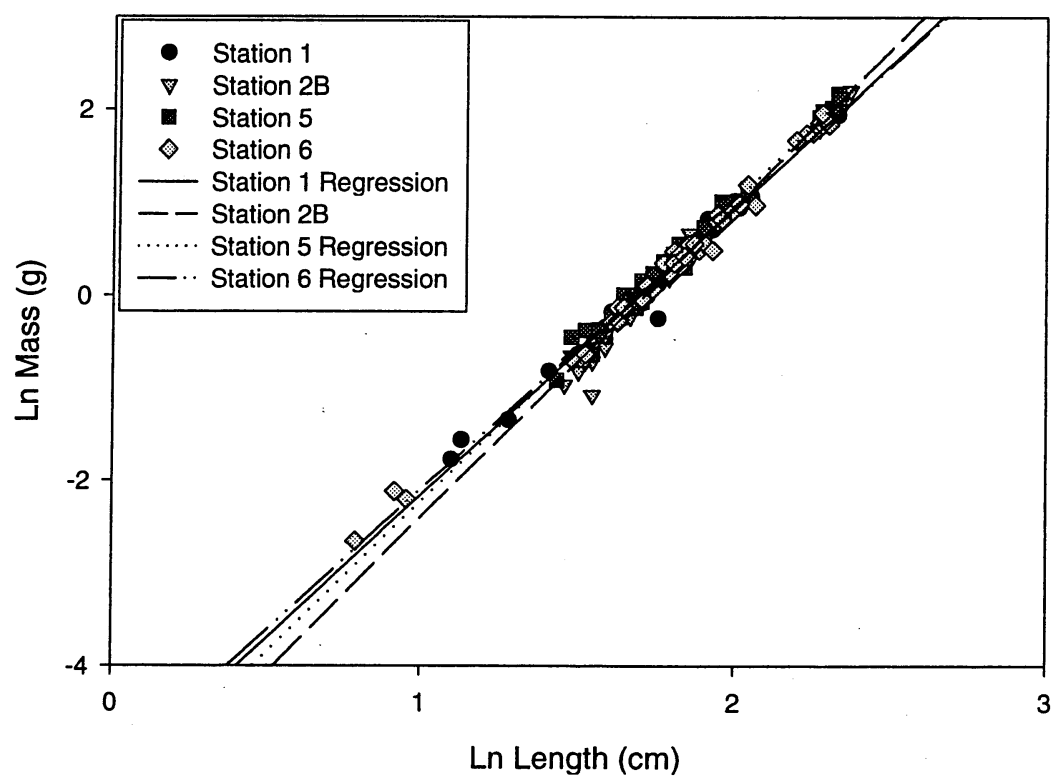

Figure E-2. Length-weight relationships of spottail shiner (Notropis hudsonius) in the 2000 ANSP Savannah River surveys. See text for information on significance of difference among slopes and intercepts of regressions.

Whitefin shiner (Cyprinella nivea) Condition Analysis

Ln Length (cm) vs. Ln Mass (g)

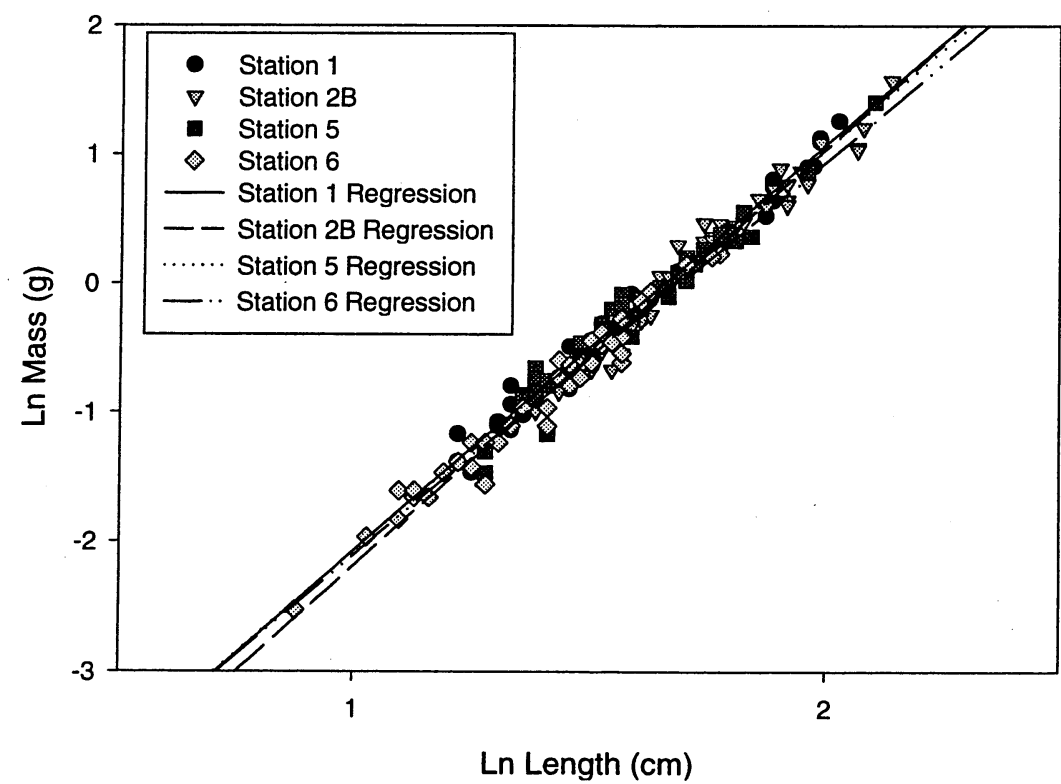

Figure E-3. Length-weight relationships of whitefin shiner (Cyprinella nivea) in the 2000 ANSP Savannah River surveys. See text for information on significance of difference among slopes and intercepts of regressions. 
Redbreast sunfish (Lepomis auritus) Condition Analysis Ln Length (cm) vs. Ln Mass (g)

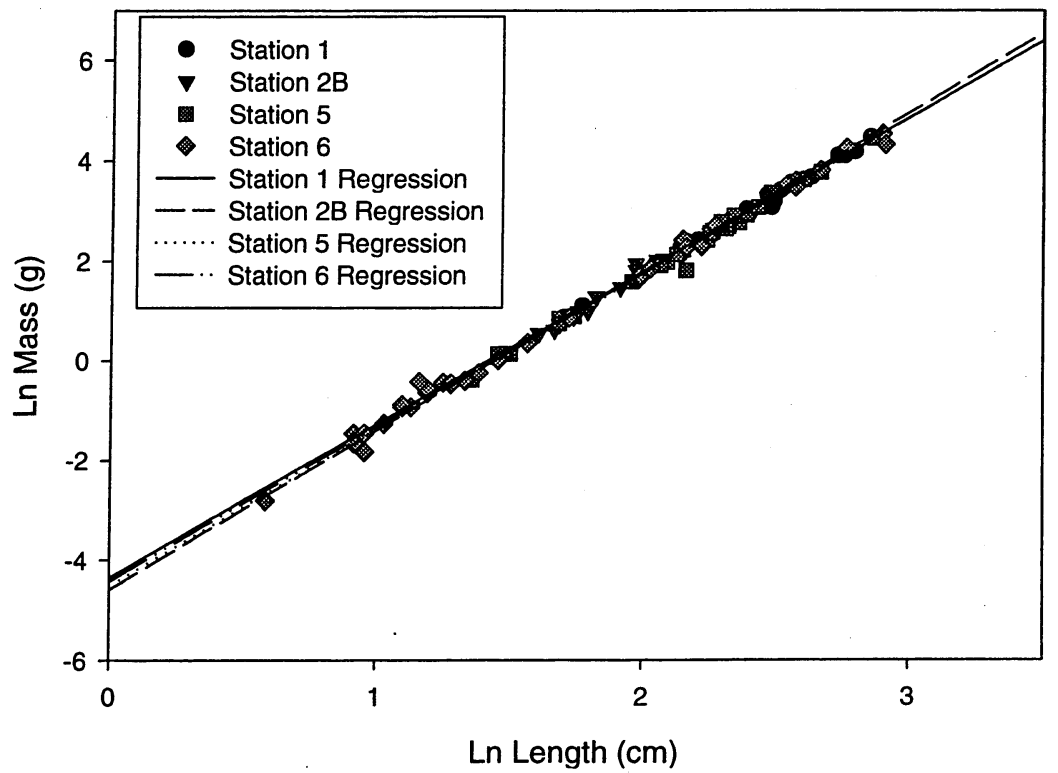

Figure E-4. Length-weight relationships of redbreast sunfish (Lepomis auritus) in the 2000 ANSP Savannah River surveys. See text for information on significance of difference among slopes and intercepts of regressions.

\section{Bluegill (Lepomis macrochirus) Condition Analysis} Ln Length (cm) vs. Ln Mass (g)

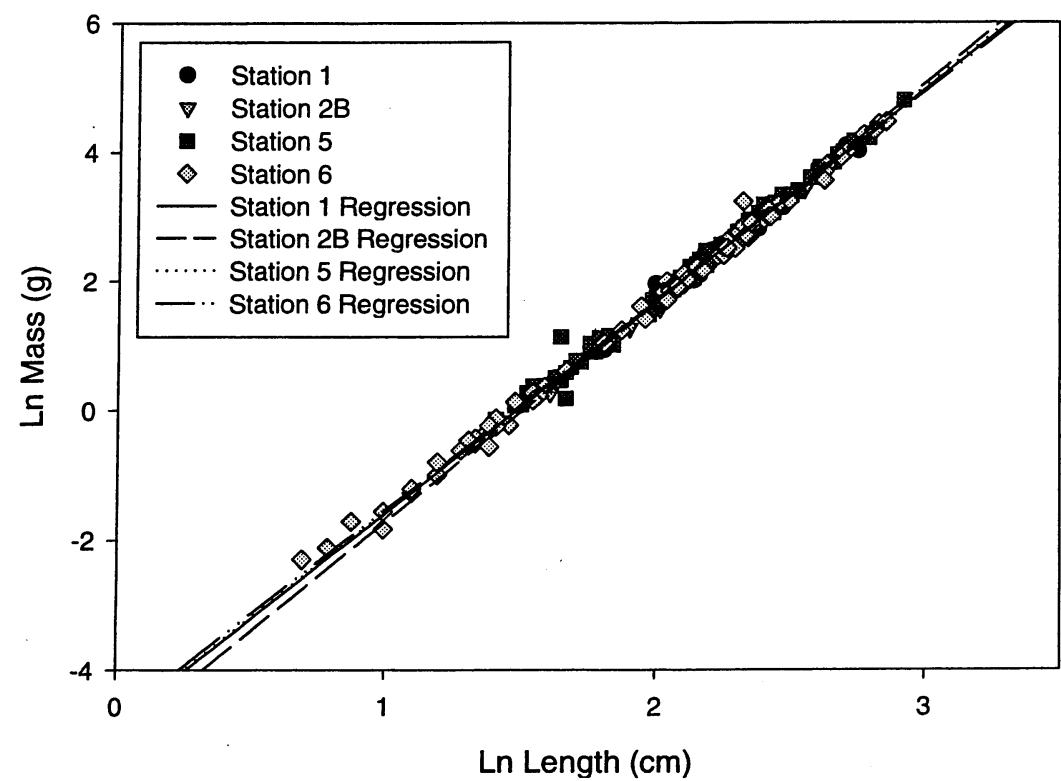

Figure E-5. Length-weight relationships of bluegill (Lepomis macrochirus) in the 2000 ANSP Savannah River surveys. See text for information on significance of difference among slopes and intercepts of regressions. 
Differences in slopes and intercepts of the length-weight relationships were tested. Because of the large number of individuals analyzed, tests have the power to detect very small differences in the regressions, and some of the observed differences may have been affected strongly by a few outliers. For the spottail shiner, there were highly significant differences in slopes $(\mathrm{p}<0.0001)$ and intercepts $(\mathrm{p}<0.0002)$ among stations. The adjusted means (least squares means) were higher at Stations 5 and 6 than at Stations 1 and 2B, and the apparent difference may have been due to single specimens at Stations 1 and 2B which had low weight for size (Fig. E-2). For whitefin shiner, there was a significant difference in intercepts $(\mathrm{p}<0.0045)$, but no difference in slopes. The order of least squares means $(1>5>2 \mathrm{~B}>6)$ does not correspond to obvious spatial patterns relative to plant operation or river conditions and may reflect the influence of a few outliers (Fig. E-3). There was no difference in intercepts or slopes for redbreast sunfish. There was marginally significant difference in intercepts $(\mathrm{p}<0.048)$ for bluegill, but no difference in slopes $(\mathrm{p}<0.08)$.

\section{Discussion}

\section{Temporal Trends in River Fish Communities}

The 2000 survey results are directly comparable to those of the 1997-1999 studies (Tables E-9 and E-12) and can also be compared to earlier comprehensive, cursory and Vogtle surveys (Table E-12), although these differed somewhat in sampling methods. The most direct comparisons are with the 1995-1997 walk-along backwater samples and with the rotenone backwater samples from earlier cursory surveys (summarized in ANSP 1997; 1998). Over time, there has been an apparent increase in the total number of species collected in the backwater samples (around 22-33 species before 1989, compared with 30-49 species from 1989 to 1999), with a smaller rise in the average number from each station. The increase is probably partly due to increasing effort, with only one sample per station in the earlier samples and two per station in the most recent samples. In 2000, only 


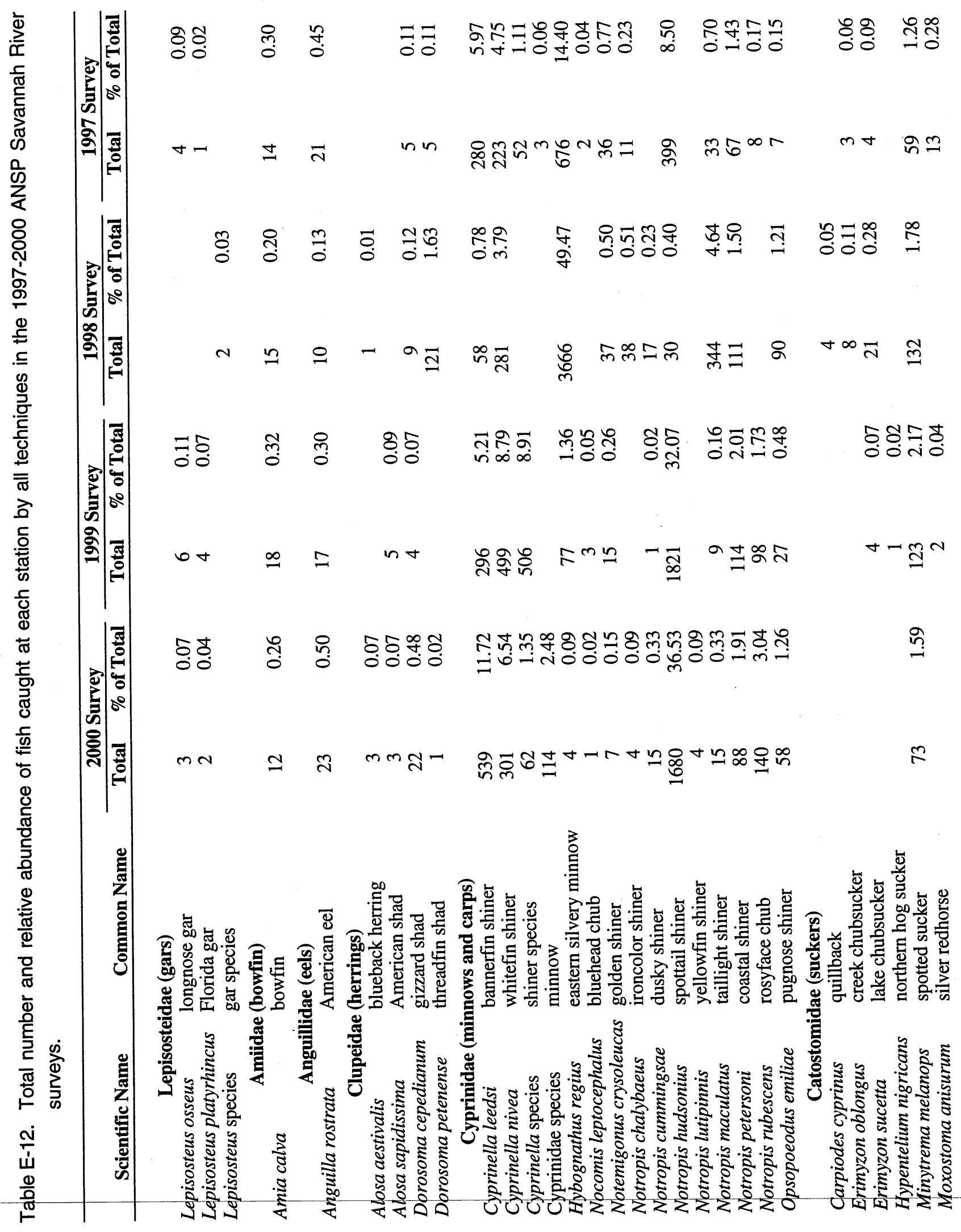




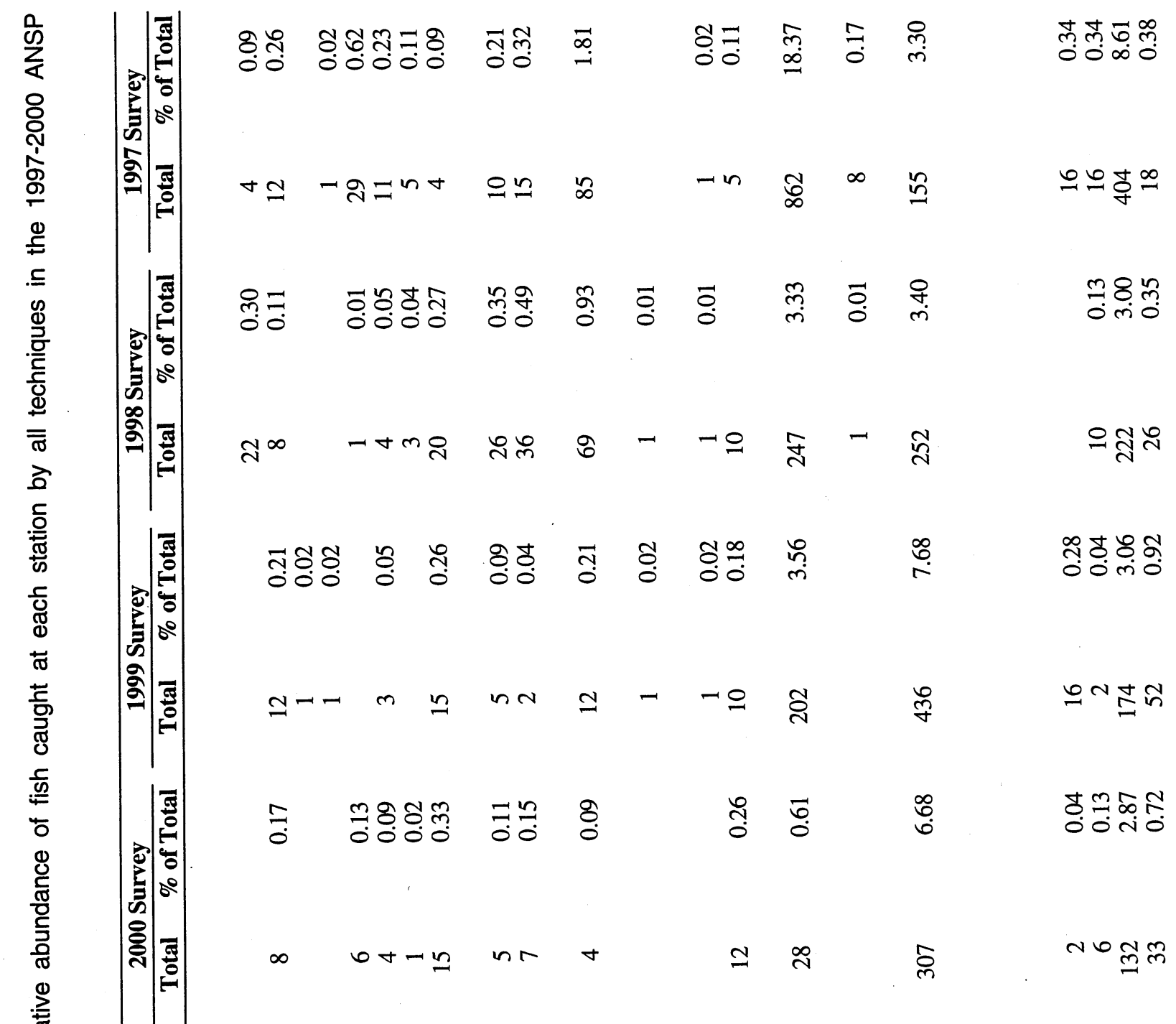

$\frac{\text { T }}{10}$

담

ฆ 


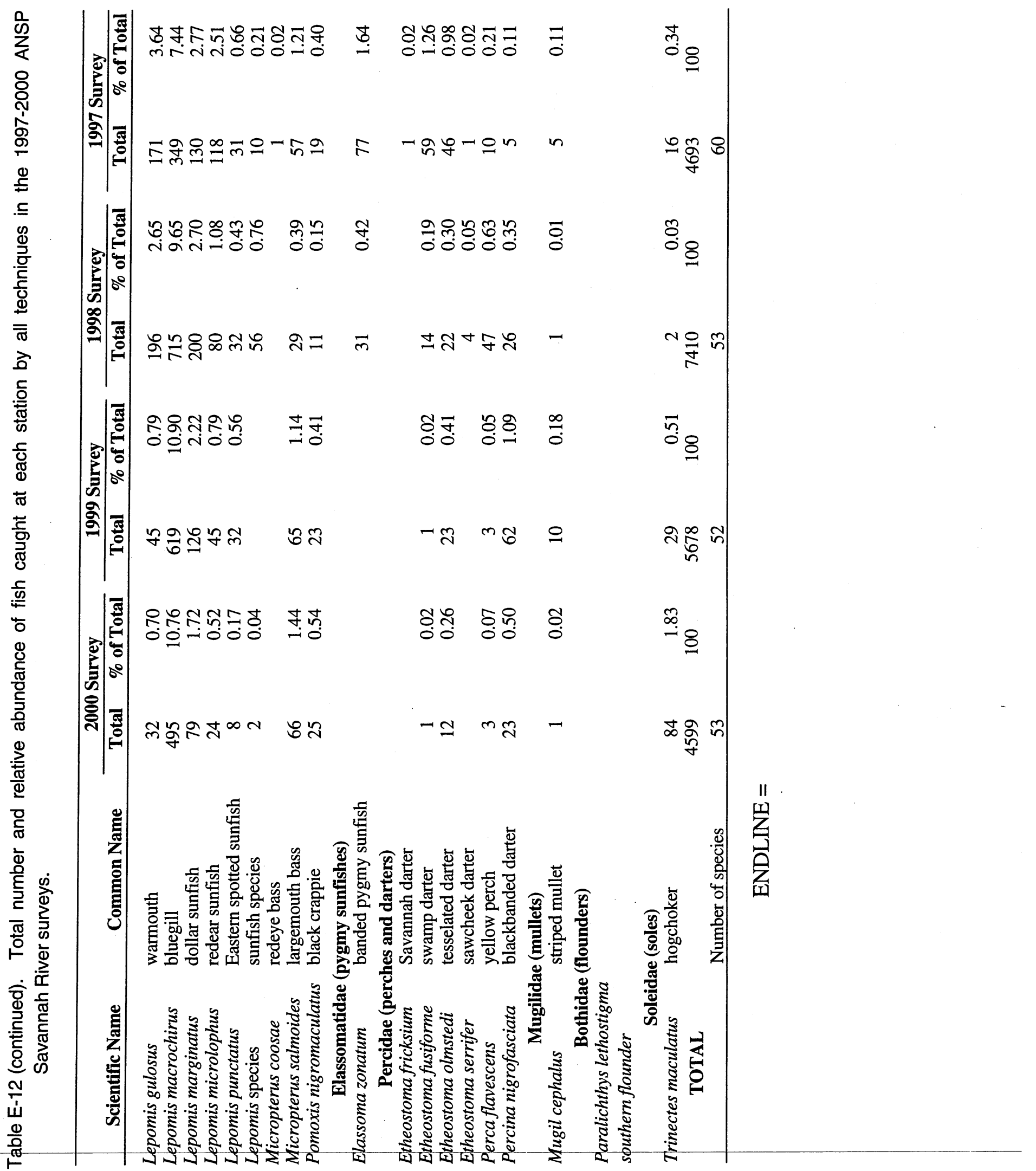


one sample was taken per station and the total species richness (29 species) and the richness at each station (14-24 species) was similar to that of the earlier surveys.

Typically, abundances of some species have varied over different surveys (Tables E-9, E-12 and E-13). Variations in abundance have been prominent in a number of species associated with vegetation (e.g., ironcolor shiner, chubsuckers, banded pygmy sunfish, bluespotted sunfish), bullhead species, and the Eastern silvery minnow. For example, the Eastern silvery minnow was rare or absent in most of the 1980s and early 1990s. It appears to have increased in the mid1990s. In 1996 and 1997, it was common at one of the Station 6 backwater sites. In 1998, it was the most abundant species in seine samples at all stations, and at two of the backwater sites, where it was found in very high densities. Overall, it was the most commonly collected species. In contrast, it was uncommon in both the 1999 and 2000 surveys, while the spottail shiner was abundant in both of these surveys. The Eastern silvery minnow has apparently fluctuated in abundance in the past; it was apparently common in the 1960s and early 1970s, as well. A few species were more common in 2000 than in previous surveys, including the American shad, blueback herring, and hogchoker.

In 1999-2000, a number of species associated with vegetation or other cover were absent or less common than in recent surveys. These species include the creek and lake chubsuckers and banded pygmy sunfish (none caught in 2000) and ironcolor shiner, redfin pickerel, chain pickerel, taillight shiner, pirateperch, warmouth, bluespotted sunfish, and swamp darter (less common in 1999). The Eastern mosquitofish was very uncommon in 2000 ( $0.61 \%$ of total catch), compared with low numbers in 1998-1999 (3.3\% and 3.6\%, respectively), and high numbers in 1997 (18.4\%).

The boat shocking samples provide standardized sampling of a variety of fishes in the main channel. These samples have been taken since 1997 (Table E-9), although improvements in sampling efficiency after 1997 make the 1997 samples less comparable than the 1998-2000 data. These data show similar patterns as the overall changes in relative abundance noted above. There appears to have been a decrease in the catch rates of Eastern silvery minnow and warmouth, and an increase in the catch rates of bannerfin shiner and spottail 


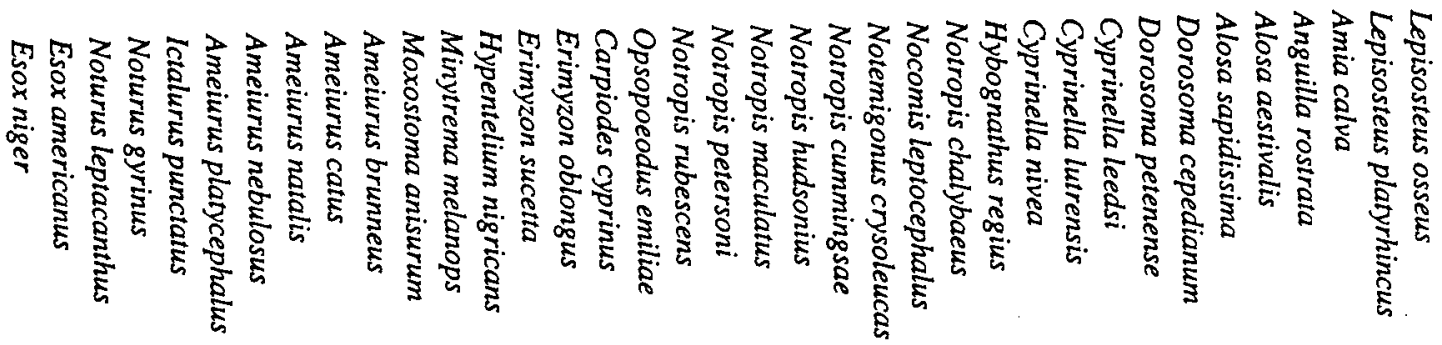

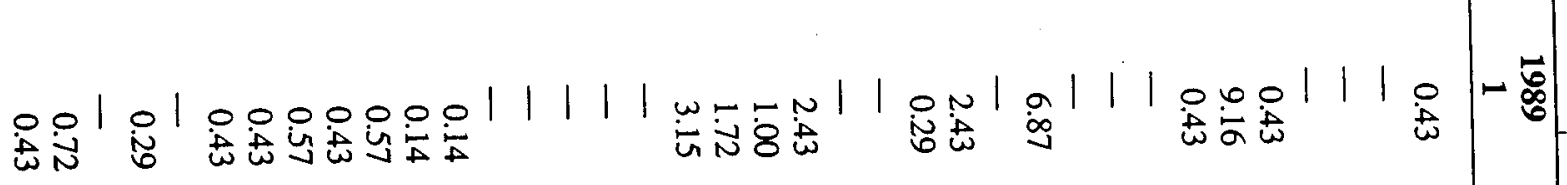

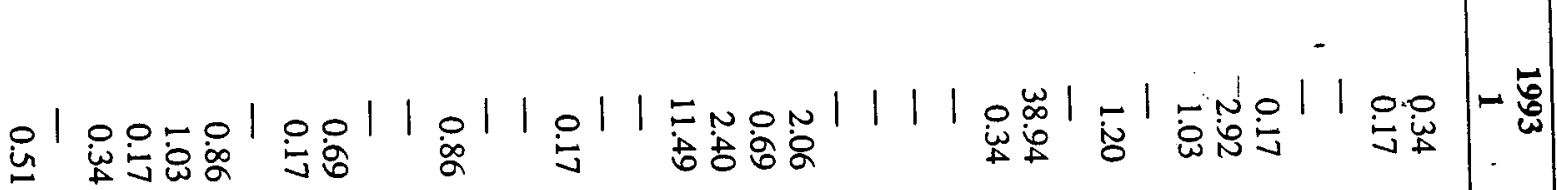
:

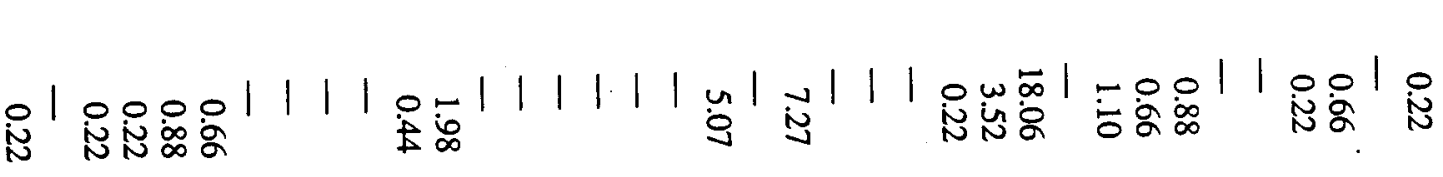

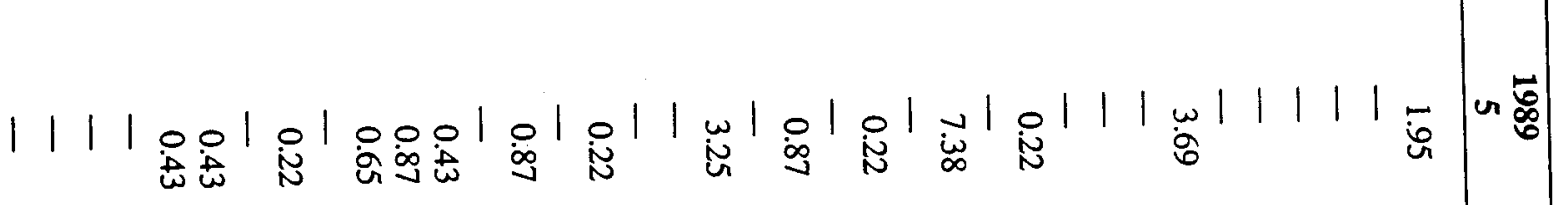

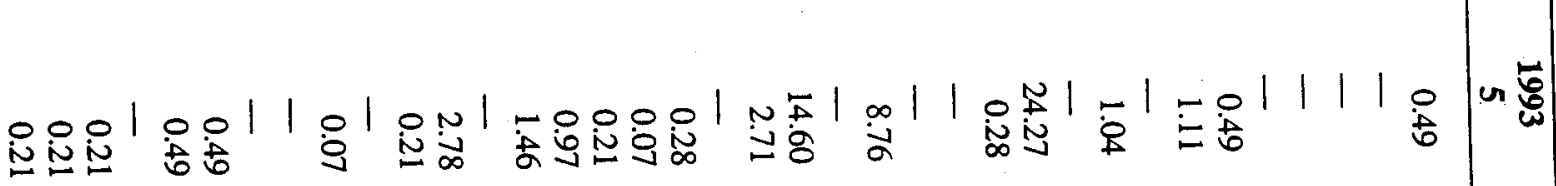

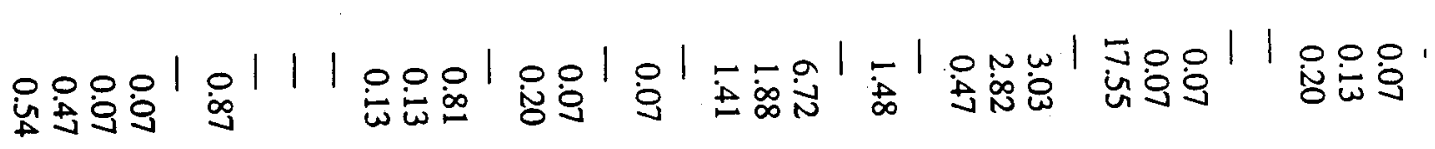

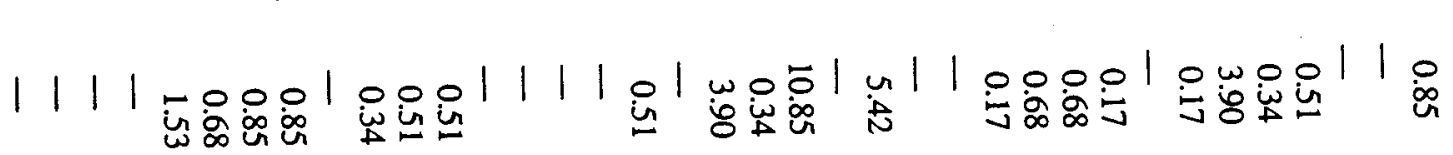

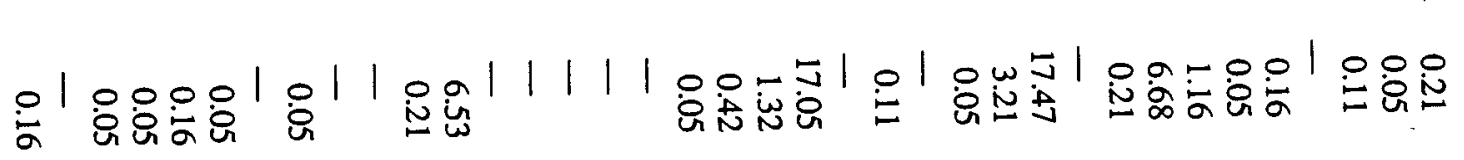

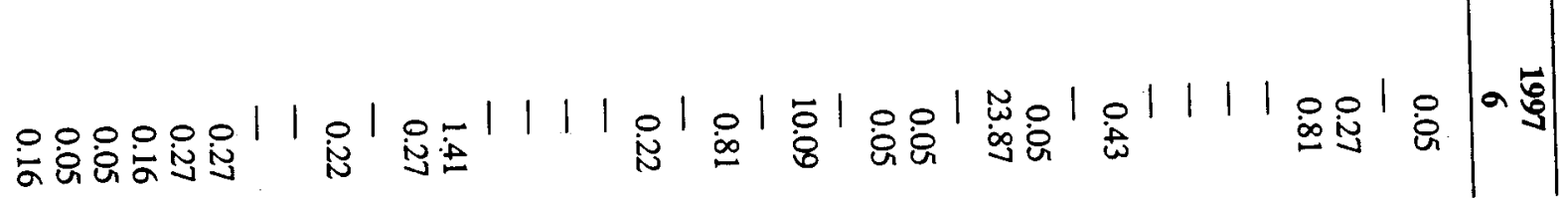




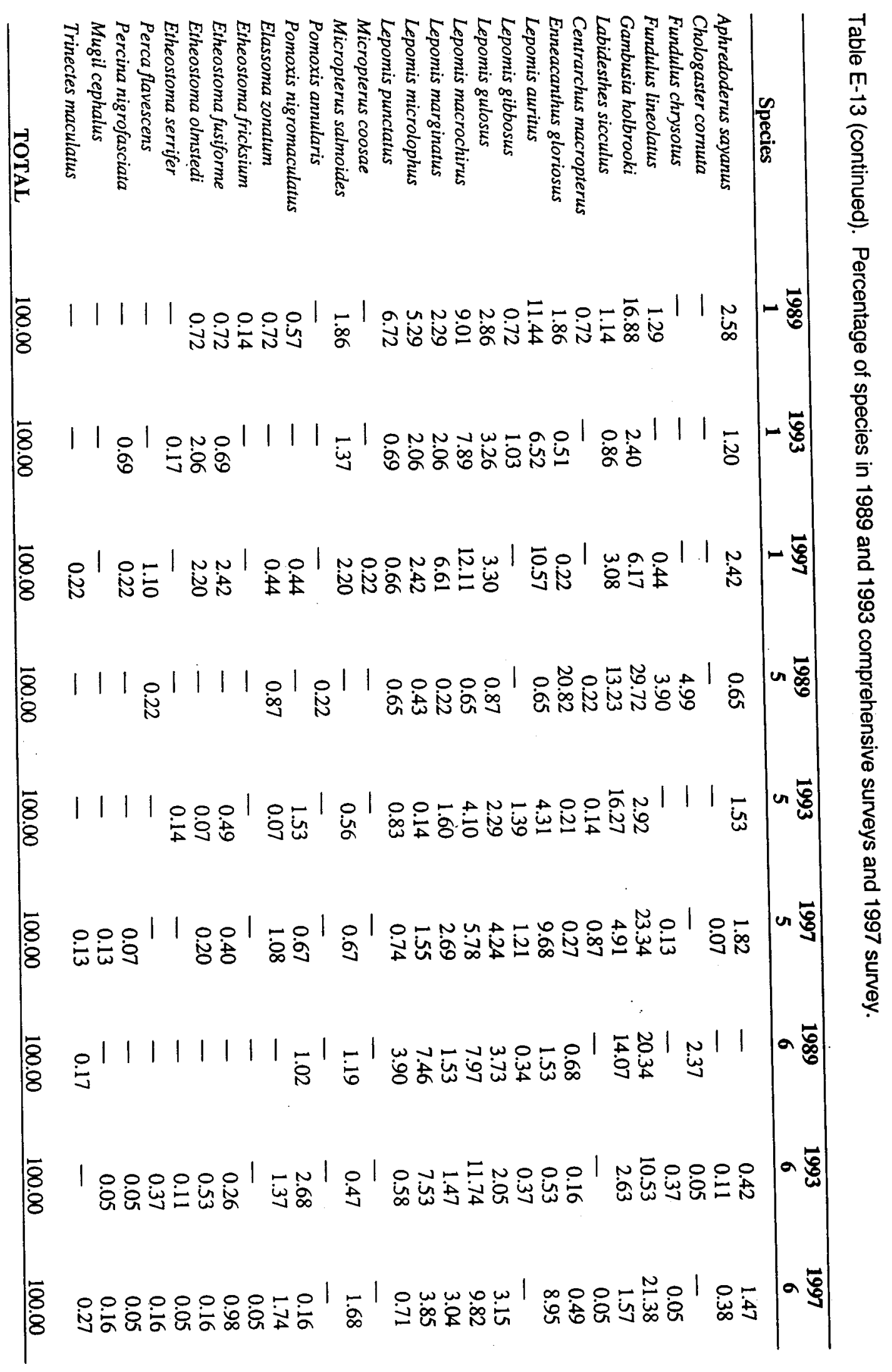


shiner. Catch rates of rosyface chub, largemouth bass and pugnose minnow may have increased as well, but these species are not as common and the changes not as large.

It is plausible that these changes reflect short-term effects of water level fluctuations. Water levels were low prior to the 2000 survey and during the 1999 survey relative to recent previous surveys. Moreover, the presence of terrestrial and emergent grasses on the shoreline indicate that water levels had been low prior to the sampling period in both years. This could result in decreased volume of backwater habitat, including vegetated habitats, and lead to reductions in species associated with these habitats. Variations may also reflect longterm changes in river ecology. For example, there was a major decrease in the amount of submergent vegetation in the river after 1989, and some fish populations may be showing gradual responses to the change in the amount of vegetated habitat.

\section{Differences Among Stations}

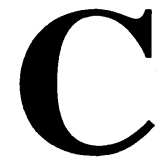
onsistent differences in the fish communities at the survey stations attributable to plant operations have not been detected in the surveys. Much of the spatial variation in fish communities is attributable to differences in habitat. There has been a general trend of higher species richness at the lower stations. Backwater sampling indicates that there is high variability in richness and abundance among sites, so that there is no consistent station difference in these habitats. However, the surveys at Stations 5 and 6 indicate backwaters and other habitats with much higher abundance and richness than other sites within the same station or at other stations. The greater complexity of the river at the lower stations, with complex backwaters, side channels and meander bends likely promotes these local sites of abundance. Other habitats, such as the open shores and bars, have usually shown similar patterns of fish occurrence among the different stations. The monitoring of several habitat types, along with the repeated temporal sampling has demonstrated complex patterns of consistent temporal changes in abundance of species over different habitats and stations, superimposed on differences in assemblages among different habitat types. 


\section{F. LTERATURE CITED}

Abel, P.D. 1989. Water Pollution Biology. Ellis Horwood Limited. Chichester, England. John Wiley \& Sons, Inc. New York (distributor). 231 pp.

Academy of Natural Sciences of Philadelphia (ANSP). 1953. Savannah River biological survey, South Carolina and Georgia, June 1951-May 1952. Final Report for E.I. du Pont de Nemours and Company Savannah River Plant. Acad. Nat. Sci. Phila. 1957. Savannah River biological survey, South Carolina and Georgia, August-September 1955, May 1956. Progress Report for E.I. du Pont de Nemours and Company Savannah River Plant. Acad. Nat. Sci. Phila. $210 \mathrm{pp}$.

1961. Savannah River biological survey, South Carolina and Georgia, May-June and August-September 1960 for the E.I. duPont de Nemours and Company. Acad Nat. Sci. Phila.

1966. Savannah River biological survey, South Carolina and Georgia, May-June and September, 1965, for the the E.I. duPont de Nemours and Company. Acad. Nat. Sci. Phila. 112 pp.

. 1970. Savannah River biological survey, South Carolina and Georgia, May and August 1968 for the E.I. duPont de Nemours and Company. Acad. Nat. Sci. Phila. 130 pp.

1974a. Savannah River biological survey, South Carolina and Georgia, May and September 1972 for the E.I. du Pont de Nemours and Company. Acad. Nat. Sci. Phila. 173 pp.

1974b. Catherwood Diatometer readings for the E.I. du Pont de Nemours and Company, Savannah River Plant, January through December 1973. Acad. Nat. Sci.

Phila. 23 pp. 
1977. Savannah River biological survey South Carolina and Georgia, August 1976 for the E.I. du Pont de Nemours and Company. Rept. No. 77-37. Acad. Nat. Sci. Phila. 118 pp.

1978. Savannah River Catherwood Diatometer studies for the Savannah River Plant, E.I. du Pont de Nemours and Company, January through December 1977. Report No. 88-38. Acad. Nat. Sci. Phila. 31 pp.

1980a. 1979 Savannah River Catherwood Diatometer studies for E.I. du Pont de Nemours and Company. Report No. 80-12. Acad. Nat. Sci. Phila. 44 pp.

1980b. Savannah River Cursory Surveys for E.I. du Pont de Nemours \& Company 1979. Report No. 80-5. Acad. Nat. Sci. Phila.

1981a. Savannah River biological surveys, South Carolina and Georgia, June and September 1980 for the E.I. du Pont de Nemours Company. Rept. No. 81-14. Acad. Nat. Sci. Phila. 128 pp. 1981b. 1980 Savannah River Catherwood Diatometer studies for E.I. du Pont de Nemours and Company. Report No. 81-17. Acad. Nat. Sci. Phila. 43 pp.

1982. 1981 Savannah River Catherwood Diatometer studies for E.I. du Pont de Nemours and Company. Report No. 82-13. Acad. Nat. Sci. Phila. 40 pp. . 1984a. 1983 Savannah River Catherwood Diatometer studies for E.I. du Pont de Nemours and Company. Report. No. 84-10. Acad. Nat. Sci. Phila. $56 \mathrm{pp}$.

1984b. 1982 Savannah River Catherwood Diatometer studies for the E.I. du Pont de Nemours and Company. Report No. 84-4. Acad. Nat. Sci. Phila. 60 pp.

1985a. 1984 Savannah River Catherwood Diatometer Studies for E.I. du Pont de Nemours and Company. Acad. Nat. Sci. Phila. 47 pp. 
1985b. Savannah River Biological Surveys, June and September 1984 for E.I. du Pont de Nemours \& Company. Report No. 85-14. Acad. Nat. Sci. Phila. $173 \mathrm{pp}$.

1988a. 1985 Savannah River Catherwood Diatometer Studies for the E.I. du Pont de Nemours and Company. Report No. 87-9F. Acad. Nat. Sci. Phila. 36 pp.

. 1988b. 1986 Savannah River Catherwood Diatometer studies for E.I. du Pont de Nemours and Company. Report No. 88-6. Acad. Nat. Sci. Phila. 34 pp.

1988c. 1987 Savannah River Catherwood Diatometer studies for E.I. du Pont de Nemours and Company. Report No. 88-16. Acad. Nat. Sci. Phila. 45 pp.

1990a. 1988 Savannah River biological survey in the vicinity of Georgia Power and Light's Vogtle Nuclear Power Plant site for E.I. du Pont de Nemours \& Company. Rept. No. 89-17F. 128 pp.

. 1990b. 1988 Savannah River Catherwood

Diatometer studies for the E.I. du Pont de Nemours and Company. Report No. 89-13F. 44 pp.

1991a. 1990 Savannah River biological survey in the vicinity of Georgia Power and Light's Vogtle Nuclear Power Plant site for Westinghouse Savannah River Company. Rept. No. 91-18F. 151 pp.

1991b. Savannah River biological surveys, June and September 1989 for Westinghouse Savannah River Company. Rept. No. 90-25F. Acad. Nat. Sci. Phila. $221 \mathrm{pp}$.

1991c. 1989 Savannah River Catherwood Diatometer studies for the E.I. du Pont de Nemours and Company. Report No. 90-22F. 44 pp. 1992a. 1990 Savannah River Catherwood Diatometer studies for the Westinghouse Savannah River Company. Report No. 91-15F. 47 pp. 
1992b. 1991 Savannah River Catherwood

Diatometer studies for Westinghouse Savannah River

Company. Report No. 92-13F. 50 pp.

- 1992c. 1991 Savannah River biological survey

in the vicinity of Georgia Power and Light's Vogtle

Nuclear Power Plant Site for Westinghouse Savannah

River Company. Report No. 92-27F. Acad. Nat. Sci.

Phila. 169 pp.

- 1993a. 1992 Savannah River Catherwood

Diatometer studies for the Westinghouse Savannah River

Company, Rept. No. 93-9F. 40 pp.

1993b. Savannah River cursory surveys for

Westinghouse Savannah River Company 1992. Report

No. 93-8F. Acad. Nat. Sci. Phila. 93 pp.

. 1994a. 1993 Savannah River biological survey

in the vicinity of Georgia Power and Light's Vogtle

Nuclear Power Plant site for Westinghouse Savannah

River Company. Rept. No. 94-9F. 188 pp.

. 1994b. Savannah River biological surveys 1993

for Westinghouse Savannah River Company. Rept. No.

94-14F. $341 \mathrm{pp}$.

1994c. 1993 Savannah River Catherwood

Diatometer studies for the Westinghouse Savannah River

Company, Rept. No. 94-10F. 48 pp.

. 1995. 1994 Savannah River Catherwood

Diatometer studies for the Westinghouse Savannah River

Company, Rept. No. 95-10F. 49 pp.

. 1996a. 1995 Savannah River biological survey

in the vicinity of Georgia Power and Light's Vogtle

Nuclear Power Plant Site for Westinghouse Savannah

River Company. Report No. 96-11F. Acad. Nat. Sci.

Phila. 221 pp.

. 1996b. Savannah River Cursory Surveys for

Westinghouse Savannah River Company 1995. Report

No. 96-13F. Acad. Nat. Sci. Phila. 104 pp.

1997. 1996 Savannah River biological surveys

for Westinghouse Savannah River Company. Rept. No.

97-14F. 336pp. 
. 1998. Savannah River biological surveys 1997

for Westinghouse Savannah River Company. Rept. No. 98-10F. Acad. Nat. Sci. Phila. 201 pp.

1999. Savannah River biological surveys 1998

for Westinghouse Savannah River Company. Rept. No. 99-12F. Acad. Nat. Sci. Phila. 246 pp.

2000. Savannah River biological surveys 1999

for Westinghouse Savannah River Company. Rept. No. 00-14F. Acad. Nat. Sci. Phila. 235 pp.

Barbour, M.T., J. Gerritsen, G.E. Griffith, R. Frydenborg, E. McCarron, J.S. White and M.L. Bastian. 1996. A framework for biological criteria for Florida streams using benthic macroinvertebrates. J. N. Am. Benthol. Soc. 15(2):185-211.

Beaver, J. 1981. Apparent ecological characteristics of some common freshwater diatoms. Ministry of the Environment. Rexdale, Ontario. 517 pp.

Bennett, D.H. and R.W. McFarlane. 1983. The Fishes of the Savannah River Plant: National Environmental Research Park. Savannah R. Ecology Lab, SRO-NERP-12. 152 pp.

Blair, W.F., A.P. Blair, P. Brodkorb, F.R. Cagle and G. A. Moore. 1968. Vertebrates of the United States, 2nd ed. McGraw-Hill Book Co., NY.

Bournaud, M., B. Cellot, P. Richoux and A. Berrahou. 1996. Macroinvertebrate community structure and environmental characteristics along a large river: congruity of patterns for identification to species or family. J. N. Am. Benthol. Soc. 15(2):232-253.

Bright, G.R. 1994 (1988). Recent water quality in the Grand Calumet River as measured by benthic invertebrates.

Proc. Indiana Acad. Sci. 98:229-233.

Britton, J. C. and S. L. H. Fuller. 1979. (1980 cover)

Freshwater bivalve mollusca (Unionidae, Sphaeriidae, Corbiculidae) of the Savannah River plant, South Carolina. Savannah River plant National Environmental Research Park Program, U.S. Dept. of Energy SRO-NERP-3, $37 \mathrm{pp}$.

Brown, C.A. 1996. Macroinvertebrate community patterns in relation to physico-chemical parameters measured at 
two land-based trout farms affecting streams in the south-western Cape, South Africa. Arch. Hydrobiol. 138(1):57-76.

Cairns, J. and J.R. Pratt. 1993. A history of biological monitoring using benthic macroinvertebrates. Pages 10-27 in: D.M. Rosenberg and V.H. Resh, eds. Freshwater Biomonitoring and Benthic Macroinvertebrates. Chapman and Hall, New York.

Clarke, A.H. 1981. The tribe Alasmidontini (Unionidae: Anodontinae), Part I: Pegias, Alasmidonta, and Arcidens. Smithsonian Contributions to Zoology. Number 326:iii $+101 \mathrm{pp}$.

Cohen, A.C. 1961. Table for maximum likelihood estimates: Singly truncated and singly censored samples. Technometrics 3:535-541.

Downing, J.A. and F.H. Rigler, eds. 1984. A Manual on Methods of Secondary Productivity in Freshwaters. Second edition. Blackwell Scientific Publications. Oxford, England. 389 pp.

Elliott, J.M. 1977. Some methods for the statistical analysis of samples of benthic invertebrates. 2nd ed. Freshwat. Biol. Assoc. Sci. Publ. No. 25. 156 pp.

Ferren, W. and A.E. Schuyler. 1980. Intertidal vascular plants of river systems near Philadelphia. Proc. Acad. Nat. Sci. Phila. 132:86-120.

Fuller, S.L.H. and J.W. Richardson. 1977. Amensalistic competition between Corbicula manilensis (Philippi), the Asiatic clam (Corbiculidae), and fresh-water mussels (Unionidae) in the Savannah River of Georgia and South Carolina. The Association of Southeastern Biologists Bulletin. 24(2):52.

Goodnight, C.J. 1973. The use of aquatic macroinvertebrates as indicators of stream pollution. Trans. Amer. Micro. Soc. 92:1-13.

Hart, C.W., Jr. and S.L.H. Fuller, eds. 1974. Pollution Ecology of Freshwater Invertebrates. Academic Press, New York. 89 pp. 
Hellawell, J.M. 1986. Biological Indicators of Freshwater Pollution and Environmental Management. Elsevier Applied Science, London, England.

Hendrickson, J. 1998. A study on the estimation of parameters of the normal distribution from singly truncated samples, with application to diatom communities. Revised draft report submitted to Dr. Ruth Patrick.

Hilsenhoff, W.L. 1987. An improved biotic index of organic stream pollution. Great Lakes Entomol. 20:31-39.

Hohn, M.H. 1961. Determining the pattern of the diatom flora. J. Water Pollut. Contr. Fed. 33:48-53.

Hynes, H.B.N. 1972. The Ecology of Running Waters. University of Toronto Press. $555 \mathrm{pp}$. 1974. The Biology of Polluted Waters. University of Toronto Press. 202 pp.

Jenkins, R.E. and N.M. Burkhead. 1994. Freshwater Fishes of Virginia. American Fisheries Society Bethesda, MD.

Johnson, R.I. 1967. Carunculina pulla (Conrad), an overlooked Atlantic drainage unionid. Nautilus. 80(4):127-131.

1970. The systematics and zoogeography of the Unionidae (Mollusca: Bivalvia) of the Southern Atlantic Slope Region. Bull.f Comp. Zool. 140(6):263-450.

Karr, J.R. and E.W. Chu. 1998. Restoring life in running waters: Better biological monitoring. Island Press, Washington, D.C. 207 pp.

Klemm, D.J. 1985. Freshwater leeches (Annelida: Hirudinea). Pages 70-198 in D.J. Klemm, ed. A Guide to the Freshwater Annelida (Polychaeta, Naidid and Tubificid Oligochaeta, and Hirudinea) of North America. Kendall Hunt Publishing Company. Dubuque, IA. 198 pp.

Krueger, H.O., J.P. Ward and S.H. Anderson. 1988. A resource manager's guide for using aquatic organisms to assess water quality for evaluation of contaminants. Biological Report 88(20). Fish and Wildl. Serv., U.S. Dept. Int. $45 \mathrm{pp}$. 
Lenat, D.R. 1993. A biotic index for the southeastern United States: Derivation and list of tolerance values, with criteria for assigning water-quality ratings. J. N. Am. Benthol. Soc. 12:279-290.

Loeb, S.L. and A. Spacie, eds. 1994. Biological monitoring of aquatic systems. Lewis Publishers. Boca Raton, FL. $400 \mathrm{pp}$.

Lowe, R.L. 1974. Environmental requirements and pollution tolerance of freshwater diatoms. National Environmental Research Center, USEPA. Cincinnati, Ohio. 334 pp.

Maret, T.R. 1988. A water-quality assessment using aquatic macroinvertebrates from streams of the Long Pine Creek watershed in Brown County, Nebraska. Trans. Nebraska Acad. Sci. XVI:69-84.

Menhinick, E.F. 1991. The Freshwater Fishes of North Carolina. North Carolina Wildlife Resources Commission, Charlotte, NC.

Merritt, R.W. and K.W. Cummins, eds. 1984. An Introduction to the Aquatic Insects of North America, $2^{\text {nd }}$ ed. Kendall/Hunt Publishing Co., Dubuque, IA. 1996. An Introduction to the Aquatic Insects of North America, $3^{\text {rd }}$ ed. Kendall/Hunt Publishing Co., Dubuque, IA.

Miller, R.J. and H.W. Robison. 1973. The Fishes of Oklahoma. Oklahoma State University Press, Stillwater, OK.

Norris, R.H., B.T. Hart, M. Finlayson and K.R. Norris, eds. 1995. Use of biota to assess water quality. An international conference. Australian J. Ecol. 20:1-227.

Olive, J.H. and K.R. Smith. 1975. Benthic macroinvertebrates as indexes of water quality in the Scioto River basin. Ohio Bull. Ohio Biol. Surv., New Series. 5:124 pp.

Patrick, R., M.H. Hohn and J.H. Wallace. 1954. A new method for determining the pattern of the diatom flora. Notul. Natur. 259:1-12. 
Patrick, R. and D.M. Palavage. 1994. The value of species as indicators of water quality. Proc. Acad. Nat. Sci. Phila. 145:55-92.

Peterson, C.E. 1993. The extent of anthropogenic disturbance on the aquatic assemblages of the East Branch of the DuPage River, Illinois, as evaluated using stream arthropods. Trans. Illinois Acad. Sci. 87(1-2):29-35.

Plafkin, J.L., M.T. Barbour, K.D. Porter, S.K. Gross and R.M. Hughes. 1989. Rapid bioassessment protocols for use in streams and rivers: Benthic macroinvertebrates and fish. U.S.EPA, Assessment and Watershed Protection Rept. EPA-444/4-89-001.

Preston, F.W. 1948. The commonness, and rarity, of species. Ecology 39:254-283.

Rabeni, C.F., N. Wang and R.J. Sarver. 1999. Evaluating adequacy of the representative stream reach used in invertebrate monitoring programs. J. N. Am. Benth. Soc. 18(2):284-291.

Robins, C.R., R.M. Bailey, C.E. Bond, J.R. Brooker, E.A. Lachner, R.N. Lea and W.B. Scott. 1991. Common and Scientific Names Of Fishes from the United States and Canada. 5th ed. Amer. Fish. Soc. Spec. Publ. No. 20. $183 \mathrm{pp}$.

Root, M. 1990. Biological monitors of pollution. BioScience. 40:83-86.

Rosenberg, D.M. and V.M. Resh. 1993. Freshwater Biomonitoring and Benthic Macroinvertebrates. Chapman and Hall, NY. 488 pp.

SAS Institute Inc. 1985. SAS User's Guide: Statistics, Version 5 edition. SAS Institute Inc., Cary, NC. 956 pp. 1990. SAS/STAT® User's Guide, Release 6.04 Edition. Cary, NC.

Schuyler, A.E. 1988. Submergent and planmergent flora of the freshwater portion of the Delaware estuary. Chap. 10 in: S.K. Majumdar, E.W. Miller and L.E. Sage, eds. Ecology and Restoration of the Delaware River. Pa. Acad. Sci. 431 pp. 
Seber, G.A.F. 1973. The estimation of animal abundance and related parameters. Hafner Press. New York. 506 pp.

Shannon, C.E. and W. Wiener. 1949. The Mathematical Theory of Communication. Univ. Ill. Press, Urbana, IL. $125 \mathrm{pp}$.

Sladecek, V. 1973. System of water quality from the biological point of view. In Elster and W. Ohle, eds. Ergebnisse der Limnologie. Vol.7. Archiv fur Hydrobiologie. 218 pp.

Smith, E.P. and J.R. Voshell, Jr. 1997. Studies of benthic macroinvertebrates and fish in streams within EPA Region 3 for development of biological indicators of ecological condition. Part 1. Benthic Macroinvertebrates. Final report for Cooperative Agreement CF821462010. U.S. Environmental Protection Agency, Washington, D.C.

Starrett, W.C. 1971. A survey of the mussels (Unionacea) of the Illinois River: A polluted stream. Bull. Illinois Nat. Hist. Survey. 30:265-403.

Taylor, R.W. 1980. A survey of the freshwater mussels of the Ohio River from Greenup Locks and Dam to Pittsburgh, Pennsylvania. Rept. to U.S. Army Corps of Engineers, Huntington District, Huntington, West Virginia. $71 \mathrm{pp}$.

Ter Braak, C.J.F. and P. Smilauer. 1998. CANOCO Reference manual and user's guide to Canoco for Windows: Software for Canonical Community Ordination (version 4). Centre for Biometry Wageningen. Microcomputer Power. Ithaca, NY. 352 pp.

Turgeon, D.D., A.E. Bogan, E.V. Coan, W.K. Emerson, W.G. Lyons, W.L. Pratt, C.F.E. Roper, A. Scheltema, F.G. Thompson, and J.D. Williams. 1988. Common and scientific names of aquatic invertebrates from the United States and Canada: Mollusks. Amer. Fish. Soc. Spec. Publ. 16:vii + 277 pp.

Van Deventer, J.S. and W.S. Platts. 1983. Sampling and estimating fish populations from streams. Transactions of the North American Wildlife and Natural Resources Conference 48:349-354. 
1989. Microcomputer software system for generating population statistics from electrofishing data-User's Guide for MicroFish 3.0. United States Department of Agriculture Forest Service. Intermountain Research Station. General Technical Report INT-254.

VanLandingham, S.L. 1982. Guide to the Identification, Environmental Requirements and Pollution Tolerance of Freshwater Blue-green Algae (Cyanophyta). Envir. Mon. Supp. Lab. Off. Res. Develop. USEPA EPA-600/3-82-073. 341 pp.

Weber, C.I. 1973. Biological field and laboratory methods for measuring the quality of surface waters and effluents. EPA-670/4-73-001.

Weiderholm, T. 1984. Responses of aquatic insects to environmental pollution. Pages 508-557 in: V.H. Resh and D.M. Rosenberg, eds.. The Ecology of Aquatic Insects. Praeger Publishers, New York.

Weitzel, R.L. 1979. Periphyton measurements and applications. Pages 3-33 in R.L. Weitzel, ed. Methods and measurements of periphyton communities: A review. ASTM STP 690. 183 pp.

Whitton, B.A., ed. 1975. River Ecology. Studies in Ecology. Vol. 2. Univ. California Press, Berkeley. 725 pp.

Wilhm, J.L. and T.C. Dorris. 1968. Biological parameters for water quality criteria. Bioscience. 6:477-481. 